\author{
Universidade de São Paulo \\ Instituto de Astronomia, Geofísica e Ciências Atmosféricas \\ Departamento de Ciências Atmosféricas
}

Carolina Barnez Gramcianinov

\title{
Changes in South Atlantic Cyclones due Climate Change
}

\section{(Mudanças nos Ciclones do Atlântico Sul devido às Mudanças Climáticas)}

São Paulo 

Changes in South Atlantic Cyclones due Climate Change

\section{(Mudanças nos Ciclones do Atlântico Sul devido às Mudanças Climáticas)}

Tese apresentada ao Departamento de Ciências Atmosféricas do Instituto de Astronomia, Geofísica

e Ciências Atmosféricas da Universidade de São Paulo como requisito parcial para a obtenção do título de Doutor em Ciências.

Área de Concentração: Meteorologia Orientador: Prof. Dr. Ricardo de Camargo Co-orientador: Prof. Dr. Pedro L. da Silva Dias

Versão corrigida. O original encontra-se disponível na Unidade.

São Paulo 

À minha avó Wanda P. Barnez 



\section{Acknowledgements}

Agradeço em primeiro lugar à minha família, pelo amor e apoio que me fizeram chegar até aqui. Meu marido, mãe, pai, irmão, avós, sogra, sogro, tios, tias, cunhadas, primos e primas: muito obrigada! Aos meus pais eu devo muito: obrigada por sempre me incentivarem e apoiarem minha escolha profissional. Agradeço em especial ao meu marido, que foi meu maior companheiro nessa jornada - obrigada por sempre acreditar em mim.

Agradeço imensamente ao meu orientador, Prof. Ricardo de Camargo - Obrigada por todo incentivo, atenção e confiança ao longo desse projeto. Ao IAG, professores e funcionários, agradeço muito todo o suporte e simpatia. Agradeço especialmente aos Professores Tercio Ambrizzi, Rosmeri P. da Rocha, Carlos Raupp, Edmilson Freitas e Pedro L. da Silva Dias por toda atenção e tempo gastos comigo. Ao pessoal do MASTER, agradeço toda ajuda (que não foi pouca!): Bruno, Enzo e Jean. Em especial agradeço ao Jean pelo suporte, disponibilidade e compreensão.

Gostaria também de agradecer a todas as pessoas que me ajudaram de alguma forma nesses anos de doutorado. Ajudas que vão desde cafezinho na sala, almoços no bandejão, até compartilhamento de scrips e artigos. Angel Vela, Mario Calderón, Ana Maria Nunes, Natália Pillar, Alberto Bié, Elisa Glitzenhirn, Alexandre Tique, Thomas Martin, João Hackerott... é impossível colocar o nome de todos. Agradeço especialmente a Natália Crespo, pelas inúmeras discussões e correções. Agradeço também aos amigos que foram quase minha família nesses últimos meses: Raianny Wanderley, Leonardo Domingues e Felipe Massarico - obrigada por me ajudarem a manter o mínimo de sanidade nesses últimos passos. Em especial ao Leo: obrigada por toda atenção e disposição em me ajudar. Muito obrigada também as amigas de longa data que nunca me deixam desamparada: Alynne, Sarah, Pri, Rê, Quel, Lívia, Ana Lídia, Lidia e Silvia. Obrigada ao amigo de 
longa data Dalton Sasaki, que ressurgiu nesse último ano para me dar motivação e novas oportunidades.

I am very grateful to Dr. Kevin Hodges, who gave me a lot of help and guidance about the cyclone tracking and diagnostics. I am also grateful to him and the staff of Department of Meteorology of University of Reading for receiving me as an associated researcher and managed everything to make my internship possible. I also want to say thank you to Robert Lee, for all the help.

I acknowledge the Coordenação de Aperfeiçoamento de Pessoal de Nível Superior Brasil (CAPES) - Finance Code 001 - and Conselho Nacional de Pesquisa e Desenvolvimento - Brasil (CNPq) - Grant 141658/2015-0 - for awarding me a PhD studentship during the development of this project and also make it possible my internship at University of Reading and my participation on international conferences. 
"Não é sobre chegar no topo do mundo e saber que venceu É sobre escalar e sentir que o caminho te fortaleceu"

Ana Vilela 



\section{Resumo}

A distribuição e intensidade dos ciclones afeta diretamente as atividades humanas devido a precipitação e fortes ventos associados a esses sistemas. O objetivo principal deste trabalho é entender as mudanças nos ciclones gerados no Atlântico Sul devido as mudanças climáticas, focando em seus mecanismos geradores e intensificadores. Os ciclones foram identificados e rastreados utilizando a vorticidade relativa em $850 \mathrm{hPa}$, calculada a partir do campo de ventos horizontal. Também foram usadas composições centradas para a análise da estrutura e evolução dos ciclones durante seu desenvolvimento. A climatologia de ciclones feita com o NCEP-CFSR mostra quatro regiões ciclogenéticas principais no Oceano Atlântico Sul: na costa sul do Brasil (SE-BR, $\left.30^{\circ} \mathrm{S}\right)$, sobre o continente próximo da desembocadura do Rio da Prata (LA PLATA, $35^{\circ} \mathrm{S}$ ), na costa sudeste da Argentina (ARG, $40^{\circ} \mathrm{S}-55^{\circ} \mathrm{S}$ ) e no Sudeste do Atlântico (SE-SAO, centrada em $55^{\circ} \mathrm{S}, 10^{\circ} \mathrm{W}$ ). Para analisar as mudanças no desenvolvimento dos ciclones, nós utilizamos os experimentos histórico (1980-2005) e RCP8.5 (2074-2099) do HadGEM2-ES (CMIP5). O HadGEM2-ES é capaz de representar as principais características dos ciclones do Atlântico Sul, quando comparado à climatologia. No entanto, existe uma subestimativa do número de ciclones no lado equatorial da região de máxima atividade ciclônica, principalmente na região LA PLATA. A projeção futura HadGEM2-ES no cenário RCP8.5 mostra uma redução de aproximadamente $10 \%$ na ciclogêneses no domînio do Atlântico Sul, principalmente associada ao deslocamento em direção ao polo da região de máxima atividade ciclônica . Porém, a região LA PLATA apresenta um pequeno aumento em sua atividade ciclogenética (6.1 e 3.6\%, no verão e inverno, respectivamente). O aumento na ciclogênese em $30^{\circ} \mathrm{S}$ está associada ao fortalecimento do jato de altos níveis e ao aumento da advecção quente e de umidade nessa localidade. O aumento do transporte de umidade dos trópicos está associado também à 
intensificação dos ciclones observada na projeção futura, principalmente ao norte de $35^{\circ} \mathrm{S}$. Por fim, uma regionalização com o modelo WRF foi usada para melhorar a resolução do modelo climático. Porém, as simulações regionais subestimaram os ciclones em número e intensidade. A única região em que as regionalizações apresentaram melhor desempenho foi a LA PLATA, devido a uma melhor representação de feições locais associadas a orografia e processos úmidos. A regionalização do cenário futuro RCP8.5 também apresentou aumento da ciclogênese do LA PLATA, mas para o inverno. Tanto a projeção RCP8.5 do HadGEM2-ES quanto sua regionalização mostram que a ciclogênese em algumas regiões da América do Sul está aumentando, principalmente devido ao aumento de umidade em baixos níveis da atmosfera e fortalecimento do ramo equatorial do jato de altos níveis. Os ciclones nessas localidades serão intensos (entre $20^{\circ} \mathrm{S}$ and $30^{\circ} \mathrm{S}$ ) e tendem a afetar uma região mais próxima à costa.

Palavras-chave: Ciclogênese; Ciclones Extra-tropicais; Regionalização Climática; Tendência Climática; WRF. 


\section{Abstract}

Cyclones distribution and intensities impact directly on human activities, mainly due to their associated intense precipitation and winds. The main aim of this thesis is to understand changes in the cyclones originated in the South Atlantic focusing on their genesis and intensifying mechanisms. Cyclones are identified and tracked based on the relative vorticity field at $850 \mathrm{hPa}$ computed from the winds. The characteristics of the cyclones are obtained by diagnostic variables sampled within a radial distance from each cyclone center and to produce a spatial distribution of the cyclone properties at the time of genesis. Also, cyclone centered composites are used to analyze the cyclone structure and the evolution of cyclones during their genesis. The climatology of cyclones was done using NCEP-CFSR and shows four main cyclogenesis regions in the South Atlantic Ocean: on the Southern Brazilian coast (SE-BR, $30^{\circ} \mathrm{S}$ ), over the continent near the La Plata river discharge region (LA PLATA, $35^{\circ} \mathrm{S}$ ), on the southeastern coast of Argentina (ARG, $40^{\circ} \mathrm{S}$ $55^{\circ} \mathrm{S}$ ) and on the Southeastern Atlantic (SE-SAO, centered at $55^{\circ} \mathrm{S}$ and $10^{\circ} \mathrm{W}$ ). To access changes in cyclone development, we used the CMIP5 HadGEM2-ES historical experiment (1980-2005) and RCP8.5 future projection (2074-2099). The HadGEM2-ES can represent the main South Atlantic characteristics of cyclones according to NCEP-CFSR climatology. However, there is an underestimation in cyclone frequency in the equatorward side of the storm track, particularly in the LA PLATA region. The HadGEM2-ES RCP8.5 future projection shows a general decrease of approximately $10 \%$ of cyclogenesis in the South Atlantic domain, which is mainly related to the poleward shift of the storm track. However, LA PLATA region presents a slight increase in its cyclogenetic activity (6.1 and 3.6\%, in the summer and winter, respectively). The increase in genesis at $30^{\circ} \mathrm{S}$ over the continent is associated with the strengthening of the upper-level jet and the increase of warm 
and moisture advections at the same location. The enhance in the moisture transport from the tropics is also related to the intensification of the cyclone in the domain, mainly northward of $35^{\circ} \mathrm{S}$. Finally, a downscaling using WRF was performed in an attempt to improve the climate model resolution. However the downscaling produces less and weaker cyclones in the NCEP-CFSR and HadGEM2-ES runs. The only region that presented an improvement was LA PLATA, due to the better representation of local features related to orography and moisture processes. The downscaled HadGEM2-ES RCP8.5 also shows an increase in cyclogenesis in the LA PLATA region and other locations. The HadGEM2-ES RCP8.5 projection and its downscaling shows that the cyclogenesis in some locations of South America is increasing, mainly due to the increase in the low-level moisture content and the strengthening of the equatorward flank of the upper-level jet. The cyclones in this locations will be slightly intense (between $20^{\circ} \mathrm{S}$ and $30^{\circ} \mathrm{S}$ ) and will affect a narrow area close to the South American coast.

keywords: Cyclogenesis; Extratropical Cyclones; Storm track; Climate Downscaling; Climate trends; WRF. 


\section{List of Figures}

2.1 Schematic picture of cyclogenesis associated with the arrival of an upper air isentropic potential vorticity (IPV) anomaly over a low-level baroclinic zonal. In (a) the upper-level cyclonic IPV anomaly, indicated by the solid plus sign and associated with the low tropopause height shown, has just arrived over a region of significant low-level baroclinicity. The circulation induced by the anomaly is indicated by solid arrows, and potential temperature contours are shown on the ground. The low-level circulation is shown above the ground for clarity. The advection by this circulation leads to a warm temperature anomaly somewhat ahead of the upper IPV anomaly in (b), and marked with an open plus sign. If the equatorward motion at upper levels advects high-PV polar lower-stratospheric air, and the poleward motion advects low-PV subtropical upper tropospheric air, then the reaction of the upper-level circulation induced by the surface potential temperature anomaly will, in effect, reinforce the upper air IPV anomaly and slow down its eastward progression. This scheme was made for the Northern Hemisphere and the figure and caption were taken from Hoskins et al. (1985). . . . . 
2.2 Conceptual models of cyclone evolution for the Southern Hemisphere. The top schemes show low-level geopotential height, cold (blue), warm (red) and occluded (purple) fronts; the bottom schemes show potential temperature at low-level, which decreases southward. (a) The phases of the Norwegian cyclone model are: (I) incipient frontal cyclone, (II and III) narrowing warm sector, and (IV) occlusion; (b) The phases of the Shapiro-Keyser cyclone model: (I) incipient frontal cyclone, (II) frontal fracture, (III) T-bone structure and bent-back front, and (IV) T-bone structure and warm seclusion. The stages are separated from each other by 6-24h. Adapted from Schultz et al. (1998) (original) and Reboita et al. (2017) (Southern Hemisphere adaptations). . . . . . . . . . . . . . . . .

3.1 The grid domain used to the climate experiment. The grid was build using a polar projection centered in $37^{\circ} \mathrm{S}$ and $50.3^{\circ} \mathrm{W}$ with a horizontal resolution

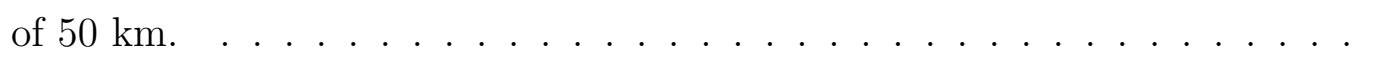

4.1 Cyclone track density for (a) summer (DJF) and (b) winter (JJA), and the genesis density for (c) summer (DJF) and (d) winter (JJA). The densities are computed using only cyclones with the first time step within South Atlantic domain, in a box between $15^{\circ} \mathrm{S}-55^{\circ} \mathrm{S}$ and $75^{\circ} \mathrm{W}-20^{\circ} \mathrm{E}$. The density unit is cyclone per $10^{6} \mathrm{~km}^{2}$ per month. . . . . . . . . . 70

4.2 Genesis density for South Atlantic domain (marked in dashed gray line) computed for all period from 1979 to 2010. The four genesis regions are marked in black line. The density unit is cyclone per $10^{6} \mathrm{~km}^{2}$ per month. .

4.3 Track density (first column), lysis density (middle) and mean intensity distribution (last column) for each genesis region following this sequence from above: SE-BR, LA PLATA, ARG and SE-SAO. The density unit is cyclone per $10^{6} \mathrm{~km}^{2}$ per month and mean intensity unit is $-1 \times 10^{-5} \mathrm{~s}^{-1} \ldots \ldots$. .

4.4 Histograms of the vorticity at the genesis time in the (a) summer and (b) winter for the cyclones which originate in SE-BR (red), LA PLATA (green), ARG (blue) and SE-SAO (orange) regions. The relative vorticity is scaled by $-1 \times 10^{-5} s^{-1}$ and the y-axis shows the percentage computed based on the total number of cyclones detected in each defined genesis region. . . . . 
4.5 Histograms of the maximum filtered vorticity at $850 \mathrm{hPa}$ in the (a) summer and (b) winter; and the MSLP (hPa) in the (c) summer and (d) winter. The vorticity is multiplied by $-1 \times 10^{-5} s^{-1}$ and the MSLP was searched within $5^{\circ}$ radius from the center of the cyclone. The intensity histograms were produced for cyclones originated in each genesis region separately. The percentage was computed based on the mean cyclones per month for each region. . . . . . . . . . . . . . . . .

4.6 Histograms of the maximum wind speed at $925 \mathrm{hPa}$ in the (a) summer and (b) winter; and the precipitation rate $(m m$ day -1$)$ in the (c) summer and (d) winter. The maximum wind speed at $925 \mathrm{hPa}$ is searched within $6^{\circ}$ radius from the center of the cyclone and the precipitation is averaged within $5^{\circ}$ radius. The intensity histograms were produced for cyclones originated in each genesis region separately. The percentage was computed based on the mean cyclones per month for each region.

4.7 Spatial distribution of the mean intensity based on the maximum wind speed at $925 \mathrm{hPa}\left(\mathrm{m} \mathrm{s}^{-1}\right)$ in the (a) summer and (b) winter, and the mean growth rate $\left(-1 \times 10^{-5} s^{-1} d a y^{-1}\right)$ in the (c) summer and (d) winter. The fields are not plotted where track density $<0.3$ cyclones $\left(10^{6} \mathrm{~km}^{2}\right)^{-1} \mathrm{month}^{-1}$. . . .

4.8 Spatial distribution of SST gradient at the time of genesis in the (a) summer and (b) winter. Sea surface temperature (SST) gradient in South Atlantic Ocean in the austral (c) summer and (d) winter. The gradient unit is $10^{-3}$ $K \mathrm{~km}^{-1}$. The fields are not plotted where genesis density $<0.2$ cyclones $\left(10^{6} \mathrm{~km}^{2}\right)^{-1}$ month $^{-1} \ldots \ldots \ldots \ldots \ldots$

4.9 Spatial distribution of anomalies at the time of genesis of the integrated humidity at lower-level $\left(k g \mathrm{~kg}^{-1}\right)$ in (a) austral summer and (b) winter; $\partial \theta / \partial p\left(10^{-2} K_{h P a^{-1}}\right)$ in (c) summer and (d) winter, and; $\partial \theta_{e} / \partial p\left(10^{-2} K\right.$ $h \mathrm{~Pa}^{-1}$ ) in (e) summer and (f) winter. The anomalies are computed using the season climatology and the fields are not plotted where genesis density $<0.2$ cyclones $\left(10^{6} \mathrm{~km}^{2}\right)^{-1} \mathrm{month}^{-1}$. . . . . . . . . . . . . 
4.10 Spatial distribution of potential vorticity at $300 \mathrm{hPa}(\times-1 P V U)$ at genesis time and maximum intensity time in the austral (a,b) summer and (c,d) winter, respectively. The field distribution at genesis and at the maximum intensity are not plotted where genesis and track density $<0.2$ cyclones $\left(10^{6} \mathrm{~km}^{2}\right)^{-1} \mathrm{month}^{-1}$ and $<0.5$ cyclones $\left(10^{6} \mathrm{~km}^{2}\right)^{-1} \mathrm{month}^{-1}$, respectively.

4.11 Spatial distribution of upper-level jet $\left(\mathrm{m} \mathrm{s}^{-2}\right)$ in austral (a) summer and (b) winter at the time of genesis. The field distribution at genesis is not plotted where genesis density $<0.2$ cyclones $\left(10^{6} \mathrm{~km}^{2}\right)^{-1} \mathrm{month}^{-1}$.

4.12 Composites of mean equivalent potential temperature $\left(\theta_{e}\right)$ at $925 \mathrm{hPa}(\mathrm{K}$; shaded) and MSLP (hPa; black line) from different genesis regions in the (a-d) summer and (f-g) winter : (a,e) SE-BR, (b,f) LA PLATA, (c,g) ARG and $(\mathrm{d}, \mathrm{h}) \mathrm{SE}-\mathrm{SAO} \ldots \ldots \ldots \ldots \ldots \ldots$

4.13 Composites of mean equivalent potential temperature $\left(\theta_{e}\right)$ at $925 \mathrm{hPa}(\mathrm{K}$; black lines), RH (\%; shaded) and PV at $300 \mathrm{hPa}$ (PVU; red line) from different genesis regions in the (a-d) summer and (f-g) winter : (a,e) SEBR, $(\mathrm{b}, \mathrm{f})$ LA PLATA, $(\mathrm{c}, \mathrm{g})$ ARG and $(\mathrm{d}, \mathrm{h}) \mathrm{SE-SAO} . \ldots . . . . . . .$.

4.14 Composites of SE-BR cyclones temperature advection at $850 \mathrm{hPa}\left(10^{-5} \mathrm{~K}\right.$ $s^{-1}$; shaded), geopotential height at $500 \mathrm{hPa}$ (gpm; black line) and winds at $850 \mathrm{hPa}\left(\mathrm{m} \mathrm{s}^{-1}\right)$ in the (a-c) summer and (d-f) winter: (a,d) at 12 hours before time of genesis; (b,e) at time of genesis, and; $(c, f)$ at 24 hours after genesis. . . . . . . . . . . . . . . . . .

4.15 Composites of SE-BR cyclones omega at $700 \mathrm{hPa}\left(10^{-2} \mathrm{~Pa} \mathrm{~s}^{-1}\right.$; shaded), vertically integrated moisture transport $\left(\mathrm{kg} \mathrm{m}^{-1} \mathrm{~s}^{-1}\right.$; arrows) and moisture flux convergence $\left(10^{-3} \mathrm{~kg} \mathrm{~m}^{-2} \mathrm{~s}-1\right.$; contour) at low level $(925-700 \mathrm{hPa})$ in the (a-c) summer and (d-f) winter: (a,d) at 12 hours before time of genesis; (b,e) at time of genesis, and; (c,f) at 24 hours after genesis. The vertical velocity is contoured every $0.2 \times 10^{-3} \mathrm{~kg} \mathrm{~m}^{-2} \mathrm{~s}-1$, without the zero line and negative values (downward movement) are in dashed line. . . . . . . . . .

4.16 Composites of SE-BR cyclones potential temperature ( $K$; black line), geopotential height (gpm; blue line) and divergence of mass $\left(s^{-1}\right.$; shaded) at $200 \mathrm{hPa}$ in the (a-c) summer and (d-f) winter: (a,d) at 12 hours before time of genesis; (b,e) at time of genesis, and; (c,f) at 24 hours after genesis. . . . 
4.17 Composites of LA PLATA cyclones in the winter: (a-c) temperature advection at $850 \mathrm{hPa}\left(10^{-5} \mathrm{~K}^{-1}\right.$; shaded), geopotential height at $500 \mathrm{hPa}$ (gpm; black line) and winds at $850 \mathrm{hPa}\left(\mathrm{m} \mathrm{s}^{-1}\right) ;(\mathrm{d}-\mathrm{f})$ omega at $700 \mathrm{hPa}\left(10^{-2} \mathrm{~Pa}\right.$ $\mathrm{s}^{-1}$; shaded), vertically integrated moisture transport $\left(\mathrm{kg} \mathrm{m}^{-1} \mathrm{~s}^{-1}\right.$; arrows $)$ and moisture flux convergence $\left(10^{-3} \mathrm{~kg} \mathrm{~m}^{-2} \mathrm{~s}-1\right.$; contour) at low level (925 - $700 \mathrm{hPa}$ ), and; (g-i) potential temperature ( $K$; black line), geopotential height (gpm; blue line) and divergence of mass $\left(s^{-1}\right.$; shaded) at $200 \mathrm{hPa}$. Composites $(\mathrm{a}, \mathrm{d}, \mathrm{g})$ at 12 hours before the time of genesis; $(\mathrm{b}, \mathrm{e}, \mathrm{h})$ at the time of genesis, and; (c,f,i) at 24 hours after the time of genesis. The vertical velocity is contoured every $0.2 \times 10^{-3} \mathrm{~kg} \mathrm{~m}^{-2} \mathrm{~s}-1$, without the zero line and negative values (downward movement) are in dashed line. . . . . . . . 95

4.18 As in Fig 4.17 but for the composites of ARG cyclones in the summer. . 97

4.19 As in Fig 4.17 but for the composites of SE-SAO cyclones in the winter. . .

5.1 NCEP-CFSR genesis density for 1980-2005 period in the (a) summer and (b) winter, and track density in the (c) summer and (d) winter for South Atlantic domain. The density unit is cyclone per $10^{6} \mathrm{~km}^{2}$ per month. . . . 104

5.2 HadGEM2-ES genesis density in the (a) summer and (b) winter and the associated biases in the (c) summer and (d) winter. Unit for the bias and genesis density is cyclone per $10^{6} \mathrm{~km}^{2}$ per month. . . . . . . . . 106

5.3 HadGEM2-ES track density in the (a) summer and (b) winter and the associated biases in the (c) summer and (d) winter. Unit for the bias and track density unit is cyclone per $10^{6} \mathrm{~km}^{2}$ per month. . . . . . . . . . . . . 108

5.4 HadGEM2-ES historical (dashed line) and NCEP-CFSR (solid line) histograms of the maximum filtered vorticity at $850 \mathrm{hPa}$ in the summer (left) and winter (right) for (a,b) South Atlantic, (c,d) SE-BR, (e,f) LA PLATA, (g,h) ARG, and (i,j) SE-SAO regions. The vorticity is scaled by $-1 \times 10^{-5} s^{-1}$. The intensity histograms were produced for cyclones originated in each genesis region separately. The percentage was computed based on the mean cyclones per month for each region. 
5.5 Spatial distribution of the mean growth rate $\left(-1 \times 10^{-5} s^{-1} d a y^{-1}\right)$ in the (a) summer and (b) winter. The fields are not plotted where track density $<0.3$ cyclones $\left(10^{6} \mathrm{~km}^{2}\right)^{-1}$ mont $^{-1}$.

5.6 Spatial distribution of SST gradient at the time of genesis in the (a) summer and (b) winter. Sea surface temperature (SST) gradient in South Atlantic Ocean in the austral (c) summer and (d) winter. The gradient unit is $10^{-3}$ $K \mathrm{~km}^{-1}$. The fields are not plotted where genesis density $<0.2$ cyclones $\left(10^{6} \mathrm{~km}^{2}\right)^{-1} \mathrm{month}^{-1} \ldots \ldots \ldots \ldots \ldots \ldots \ldots$

5.7 Spatial distribution of the integrated humidity at lower-level $\left(\mathrm{kg} \mathrm{kg}^{-1}\right)$ at genesis time in the austral (a) summer and (b) winter; $\partial \theta / \partial p\left(10^{-2} \mathrm{~K}\right.$ $\left.h \mathrm{~Pa}^{-1}\right)$ at genesis time in the (c) summer and (d) winter, and; $\partial \theta_{e} / \partial p\left(10^{-2}\right.$ $K h \mathrm{~Pa}^{-1}$ ) at genesis time in the (e) summer and (f) winter. The fields are not plotted where genesis density $<0.2$ cyclones $\left(10^{6} \mathrm{~km}^{2}\right)^{-1} \mathrm{month}^{-1}$. . . 113

5.8 Spatial distribution of upper-level jet $\left(\mathrm{ms}^{-1}\right)$ in the austral (a) summer and (b) winter; and the potential vorticity at $300 \mathrm{hPa}(\times-1 P V U)$ in the (c) summer and (d) winter at the time of genesis. The field distribution at genesis and at the maximum intensity are not plotted where genesis and track density $<0.2$ cyclones $\left(10^{6} \mathrm{~km}^{2}\right)^{-1}$ mont $^{-1}$ and $<0.5$ cyclones $\left(10^{6} \mathrm{~km}^{2}\right)^{-1}$ month $^{-1}$, respectively. . . . . . . . . . . . .

5.9 Composites of mean equivalent potential temperature $\left(\theta_{e}\right)$ at $925 \mathrm{hPa}(\mathrm{K}$; shaded) and MSLP (hPa; black line) from different genesis regions in the (a-d) summer and (f-g) winter : (a,e) SE-BR, (b,f) LA PLATA, (c,g) ARG and $(\mathrm{d}, \mathrm{h}) \mathrm{SE}-\mathrm{SAO} \ldots \ldots \ldots \ldots . \ldots \ldots$

5.10 Composites of mean equivalent potential temperature $\left(\theta_{e}\right)$ at $925 \mathrm{hPa}(\mathrm{K}$; black lines), RH (\%; shaded) and PV at $300 \mathrm{hPa}$ (PVU; red line) from different genesis regions in the (a-d) summer and (f-g) winter : (a,e) SEBR, (b,f) LA PLATA, $(\mathrm{c}, \mathrm{g})$ ARG and $(\mathrm{d}, \mathrm{h})$ SE-SAO. . . . . . . . . . . . . 117

5.11 Composites of temperature advection at $850 \mathrm{hPa}\left(10^{-5} \mathrm{~K} \mathrm{~s}^{-1}\right.$; shaded $)$, geopotential height at $500 \mathrm{hPa}$ (gpm; black line) and winds at $850 \mathrm{hPa}(\mathrm{m}$ $s^{-1}$ ) for SE-BR cyclones in the (a-c) summer and (d-f) winter: (a,d) at 12 hours before the time of genesis; (b,e) at the time of genesis, and; (c,f) at 24 hours after genesis. . . . . . . . . . . . . . . . 
5.12 Composites of vertically integrated moisture flux convergence $\left(10^{-3} \mathrm{~kg} \mathrm{~m}^{-2} \mathrm{~s}-1\right.$; shaded) and moisture transport $\left(\mathrm{kg} \mathrm{m}^{-1} \mathrm{~s}^{-1}\right.$; arrows) at low levels (925 - 700 $\mathrm{hPa}$ ) for SE-BR cyclones in the (a-c) summer and (d-f) winter: (a,d) at 12 hours before the time of genesis; (b,e) at the time of genesis, and (c,f) at 24 hours after genesis. . . . . . . . . . . . . . . . . . 120

5.13 Winter composites of (a-c) temperature advection at $850 \mathrm{hPa}\left(10^{-5} \mathrm{~K} \mathrm{~s}^{-1}\right.$; shaded), geopotential height at $500 \mathrm{hPa}$ (gpm; black line) and winds at $850 \mathrm{hPa}\left(\mathrm{m} \mathrm{s}^{-1}\right)$; and (d-f) vertically integrated moisture flux convergence $\left(10^{-3} \mathrm{~kg} \mathrm{~m}^{-2} \mathrm{~s}-1\right.$; shaded $)$ and moisture transport $\left(\mathrm{kg} \mathrm{m}^{-1} \mathrm{~s}^{-1}\right.$; arrows $)$ at low levels (925 - $700 \mathrm{hPa}$ ) for LA PLATA cyclones: (a,d) at 12 hours before the time of genesis; (b,e) at the time of genesis, and; (c,f) at 24 hours after

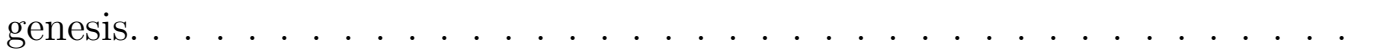

5.14 Composites of temperature advection at $850 \mathrm{hPa}\left(10^{-5} \mathrm{~K}^{-1}\right.$; shaded), geopotential height at $500 \mathrm{hPa}$ (gpm; black line) and winds at $850 \mathrm{hPa}(\mathrm{m}$ $s^{-1}$ ) for ARG cyclones in the summer: (a) at 12 hours before the time of genesis; (b) at the time of genesis, and; (c) at 24 hours after genesis. . . . . 123

5.15 As in Fig 5.14 but for the composites of SE-SAO cyclones in the winter. . . 124

6.1 Genesis density in the austral (a) summer and (b) winter, and genesis density from RCP8.5 future projected changes for (c) summer and (d) winter. The density unit is cyclone per $10^{6} \mathrm{~km}^{2}$ per month. . . . . . . . . . .

6.2 Track density in the austral (a) summer and (b) winter, and track density from RCP8.5 future projected changes for (c) summer and (d) winter. The density unit is cyclone per $10^{6} \mathrm{~km}^{2}$ per month. . . . . . . . . . . 130

6.3 HadGEM2-ES RCP8.5 (dashed line) and historical (solid line) histograms of the maximum filtered vorticity at $850 \mathrm{hPa}$ in the (left) summer and (right) winter, for the regions: (a,b) South Atlantic, (c,d) SE-BR, (e,f) LA PLATA, $(\mathrm{g}, \mathrm{h}) \mathrm{ARG}$, and $(\mathrm{i}, \mathrm{j})$ SE-SAO. The vorticity is scaled by $-1 \times 10^{-5} \mathrm{~s}^{-1}$. The intensity histograms were produced for cyclones originated in each genesis region separately. The percentage was computed based on the mean cyclones per month for each region. 
6.4 HadGEM2-ES RCP8.5 (dashed line) and historical (solid line) histograms of the minimum MSLP (hPa) in the (left) summer and (right) winter, for the regions: (a,f) South Atlantic, (b,g) SE-BR, (c,h) LA PLATA, (d,i) ARG, and $(\mathrm{e}, \mathrm{j})$ SE-SAO. The minimum MSLP was searched within $5^{\circ}$ radius from the center of the cyclone. The intensity histograms were produced for cyclones originated in each genesis region separately. The percentage was computed based on the mean cyclones per month for each region. . . . . . . . . .

6.5 HadGEM2-ES RCP8.5 (dashed line) and historical (solid line) histograms of the maximum wind speed at $925 \mathrm{hPa}\left(\mathrm{m} \mathrm{s}^{-1}\right)$ in the (left) summer and (right) winter for the regions: (a,f) South Atlantic, (b,g) SE-BR, (c,h) LA PLATA, (d,i) ARG, and (e,j) SE-SAO. The maximum wind speed was searched within $6^{\circ}$ radius from the center of the cyclone. The intensity histograms were produced for cyclones originated in each genesis region separately. The percentage was computed based on the mean cyclones per month for each region. . . . . . . . . . . . . . . . .

6.6 RCP8.5 future projected changes in the spatial distribution of the mean speed $(a, b)$ and mean growth rate $(c, d)$ in the $(a, c)$ summer and $(b, d)$ winter. The units are $m s^{-1}$ for the speed and $-1 \times 10^{-5} s^{-1} d a y^{-1}$ for the growth rate. The fields are not plotted where HadGEM2-ES RCP8.5 track density $<0.3$ cyclones $\left(10^{6} \mathrm{~km}^{2}\right)^{-1}$ month $^{-1}$. . . . . . . . . . . . .

6.7 RCP8.5 future projected changes in the spatial distribution of SST gradient at genesis time in the (a) summer and (b) winter, and the changes in the mean SST gradient field in the (c) summer and (d) winter. The gradient unit is $10^{-3} \mathrm{~K} \mathrm{~km}^{-1}$ and the field is not plotted where genesis density < 0.2 cyclones $\left(10^{6} \mathrm{~km}^{2}\right)^{-1} \mathrm{month}^{-1} \ldots \ldots \ldots \ldots \ldots$

6.8 RCP8.5 future projected changes in the spatial distribution of the integrated humidity at lower-level $\left(\mathrm{kg} \mathrm{kg}^{-1}\right)$ at the genesis time in the (a) austral summer and (b) winter; $\partial \theta / \partial p\left(10^{-2} K_{\left.h P a^{-1}\right)}\right.$ at the genesis time in the (c) summer and (d) winter, and; $\partial \theta_{e} / \partial p\left(10^{-2} K_{h P a^{-1}}\right)$ at the genesis time in the (e) summer and (f) winter. The fields are not plotted where genesis density $<0.2$ cyclones $\left(10^{6} \mathrm{~km}^{2}\right)^{-1}$ month $^{-1} \ldots$. . . . . . . . . . 137 
6.9 RCP8.5 future projected changes in the spatial distribution of upper-level jet $\left(\mathrm{m} \mathrm{s}^{-1}\right)$ in the austral (a) summer and (b) winter; and the potential vorticity at $300 \mathrm{hPa}(\times-1 P V U)$ in the $(\mathrm{c})$ summer and $(\mathrm{d})$ winter at the time of genesis. The field distribution at genesis and at the maximum intensity are not plotted where genesis and track density were $<0.2$ cyclones $\left(10^{6} \mathrm{~km}^{2}\right)^{-1}$ mont $^{-1}$ and $<0.5$ cyclones $\left(10^{6} \mathrm{~km}^{2}\right)^{-1}$ mont $^{-1}$, respectively. 139

$6.10 \mathrm{RCP} 8.5$ future projected changes in mean upper-level jet speed $\left(\mathrm{m} \mathrm{s}^{-1}\right)$ in the austral (a) summer and (b) winter. . . . . . . . . . . . . 139

6.11 Composites of mean equivalent potential temperature $\left(\theta_{e}\right)$ at $925 \mathrm{hPa}(\mathrm{K}$; shaded) and MSLP (hPa; black line) from different genesis regions in the (a-d) summer and (f-g) winter : (a,e) SE-BR, (b,f) LA PLATA, (c,g) ARG

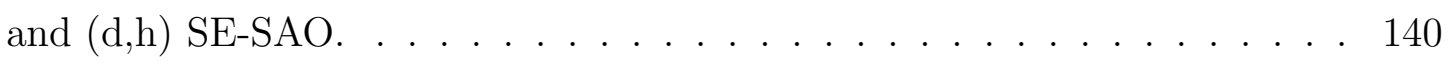

6.12 Composites of the SE-BR cyclones in the winter, for the fields: (a-c) temperature advection at $850 \mathrm{hPa}\left(10^{-5} \mathrm{~K}^{-1}\right.$; shaded $)$, geopotential height at $500 \mathrm{hPa}\left(\mathrm{gpm}\right.$; black line) and winds at $850 \mathrm{hPa}\left(\mathrm{m} \mathrm{s}^{-1}\right)$; (d-f) vertically integrated moisture flux convergence $\left(10^{-3} \mathrm{~kg} \mathrm{~m}^{-2} \mathrm{~s}-1\right.$; shaded) and moisture transport $\left(\mathrm{kg} \mathrm{m}^{-1} \mathrm{~s}^{-1}\right.$; arrows) and at low level (925 - $\left.700 \mathrm{hPa}\right)$, and; (g-i) potential temperature ( $K$; black line), geopotential height (gpm; blue line) and divergence of mass $\left(s^{-1}\right.$; shaded) at $200 \mathrm{hPa}$. Composites (a,d,g) at 12 hours before the time of genesis; (b,e,h) at the time of genesis, and; $(\mathrm{c}, \mathrm{f}, \mathrm{i})$ at 24 hours after the time of genesis. . . . . . . . . . . . 142

6.13 As in Fig 6.12 but for the composites of LA PLATA cyclones in the summer.143

7.1 Mean temperature at $2 \mathrm{~m}\left({ }^{\circ} \mathrm{C}\right)$ distribution in austral summer for the ExpCFSR, NCEP-CFSR, NASA-MERRA; and the differences ExpCFSR NCEP-CFSR and ExpCFSR - NASA-MERRA. The climatological mean comprises the 1991-2005 period. . . . . . . . . . . . . . . 149

7.2 As in Fig 7.1 but for the winter. . . . . . . . . . . . . 150

7.3 As in Fig 7.1 but for the mean precipitation $\left(m m d a y^{-1}\right)$ distribution in the austral summer. . . . . . . . . . . . . . . . . . 151

7.4 As in Fig 7.1 but for the mean precipitation $\left(m m d a y^{-1}\right)$ distribution in the winter. . . . . . . . . . . . . . . . . . . 152 
7.5 As in Fig. 7.1 but for the mean meridional wind speed at $850 \mathrm{hPa}\left(\mathrm{ms}^{-1}\right)$ in the austral summer. . . . . . . . . . . . . . . . . 153

7.6 As in Fig.7.1 but for the mean meridional wind speed at $850 \mathrm{hPa}\left(\mathrm{ms}^{-1}\right)$ in the winter. . . . . . . . . . . . . . . . . . 154

7.7 Orographic representation (m) in the (a) ExpCFSR, (b) NCEP-CFSR and (c) HadGEM2-ES; and the differences (d) ExpCFSR - NCEP-CFSR and (e) ExpCFSR - HadGEM2-ES. . . . . . . . . . . . . . . .

7.8 ExpCFSR genesis density in the (a) summer and (b) winter and the differences (ExpCFSR - NCEP-CFSR) in the (c) summer and (d) winter. The units for the genesis density and the differences are cyclone per $10^{6} \mathrm{~km}^{2}$ per month. . . . . . . . . . . . . . . . . . .

7.9 Example of the filtered relative vorticity field (at $850 \mathrm{hPa}$ ) in a given time step for the (a) NCEP-CFSR and (b) ExpCFSR. Each number indicates a tracking identification label in the algorithm. The vorticity unit is $\left(s^{-1}\right)$. .

7.10 Spatial distribution of the integrated humidity at lower-level $\left(\mathrm{kg} \mathrm{kg}^{-1}\right)$, $\partial \theta / \partial p\left(10^{-2} K h \mathrm{~Pa}^{-1}\right), \partial \theta_{e} / \partial p\left(10^{-2} K h P a^{-1}\right)$ and the upper-level jet $\left(m s^{-1}\right)$ for ExpCFSR, at the genesis time in the austral summer (a, c, e and $\mathrm{g}$, respectively) and winter (b,d, f and $\mathrm{h}$, respectively). The fields are not plotted where genesis density $<0.2$ cyclones $\left(10^{6} \mathrm{~km}^{2}\right)^{-1} \mathrm{month}^{-1}$. . . . . 160

7.11 ExpCFSR track density in the (a) summer and (b) winter and the differences (ExpCFSR - NCEP-CFSR) in the (c) summer and (d) winter. The units for the track density and the differences are track per $10^{6} \mathrm{~km}^{2}$ per month. . 161

7.12 Histograms of the maximum filtered vorticity at $850 \mathrm{hPa}$ in the summer (left) and winter (right) for (a,b) South Atlantic, (c,d) SE-BR, (e,f) LA PLATA and (g,h) ARG. The NCEP-CFSR (dashed line), ExpCFSR (black solid line) and ExpHad-Hist (blue line) for 1991-2005, and ExpHadRCP85 (red line) for 2085-2099. The vorticity is scaled by $-1 \times 10^{-5} s^{-1}$. The intensity histograms were produced for cyclones originated in each genesis region separately. The percentage was computed based on the mean cyclones per month for each region. 
7.13 ExpHad-Hist genesis density in the (a) summer and (b) winter and the biases (ExpHad-Hist - ExpCFSR) in the (c) summer and (d) winter. The units for the genesis density and the differences are cyclone per $10^{6} \mathrm{~km}^{2}$ per

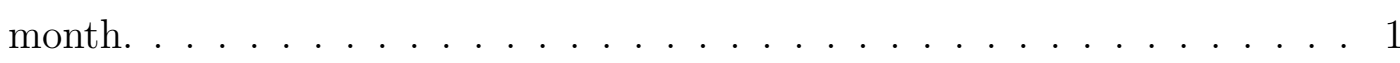

7.14 Spatial distribution of the integrated humidity at lower-level $\left(\mathrm{kg} \mathrm{kg}^{-1}\right)$, $\partial \theta / \partial p\left(10^{-2} K h \mathrm{~Pa}^{-1}\right), \partial \theta_{e} / \partial p\left(10^{-2} K h P a^{-1}\right)$ and the upper-level jet for ExpHad-Hist, at the genesis time in the austral summer (a, c, e and g, respectively) and winter (b, $\mathrm{d}, \mathrm{f}$ and $\mathrm{h}$, respectively). The fields are not plotted where genesis density $<0.2$ cyclones $\left(10^{6} \mathrm{~km}^{2}\right)^{-1} \mathrm{month}^{-1} \ldots$. . . . 165

7.15 ExpHad-Hist track density in the (a) summer and (b) winter and biases (ExpHad-Hist - ExpCFSR) in the (c) summer and (d) winter. The units for the track density and the differences are cyclone per $10^{6} \mathrm{~km}^{2}$ per month. 166

7.16 ExpHad-RCP85 genesis density in the (a) summer and (b) winter and the changes (ExpHad-RCP85 - ExpHad-Hist) in the (c) summer and (d) winter. The units for the genesis density and the changes are cyclones per $10^{6} \mathrm{~km}^{2}$ per month. . . . . . . . . . . . . . . . . . .

7.17 Spatial distribution of the integrated humidity at lower-level $\left(\mathrm{kg} \mathrm{kg}^{-1}\right)$, $\partial \theta / \partial p\left(10^{-2} K h \mathrm{~Pa}^{-1}\right), \partial \theta_{e} / \partial p\left(10^{-2} K h \mathrm{~Pa}^{-1}\right)$ and the upper-level jet $\left(m s^{-1}\right)$ for ExpHad-RCP85, at the genesis time in the austral summer (a, c, e and g, respectively) and winter (b, d, f and h, respectively). The fields are not plotted where genesis density $<0.2$ cyclones $\left(10^{6} \mathrm{~km}^{2}\right)^{-1} \mathrm{month}^{-1}$.

7.18 ExpHad-RCP85 track density in the (a) summer and (b) winter and the changes (ExpHad-RCP85 - ExpHad-Hist) in the (c) summer and (d) winter. The units for the track density and the changes are cyclone per $10^{6} \mathrm{~km}^{2}$ per

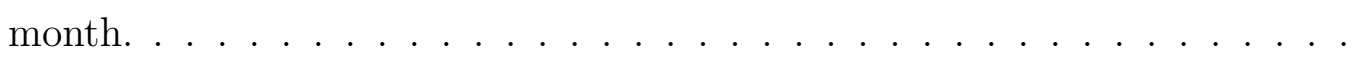

A.1 Spatial distribution at the time of genesis of the integrated humidity at lower-level $\left(\mathrm{kg} \mathrm{kg}^{-1}\right)$ in (a) austral summer and (b) winter; $\partial \theta / \partial p\left(10^{-2} \mathrm{~K}\right.$ $\left.h \mathrm{~Pa}^{-1}\right)$ in (c) summer and (d) winter, and; $\partial \theta_{e} / \partial p\left(10^{-2} K h P a^{-1}\right)$ in (e) summer and (f) winter. The fields are not plotted where genesis density < 0.2 cyclones $\left(10^{6} \mathrm{~km}^{2}\right)^{-1}$ month $^{-1} \ldots \ldots \ldots \ldots$. . . . . . . . . 
B.1 HadGEM2-ES historical (dashed line) and NCEP-CFSR (solid line) histograms of the minimum MSLP (hPa) in the (upper) summer and (lower) winter; (a,f) South Atlantic, (b,g) SE-BR, (c,h) LA PLATA, (d,i) ARG, and $(e, j)$ SE-SAO regions. The minimum MSLP was searched within $5^{\circ}$ radius from the center of the cyclone. The intensity histograms were produced for cyclones originate in each genesis region separately. The percentage was computed based on the mean cyclones per month for each region. . . . . . 204

B.2 HadGEM2-ES historical (dashed line) and NCEP-CFSR (solid line) histograms of the maximum wind speed at $925 \mathrm{hPa}\left(\mathrm{m} \mathrm{s}^{-1}\right)$ in the (upper) summer and (lower) winter; (a,f) South Atlantic, (b,g) SE-BR, (c,h) LA PLATA, (d,i) ARG, and (e,j) SE-SAO regions. The maximum wind speed was searched within $6^{\circ}$ radius from the center of the cyclone. The intensity histograms were produced for cyclones originate in each genesis region separately. The percentage was computed based on the mean cyclones per month for each region. . . . . . . . . . . . . . . . . 205

B.3 HadGEM2-ES historical climatological mean (1980-2005) of $\delta \theta / \delta p\left(10^{-2} \mathrm{~K}\right.$ $h P a^{-1}$ in the (c) summer and (d) winter; $\delta \theta_{e} / \delta p\left(10^{-2} K h P a^{-1}\right.$ in the (e) summer and (f) winter; and low-level vertically integrated humidity ( $k g$ $\left.k g^{-1} \mathrm{~Pa}\right)$ in the $(\mathrm{g})$ summer and $(\mathrm{h})$ winter. . . . . . . . . . . 206

B.4 HadGEM2-ES historical climatological mean (1980-2005) of the PV at 300 $\mathrm{hPa}(\times-1 P V U)$ in the (a) summer and (b) winter; and the upper level jet speed $\left(\mathrm{m} \mathrm{s}^{-1}\right)$ in the $(\mathrm{c})$ summer and $(\mathrm{d})$ winter. . . . . . . . . . . 207

C.1 Composites of mean equivalent potential temperature $\left(\theta_{e}\right)$ at $925 \mathrm{hPa}(\mathrm{K}$; black lines), $\mathrm{RH}$ (\%; shaded) and $\mathrm{PV}$ at $300 \mathrm{hPa}$ (PVU; red line) from different genesis regions in the (a-d) summer and (f-g) winter : (a,e) SEBR, (b,f) LA PLATA, (c,g) ARG and $(d, h)$ SE-SAO. 
C.2 Composites of SE-BR cyclones in the summer: (a-c) temperature advection at $850 \mathrm{hPa}\left(10^{-5} \mathrm{~K} \mathrm{~s}^{-1}\right.$; shaded), geopotential height at $500 \mathrm{hPa}$ (gpm; black line) and winds at $850 \mathrm{hPa}\left(\mathrm{m} \mathrm{s}^{-1}\right)$; (d-f) vertically integrated moisture flux convergence $\left(10^{-3} \mathrm{~kg} \mathrm{~m}^{-2} \mathrm{~s}-1\right.$; shaded $)$ and moisture transport $\left(\mathrm{kg} \mathrm{m}^{-1} \mathrm{~s}^{-1}\right.$; arrows) and at low level $(925-700 \mathrm{hPa})$, and; (g-i) potential temperature ( $K$; black line), geopotential height (gpm; blue line) and divergence of mass $\left(s^{-1}\right.$; shaded) at $200 \mathrm{hPa}$. Composites $(\mathrm{a}, \mathrm{d}, \mathrm{g})$ at 12 hours before the time of genesis; (b,e,h) at the time of genesis, and; (c,f,i) at 24 hours after the time of genesis. . . . . . . . . . . . . . . . . . . 212

C.3 As Fig. C.2 but for the LA PLATA cyclones in the winter. . . . . . . . . . 213

C.4 As Fig.C.2 but for the ARG cyclones in the summer. . . . . . . . . . . . 214

C.5 As Fig. C.2 but for the SE-SAO cyclones in the winter. . . . . . . . . . . 215

D.1 Mean velocity at $850 \mathrm{hPa}\left(\mathrm{ms}^{-1}\right)$ distribution in austral summer for the ExpCFSR, NCEP-CFSR, NASA-MERRA; and the differences ExpCFSR NCEP-CFSR and ExpCFSR - NASA-MERRA. The climatological mean comprises the 1991-2005 period. . . . . . . . . . . . . 218

D.2 As in Fig. D.1 but for the winter. . . . . . . . . . . . . . 219

D.3 Genesis and track density in the austral summer for the (a,b) NCEP-CFSR T42 global data, (c,d) NCEP-CFSR spatial filter in the regional model grid. 220

D.4 Histograms of the minimum MSLP (hPa) in the summer (left) and winter (right) for (a,b) South Atlantic, (c,d) SE-BR, (e,f) LA PLATA, and (g,h) ARG. The minimum MSLP was searched within $5^{\circ}$ radius from the center of the cyclone. The NCEP-CFSR (dashed line), ExpCFSR (black solid line) and ExpHad-Hist (blue line) for 1991-2005, and ExpHadRCP85 (red line) for 2085-2099. The intensity histograms were produced for cyclones originated in each genesis region separately. The percentage was computed based on the mean cyclones per month for each region. . . . . . . . . . . 
D.5 Histograms of the maximum wind speed at $925 \mathrm{hPa}\left(\mathrm{ms}^{-1}\right)$ in the summer (left) and winter (right) for (a,b) South Atlantic, (c,d) SE-BR, (e,f) LA PLATA, and (g,h) ARG. The NCEP-CFSR (dashed line), ExpCFSR (black solid line) and ExpHad-Hist (blue line) for 1991-2005, and ExpHadRCP85 (red line) for 2085-2099. The maximum wind speed was searched within $6^{\circ}$ radius from the center of the cyclone. The intensity histograms were produced for cyclones originated in each genesis region separately. The percentage was computed based on the mean cyclones per month for each region. . . . . . . . . . . . . . . . . . . . . 222 


\section{List of Tables}

3.1 Parametrization set-up applied in the climate experiments. These options are suggested by the WRF model guide for "regional climate" . . . . . . . . 60

3.2 Comparison between the constraints suggested by Hoskins and Hodges (2002) and the ones used in this work. . . . . . . . . . . . . . . . . 64

4.1 Total number of cyclones, annual mean and standard deviation for South Atlantic domain $\left(15^{\circ} \mathrm{S}-55^{\circ} \mathrm{S}, 75^{\circ} \mathrm{W}-20^{\circ} \mathrm{E}\right)$ and each genesis region within the domain. The values were computed for all analysis period (1980-2010), and separately for summer (DJF) and winter (JJA) . . . . . . . . . . 72

4.2 The mean $850 \mathrm{hPa}$ relative vorticity at genesis time (scaled by $-1 \times 10^{-5} \mathrm{~s}^{-1}$ ), mean lifetime (days) and mean cyclone displacement speed $\left(m s^{-1}\right)$ and standard deviations computed within South Atlantic domain $\left(15^{\circ} \mathrm{S}-55^{\circ} \mathrm{S}\right.$, $\left.75^{\circ} \mathrm{W}-20^{\circ} \mathrm{E}\right)$ and within each defined genesis region. The means were calculated for the whole analysis period (1980-2010), only for summer (DJF) and only for winter $(\mathrm{JJA}) \ldots \ldots \ldots \ldots \ldots$

4.3 Intensity threshold (scaled by $-1 \times 10^{-5} \mathrm{~s}^{-1}$ ) applied to the selection of $30 \%$ most intense cyclone of each defined genesis region in summer and winter and the number of cyclones used to compute the each composites. . . . . . 
5.1 Total number of cyclones, annual mean and standard deviation for South Atlantic domain $\left(15^{\circ} \mathrm{S}-55^{\circ} \mathrm{S}, 75^{\circ} \mathrm{W}-20^{\circ} \mathrm{E}\right)$ and for each defined cyclogenesis region within the domain. The values were computed for the 1980-2005 period and divided in summer (DJF) and winter (JJA). The number in parentheses at the third column is the percentage of the HadGEM2-ES total relative to NCEP-CFSR. . . . . . . . . . . . . . . . 105

5.2 The mean $850 \mathrm{hPa}$ relative vorticity at genesis time $\left(-1 \times 10^{-5} \mathrm{~s}^{-1}\right)$, mean lifetime (days), mean cyclone displacement speed $\left(m s^{-1}\right)$ and standards deviations computed within South Atlantic domain $\left(15^{\circ} \mathrm{S}-55^{\circ} \mathrm{S}, 75^{\circ} \mathrm{W}-20^{\circ} \mathrm{E}\right)$ and within each defined genesis region. The means were calculated for the HadGEM2-ES historical (1980-2005) for the summer (DJF) and winter (JJA).110

5.3 Intensity threshold (multiplied by $-1 \times 10^{-5}$ ) applied to select the $30 \%$ most intense cyclones of each defined genesis region in the summer and winter, and the number of cyclones used to compute each composite in the HadGEM2-

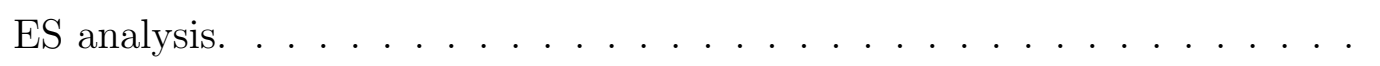

6.1 Total number of cyclones, annual mean and standard deviation for South Atlantic domain $\left(15^{\circ} \mathrm{S}-55^{\circ} \mathrm{S}, 75^{\circ} \mathrm{W}-20^{\circ} \mathrm{E}\right)$ and for each defined cyclogenesis region within the domain. The values were computed for the 2074-2099 time period for the summer (DJF) and winter (JJA). The numbers in parentheses at the third column are the percentage of the HadGEM2-ES RCP8.5 total on the historical experiment total number. . . . . . . . . . . . . . . 128

6.2 Intensity threshold (scaled by $-1 \times 10^{-5}$ ) applied to select the $30 \%$ most intense cyclones of each defined genesis region in the summer and winter and the number of cyclones used to compute each composite in the HadGEM2ES RCP8.5 analysis. . . . . . . . . . . . . . . . . . . 139

7.1 Total number, annual mean and standard deviation of cyclones in South Atlantic domain (model grid) and in each defined cyclogenesis region within the domain. The values were computed for the 1991-2005 in the summer (DJF) and winter (JJA). The number in parentheses at the third column is the percentage of the ExpCFSR total relative to NCEP-CFSR . . . . . . . 156 
7.2 Total number, annual mean and standard deviation of cyclones for South Atlantic domain (model grid) and each defined cyclogenesis region within the domain. The values were computed for the 1991-2005 period in the summer (DJF) and winter (JJA). The number in parentheses at the second column is the percentage of the ExpHad-Hist total relative to ExpHad-RCP85.163.

C.1 The mean $850 \mathrm{hPa}$ relative vorticity at genesis time $\left(-1 \times 10^{-5} \mathrm{~s}^{-1}\right)$, mean lifetime (days) and mean cyclone displacement speed $\left(\mathrm{ms}^{-1}\right)$ and standards deviations computed within South Atlantic domain $\left(15^{\circ} \mathrm{S}-55^{\circ} \mathrm{S}, 75^{\circ} \mathrm{W}-20^{\circ} \mathrm{E}\right)$ and within each defined genesis region. The means were calculated for the HadGEM2-ES RCP8.5 experiment (2074-2099) for the summer (DJF) and winter $(\mathrm{JJA}) . \ldots \ldots \ldots \ldots$. . . . . . . . . . . . . . . . . . . . . . 



\section{Contents}

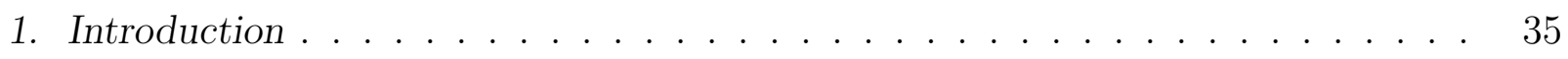

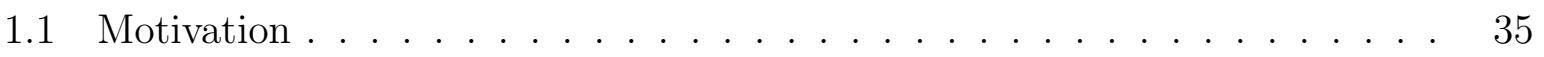

1.2 Scientific gap and Goals . . . . . . . . . . . . . . . 36

2. Theoretical background . . . . . . . . . . . . . . . . . 39

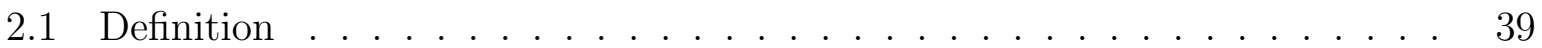

2.2 Cyclone development and intensification mechanisms . . . . . . . . . . 40

$2.2 .1 \quad$ Baroclinic Instability . . . . . . . . . . . . . . 40

2.2.2 Diabatic heating and oceanic interactions . . . . . . . . . 41

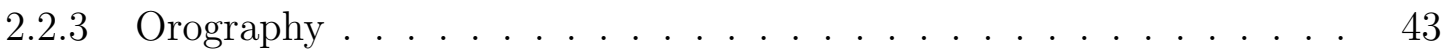

2.3 Classification schemes . . . . . . . . . . . . . . . . . 44

2.3 .1 Conceptual models . . . . . . . . . . . . . . 44

2.4 South Atlantic Cyclones . . . . . . . . . . . . . . . . . 45

2.5 Cyclones and Climate Change . . . . . . . . . . . . . . 48

2.5.1 Observed trends in reanalysis data . . . . . . . . . 48

2.5.2 Changes in cyclones in global climate models . . . . . . . . . . 49

2.5.3 Possible driving mechanisms of cyclone changes . . . . . . . . . 50 50

3. Data, Models and Methods ................... 55

3.1 Reanalysis ........................... 53

3.2 Climate Model . . . . . . . . . . . . . . . . . . 54

3.2.1 CMIP5 experiments . . . . . . . . . . . . 54

3.2 .2 HadGEM2-ES . . . . . . . . . . . . . . . . . . 56

3.2 .3 Data pre-processing . . . . . . . . . . . . . 56 
3.3 Dynamical Downscaling . . . . . . . . . . . . . . . . 57

3.3 .1 Climate experiment . . . . . . . . . . . . . 58

3.3.2 Evaluation of the climate experiment setup . . . . . . . . 60

3.4 Cyclone identification . . . . . . . . . . . . . . . . . 61 61

3.4 .1 TRACK Algorithm . . . . . . . . . . . . . . . . . 62

3.4 .2 Validation and applied constraints . . . . . . . . 6 63

3.4.3 Remarks about tracking in a limited area . . . . . . . . . 64

3.5 Cyclone Diagnostics . . . . . . . . . . . . . . . . . . . 65 65

3.6 Compositing of cyclones structure . . . . . . . . . . . . . 66

4. Spatial Distribution and Characteristics of the South Atlantic Cyclones ..... 69

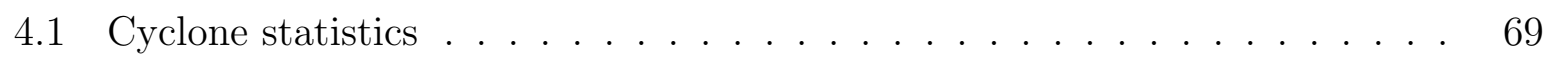

4.1.1 Track and Genesis Density . . . . . . . . . . . . . . . 69

4.1.2 Cyclones tracks per regions . . . . . . . . . . . . 71

4.1.3 Intensity, lifetime and other aspects . . . . . . . . . . . 73

4.2 Spatial Distribution of cyclone properties . . . . . . . . . . 8 80

4.3 Cyclones structure . . . . . . . . . . . . . . . . 85

4.3.1 General structure of cyclone genesis . . . . . . . . . . . 87

4.3.2 Cyclone structure evolution during genesis . . . . . . . . 88

4.4 Discussion and Conclusions _. . . . . . . . . . . . . . . . 98

5. HadGEM2-ES evaluation . . . . . . . . . . . . . . . . . . . 103

5.1 Genesis and track density biases . . . . . . . . . . . . . . 103

5.2 Intensity and other aspects . . . . . . . . . . . . . . 107

5.3 Spatial distribution of cyclone properties . . . . . . . . . . . 111

5.4 Cyclones structure . . . . . . . . . . . . . . . . . . . 115

5.4.1 General structure of cyclone genesis . . . . . . . . . . 115

5.4.2 Cyclone structure evolution during genesis . . . . . . . . . 117

5.5 Discussion and Conclusions . . . . . . . . . . . . . . . 124

6. Cyclones in the HadGEM2-ES future projection . . . . . . . . . . . . . 127

6.1 Genesis and track density $\ldots \ldots \ldots \ldots \ldots \ldots$

6.2 Intensity and other aspects . . . . . . . . . . . . . 129 
6.3 Spatial distribution of cyclone properties . . . . . . . . . . . . . 134

6.4 Cyclones structure . . . . . . . . . . . . . . . . . 138

6.4.1 General structure of cyclone genesis . . . . . . . . . . . . . 140

6.4.2 Cyclone structure evolution during the genesis . . . . . . . . . . . 140

6.5 Discussion and Conclusion . . . . . . . . . . . . . . . . 141

7. Dynamical Downscaling . . . . . . . . . . . . . . . . . . . 147

7.1 NCEP-CFSR simulation . . . . . . . . . . . . . . . . . 147

7.1 .1 Evaluation . . . . . . . . . . . . . . . 147

7.1.2 Cyclones representation . . . . . . . . . . . . . 156

7.2 HadGEM2-ES simulations . . . . . . . . . . . . . . . . . 161

7.2 .1 Present climate . . . . . . . . . . . . . . 161

7.2 .2 Future climate. . . . . . . . . . . . . . 166

7.3 Discussion and Conclusions . . . . . . . . . . . . . 168

8. Conclusions . . . . . . . . . . . . . . . . . . . . 173

8.1 Summary of key findings . . . . . . . . . . . . . . . 173

8.2 Final remarks and Recommendations for future work . . . . . . . . . 176

Bibliography ........................... 179

Appendix 199

A. Complementary figures of Chapter $4 \ldots \ldots$. . . . . . . . . . . . . . . . .

B. Complementary figures of Chapter $5 \ldots \ldots \ldots$

C. Complementary figures of Chapter $6 \ldots \ldots$. . . . . . . . . . 209

D. Complementary figures of Chapter $7 \ldots \ldots \ldots \ldots$. . . . . . . . . . . . . . . . 

Chapter 1

\section{Introduction}

Cyclones are important features observed in weather and climate. The general term "cyclone" is related with clockwise (anti-clockwise) circulation systems in Southern (Northern) Hemisphere that can occur at all atmospheric levels. In this work, we are going to use the word cyclone referring to surface cyclones in synoptic time scale. Lower-level cyclones are often named according to their latitude of formation and vertical structure as extratropical, subtropical and tropical cyclones.

Regions influenced by these transient systems are not only affected by the cloud covering and precipitation but also by a high weather variability due to the oscillation between cyclone and anticyclone patterns. Flood, storm surge, extreme sea weather conditions, cooling, and heat wave events are usually related to the occurrence of surface cyclones and their associated strong winds, fronts and precipitation.

In the section 1.1, the importance of cyclone studies is listed with a focus on their impacts on South Atlantic Ocean sector. Section 1.2 presents some scientific gaps, aims and the structure of this work.

\subsection{Motivation}

Extratropical and subtropical cyclones play a crucial role in the weather of South America, where most of the population lives in coastal cities surrounded by cyclogenenetic areas. Precipitation patterns, extreme events and also storm surges due to these systems have strong societal impacts. Therefore, understanding the physical and dynamical characteristics of these systems and their evolution is essential for mitigation policies and improvement of prediction methods. 
Reboita et al. (2010b) showed that the precipitation pattern of Southeastern South America is ruled basically by frontal systems and cyclones. Moreover, these authors highlighted the importance of surface cyclones conditioning the equatorial moisture flux to mid-latitudes and establishing the South Atlantic Convergence Zone (SACZ), essential elements of the South America Monsoon and the precipitation regime over the continent. Following this idea, while the occurrence of more cyclones could strength or elongate rain period promoting floods, the absence of cyclones could cause issues related to the shift of the rain zone or less precipitation. Drought events, like the one reported in Southeastern Brazil in 2014, caused political and social problems due to the management of urban water resources and food production. Coelho et al. (2016) showed that the presence of an anomalous high-pressure center over the South Atlantic was unfavorable for the low-pressure transients over that region.

The cyclones also impact the coastal zone, sea navigation and oil exploration activities. The strong winds from low surface pressures are associated with the elevation or reduction of the sea level, promoting several natural hazards along the coast through storm surges and flooding (e.g., Seluchi and Saulo, 1998; Parise et al., 2009). Moreover, the cyclone winds over the ocean are responsible for wave generation (e.g., Innocentini and Neto, 1996; da Rocha et al., 2004; Campos et al. 2012), impacting economic activities such as oil exploration, harbors and navigation.

\subsection{Scientific gap and Goals}

Regarding the importance of cyclones in the South Atlantic sector and their influence in the weather and climate, it is crucial to understand possible changes in their occurrence and intensity throughout the years. In a global perspective, there is some evidence of a general decrease of cyclones, a poleward shift of the storm track and an increase in the most severe systems (e.g., Geng and Sugi, 2003, Bengtsson et al., 2006). Although there are many studies about drivers of global climate change which encompass cyclones and storm track, information about their effects on climate change in the South Atlantic Ocean is still scarce. Based on this gap, the primary goal of this thesis is to contribute to the understanding of the changes in the cyclones originated in the South Atlantic, focusing on their genesis and intensifying mechanisms. Secondary objectives were 
defined to accomplish the main aim:

- Develop a new climatology of the South Atlantic cyclones considering their genesis and intensifying mechanisms, and their structure;

- Evaluate how a climate model represents cyclones in the South Atlantic sector;

- Analyse how cyclones will change in future projections and what are the driven mechanisms;

- Perform a climate downscaling to analyze future changes in a higher resolution;

Chapter 2 is dedicated to a theoretical overview of the cyclone development, intensification mechanisms and conceptual models. It also summarizes the climatology for South Atlantic cyclones and the climate change impacts on cyclones. In Chapter 3 , the reanalysis and models used are described, as well as the cyclone tracking and diagnostic methods; moreover, the downscaling experiments are presented. Chapter 4 contains the new climatology for South Atlantic cyclones, the distribution of cyclone properties, and structure composites. Chapter 5 shows how the cyclones are represented in the study region by one of the CMIP5 model. The future projected changes in cyclone behavior are shown in Chapter 6, while the climate downscaling results are presented in Chapter 7. Finally, Chapter 8 contains a summary of the most important conclusions and final remarks of this Thesis. 
Chapter 2

\section{Theoretical background}

\subsection{Definition}

In this work the term 'cyclone' is defined as a cyclone in the lower levels, close to the surface. Genesis or cyclogenesis is used in the early stage of cyclone development, and lysis in the dissipation phase.

Generally, cyclones can be categorized according to their genesis conditions as Tropical, Subtropical and Extratropical (e.g., Reboita et al., 2017). This simplified definition is given following the idea that zones between the same latitude range around the globe correspond to similar genesis environment. Although this separation works well for Tropical Cyclones that need an environment with specific characteristics only existent at lower latitudes, the distinction between extratropical and subtropical cyclones is not so clear.

The term subtropical cyclone is used for hybrid systems with warm surface core and cold middle or upper core, that maintains tropical and extratropical characteristics, respectively. The classification of cyclones as hybrid systems and the knowledge about them are relatively new (e.g., Hart, 2003, Guishard et al., 2009; Evans and Braun, 2012; Gozzo et al., 2014). Hart (2003), one of the pioneers studying hybrid cyclones, realized that a cyclone can develop itself as a subtropical system during all its lifecycle or shift from tropical to extratropical and vice-versa, presenting a hybrid phase. Due to scale similarities with extratropical cases, some subtropical cyclones are usually included in the cyclone climatology, and a specific method of distinction is needed to separate them (e.g., Cyclone Phase Space, Hart, 2003). Hoskins and Hodges (2005) and Reboita et al. (2010a) highlighted in their works the development of weak and shallow lows in the Southeastern Brazilian coast. These weak cyclones were not detected by Gan and Rao (1991) because they do not 
present a closed low-pressure center. Later, Gozzo et al. (2014), using the Cyclone Phase Space and other criteria, showed that almost $30 \%$ of cyclones from Southeastern Brazilian coast could be classified as subtropical systems.

\subsection{Cyclone development and intensification mechanisms}

\subsubsection{Baroclinic Instability}

The baroclinic instability or baroclinicity is considered the primary mechanism of extratropical cyclone development (Bjerknes et al., 1922; Charney, 1947). This type of hydrodynamic instability is associated with the vertical shear of the mean flow (e.g., a jet-like current). The baroclinic instability occurs by converting available potential energy into kinetic energy. The Equator-to-pole differential heating produces meridional temperature gradients associated with the generation of available potential energy and vertical wind shear by thermal wind balance equation. The mid-latitudes and frontal zones are typically baroclinic environments due to their intense temperature gradients at the surface.

Charney (1947) and Eady (1949) led the early theoretical studies relating mid-latitude cyclone development to baroclinic instability. These authors demonstrated that a vertically sheared zonal flow is unstable to small perturbations. Following the Hoskins and Valdes (1990) formulation, the baroclinicity can be defined as the maximum Eady growth rate Eady, 1949), given by

$$
\sigma_{E a d y}=0.31 f\left|\frac{\partial \vec{v}}{\partial z}\right| N^{-1}
$$

where $f$ is the Coriolis parameter, $\vec{v}$ is the wind vector, $z$ is the geometric height, and $N$ is the Brunt-Väisälä frequency. The Equation 2.1 indicates that the baroclinic wave growth is proportional to the vertical wind shear but presents an inverse relation with the vertical static stability $(d \theta / d z)$. The static stability is related to the coupling between upper and low-levels of the atmosphere.

Figure 2.1, taken from Hoskins et al. (1985), presents a scheme of the concept of baroclinic growth considering an upper-level trough (i.e., a cyclonic PV anomaly) acting in a low-level baroclinic region (i.e., strong gradient in meridional temperature), formulated for Northern Hemisphere. The PV anomaly induces a cyclonic circulation at the surface 
a)

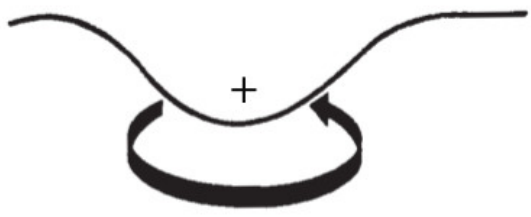

b)
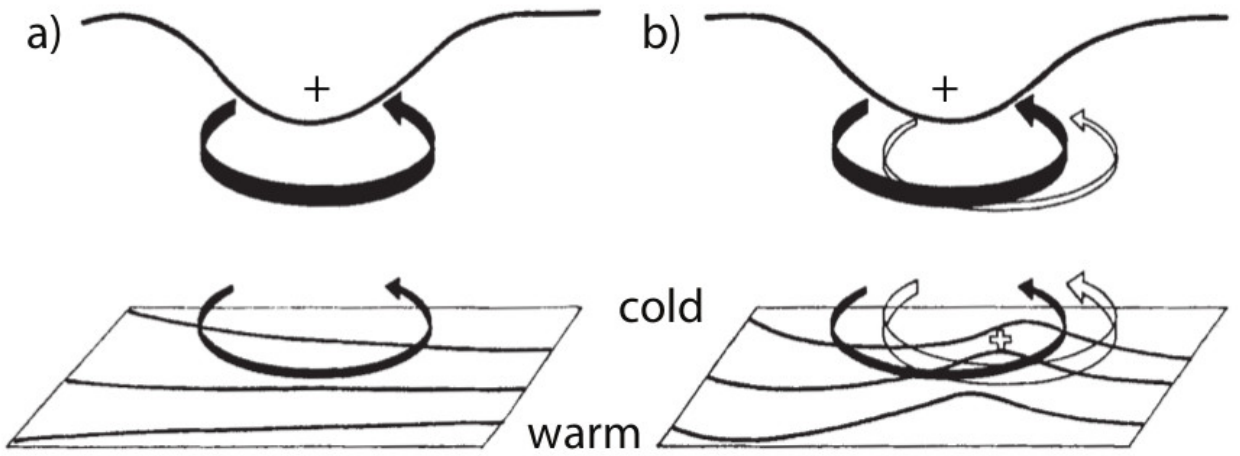

warm

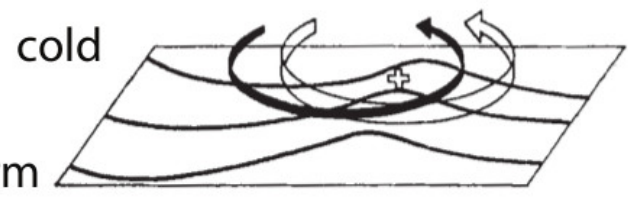

Figure 2.1: Schematic picture of cyclogenesis associated with the arrival of an upper air isentropic potential vorticity (IPV) anomaly over a low-level baroclinic zonal. In (a) the upperlevel cyclonic IPV anomaly, indicated by the solid plus sign and associated with the low tropopause height shown, has just arrived over a region of significant low-level baroclinicity. The circulation induced by the anomaly is indicated by solid arrows, and potential temperature contours are shown on the ground. The low-level circulation is shown above the ground for clarity. The advection by this circulation leads to a warm temperature anomaly somewhat ahead of the upper IPV anomaly in (b), and marked with an open plus sign. If the equatorward motion at upper levels advects high-PV polar lower-stratospheric air, and the poleward motion advects low-PV subtropical upper tropospheric air, then the reaction of the upper-level circulation induced by the surface potential temperature anomaly will, in effect, reinforce the upper air IPV anomaly and slow down its eastward progression. This scheme was made for the Northern Hemisphere and the figure and caption were taken from Hoskins et al. (1985).

(thin black arrow) that produces temperature advection, and consequently, temperature anomalies. The warm temperature anomaly at the surface (open plus sign) will induce a cyclonic circulation that extends eastward and upward to the upper-levels (open arrow). The new cyclonic circulation at upper level reinforces the PV anomaly and slows down its movement through equatorward positive PV advection. Thus, the combination of lowlevel warm advection and upper-level positive PV advection produces an unstable growth mechanism and hence, a cyclonic development (Hoskins et al., 1985).

\subsubsection{Diabatic heating and oceanic interactions}

The diabatic heating occurs when a system (e.g., a cyclone) exchanges thermal energy with its local environment, by condensation, evaporation or radiative processes. Within a cyclone, the rising air over its warm sector condensates releasing latent heat, i.e., an 
additional source of energy to the cyclone development. Moreover, latent heat release can destabilize short length scales with respect to adiabatic baroclinic instability (Whitaker and Davis, 1994).

Over the ocean, the surface heat and moisture fluxes are intense, particularly over the warm western boundary currents (e.g., Brayshaw et al., 2011). The western boundary currents act to strengthen the downstream storm track, enhancing the extratropical SST gradient, near-surface baroclinicity, and upper-level jet structure (Brayshaw et al., 2011).

Numerical studies have shown that surface heating fluxes act particularly in the cyclone intensification and rapid development (e.g., Uccellini et al., 1987; Kuo et al., 1991; Piva et al., 2008; Gozzo and da Rocha, 2013). Piva et al. (2008) and Gozzo and da Rocha (2013), using a limited area model, simulated a cyclone in the Southeastern South American coast with and without surface sensible and latent heating fluxes. These authors found that the surface heating fluxes are not decisive to cyclogenesis, but are essential to intensify the system. The experiment without fluxes simulates a weak and short-lived cyclone, distinct from the system observed in reanalysis and the experiment with fluxes (Gozzo and da Rocha, 2013).

Kuo et al. (1991) showed that diabatic processes act heating the air in the warm side of the cyclone and reinforcing the vertical movement during a marine cyclone intensification. The sensible heating and moisture fluxes above the ocean also decrease the vertical stability at low-levels and enhance the precipitation rate and latent heat release (Uccellini et al. 1987). Both studies used numerical experiments to understand the rapid intensification of two marine cyclones, which developed in a moist baroclinic condition under adiabatic dynamic (i.e., large-scale fields) and diabatic processes (Kuo et al., 1991). Besides that, it is important to consider the negative and damping effects of ocean interactions on cyclone development. In some cases, the surface fluxes reduce the surface thermal wave pattern by cooling (warming) the warm (cold) sector of the cyclone (e.g. Nuss and Anthes, 1987 Reed and Simmons, 1991).

Nuss and Anthes (1987) used a baroclinic channel-flow model for understanding how the development rate of a cyclone is influenced by surface fluxes. These authors found that the heating and moisture fluxes can increase or decrease development rates depending on the distribution of fluxes along the cyclone. The interaction between the cyclone fluxes and the sea surface will vary according to their relative phase and the temperature distribution 
at low-levels. If the surface fluxes enhance (reduce) the low-level baroclinicity, the cyclone rate development will be increased (damped).

Besides acting in the development and intensification of individual cyclones, the diabatic heating also acts as a source of Eddy Available Potential Energy (EAPE) over the storm track region (Chang et al., 2002), what helps to maintain the baroclinicity.

\subsubsection{Orography}

The interaction of mountain chains with the atmospheric flow provides disturbances that may become cyclones through baroclinic instability (e.g. Tibaldi et al., 1980). An orographically induced cyclone development is commonly named by lee or orographic cyclogenesis, where the "lee" side of a mountain barrier is relative to the mean airflow. The lee development can be performed by form drag mechanisms, i. e., angular momentum conservation, or by an interaction between the large-scale topographic wave and synoptic scale wave (Frederiksen and Frederiksen, 1991). However, the lee cyclone development may present different evolution according to the mountain chain shape, height and position relative to the mean flow, and also mesoscale factors (Buzzi et al., 1987).

When the westerlies blow across a mountain barrier, a pressure trough forms downstream, via conservation of potential vorticity. When an air column passes over the mountain ridge and sinks on the lee side, it stretches vertically acquiring relative vorticity by compensation. In a thermodynamic point of view, the descending air on the lee slope warms due to adiabatic compression decreasing the low-level pressure. The effect of a mountain barrier in the westerlies flow at mid-latitudes results in a quasi-stationary wave pattern, with a ridge above the mountain and a trough at its lee side (Gan and Rao, 1994).

The lee cyclogenesis mainly occurs when the stationary trough interacts with a baroclinic wave (Frederiksen and Frederiksen, 1991; Gan and Rao, 1994). A pre-existing low-level cyclone propagating eastward dissipates as it crosses a mountain ridge and a new system may develop at the lee side. However, a mid-level perturbation without an associated low-level structure may also interact with the orography and induce lee cyclogenesis. The mountain barrier increases the westward vertical tilt of the disturbance enhancing the baroclinicity (e.g. Gan and Rao, 1994). Hoskins and Hodges (2005) showed that the cyclogenesis density at the lee side of Andes Cordillera is larger than the lysis density, which indicates that a mountain ridge may promote lee development without a 
pre-existing low-level system.

Cold fronts associated to pre-existing cyclones interacting with the orography also have an important role in the lee cyclogenesis (e.g. Tibaldi et al., 1980; Gan and Rao, 1994). The cold advection of the "parental" cyclone, usually located poleward of the lee development, is disrupted by the mountain barrier. The lack of cold air at low-level and the sinking upperlevel air generate a warm anomaly which decreases the static stability at the lee slope. The reduction of static stability, as discussed in Section 2.2.1, increases the baroclinicity and enhances the vertical coupling between the approaching upper-level trough and the incipient lee disturbance at lower levels (e.g. Seluchi and Saulo, 1998; Funatsu et al., 2004).

\subsection{Classification schemes}

The occurrence or prevalence of one or a set of mechanisms exposed in section 2.2 may classify cyclogenesis or cyclone lifecycle within groups. The advantages of categorizing cyclones according to their similarities are related to the understanding of the atmospheric flow during a cyclone development and, sometimes, to the possibility to forecast their behavior during their evolution. Despite that, some cyclones do not fit a conceptual model or scheme due to changes in their lifecycle or to the non-existence of a scheme that better suits their features.

The present work will not attain to a unique set of classification schemes but aims to understand the fundamental dynamical mechanisms acting throughout the cyclone, as proposed and discussed by Semple $(2003)$. In this section, a brief review of the classical conceptual models will be presented once most of the previous results about cyclone growth and lifecycle belongs to them. See Catto (2016) and Semple (2003) for a more detailed discussion about conceptual models and classification schemes.

\subsubsection{Conceptual models}

The early extratropical conceptual model was developed based on surface weather observations by Bjerknes et al. (1922). The Norwegian model, as it is known, describes a cyclone developing along a sharp meridional temperature gradient (e.g., polar front). Figure 2.2 a shows the Norwegian model of cyclone evolution, also named Polar Front Theory. An incipient frontal wave slightly twists, originating a low-pressure system with cold and 
warm fronts. During the wave growth, the warm sector narrows until the cold front advances toward the center. As the cyclone deepens, the cold front wraps up the warm front and they become occluded. Although the Polar Front Theory was widely used in forecasting and synoptic Meteorology teaching, some aspects of this model were not observed in some observed and simulated cyclones (e.g. Hoskins, 1976; Hoskins and Heckley, 1981; Keyser et al., 1989; Neiman and Shapiro, 1993).

After an extensive observing campaign focused on the understanding of rapid cyclogenesis (e.g. Hadlock and Kreitzberg, 1988; Joly et al., 1997), Shapiro and Keyser (1990) proposed a new conceptual model of the lifecycle of a marine extratropical cyclone. The Shapiro-Keyser model, named after these authors, shows an incipient wave starting similarly to the Norwegian model (Fig, 2.2p). The early stage cyclone develops in a broad frontal zone, but as its lifecycle goes on, a front fracture is originated, separating the cold and warm fronts from each other. The cold front moves across the cyclone while the warm front extends rearward, forming the "T-bone" structure described by Shapiro and Keyser (1990, Fig 2.2p, stages III and IV).

Schultz et al. (1998) suggested that a cyclone developed in a diffluent upper-level flow resembles more the Norwegian model whereas one that occurs in a confluent flow is closer to the Shapiro-Keyser model. The cold front in the former is oriented in a meridional direction while the latter presents a more zonally elongated cold front. Other remarkable difference between the two models is that in Shapiro-Keyser the warm front is stronger than the cold front (Neiman and Shapiro, 1993), and the opposite behavior is expected in the Norwegian model.

\subsection{South Atlantic Cyclones}

During previous decades, several studies have led to a better understanding of the distribution of cyclones and their development in the Southern Hemisphere through synoptic analysis (Taljaard, 1967) and automated tracking methods, using satellite data (Streten and Troup, 1973; Satyamurty et al., 1990), operational analyses (Jones and Simmonds, 1993 Sinclair, 1994) and reanalyses (Simmonds and Keay, 2000a; Hoskins and Hodges, 2005). Extra-tropical cyclones in the Southern Hemisphere primarily occur within $55^{\circ} \mathrm{S}$ to $35^{\circ} \mathrm{S}$ (maximum at $45^{\circ} \mathrm{S}$ ) and near Antarctica (e.g. Hoskins and Hodges, 2005). During 
(a) Norwegian model

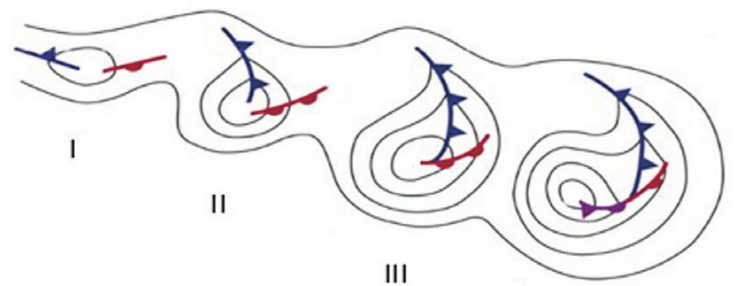

IV
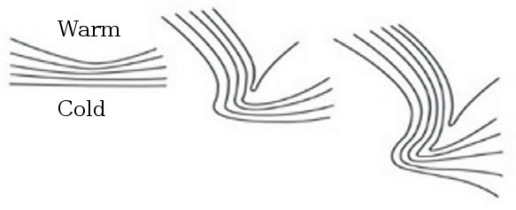

(b) Shapiro-Keyser model

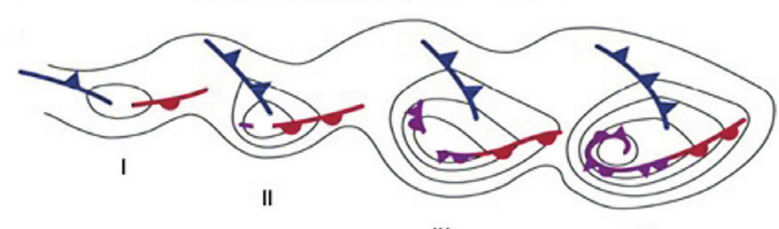

III

IV

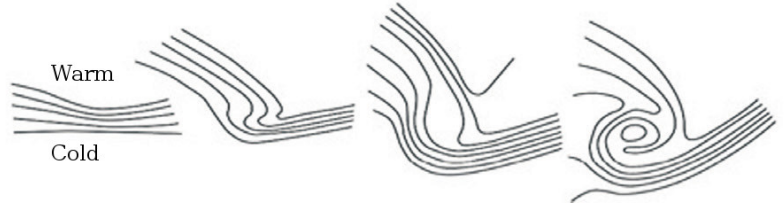

Figure 2.2: Conceptual models of cyclone evolution for the Southern Hemisphere. The top schemes show low-level geopotential height, cold (blue), warm (red) and occluded (purple) fronts; the bottom schemes show potential temperature at low-level, which decreases southward. (a) The phases of the Norwegian cyclone model are: (I) incipient frontal cyclone, (II and III) narrowing warm sector, and (IV) occlusion; (b) The phases of the Shapiro-Keyser cyclone model: (I) incipient frontal cyclone, (II) frontal fracture, (III) T-bone structure and bent-back front, and (IV) T-bone structure and warm seclusion. The stages are separated from each other by 6-24h. Adapted from Schultz et al. (1998) (original) and Reboita et al. (2017) (Southern Hemisphere adaptations). 
the austral summer (DJF) the main storm track shifts poleward (Taljaard, 1967). The preferential orientation is in a south-southeast direction with a spiral pattern towards Antarctica in the winter (e.g., Hoskins and Hodges, 2005). In previous studies, the eastern coast of South America has always been highlighted as an important genesis region for the Southern Hemisphere.

One of the first studies with a regional approach was made by Gan and Rao (1991), that used sea level pressure in synoptic charts from 1979 to 1988 to develop a climatology of cyclogenesis in South America. They found two main genesis regions on the eastern coast of South America: one in Southeast Argentina and another above Uruguay. Using relative vorticity instead of pressure field, more recent works have found a third genesis region in Southeastern Brazilian coast (Sinclair, 1995; Hoskins and Hodges, 2005; Reboita et al., 2010a).

The Southeastern Argentina coast, around $45^{\circ} \mathrm{S}$, is the most active cyclogenesis region. High values of cyclogenesis are found all over the year, but in the summer the occurrence of cyclones is even more significant. The genesis is more active during winter in Uruguay $\left(30^{\circ} \mathrm{S}\right)$ and more active during austral summer in the Southeastern Brazilian coast Hoskins and Hodges, 2005; Reboita et al., 2010a). Hoskins and Hodges (2005) described the last two regions as subtropical paths of the South Atlantic storm track occurring in lower latitudes than the main storm tracks of Southern Hemisphere.

Cyclone development in South America is related mainly to upper and middle-level transients troughs from Pacific and their interaction with Andes Cordillera Gan and Rao, 1994; Vera et al., 2002; Hoskins and Hodges, 2005). Mendes et al. (2007) showed that Andes Cordillera not only fosters cyclonic anomaly through lee effect but also channels the tropical moist and warm air to subtropical latitudes generating moist and wind convergence at the surface. Middle-level ascent movement may enhance this low-level convergence through latent heat release due to precipitation (Vera et al., 2002). The sensible and latent heat fluxes are particularly important in the genesis around $30^{\circ} \mathrm{S}$ where the diabatic heating plays an important role to cyclone development (e.g., reduction of static stability) and intensification (e.g. Seluchi and Saulo, 1998; Vera et al., 2002; Piva et al., 2008; Mendes et al., 2010; Reboita et al., 2010a; Gozzo and da Rocha, 2013).

The ocean conditions can also influence the genesis in the South American coast. Vera et al. (2002) suggested that the warm waters of Brazil Current provide moisture and heat 
that reduce static stability at low levels. The strong surface fluxes above the Southwestern South Atlantic (Reboita et al., 2010) also support cyclone intensification (Piva et al., 2008 Gozzo and da Rocha, 2013). Besides that, the presence of Brazil-Malvinas Confluence nearby $38^{\circ} \mathrm{S}$ (Gordon, 1989) is responsible for introducing high SST gradient that can generate low-level baroclinicity (Sanders and Gyakum, 1980).

There is also evidence of the influence of stratospheric intrusion and cut-off lows in the South Atlantic cyclogenesis (e.g., Funatsu et al., 2004, Iwabe and da Rocha, 2009). When the stratospheric air (with high potential vorticity) moves to the troposphere it acquires cyclonic vorticity and can promote low-level circulation in a baroclinic environment as shown in Fig.2.1.

\subsection{Cyclones and Climate Change}

The study of cyclones from a climate change perspective is essential to evaluate climate models and to understand the dynamical mechanisms of change and further consequences. The analysis of transient systems may be more valuable than the mean temporal and spatial analysis to access the numerical model ability to reproduce the atmospheric behavior. Even if a climate model presents the atmosphere basic state correctly, the weather systems that compound this climate may be incorrectly simulated (Catto, 2016). Moreover, as discussed in section 1.1, cyclones play a huge role in weather and climate patterns, which reinforce the necessity of understanding how they are simulated in climate models and projected in future scenarios.

For clarity, this section is separated in parts: (i) observed trends in reanalysis data; (ii) changes in cyclones in global climate models; and (iii) possible driving mechanisms of cyclone changes. Although some of the mentioned works present a global analysis, the discussion will be focused on the Southern Hemisphere (SH).

\subsubsection{Observed trends in reanalysis data}

Considering the recent past period, the studies based on reanalysis generally show a poleward shift of cyclonic activity, and, as consequence, a decrease in the number of cyclones in the Southern Hemisphere (SH), particularly between $40^{\circ} \mathrm{S}-60^{\circ} \mathrm{S}$ (e.g., Simmonds and Keay, 2000b; Fyfe, 2003; Wang et al., 2006). Although Pezza and Ambrizzi (2003) 
found only in the winter a decline of the total number of cyclones, they diagnosed an increase in the occurrence of deep cyclones (pressure at the center $\leq 980 \mathrm{hPa}$ ), what is also reported in the recent study of Reboita et al. (2015). Lim and Simmonds (2002) also found a significant positive trend of "bomb cyclones" (at least $1 \mathrm{hPa}$ per hour) in SH.

Most of the studies mentioned above identify cyclones using the mean sea level pressure field. Bengtsson et al. (2006) highlighted some issues of using a field that may be affected by climate change to identify the modifications in cyclone intensity. Moreover, it is important to note that differences in the cyclone identification method, intensity threshold, inconsistency in reanalysis quality and the period analyzed also affect the assessment of the cyclone activity trend. Pezza and Ambrizzi (2003) showed that observed trends are sensitive to the pressure selection criteria, having found a different trend from Simmonds and Keay (2000b) in cyclone number by selecting those with center pressure above 980 hPa. Fyfe (2003) and Simmonds and Keay (2000b) discussed that the modest increase in cyclones south of $60^{\circ} \mathrm{S}$ found by them can be an artifact of the improvement in data quality and sea ice specification along the Antarctic region.

\subsubsection{Changes in cyclones in global climate models}

Although the Global Climate Models (GCMs) are valuable tools in the study of cyclones, regarding sensibility tests and realistic simulations, it is essential to evaluate the simulated cyclone activity with a reanalysis-based climatology. The reanalysis assimilates observed data, improving the cyclone representation, while the cyclones simulated by a GCM are the sole results of numerical integration (Ulbrich et al., 2009).

In general climate models simulate less and weaker cyclones when compared to the reanalysis (e.g., Catto et al., 2010; Krüger et al., 2012, Grieger et al., 2014). The models also have a zonal bias in their storm tracks associated with the non-representation of the equatorward-poleward tilt (e.g., Ulbrich et al., 2009). However, the biases may vary according to the method and the model used. Most of the biases in climate models (e.g., number of cyclones and intensity) can be associated with low resolution in the atmospheric and oceanic components (Bengtsson et al., 2006; Lee, 2014; Grieger et al., 2014).

Grieger et al. (2014) used a multi-model mean of nine coupled Atmosphere-Ocean Global Circulation Models (AOGCMs) to study the cyclonic activity changes from Southern Hemisphere winter. They found a large difference in the absolute number of cyclones in 
some models when compared to the ERA40 reanalysis. The bias was large in the cyclonic strength distribution of AOGCMs with coarse resolution. Krüger et al. (2012) accessed the changes in the surface cyclones from Southwestern Atlantic Ocean, using the HadAM3 (CMIP3), and found an underestimation of $12.3 \%$ in the number of cyclones when compared to the NCEP reanalysis. This underestimation increases to $70 \%$ when only initially intense cyclones are considered (starting $\zeta \leq-2.5 \times 10^{-5} s^{-1}$; relative vorticity derived from 10-m height wind). On the counterpart, Reboita et al. (2018) showed that HadGEM2-ES, an Earth System model from CMIP5, overestimates the annual frequency of cyclones in the Southwestern South Atlantic when compared to reanalysis. Reboita et al. (2018) used a more complex and higher resolution climate model, and also computed the relative vorticity using $925 \mathrm{hPa}$ winds, what may justify the identification of more cyclones. Future climate predictions by GCMs indicate that the poleward shift of the storm tracks is going to continue throughout the 21st century (e.g., Fyfe, 2003; Bengtsson et al., 2006), followed by a decrease in the frequency of cyclones, particularly in the mid-latitudes (e.g. Geng and Sugi, 2003; Bengtsson et al., 2006; Lambert and Fyfe, 2006; Mizuta, 2012; Grieger et al., 2014). There are, however, several authors suggesting a potential increase in the number of strong systems, that used fields such as the central pressure gradient $\left(\leq 40 h P a \times 10^{-3} \mathrm{~km}^{-1}\right)($ Geng and Sugi, 2003) and minimum central pressure $(\leq 960 h P a)$ (Lambert and Fyfe, 2006) in their analysis. Bengtsson et al. (2009), using the relative vorticity derived from $850 \mathrm{hPa}$ winds, showed that the reduction in the number of cyclones is smaller when only strong cyclones are considered $\left(\left|\zeta_{850}\right| \geq 8 \times 10^{-5} s-1\right)$.

Reboita et al. (2018) found a decrease of $10.4 \%$ in the HadGEM2-ES RCP8.5 projection by the end of the $20^{t h}$ century in the Southwestern South Atlantic. These authors did not find evidence of an increased cyclone intensity, as also reported by Krüger et al. (2012) for the same region.

\subsubsection{Possible driving mechanisms of cyclone changes}

The reduction in the frequency of cyclones is generally related to the weakening of the large-scale baroclinicity at low-level troposphere, as stated by Geng and Sugi (2003), who investigated whether the reduction of low-level baroclinicity was associated with changes in the wind-shear or static stability, using the Eady Growth Rate definition Eady, 1949 , Eq.2.1. 
The reduction of the Equator-to-Pole low-level temperature gradient may affect the wind-shear negatively (as seen in section 2.2.1). The decrease in the meridional temperature gradient in mid and low levels of the troposphere occurs in a warming scenario because the high latitudes usually warm more than the lower latitudes. Although this decrease occurs in the Northern Hemisphere, in the SH the equatorward gradient of meridional temperature seems to increase with the global warming (Geng and Sugi, 2003). The Equator-to-Pole temperature gradient in the $\mathrm{SH}$ is not decreasing because in its high latitudes there is a strong coupling with deep ocean (Held, 1993).

In this way, Geng and Sugi (2003) showed that the decrease in the mid-latitude baroclinicity in the SH happens due to the increase of the static stability. Changes in the static stability are associated with the anomalous warming at the upper troposphere with enhanced greenhouse gases and sulfate aerosols. Moreover, the increase in the static stability is enhanced in the SH due to the relatively less warming over its extratropical oceans.

However, the projected poleward shift of the maximum meridional SST gradient in $\mathrm{SH}$ can also be related to the decrease in the number of cyclones in mid-latitude, and consequent increase in high-latitudes (Fyfe, 2003; Grieger et al., 2014). The poleward displacement of the SH baroclinic zone may be related to the intensification and southward shift of the upper-level jet seen in future projections (e.g. Kidston and Gerber, 2010; Simpson and Polvani, 2016; Reboita et al., 2018). However, Kidston and Gerber (2010), analyzing CMIP3 AOGCMs, found some correlation between the bias in the latitude from $20^{\text {th }}$ century jet and the magnitude of the shift. Models that present an equatorward bias in the upper-level jet tend to simulate it further poleward in the future projections. The same pattern is observed in the upper-level jet (Simpson and Polvani, 2016) and in storm tracks (Chang et al., 2012) in CMIP5 AOGCM simulations.

Changes in cyclone intensity may be linked to changes in the mean available potential energy (MAPE) of the atmosphere (O'Gorman, 2010). The MAPE increase is related to the increase of the horizontal temperature gradients and latent heat release, and the decrease of static stability. Using several baroclinic models, Held (1993) studied changes in the meridional temperature gradient in the $\mathrm{SH}$ under increased $\mathrm{CO}_{2}$. This author found that the increase in Equator-to-Pole temperature gradient in the $\mathrm{SH}$ will lead to an enhancement of horizontal heat and momentum transport due to the greater conversion of potential energy into larger eddies. 
Chapter 3

\section{Data, Models and Methods}

\subsection{Reanalysis}

The Climate Forecast System Reanalysis produced by the National Centers for Environmental Prediction (NCEP-CFSR; Saha et al., 2010) was used as reference for the atmospheric state in the present climate. The climatology and diagnostics produced from 32 years (1979-2010) of 6 hourly data from the NCEP-CFSR were used to analyze the main properties of cyclone genesis and the evolution of its life cycle, and also to evaluate the climate model and the downscaling procedure.

The NCEP-CFSR presents improved model formulation, resolution and data assimilation technique when compared to its predecessors, NCEP-NCAR and NCEP-DOE, which are also produced by NCEP. It includes coupled atmosphere, ocean and land surface models, an interactive sea-ice model, assimilation of satellite radiances, and a significant increase in horizontal and vertical resolution of the atmospheric spectral model compared to the earlier NCEP reanalyses (Saha et al., 2010).

The atmospheric component is the Global Forecast System (GFS; Saha et al., 2010), which is a spectral model with a $38 \mathrm{~km}$ horizontal resolution (T382) and 64 hybrid vertical levels extending from the surface to $0.26 \mathrm{hPa}$. The Geophysical Fluid Dynamics Laboratory (GFDL) Modular Ocean Model version 4 (MOM4; Griffies et al., 2004) is the ocean component, with 40 vertical levels and a zonal resolution of $0.5^{\circ}$ and a meridional resolution of $0.25^{\circ}$ between $10^{\circ} \mathrm{N}$ and $10^{\circ} \mathrm{S}$ that gradually increases to $0.5^{\circ}$ poleward of $30^{\circ} \mathrm{N}$ and $30^{\circ} \mathrm{S}$. The NOAH land surface model (Ek et al., 2003) includes four soil layers and the ice model (Griffies et al., 2004) has two layers to account for variations below the surface.

Some studies have shown that the latest set of reanalyses represents a significant im- 
provement over earlier reanalyses (e.g. Saha et al., 2010; Hodges et al., 2011; Stopa and Cheung, 2014), especially in the Southern Hemisphere. New data assimilation techniques and sources of observational data (e.g., satellite, ARGO floats) have played an enormous role in the better representation of atmospheric features in regions where the observational network had previously a poor coverage, such as in the SH.

Stopa and Cheung (2014) showed that NCEP-CFSR reproduces global wind pattern in agreement with observed seasonal variability from buoy data and satellite products. These authors also recommend the use of NCEP-CFSR for analyzing extreme events. While other reanalysis products use to underestimate extreme events, the NCEP-CFSR tends to overestimate them. Moreover, the NCEP-CFSR was evaluated by Hodges et al. (2011) under the perspective of extratropical cyclones. They compared four reanalyses regarding their ability to represent genesis and track density, maximum intensity and surface structure of extratropical cyclones. The ERA-Interim (ECMWF) and NCEP-CFSR have similar good results, especially in representing cyclogenesis associated to orography. The NCEP-CFSR also presents the most intense systems, reinforcing Stopa and Cheung (2014) results.

\subsection{Climate Model}

The Coupled Model Intercomparison Project Phase 5 (CMIP5, Taylor et al., 2012) is composed of climate model experiments coordinated by more than 20 climate modeling groups around the world. These experiments supports scientifically the Intergovernmental Panel on Climate Change Fifth Assessment Report (AR5, IPCC, 2013). Earth System Models try to represent most of global climate drivers and possible feedback among them. The complexity required by climate models to reproduce those processes and responses is high, and the expenses to build and run them are even higher. For this reason, a combined action to develop and evaluate the CMIP5 is essential.

\subsubsection{CMIP5 experiments}

The CMIP5 has many experiments established to evaluate future climate, models skills, coupling effects, etc. To access future changes in the climate, it is necessary to previously evaluate the present climate state, the so-called historical experiment, and the future 
projection scenarios, which are defined according to their Representative Concentration Pathways (RCP). In this work, we used only two CMIP5 experiments: the historical and RCP8.5 future projection scenario.

The historical experiment represents the climate from 1850 to 2005, covering the start of the modern industrial period until the present. The forcing conditions are based on observed atmospheric composition changes and time-evolving land cover. In this work, the historical period was used to evaluate the ability of the model to reproduce the climate based on the reanalysis climatology. Moreover, the future projection changes are estimated considering the historical experiment as present climate to avoid differences inherent to the model source.

The last 27 years of historical experiment (1979 to 2005) were used to represent the present climate in comparison to the RCP8.5 scenario and its skill was accessed using NCEP-CFSR. The time length used gives consistency to a climate study, avoiding the interference of interannual variabilities as ENSO and others. However, the time series is still being affected by interdecadal variabilities, which is one of the issues of using time slices in climate studies.

The RCP8.5 is the highest emission scenario. It indicates that by 2100 the radiative forcing will have increased $8.5 \mathrm{~W}^{-2}$ if humans would not reduce the gas emissions (Riahi et al., 2011). The RCP experiments do not consider only the $\mathrm{CO}_{2}$ concentration variation, but also the other greenhouse gases (e.g., $\mathrm{CH}_{4}$ and $\mathrm{O}_{3}$, both stratospheric and tropospheric), aerosols (e.g., black and organic carbon, dust, nitrate) and other forcing changes (e.g., solar and land use). The RCP8.5 scenario is run in most of the CMIP5 models from 2006-2100, and in this study we compared the 2074-2099 time slice with the historical experiment.

Although there are four RCPs scenarios available, only RCP4.5 ('medium-low' emissions scenario, Thomson et al., 2011) and RCP8.5 are considered part of the 'core' of model runs. The other two, RCP2.6 (extensive mitigation) and RCP6.0 ('medium-high' emissions scenario), are lower priority experiments. In this work only RCP8.5 is used, as one of the goals is to understand dynamical changes in a warming world. Lee (2014) analyzed changes in global storm track, including large-scale fields changes, and found that RCP4.5 changes account to a half of variation observed in RCP8.5. 


\subsubsection{HadGEM2-ES}

The Hadley Center Global Environment Model version 2 Earth System (HadGEM2-ES, Martin et al., 2011; Collins et al., 2011) was chosen for the assessment of cyclones changes in South Atlantic in a projected future. CMIP5 contains many last generation models, but despite all those models being fully coupled, not all of them are Earth System Models like HadGEM2-ES. Moreover, many studies around the world and, particularly in South America, were made using HadGEM2-ES, what facilitates comparisons and the discussion of the findings in this work (e.g., Reboita et al., 2018).

Besides that, Robert Lee (personal communication, June, 2015) compared more than 20 models and found that HadGEM2-ES can represent the South Atlantic cyclones intensity and distribution similarly to ERA-Interim (Lee, 2014). Reboita et al. (2018) also found that HadGEM2-ES simulates cyclones characteristics, e.g., displacement distance and mean intensity, similar to NCEP-CFSR and ERA-Interim over the Southeastern South Atlantic, despite presenting longer-lived systems.

The HadGEM2-ES physical model configuration is derived from the HadGEM1 climate model (Johns et al., 2006). The atmospheric component uses a horizontal resolution of $1.25^{\circ} \times 1.875^{\circ}$ in latitude and longitude, respectively, with 38 layers in the vertical (until 39 $\mathrm{km}$ height). The oceanic component uses a vertical resolution of 40 levels and a horizontal resolution of $1^{\circ} \times 1^{\circ}$ between the poles and $30^{\circ}$ latitude, which increases to $1 / 3^{\circ}$ at the Equator.

Moreover, the HadGEM2-ES contains terrestrial and oceanic ecosystems, and tropospheric chemistry components. The ecosystem components (TRIFFID and diat-HadOCC; Cox, 2001; Palmer and Totterdell, 2001) enable the simulation of the carbon cycle, including complex interactions such as the feedback of dust fertilization on plankton growth. The tropospheric chemistry is modeled by UKCA scheme (O'Connor et al., 2014), which enables the effect of changes in methane and ozone in the radiative forcing.

\subsubsection{Data pre-processing}

The HadGEM2-ES experiments are available in hybrid vertical coordinates, and it is necessary to interpolate them to the pressure levels of the cyclones analysis and the downscaling process. The hybrid vertical coordinates in HadGEM2-ES are defined by 
$Z_{l}=a_{l}+b_{l} * h$, where, for an hybrid layer $l, Z_{l}$ is the geopotential height of the model layer in each grid point, $a_{l}$ is the hybrid coordinate, $b_{l}$ is a coefficient and $h$ is the surface height $(\mathrm{m})$. Once $\mathrm{Z}$ is found it is possible to compute the pressure using the hypsometric equation, where the pressure in a layer $\left(p_{2}\right)$ can be calculated using the pressure in the layer below $\left(p_{1}\right)$, the mean virtual temperature between both layers $\left(\overline{T_{v}}\right)$, and the height difference between them $\left(h=z_{2}-z_{1}\right)$ :

$$
p_{2}=p_{1} e^{g h / R \overline{T_{v}}}
$$

where $g$ is the gravitational acceleration $\left(g=9.81 \mathrm{~ms}^{-2}\right)$ and $R$ is the specific gas constant for dry air $\left(R=287 \mathrm{Jkg}^{-1} \mathrm{~K}^{-1}\right)$. The virtual temperature $\left(T_{v}\right)$ is defined as $T_{v}=T(1+(-0.61 w))$, where the mixing ratio can be found through the relation $q=\frac{w}{w+1}$, and $T$ and $q$ are the temperature $(\mathrm{K})$ and relative humidity $\left(\mathrm{kg} \mathrm{kg}^{-1}\right)$ given by the model.

The surface temperature field is not available in HadGEM2-ES first member (r1i1p1) in the CMIP5 data access portal, so a lapse-rate of $9.8 \mathrm{Kkm}^{-1}$ was used to estimate the surface temperature and the pressure in the first layer. Once the pressure field was obtained for each hybrid layer, grid point and time step, a logarithmic interpolation method was used to compute the temperature, specific humidity, geopotential height and winds in each isobaric level $(975,925,850,800,700,600,500,400,300,250,200,100,50,10 \mathrm{hPa})$.

The HadGEM2-ES SST is available in daily fields and, in order to facilitate the WRF boundary and initial conditions processes, and also the cyclone analysis, we rearranged the data to be 6 hourly by replicating the daily value 4 times. The only field that did not need any interpolation was the MSLP.

\subsection{Dynamical Downscaling}

Although Regional Circulation Models (RCM) are widely used for weather forecasting, continuous computational advances improved the code and allowed longtime integration, contributing to increase the use of these models in climate studies. The application of RCM in climate studies improves the representation of mesoscale features that are important to regional and local climate, e.g., precipitation pattern and surface temperature (Giorgi and Mearns, 1991). 
In last decade, the dynamical downscaling has been used to study the South American climate both for present regional climate (e.g., Chou et al., 2000; da Rocha et al., 2009; Reboita et al., 2009; Seth et al., 2010; Chou et al., 2012) and future projections (e.g., Marengo et al., 2010; Krüger et al., 2012; Reboita et al., 2018).

The dynamical downscaling was done using the Weather Research and Forecasting Model (WRF; version 3.7; Skamarock et al., 2008), whose development and maintenance are performed by collaborative efforts of the National Center for Atmospheric Research (NCAR) and National Center of Environmental Prediction (NCEP) from the USA.

The WRF dynamical core solves the Eulerian movement equations in a non-hydrostatic and compressed atmosphere. The time integration is made with a $3^{\circ}$ order Runge-Kutta scheme, and the acoustic modes are integrated into a smaller time step to avoid numerical instability. In the vertical, the WRF uses sigma coordinates.

\subsubsection{Climate experiment}

The climatic simulation was done using a polar projection grid, centered in $37^{\circ} \mathrm{S}$ and $50.3^{\circ} \mathrm{W}$ with a horizontal resolution of $50 \mathrm{~km}$ and 50 vertical levels on sigma coordinates. The use of a polar projection is to avoid distortions at mid-latitudes and to facilitate the use of TRACK program. The grid domain was set up to maintain the South American coast and adjacent ocean centralized, avoiding boundary condition problems (Warner, 2010). It was also an effort to include the Andes Cordillera in the domain due to its essential effect in South America cyclogenesis (e.g., Gan and Rao, 1994). Figure 3.1 shows the grid used in the experiments.

There are extensive options of parametrization available in the WRF. Parametrization solves sub-grid processes that cannot be solved by the primitive equations integrated into a specific grid point. Some of the underlying processes that may be considered in a sub-grid scale are radiation, microphysics, convection (also named cumulus), surface boundary layer, and land and ocean-atmosphere interactions. All of them are essential for the evolution of the meteorological fields, particularly in regional atmospheric features. Although there is an idea that more elaborated schemes let to a more realistic representation of a process, there is no consensus about a group of parametrization being better than other. The parametrization choice varies according to the atmospheric system or pattern that needs to be simulated. Particularly to a climate simulation, some cautions need to be taken 


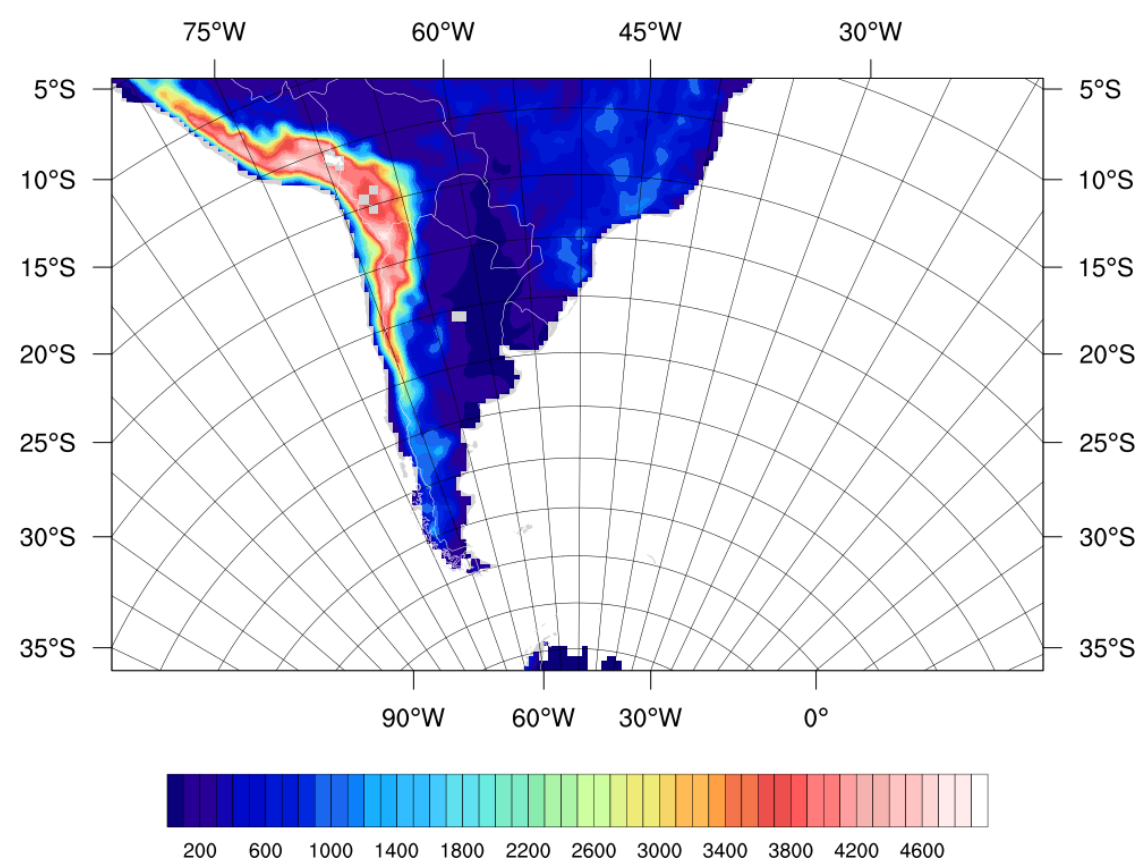

Figure 3.1: The grid domain used to the climate experiment. The grid was build using a polar projection centered in $37^{\circ} \mathrm{S}$ and $50.3^{\circ} \mathrm{W}$ with a horizontal resolution of $50 \mathrm{~km}$.

regarding the energy balance due to the extended integration period.

The climate experiment in this work is set according to the ARW WRF manual suggestion, except by microphysics parametrization that was set as WRF Single-Moment 3-class (WSM3; Table 3.1). Although the WSM3 scheme considers only three hydrometeors, it has been showed that it has a better cost-benefit (Rocha, 2017; da Silva, 2018). The reduction of the computational time-processing is almost $30 \%$, what is relevant to long-run simulations.

The downscaling was performed using the NCEP-CFSR, HadGEM2-ES historical and RCP8.5 runs for 15 years and 9 months, so that the first 8 months are the spin-up period. The present climate analysis was held for both NCEP-CFSR and HadGEM2-ES from 1991-2005 period, and from 2085 to 2099 for future projection. The NCEP-CFSR meteorological fields of 6 hour frequency were used as initial and boundary conditions for the downscaling control experiment, including the sea surface temperature (SST). Although the resolution is the same for input data and model results, this experiment shows how the regional model is solving local features. Changes between NCEP-CFSR and the control experiment are expected as long as there are differences in the orography and land surface information, parametrizations, and the ocean model is not coupled. Moreover, it 
Table 3.1 - Parametrization set-up applied in the climate experiments. These options are suggested by the WRF model guide for "regional climate".

\begin{tabular}{ccc}
\hline \hline type & name & reference \\
\hline \hline longwave radiation & RRTMG & Mlawer et al. $(1997)$ \\
\hline shortwave radiation & RRTMG & Iacono et al. $(2008)$ \\
\hline microphysics & WRF Single-Moment 3-class & Hong et al. \\
\hline cumulus & Kain-Fritsch & Kain $(2004)$ \\
\hline surface layer & MM5 & Zhang and Anthes $(1982)$ \\
\hline land surface & Noah-MP Land Surface Model & Niu et al. $(2011)$ \\
\hline planetary boundary layer & Yonsei University & Hong et al. \\
\hline
\end{tabular}

is important to evaluate the experiment set up to support the discussions of the results from HadGEM2-ES downscaling. The HadGEM2-ES historical and RCP8.5 downscaling input were made using interpolated fields, computed as described in section 3.2 .3 . The 6 hourly boundary conditions consist of 10 grid points on each edge, which 9 points are buffer zones.

Besides the boundary condition, a spatial nudging was used with the same time interval. This technique consists in nudging the regional model fields toward the large-scale driving data to avoid inconsistencies between them, and it is even more important in large domains like the one used in this work (e.g. Stauffer and Seaman, 1990; Omrani et al., 2011, 2015). Not-using the nudging generated some boundary inconsistencies after a simulation period of 6 years, resulting in numerical instability and model crash (not showed). The nudging was performed above the planetary boundary layer for specific humidity, temperature, and $\mathrm{u}$ and v-components of the winds. Omrani et al. (2015) tested several nudging variables and found that the winds and the temperature are important to maintain large and synopticscale circulation, while moisture improves the precipitation in regional model.

\subsubsection{Evaluation of the climate experiment setup}

The results from the control experiment were evaluated using the NCEP-CFSR, the Modern-ERA Retrospective Analysis for Research and Applications (NASA-MERRA; Rienecker et al., 2011) and Global Precipitation Climatology Project (GPCP; Adler et al. 2003) for the precipitation. The need to evaluate the model experiment using other data 
source than its input data relies on the fact that, despite the regional model ability to solve its equation and produce regional features, it is natural that the NCEP-CFSR central tendencies are implied to the model through the boundary condition and nudging.

The fields used in the evaluation are MSLP, temperature and specific humidity at 2 meters, winds at 850 and $200 \mathrm{hPa}$, and geopotential height. MERRA is a NASA reanalysis with a resolution of $0.5^{\circ}$ in latitude and $0.66^{\circ}$ in longitude and 72 vertical levels. The GPCP, also maintained by NASA, has the resolution of $2.5^{\circ}$ both in latitude and longitude. The evaluation is done in a climatological perspective using a seasonal mean of all simulated period for austral summer (DJF) and winter (JJA). For evaluating the cyclones in the control experiment, cyclone spatial statistics and diagnostics (as described in sections 3.4 and 3.5 are produced and compared to the results of Chap 4.

\subsection{Cyclone identification}

The study of cyclones evolves through the years, following the computational advances and resources. At first, the statistic distributions (e.g., genesis and track densities) were made combining the manual analysis of individual features using synoptic charts (e.g. van Loon, 1965, Taljaard, 1967). The technological advance has brought gridded data from numerical weather predition models and has made necessary to create a more efficient approach to cyclone activity measure. The Eulerian approach uses simple statistic (e.g., variance) in a synoptic band frequency to obtain storm track characteristics (e.g., Blackmon, 1976; Blackmon et al., 1977). The Eulerian statistic provides a broad view of synoptic activity but do not allow deep analysis about the type and properties of cyclones that constitute the storm track (Hoskins and Hodges, 2002).

In late 90 's, the emergece of automated and objective methods has brought back the feature tracking analysis (e.g., Murray and Simmonds, 1991; Sinclair, 1994; Hodges, 1994, 1995). This approach provides complementary information about the synoptic system and their characteristics. Moreover, the automatic method allows the processing of a huge amount of data. 


\subsubsection{TRACK Algorithm}

The tracking of cyclonic features is performed using the automated tracking system, TRACK (Hodges, 1994, 1995), using the relative vorticity field at $850 \mathrm{hPa}$ computed from the zonal and meridional winds. Usually, surface cyclone tracking also can be done using mean sea level pressure (MSLP; e.g. Murray and Simmonds, 1991) but, the relative vorticity permits the detection of weak and fast moving synoptic systems that are masked by the background flow (Sinclair, 1994). Between $40^{\circ} \mathrm{S}$ and $20^{\circ} \mathrm{S}$, the surface pressure gradient is intense and the cyclone may not have a closed isobar until it reaches higher latitudes or intensify itself. Because of that, the use of relative vorticity also allows the detection of the cyclone in its earlier stages, when a closed isobar is not present (Sinclair, 1994). For these reasons, tracking cyclones in the South Atlantic sector using vorticity may be a better choice rather than sea level pressure, as discussed by Sinclair (1994) and Hoskins and Hodges (2002). The relative vorticity is computed on the sphere, in spherical coordinates, to avoid projections issues.

The vorticity is a very noisy field at the resolution of NCEP-CFSR and needs to be filtered to reduce the noise, avoiding problems during the identification process and tracking. The vorticity is spectrally filtered by converting it to the spectral representation and truncating to T42. The spectral coefficients are smoothed by a tapering filter to reduce the Gibbs phenomena (Sardeshmukh and Hoskins, 1984). The large-scale background is also removed by setting total wavenumber $\geq 5$ to zero.

Cyclones are identified by determining the local minima (cyclones have negative vorticity in the $\mathrm{SH}$ ) on a polar stereographic projection which is vital to prevent a latitudinal bias (Sinclair, 1997). The relative vorticity threshold to the identification of the local minima is $-1.0 \times 10^{-5} \mathrm{~s}^{-1}$. The locations are refined by determining the off-grid locations using B-spline interpolation and the steepest descent minimization.

The tracking is performed by first initializing a set of tracks by linking the detected feature points into tracks using the nearest neighbor method. The tracks are refined by minimizing a cost function for the track smoothness, which operates both forwards and backward in time, subject to adaptive constraints on the maximum displacement in a time step and the track smoothness (Hodges, 1999). Only systems that last longer than 24 hours (4-time steps) and have displacement from start to end greater than $1000 \mathrm{~km}$ are 
considered for further analysis.

\subsubsection{Validation and applied constraints}

The tracking constraints adopted here differ from those used by Hoskins and Hodges (2002) and are presented in Table 3.2. The tracking results were compared to the synoptic charts from the Brazilian Navy from the summer (DJF) and winter (JJA) of 2005. Manual analysis was done to see if the algorithm captured cyclonic systems that influence the South American coast during the above period. However, it is important to be aware that a direct comparison between the MSLP synoptic chart and the relative vorticity automated method will not necessarily have a one to one correspondence due to the different nature of the fields (Sinclair, 1997; Hoskins and Hodges, 2002).

The narrow shape of South America south of $30^{\circ}$ allows the algorithm with the standard settings for extra-tropical cyclones to connect some tracks coming from the Pacific with tracks in the South Atlantic. The spurious tracks crossing Andes Cordillera remove genesis events of cyclones that develop near the Eastern South American coast, between $40^{\circ} \mathrm{S}$ and $20^{\circ} \mathrm{S}$. We have solved this issue by adding a rectangular region over the Andes, where the cyclones are restricted to have a maximum displacement of $1^{\circ}$ (geodesic) in one-time step (Table 3.2). In this way, a cyclonic feature on the west side of South America cannot be linked with a feature on the east side of the Andes in the next time step, because the distance between them is larger than $1^{\circ}$. Also, we have reduced the maximum displacement to $4^{\circ}$ per time step between $30^{\circ} \mathrm{S}$ and $20^{\circ} \mathrm{S}$ to inhibit the connection between thermal lows above the continent with cyclogenesis at the coast.

Finally, we have increased the constraints that allow changes in velocity (speed and direction) for slow moving systems to include in the tracking some cyclones at the Southeastern South American coast that present a quasi-stationary behavior at some stage of their lifecycle or abrupt change in their propagation direction (Dias Pinto et al., 2013; Dutra et al. 2017). These slow moving systems spend some days close to the coast before they propagate southeastward, causing strong winds and precipitation on the continent. During the validation process, a set of tests were performed to find the configuration that best solves these problems without interfering the algorithm performance. This new setup provided a $89 \%$ agreement with the synoptic chart analysis. 
Table 3.2 - Comparison between the constraints suggested by Hoskins and Hodges (2002) and the ones used in this work.

\section{Zonal Upper-bound displacements}

\begin{tabular}{cccc} 
& Longitude & Latitude & $d_{\max }$ (degree) \\
\hline Hoskins and Hodges & $0-360$ & $-90--20$ & 6.5 \\
Present work & $0-360$ & $-20-0$ & 3.0 \\
\hline & $0-360$ & $-90--45$ & 6.5 \\
& $0-285$ & $-45--30$ & 6.0 \\
& $285-295$ & $-45--30$ & 1.0 \\
& $295-360$ & $-45--30$ & 6.0 \\
& $0-360$ & $-30--20$ & 4.0 \\
& $0-360$ & $-20-0$ & 3.0 \\
\hline
\end{tabular}

\subsubsection{Remarks about tracking in a limited area}

The TRACK includes a filtering step to avoid spurious cyclone identification due to noisy vorticity fields (section 3.4.1; Hoskins and Hodges, 2002). The tracking method developed by Hodges (1994, 1995) was first design to global data where a spectral filter is adequate. However, for tracking cyclones in a limited area, e.g., a regional model grid, some adaptations are necessary.

A spatial filter was applied to smooth the vorticity field in the regional model grid. To respect the T42 spectral filter employed in the global data the equivalent spatial distance was computed using the equation of the zonal wavenumber (AMS Glossary):

$$
L=\frac{2 \pi R \cos (\phi)}{k}
$$

where $\mathrm{L}$ is the spatial distance in $k m, k$ is the wavenumber, $R$ is the Earth's radius, and $\phi$ is the reference latitude. The central latitude of the grid $\left(37^{\circ} \mathrm{S}\right)$ was used as reference latitude. In this way, the spatial filter was set up to retain scales between 6390 and 760 $\mathrm{km}$, values equivalent to wavenumber 5 and 42 , respectively.

The tracking performed in the spatially filtered vorticity field presents more systems, especially in the subtropical region. The reason is that smaller systems are not filtered in the subtropics due to the relation between $\mathrm{L}$ and $\cos (\phi)$ in Equation 3.2. The $\mathrm{L}$ that corresponds to the $\mathrm{T} 42$ in $37^{\circ} \mathrm{S}$ is smaller than in $30^{\circ} \mathrm{S}$, what allows the retention of smaller features in the data when compared to the spectral filter. Other values were applied to 
test the filter set up. However, the values computed using $37^{\circ} \mathrm{S}$ presented more similar results compared to the tracking done in the NCEP-CFSR T42 vorticity field. The tests were done using NCEP-CFSR vorticity field remapped to the regional model grid, in order to avoid inconsistencies regarding distinct projections.

\subsection{Cyclone Diagnostics}

The spatial statistics are produced by the TRACK code using the spherical kernel method (Hodges, 1996). The cyclogenesis density is computed using the starting point of each track, excluding the tracks that start at the first time step of the analysis period. In the same way, lysis density is calculated using the end point of the track and do not consider tracks that end in the last time step of the analysis period. Track density is computed using a single point from each track. The raw density statistics is then scaled to number densities per month per area. The area unit is equivalent to $5^{\circ}$ spherical cap which is approximately $10^{6} \mathrm{~km}^{2}$.

Besides the traditional statistics, other meteorological fields were added to the tracks to provide more information about the genesis environment, life cycle characteristics and vertical structure of the identified cyclones. This additional information can be added by searching for a maximum, minimum or average value within a radius from the tracked center at each time step. Statistical diagnostics are computed from these additional fields regarding histograms and spatial distribution at a given time (e.g., maximum intensity). The spatial distributions of genesis characteristics have been produced by averaging the genesis characteristics (e.g., MSLP) of all cyclones generated within a $10^{6} \mathrm{~km}^{2}$ area.

The first additional fields added to the tracks are the MSLP and the maximum wind speed at $925 \mathrm{hPa}$ for the evaluation of the mean and maximum intensity of the cyclones. Both fields are available in NCEP-CFSR, and no further calculation was required. The minimum MSLP was sampled within a radius of $5^{\circ}$ (geodesic) from the tracked center and the maximum wind speed at $925 \mathrm{hPa}$ within a radius of $6^{\circ}$. Another way to measure cyclone intensity is using precipitation, as long as it influences directly human life. The precipitation associated to the cyclone was computed using its average within $6^{\circ}$.

Other fields were added to the tracks to analyze further the cyclone development characteristics, all of them averaged within $5^{\circ}$ of the cyclone centers. These additional fields 
are the potential vorticity $(\mathrm{PV})$ at $300 \mathrm{hPa}$, geopotential height at $500 \mathrm{hPa}$ and the mean upper-level jet velocity to evaluate upper-level atmospheric environment. Only the geopotential height is available in the NCEP-CFSR data. The PV was computed on isobaric levels $(p)$ at global grid, following Bluestein (1992) (page 264, Eq. 4.5.93),

$$
P V=-\left[\zeta+f+\frac{R}{\sigma p}\left(\frac{\partial v}{\partial p} \frac{\partial T}{\partial x}-\frac{\partial u}{\partial p} \frac{\partial T}{\partial y}\right)\right]_{p} \frac{\partial \theta}{\partial p}
$$

where $\zeta$ is the relative vorticity $\left(s^{-1}\right), f$ is the planetary vorticity $\left(s^{-1}\right), T$ is the temperature $(\mathrm{K}), \theta$ is the potential temperature $(\mathrm{K}), R$ the specific gas constant for dry air and $\sigma=-\frac{R T}{p} \frac{\partial \ln \theta}{\partial p}$. The mean upper-level jet velocity was obtained through a weighted vertical average of velocity at each level between 100 and $500 \mathrm{hPa}$. The horizontal gradients in Equation 3.3 were solved using spherical harmonic functions, what justifies the need of a global grid (NCL, 2018).

To analyze the lower level atmospheric environment, we used SST gradient, static and conditional stability and integrated specific humidity. The vertical stabilities and integrated humidity were computed using the layers between $1000 \mathrm{hPa}$ and $700 \mathrm{hPa}$. The static stability was estimated by the potential temperature lapse-rate $\left(\Gamma=\frac{\partial \theta}{\partial p}\right)$, while conditional stability by the equivalent potential temperature lapse-rate $\left(\Gamma_{e}=\frac{\partial \theta_{e}}{\partial p}\right)$. The $\theta_{e}$ is computed using Bolton (1980) formulation,

$$
\theta_{e}=\theta_{L}\left[\left(\frac{3036}{T_{L}}-1.78\right) r(1+0.448 r)\right]
$$

where the potential temperature at the lifted condensation level (LCL) is defined as $\theta_{L}=T\left(\frac{p_{0}}{p-e}\right)^{k_{d}}\left(\frac{T}{T_{L}}\right)^{0.28 r}(\mathrm{~K})$, the temperature at LCL is $T_{L}=\frac{1}{\frac{1}{T_{d}-56}+\frac{\operatorname{logeT} T T_{d}}{800}}+56, p_{0}$ is the reference level pressure $(1000 \mathrm{hPa}), e$ is the water vapor pressure, $r$ is the mixing ratio of water vapor $\left(\mathrm{kg} \mathrm{kg}^{-1}\right), T_{d}$ is the dew point temperature and $k_{d}$ is the ratio of the specific gas constant to the specific heat of dry air at constant pressure $\left(k_{d}=0.2854\right)$.

\subsection{Compositing of cyclones structure}

For the structure compositing only the $30 \%$ most intense cyclones, that live at least 48 hours, from each cyclogenesis region where considered to produce a more homogeneous group regarding their evolution. 
The compositing method used here was first used by Bengtsson et al. (2007) to study tropical cyclone structure. After that, several works applied the same method to study extratropical cyclones structure (Bengtsson et al., 2009; Catto et al., 2010; Hodges et al., 2011; Dacre et al., 2012). This method consists of sampling the required field (e.g., MSLP, $\left.\theta_{e}\right)$ using a radial grid centered at the cyclone center for each time step along its track. The radial grid is of 20-degree radius with a 0.5-degree grid spacing, both azimuthally and radially. The composites are produced by averaging the fields on the radial grid at each offset time relative to the genesis (the first point where the cyclone was detected). In previous works, the grid is rotated according to the cyclone propagation direction. However, this step was not adopted here due to two main reasons. First, the cyclones that develop northward of $30^{\circ} \mathrm{S}$ propagate to a different direction in some cases that may cause problems in overlaying warm and cold sides of cyclones in the averaging processes. Moreover, a non-rotated grid allows an assessment of the geographical features that impact genesis, which are relevant to the study of genesis precursors in South America. Prior time steps to the cyclogenesis are also considered to analyze the dynamic and thermodynamic features that lead to genesis. If the time of interest is before the time of genesis, the sampling was made using the position of the cyclone at the genesis time applied at the earlier time.

Besides the traditional meteorological fields (e.g., sea level pressure, geopotential) other derived fields were use for the compositing. The variables were calculated in a hemispherical grid $\left(0^{\circ}-90^{\circ} \mathrm{S}\right)$ for each time step before being sample to the compositing. The relative humidity is estimated for a given temperature, mixing ratio, and pressure, using a lookup table procedure (Murray, 1967). The vertically integrated moisture flux convergence (VIMFC) is used as a measure of the lower tropospheric forced lifting. In this study, the VIMFC is defined as the horizontal moisture flux convergence integrated between 1000 $\mathrm{hPa}$ and $700 \mathrm{hPa}$ :

$$
V I M F C=-\frac{1}{g} \int_{700 h P a}^{1000 h P a}\left(\frac{\partial u q}{\partial x}+\frac{\partial v q}{\partial y}\right) d p
$$

where $g$ is the gravitational acceleration, $u$ and $v$ are the zonal and meridional component of the velocity, respectively, and $q$ is specific humidity. Also, the vertically integrated moisture transport (VIMT) was computed in a similar way 


$$
\overrightarrow{V I M T}=-\frac{1}{g} \int_{700 h P a}^{1000 h P a}(u q \vec{i}+v q \vec{j}) d p
$$

The VIMT has zonal and meridional components. The temperature advection at 850 $\mathrm{hPa}$ and the mass divergence at 200 and $300 \mathrm{hPa}$ were computed using the finite centered differences, as long as the partial derivatives in Equations 3.5. The $\mathrm{PV}$ at $300 \mathrm{hPa}$ and $\theta_{e}$ fields were obtained by Equations 3.3 and 3.4 . 
Chapter 4

\section{Spatial Distribution and Characteristics of the South Atlantic Cyclones}

\subsection{Cyclone statistics}

\subsubsection{Track and Genesis Density}

The cyclone track density is shown in Figs $4.1 \mathrm{a}$ and $\mathrm{b}$ for the austral summer (DJF) and winter (JJA), respectively. These figures show a region of maximum track density extending from West to East between $40^{\circ} \mathrm{S}$ and $55^{\circ} \mathrm{S}$ [ $>10$ cyclones $\left(10^{6} \mathrm{~km}^{2}\right)^{-1}(\mathrm{month})^{-1}$ ] which extends over a larger latitudinal range in the austral winter (JJA) than in the summer (DJF), representing the main South Atlantic storm track. There is also a secondary track density region $\left[>6 \text { cyclones }\left(10^{6} \mathrm{~km}^{2}\right)^{-1} \text { (month }\right)^{-1}$ ] extending Southeastward from Uruguay to the South Brazilian coast, which seems to merge with the main Southern storm track. It is considered a subtropical branch of the South Atlantic storm track (e.g., Hoskins and Hodges, 2005). During the summer, this branch originates more northward $\left(30^{\circ} \mathrm{S}\right)$, while during the other seasons it starts between $30^{\circ} \mathrm{S}$ and $35^{\circ} \mathrm{S}$.

Figures 4.1 and d show the genesis density of cyclones originating in the South Atlantic domain in austral summer and winter respectively. There are three regions of high genesis density around the South American East coast: the central Argentina coast around $50^{\circ} \mathrm{S}$ and $45^{\circ} \mathrm{S}$ (ARG, hereafter); the Northeastern Argentina and Uruguay region, close to the La Plata river discharge at $30^{\circ} \mathrm{S}$ (LA PLATA, hereafter), and the South-Southeast coast of Brazil, between $30^{\circ} \mathrm{S}$ and $25^{\circ} \mathrm{S}$ (SE-BR, hereafter). A fourth genesis region was found in the Southeastern South Atlantic Ocean (SE-SAO, hereafter), centered at $55^{\circ} \mathrm{S}$ and $10^{\circ} \mathrm{W}$. Both cyclogenetic regions at $50^{\circ} \mathrm{S}$ and $45^{\circ} \mathrm{S}$ are active throughout the year. Despite that, 


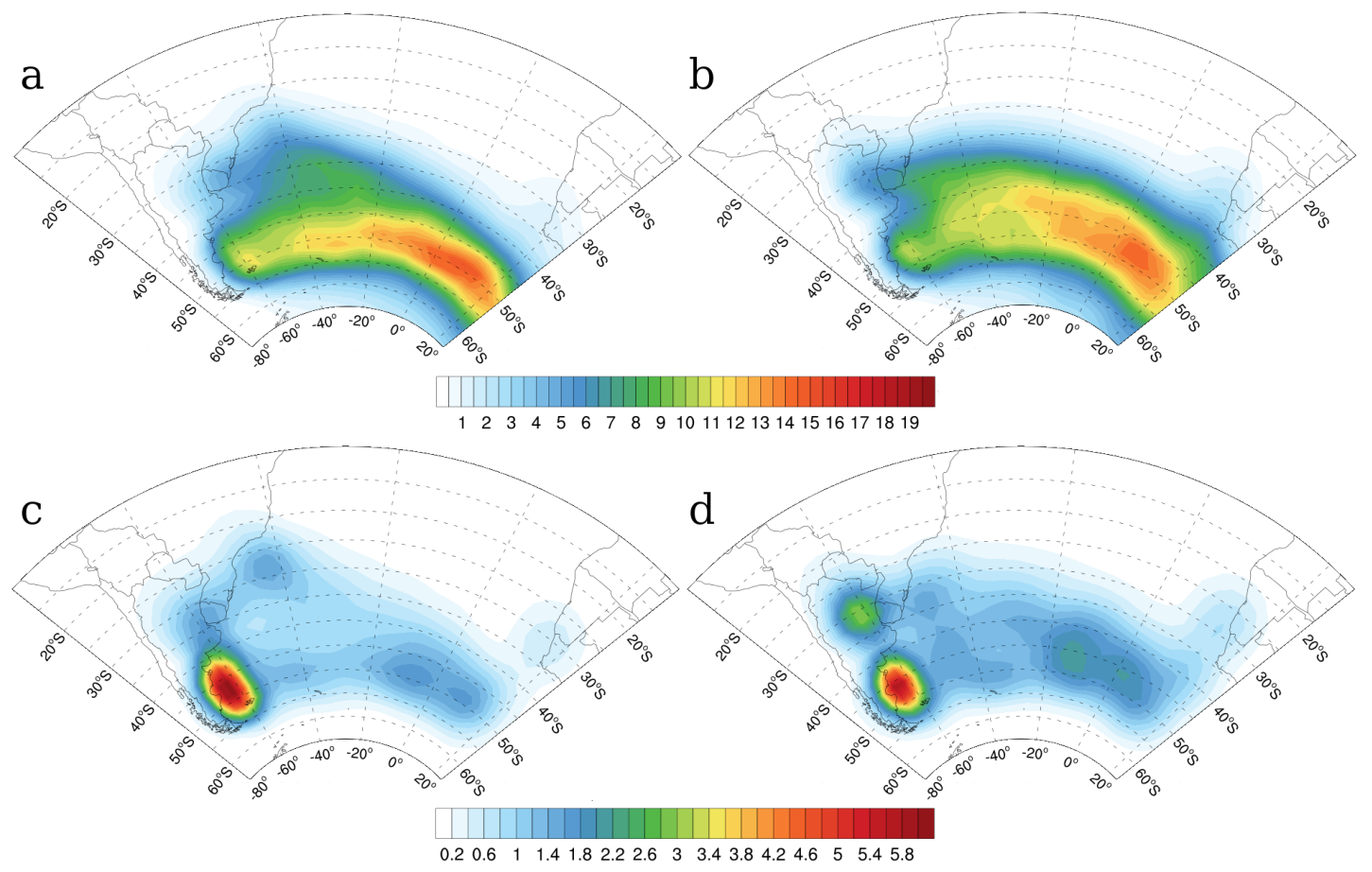

Figure 4.1: Cyclone track density for (a) summer (DJF) and (b) winter (JJA), and the genesis density for (c) summer (DJF) and (d) winter (JJA). The densities are computed using only cyclones with the first time step within South Atlantic domain, in a box between $15^{\circ} \mathrm{S}-55^{\circ} \mathrm{S}$ and $75^{\circ} \mathrm{W}-20^{\circ} \mathrm{E}$. The density unit is cyclone per $10^{6} \mathrm{~km}^{2}$ per month.

the ARG region presents slightly more genesis in summer and the SE-SAO in winter. A see-saw behavior is noted at the northward latitudes too. The LA PLATA region has more genesis in winter while the SE-BR genesis region is active in summer. The four main cyclogenesis regions that exist in the South Atlantic domain were selected based on the genesis density distribution, even if a genesis regions present high genesis density values only in one analyzed season. Figure 4.2 indicates the chosen sampling genesis regions. These regions are based on the genesis density computed for the whole 1979-2010 period and the boxes do not change according to the season.

Table 4.1 shows the number of genesis events for each defined region per season. The ARG and SE-SAO regions are together responsible for $50 \%$ of genesis within the South Atlantic Ocean. Both of them are located in the main latitude zone for storm track (Figs $4.1 \mathrm{a}$ and b). Looking at the number of cyclones in each region in different seasons, it is possible to see that there is no strong seasonal variability in some regions, such as SE-BR and ARG. In fact, these two regions have less than $20 \%$ more cyclones in summer than in winter. The SE-BR region seems to be more concentrated northward of $30^{\circ} \mathrm{S}$ in 


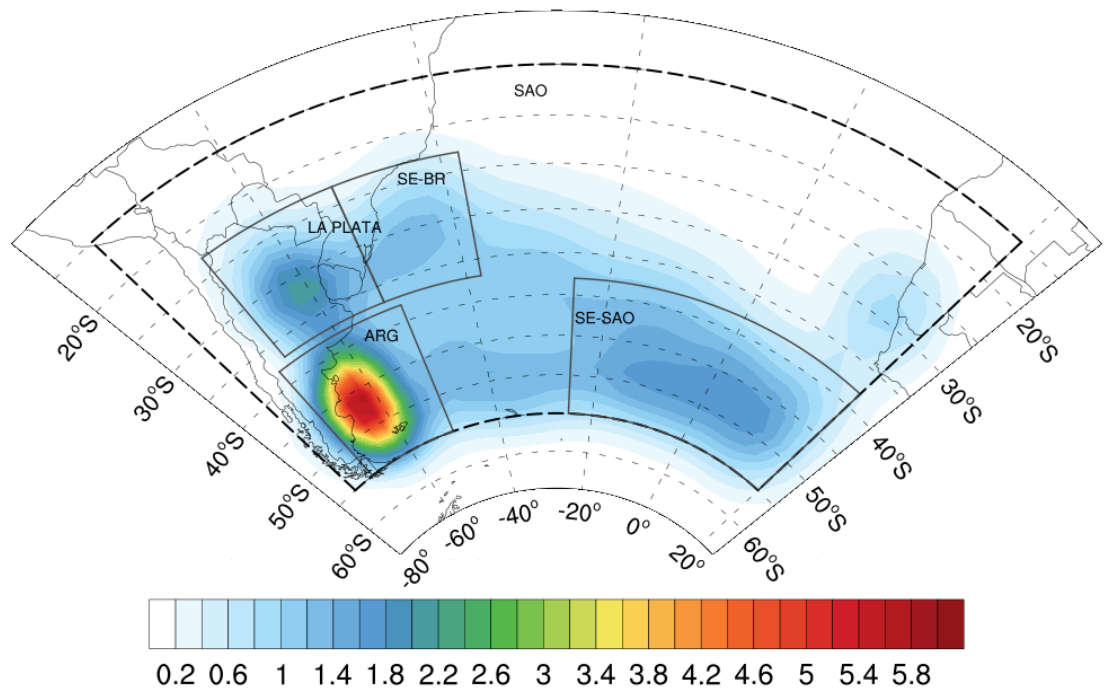

Figure 4.2: Genesis density for South Atlantic domain (marked in dashed gray line) computed for all period from 1979 to 2010. The four genesis regions are marked in black line. The density unit is cyclone per $10^{6} \mathrm{~km}^{2}$ per month.

the summer giving the idea of more genesis (Fig 4.1c). For the LA PLATA and SE-SAO regions, there is a significant increase of cyclogenesis in the winter of $56 \%$ and $34.5 \%$, respectively.

The pattern of genesis densities compares well with those produced by some other studies (Hoskins and Hodges, 2005; Reboita et al., 2010a; Hodges et al., 2011). The SESAO region is within the main South Atlantic storm track and has not often been discussed in previous studies. Hoskins and Hodges (2005) suggested a downstream development in this region, as long as it is located at the end of the storm path from the Eastern South American coast.

\subsubsection{Cyclones tracks per regions}

Cyclone density statistics have been produced for cyclones that originate in the different genesis regions marked on Figs. 4.1k and d. Hoskins and Hodges (2005) used the same method to highlight the intensity and path of cyclones originating in South America and Antarctica in the winter. Figure 4.3 presents the track and lysis density statistics, and also the mean vorticity intensity distribution calculated for each separate genesis region.

The SE-BR cyclones generally reach the end of their lifecycle in the middle of the South Atlantic Ocean at $45^{\circ} \mathrm{S}$, rarely crossing the Greenwich meridian. The lysis density 
Table 4.1 - Total number of cyclones, annual mean and standard deviation for South Atlantic domain $\left(15^{\circ} \mathrm{S}-55^{\circ} \mathrm{S}, 75^{\circ} \mathrm{W}-20^{\circ} \mathrm{E}\right)$ and each genesis region within the domain. The values were computed for all analysis period (1980-2010), and separately for summer (DJF) and winter (JJA).

\begin{tabular}{rcccccc}
\hline \hline & \multicolumn{2}{c}{$1980-2010$} & \multicolumn{2}{c}{ DJF } & \multicolumn{2}{c}{ JJA } \\
region & total & annual mean & total & annual mean & total & annual mean \\
\hline \hline South Atlantic & 12754 & $411.4 \pm 10.2$ & 2950 & $95.2 \pm 6.4$ & 3476 & $112.1 \pm 7.6$ \\
SE-BR & 856 & $27.6 \pm 2.2$ & 227 & $7.3 \pm 1.9$ & 201 & $6.5 \pm 2.4$ \\
LA PLATA & 1157 & $37.3 \pm 3.1$ & 224 & $7.2 \pm 2.2$ & 351 & $11.3 \pm 3.0$ \\
ARG & 2972 & $95.9 \pm 4.6$ & 831 & $26.8 \pm 4.0$ & 712 & $23.0 \pm 4.5$ \\
SE-SAO & 3666 & $118.3 \pm 5.8$ & 804 & $25.9 \pm 4.1$ & 1081 & $34.9 \pm 5.6$ \\
\hline
\end{tabular}

for the LA PLATA cyclones shows that most of the systems originated within this region decay in a broad region from Southern Brazilian and Uruguayan coast to the middle of the Atlantic. This is consistent with the findings of Hoskins and Hodges (2005) for cyclones generated near $30^{\circ} \mathrm{S}$ over South America. The ARG cyclones travel southeastward and there is a tendency of decaying between $40^{\circ} \mathrm{W}$ and $20^{\circ} \mathrm{W}$. However, cyclones originating in the ARG region can reach the longitude of $60^{\circ} \mathrm{E}$, traveling outside the South Atlantic domain. For the SE-SAO cyclones, the dissipation occurs south of the African continent, more concentrated between $10^{\circ} \mathrm{W}$ and $40^{\circ} \mathrm{W}$. These cyclones feed the Indian Ocean stormtrack as discussed by Hoskins and Hodges (2005). The lysis density values are much lower than genesis density because the dissipation usually occurs over a broader area than the genesis. Cyclones from ARG and SE-SAO are more likely to travel outside the South Atlantic domain, but only SE-SAO presents a high density of lysis near Antarctica. Hoskins and Hodges (2005) were the first to show the overlapping storm densities for each genesis region of the Southern Hemisphere. As reported by them and seen in Fig 4.3 the genesis regions in South America feed the South Atlantic storm track and the surface cyclone development occurs rather in favorable areas, like the eastern coast of South America, or at the end of the previous lifecycle, like the SE-SAO region.

Looking at the distribution of mean intensity computed for each separate genesis region it is possible to see a tendency of increasing mean intensity downstream and poleward of the genesis regions, as reported in previous studies (e.g. Sinclair, 1995; Hoskins and Hodges, 2005). However, the LA PLATA cyclones are more intense in the South Atlantic 
domain even at lower latitudes $\left(30^{\circ} \mathrm{S}\right)$. They also reach a high mean intensity near the coast $\left(<-5 \times 10^{-5} s^{-1}\right)$. These characteristics corroborates the analysis performed by Hoskins and Hodges (2005) and Reboita et al. (2010a) for cyclones originating at $30^{\circ} \mathrm{S}$.

\subsubsection{Intensity, lifetime and other aspects}

Figure 4.4 shows the histogram of relative vorticity from cyclones at their genesis time for summer and winter in the South Atlantic region. The starting vorticity of a cyclone may be important to estimate its impacts in the continent, considering that three main cyclogenesis regions of the domain are located near the coast and big cities. The frequency in Fig. 4.4 is displayed as a percentage to better compare between the genesis regions. The vorticity is scaled by -1 . The SE-BR and LA PLATA cyclones present a similar distribution of initial vorticity. The ARG cyclones present typically less intense cyclones at the time of genesis. The SE-SAO region has a higher frequency of cyclones with higher intensity at genesis time. The majority of the South Atlantic cyclones have the starting cyclonic vorticity weaker in summer than winter. The mean intensity at genesis time is $-3.1 \pm 1.5 \times 10^{-5} s^{-1}$ in summer and $-3.4 \pm 1.6 \times 10^{-5} s^{-1}$ in winter (Table 4.2). The SE-SAO region has the higher intensity at genesis time when compared to the other regions, reaching a mean of $-4.0 \pm 1.9 \times 10^{-5} \mathrm{~s}^{-1}$ during winter (Table 4.2 )

Table 4.2 contains the mean relative vorticity at genesis time, mean lifetime and mean cyclone displacement speed in each defined genesis region computed for the whole period, and separately for summer and winter. The mean lifetime of South Atlantic cyclones is longer in the summer ( $4.1 \pm 2.9$ days $)$ than in winter $(3.7 \pm 2.4$ days). The region that presents the longest lifetime is the LA PLATA region (5.4 \pm 2.9 days in summer). The SE-SAO has the shortest duration systems (3.4 \pm 2.4 days). In general, South Atlantic cyclones tend to be slightly faster in the winter $\left(15.7 \pm 4.9 \mathrm{~m} \mathrm{~s}^{-1}\right.$ against $14.4 \pm 4.6 \mathrm{~m} \mathrm{~s}^{-1}$ in the summer). ARG and SE-SAO regions present the highest displacement speed due to the large-scale flow dominated by the westelies. The mean values presented in Table 4.2 are higher when compared with other South Atlantic climatologies. Reboita et al. (2009), using 10 years of NCEP-DOE (Kanamitsu et al., 2002), found a mean speed of $11.0 \mathrm{~m}$ $s^{-1}$, a mean lifetime of 2.6 days and an initial vorticity of $-2.5 \times 10^{-5} s^{-1}$. These differences can be addressed by the NCEP-DOE lower resolution, but also by the fact that in Reboita et al. (2009) the cyclones are tracked based on the vorticity computed from the $10 \mathrm{~m}$ winds. 

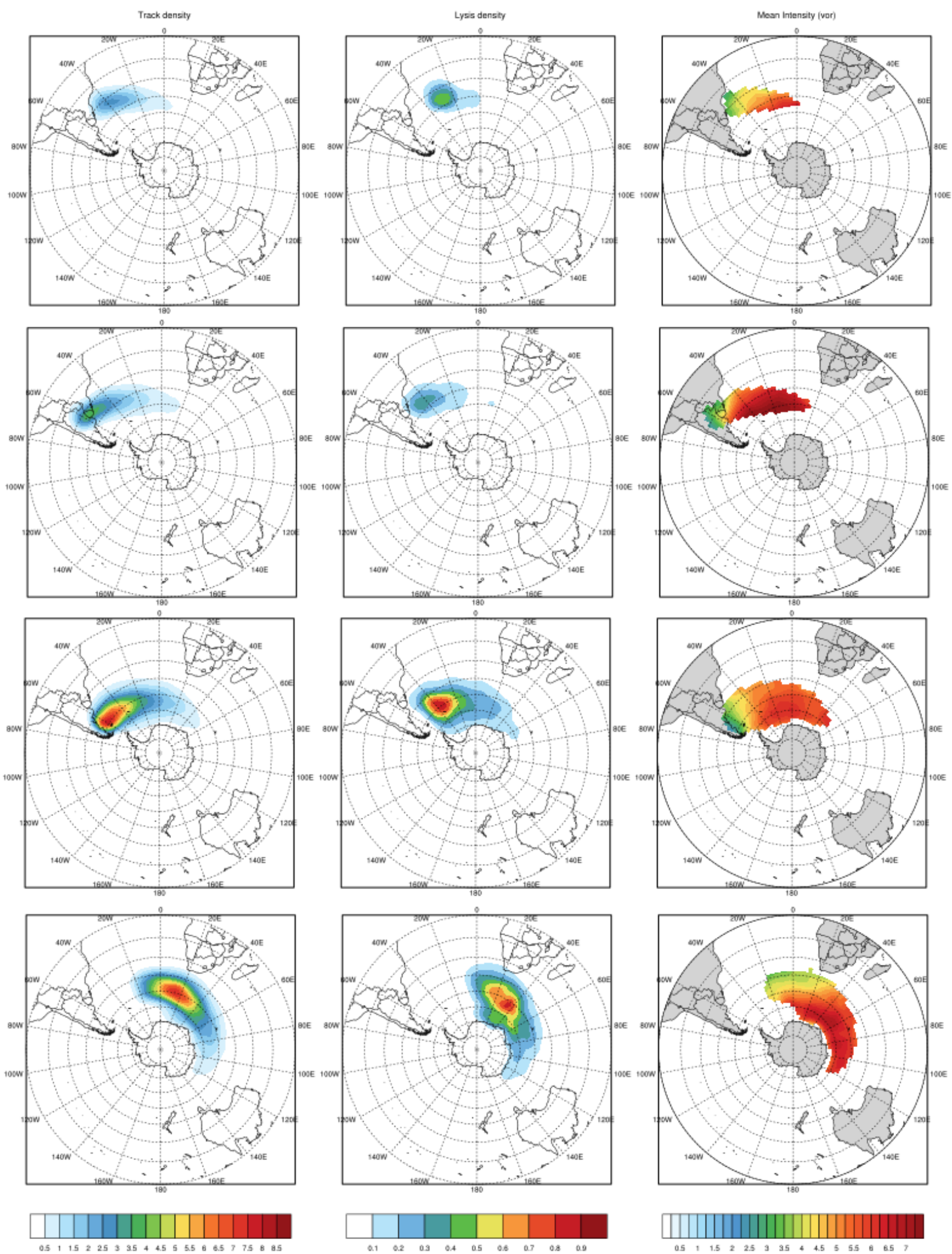

Figure 4.3: Track density (first column), lysis density (middle) and mean intensity distribution (last column) for each genesis region following this sequence from above: SE-BR, LA PLATA, ARG and SE-SAO. The density unit is cyclone per $10^{6} \mathrm{~km}^{2}$ per month and mean intensity unit is $-1 \times 10^{-5} \mathrm{~s}^{-1}$. 

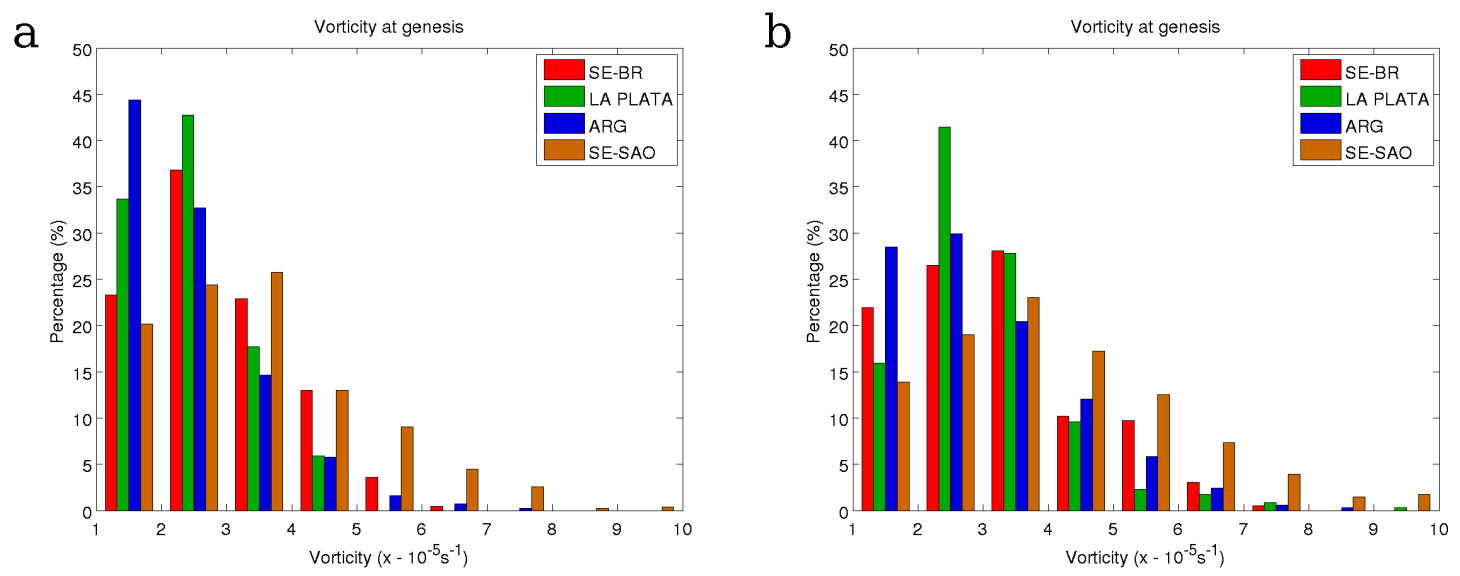

Figure 4.4: Histograms of the vorticity at the genesis time in the (a) summer and (b) winter for the cyclones which originate in SE-BR (red), LA PLATA (green), ARG (blue) and SE-SAO (orange) regions. The relative vorticity is scaled by $-1 \times 10^{-5} s^{-1}$ and the y-axis shows the percentage computed based on the total number of cyclones detected in each defined genesis region.

The cyclone structure at the surface is affected by drag and the winds are weaker when compared with the $850 \mathrm{hPa}$ field. Also, some disturbance can still be tracked at $850 \mathrm{hPa}$ and that do not exist at the surface, resulting in the longer lifetimes reported in Table 4.2 .

Figures 4.5 and 4.6 shows histograms of different types of cyclone intensity measures computed as the lifetime maximum or minimum value whithin the South Atlantic domain, defined as SAO in Fig. 4.2. The histograms of maximum intensity in terms of vorticity (Figs.4.5 and b) show that the cyclones from the LA PLATA region are the most intense within the South Atlantic Ocean, as also seen in terms of $925 \mathrm{hPa}$ wind speeds (Figs.4.6 and $\mathrm{b}$ ). This characteristic is less clearly seen when considering MSLP (Figs 4.5 and d), as this field is more likely to be influenced by the large scale background and tends to focus on larger spatial scales. However, the LA PLATA and SE-BR regions show a small peak of intense cyclones centered at $945 \mathrm{hPa}$ in the winter for the MSLP. The vorticity maximum intensity distribution shows there are three peaks, indicating three groups of cyclones in the LA PLATA region. The first is between -3.5 and $-4.5 \times 10^{-5} s^{-1}$, the second is around $-9.5 \times 10^{-5} s^{-1}$, and a third peak around $-13.0 \times 10^{-5} s^{-1}$. They exist in both seasons but in the winter their frequency are similar, showing an increase in more intense cyclones in this season. In the MSLP histograms there are only two peaks for the LA PLATA cyclones, with the second peak less pronounced in the summer. The 
Table 4.2 - The mean $850 \mathrm{hPa}$ relative vorticity at genesis time (scaled by $-1 \times 10^{-5} s^{-1}$ ), mean lifetime (days) and mean cyclone displacement speed $\left(\mathrm{m} \mathrm{s}^{-1}\right)$ and standard deviations computed within South Atlantic domain $\left(15^{\circ} \mathrm{S}-55^{\circ} \mathrm{S}, 75^{\circ} \mathrm{W}-20^{\circ} \mathrm{E}\right)$ and within each defined genesis region. The means were calculated for the whole analysis period (1980-2010), only for summer (DJF) and only for winter (JJA).

\begin{tabular}{|c|c|c|c|}
\hline \multicolumn{4}{|c|}{$1980-2010$} \\
\hline region & initial vort. & lifetime & speed \\
\hline South Atlantic & $3.1 \pm 1.5$ & $3.9 \pm 2.7$ & $15.0 \pm 4.8$ \\
\hline SE-BR & $3.0 \pm 1.3$ & $4.2 \pm 2.7$ & $13.2 \pm 4.7$ \\
\hline LA PLATA & $2.7 \pm 1.1$ & $5.3 \pm 3.1$ & $12.6 \pm 3.8$ \\
\hline $\mathrm{ARG}$ & $2.7 \pm 1.2$ & $4.0 \pm 2.6$ & $14.9 \pm 4.0$ \\
\hline SE-SAO & $3.7 \pm 1.8$ & $3.4 \pm 2.4$ & $17.1 \pm 4.7$ \\
\hline \multicolumn{4}{|c|}{ DJF } \\
\hline region & initial vort. & lifetime & speed \\
\hline South Atlantic & $2.8 \pm 1.4$ & $4.1 \pm 2.9$ & $14.4 \pm 4.6$ \\
\hline SE-BR & $2.9 \pm 1.1$ & $4.8 \pm 3.0$ & $12.1 \pm 4.2$ \\
\hline LA PLATA & $2.4 \pm 0.9$ & $5.4 \pm 2.9$ & $12.2 \pm 3.7$ \\
\hline $\mathrm{ARG}$ & $2.4 \pm 1.1$ & $4.3 \pm 2.9$ & $14.5 \pm 3.9$ \\
\hline SE-SAO & $3.4 \pm 1.6$ & $3.7 \pm 2.6$ & $16.3 \pm 4.4$ \\
\hline \multicolumn{4}{|c|}{ JJA } \\
\hline region & initial vort. & life time & mean speed \\
\hline South Atlantic & $3.4 \pm 1.6$ & $3.7 \pm 2.4$ & $15.7 \pm 4.9$ \\
\hline SE-BR & $3.2 \pm 1.3$ & $3.5 \pm 2.2$ & $14.3 \pm 4.8$ \\
\hline LA PLATA & $3.0 \pm 1.2$ & $5.1 \pm 3.0$ & $13.1 \pm 3.9$ \\
\hline $\mathrm{ARG}$ & $3.0 \pm 1.4$ & $3.7 \pm 2.2$ & $15.2 \pm 4.1$ \\
\hline SE-SAO & $4.0 \pm 1.9$ & $3.3 \pm 2.2$ & $17.6 \pm 4.8$ \\
\hline
\end{tabular}


SE-BR region shows a maximum vorticity around $-4.5 \times 10^{-5} s^{-1}$ in the summer and betweeen -2.5 and $-4.5 \times 10^{-5} s^{-1}$ in the winter, but the tail of the distribution shows an increase of strong systems in the winter. The similarity between the LA PLATA and SE-BR intensity distributions may be related to their proximity to each other. Hence, they may have the same growth mechanisms that change according to the seasonal variability. The only difference is the presence of more weak systems in the SE-BR region, especially during winter. The cyclones from the ARG and SE-SAO regions have maximum intensity distributions similar to the distribution for cyclones from all of the South Atlantic. The distribution changes if the maximum intensity is considered to be within the South Atlantic Ocean or is outside the domain (not shown). Larger intensities for vorticity and MSLP are found if we take into account all track points instead of the point within the domain which is expected because cyclones that travel long distances and move poleward tend to become more intense (e.g., Hoskins and Hodges, 2005). The most affected distribution with the change of maximum intensity point selection is the SE-SAO region due to its proximity to the SAO domain boundary.

The histogram of maximum precipitation rate within the cyclone reveals that SE-BR and LA PLATA cyclones generate the most intense precipitation with a similar pattern (Figs 4.6 c and d). The cyclones in the ARG and SE-SAO regions show maximum precipitation distributions with fewer cyclones with precipitation above $20 \mathrm{~mm} \mathrm{day}^{-1}$ when compared to cyclones from all the South Atlantic domain. According to the intensity histograms, cyclones from the SE-BR and LA PLATA regions are associated with intense winds and precipitation. Most of these systems have a lifecycle confined near the Southeastern American coast (not shown). This fact is particularly important as even with a small number of cases per year these cyclones impact the coastal region directly.

Figure 4.7 shows the spatial distribution of the mean intensity based on the maximum wind speed at $925 \mathrm{hPa}$, the mean displacement speed and the mean growth rate in both seasons. The intensity distribution (Figs. $4.7 \mathrm{a}$ and b) shows that high-intensity values used to be found southward of $45^{\circ} \mathrm{S}$ at open ocean. Despite that, there is a relative highintensity wind near of Brazilian and Uruguayan coast, associated with LA PLATA and SE-BR cyclones. The SE-SAO region, which presents the higher intensity at genesis time (Table 4.2), is located in a high-intensity zone, what may indicate a region of cyclone intensification. As reported in literature and seen in histograms (Figs 4.6) South Atlantic 


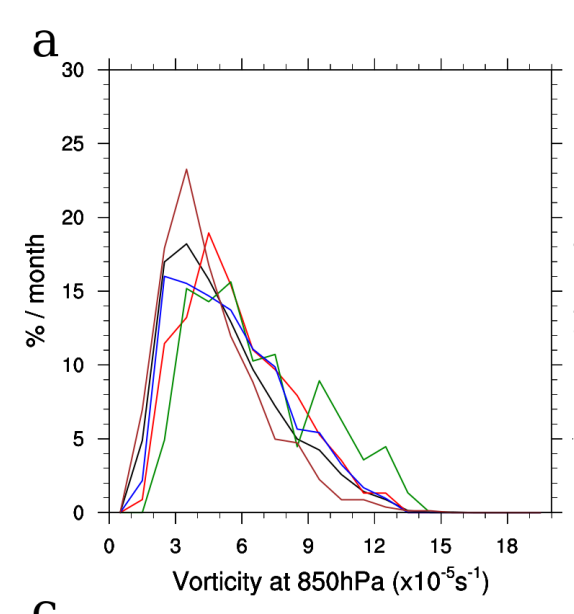

$\mathrm{b}$
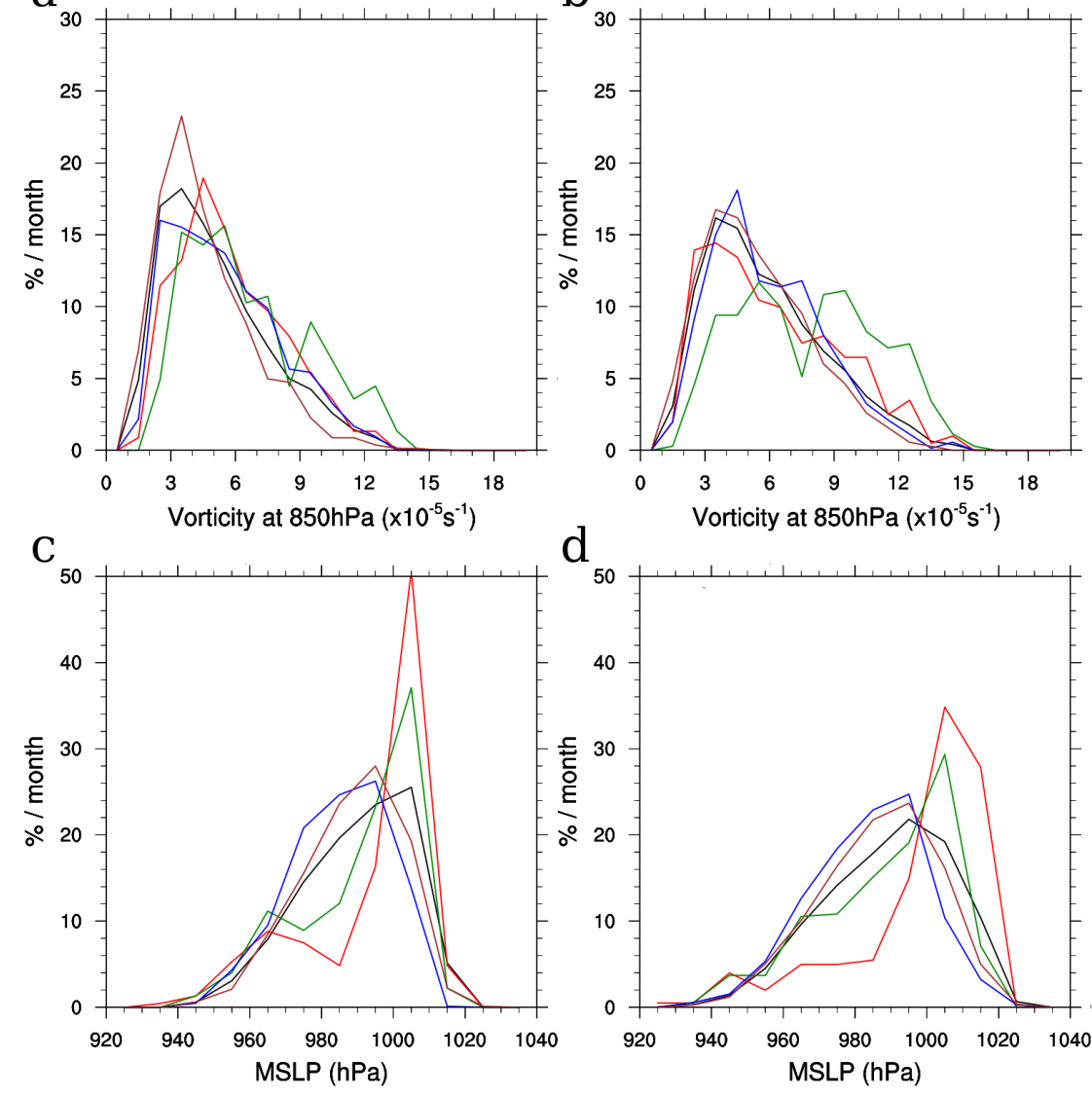

d

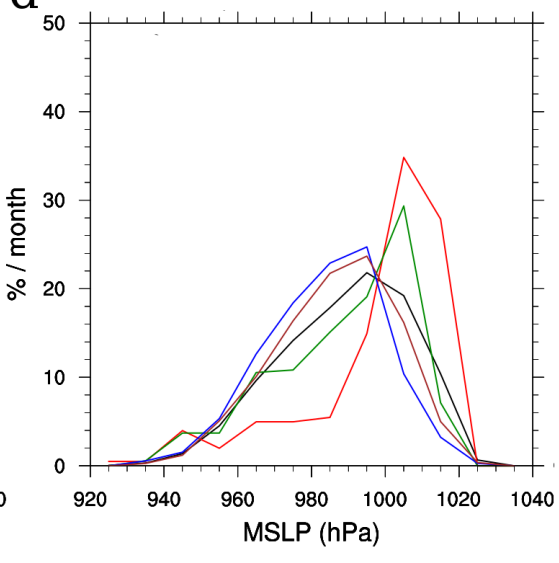

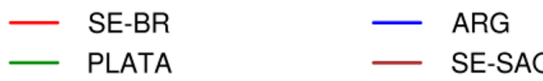

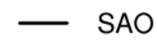

Figure 4.5: Histograms of the maximum filtered vorticity at $850 \mathrm{hPa}$ in the (a) summer and (b) winter; and the MSLP ( $\mathrm{hPa}$ ) in the (c) summer and (d) winter. The vorticity is multiplied by $-1 \times 10^{-5} s^{-1}$ and the MSLP was searched within $5^{\circ}$ radius from the center of the cyclone. The intensity histograms were produced for cyclones originated in each genesis region separately. The percentage was computed based on the mean cyclones per month for each region. 

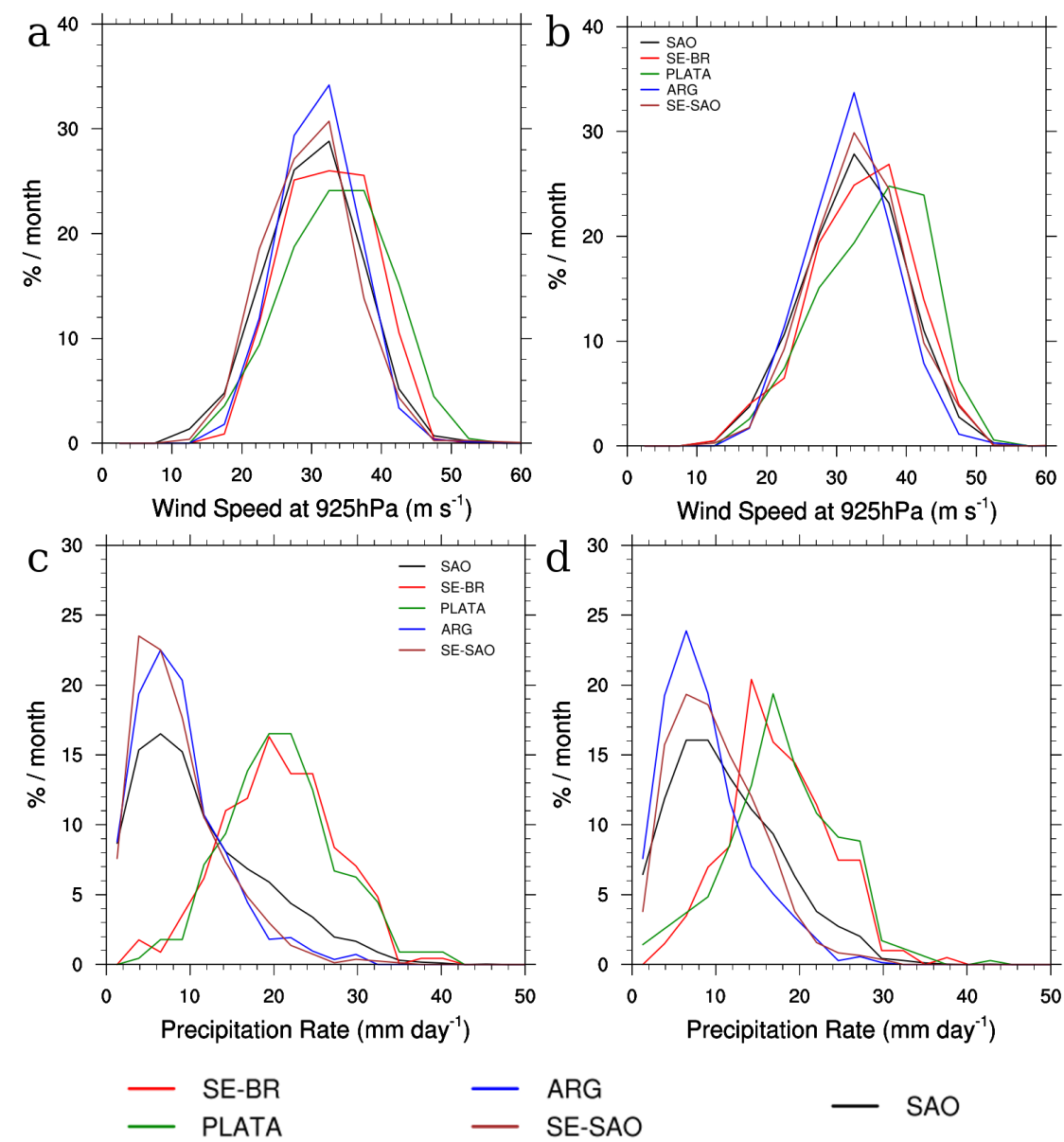

Figure 4.6: Histograms of the maximum wind speed at $925 \mathrm{hPa}$ in the (a) summer and (b) winter; and the precipitation rate $(m m$ day -1$)$ in the (c) summer and (d) winter. The maximum wind speed at $925 \mathrm{hPa}$ is searched within $6^{\circ}$ radius from the center of the cyclone and the precipitation is averaged within $5^{\circ}$ radius. The intensity histograms were produced for cyclones originated in each genesis region separately. The percentage was computed based on the mean cyclones per month for each region. 

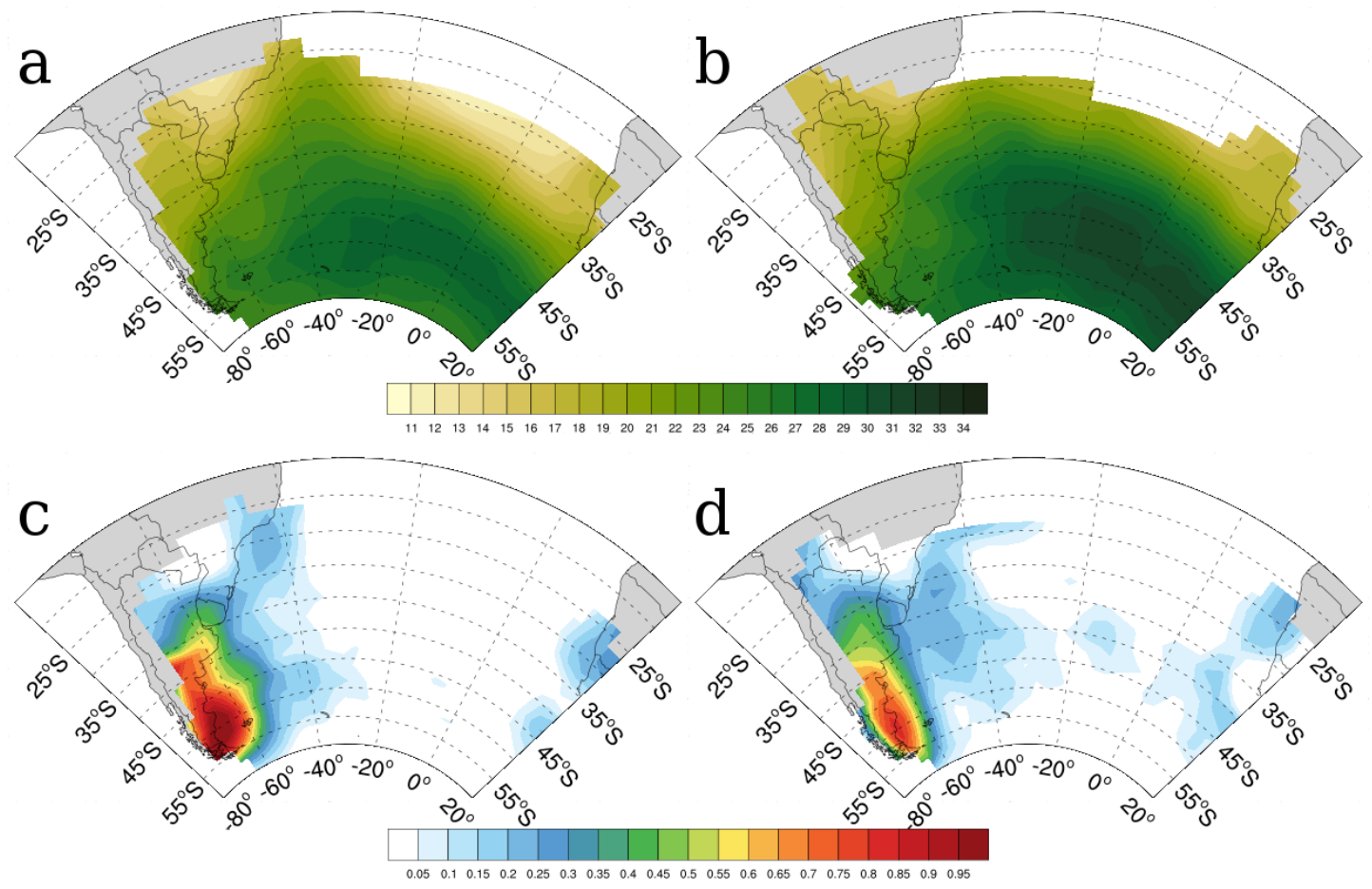

Figure 4.7: Spatial distribution of the mean intensity based on the maximum wind speed at $925 \mathrm{hPa}\left(\mathrm{m} \mathrm{s}^{-1}\right)$ in the (a) summer and (b) winter, and the mean growth rate $\left(-1 \times 10^{-5} s^{-1} d a y^{-1}\right)$ in the (c) summer and (d) winter. The fields are not plotted where track density $<0.3$ cyclones $\left(10^{6} \mathrm{~km}^{2}\right)^{-1}$ month $h^{-1}$.

cyclones are more intense during the winter than in summer.

The mean growth rate is presented in Figs. $4.7 \mathrm{k}$ and d, where the three genesis region along South America coast and the sea nearby are highlighted with positive growth rate values. The rate is calculated using the variation of the vorticity at $850 \mathrm{hPa}$ normalized by the mean vorticity of the system. The mean growth rate is higher in summer than in winter, particularly in the ARG region. In the adjoining ocean, between $30^{\circ} \mathrm{S}$ and $40^{\circ} \mathrm{S}$, high values of mean growth rate seems to follow the zonal variation of the Brazil-Malvinas Confluence that controls the SST gradient position in Southwestern South Atlantic. More of the influence of the SST gradients in cyclone development along the South American coast is discussed in next section (section 4.2).

\subsection{Spatial Distribution of cyclone properties}

The distribution of properties of South Atlantic cyclones is discussed in an attempt to understand the dynamical and thermodynamical spatial characteristics of cyclone de- 
velopment from a climatological point of view. Some of these distributions are shown as anomalies, computed as a deviation from the seasonal climatology. The spatial distributions not showed here can be found in Appendix A.

The spatial distribution of the SST gradient at the time of genesis (Figs.4.8a and b) shows that, between $30^{\circ} \mathrm{S}$ and $45^{\circ} \mathrm{S}$, cyclones develop in a high SST gradient environment (Sinclair, 1995; Hoskins and Hodges, 2005). Sinclair (1995) suggested that the correlation between high SST gradient and cyclogenesis may be related to the transfer of oceanic baroclinicity to the atmosphere. Comparing the track density (Figs 4.1 a and b) with the distributions of SST gradient at the time of genesis (Figs $4.8 \mathrm{a}$ and b), it is possible to see that the latitude of the main South Atlantic storm track and the high values of SST gradient at genesis time are related. Figures $4.8 \mathrm{c}$ and d present the mean SST gradient of the South Atlantic Ocean in summer and winter, respectively, and show that both the southeastern and southwestern boundaries are regions of high variability associated with the complex behaviour of ocean fronts. The development of cyclones along the Southeastern South American coast appears to be associated with the presence of a high SST gradient environment that, in this location, is driven by the variability of the Brazil-Malvinas Confluence (BMC) and its associated fronts. During the summer, the BMC is southward of its mean position affecting the lower troposphere baroclinicity in the ARG region; in the winter, the confluence shifts northward reaching lower latitudes (Olson et al., 1988). Combined with the BMC shift, there is a northward intrusion of the La Plata River $\left(34^{\circ} \mathrm{S}\right)$ and Patos Lagoon $\left(32^{\circ} \mathrm{S}\right)$ discharge within the continental shelf of eastern South America during the winter (Piola et al. 2000). It results in a low salinity plume $\left(<33 \mathrm{~g} \mathrm{~kg}^{-1}\right)$ that reaches $28^{\circ} \mathrm{S}$, which does not mix in the vertical, keeping a cool SST tongue over the continental shelf (Campos et al., 1999; Piola et al., 2000). The contrast between this cooler, low salinity surface water with the subtropical warmer and salty water within the continental shelf and Brazilian current generates the subtropical shelf front (STSF), that seems to be led by the BMC variability (Fig 4.8d; Piola et al., 2000, 2008). The STSF and the BMC positions in the winter affect the SST gradient at the time of genesis of the cyclones on the Southeastern South American coast, at $25^{\circ} \mathrm{S}-30^{\circ} \mathrm{S}$ (Fig $4.8 \mathrm{~b}$ ). Moreover, even cyclones that originate above the continent, in the LA PLATA region, are influenced by the increase of low-level baroclinicity as long as they move toward the ocean after genesis. 

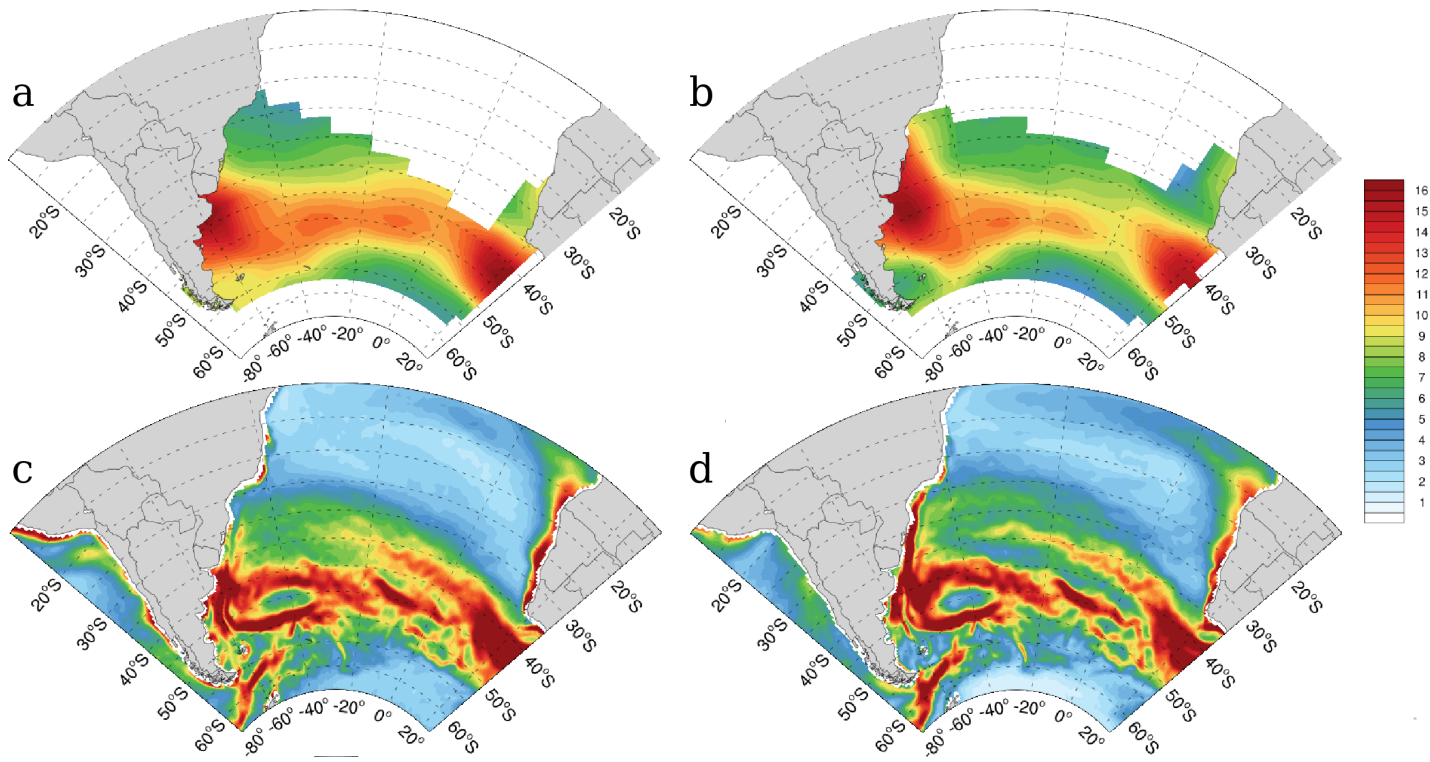

Figure 4.8: Spatial distribution of SST gradient at the time of genesis in the (a) summer and (b) winter. Sea surface temperature (SST) gradient in South Atlantic Ocean in the austral (c) summer and (d) winter. The gradient unit is $10^{-3} \mathrm{~K} \mathrm{~km}^{-1}$. The fields are not plotted where genesis density $<$ 0.2 cyclones $\left(10^{6} \mathrm{~km}^{2}\right)^{-1}$ month $^{-1}$.

Figures $4.9 \mathrm{a}$ and $\mathrm{b}$ show the low level integrated humidity anomaly distribution at the time of genesis for the summer and winter, respectively. In both distributions, the humidity anomalies are positive in most parts of the domain, but particularly on the lee side of the Andes between $25^{\circ} \mathrm{S}$ and $40^{\circ} \mathrm{S}$ and in the SE-BR region. These higher values of moisture at the time of genesis are consequence of an intensified moisture flux from the South American low-level jet (SALLJ), on the Andes western slope, and from the South Atlantic Subtropical High (SASH), towards the southeastern coast (Marengo et al., 2004; Vera et al. 2006; Drumond et al., 2008). The positive moisture anomaly is more concentrated in the LA PLATA region in the winter, when the SASH southwestward position enhances the moisture transport to this location. Vera et al. (2002) and Mendes et al. (2007) have shown the importance of moisture transport from the tropics in the development of cyclones in the Southeastern South American coast. During cyclone development the warm and humid fluxes from the SASH feeds the cyclone, providing low-level instability.

The spatial distribution of the potential temperature and equivalent potential temperature lapse rates are considered here as a measure of atmospheric static stability and conditional stability, respectively. In this way, less (more) negative values of $\partial \theta / \partial p$ mean a less (more) stable low-level atmosphere, and positive (negative) values of $\partial \theta_{e} / \partial p$ mean 
a conditionally unstable (stable) low-level atmosphere. The anomalies show a less stable genesis environment with positive values. Figures $4.9 \mathrm{c}$ and d show the static stability anomaly in both winter and summer seasons. The genesis environment over South America and its coastal environs is less statically stable in the summer than in the winter. The opposite behavior is observed over the open ocean and is related to the contrast between the low atmospheric and land surface temperatures and sea temperatures in different seasons. In the summer, the SE-BR and the ARG oceanic cyclones develop in a relatively less statically stable environment over the ocean. In the winter, the SE-BR and LA PLATA regions have less stable genesis environment. The SE-SAO region shows a less stable environment in both season, but with some variation within its domain (more stable northward). Figures $4.9 \mathrm{e}$ and $\mathrm{f}$ show the conditional stability anomalies at genesis time. The LA PLATA cyclones develop in a less conditionally stable environment when compared to the climatology that may be explained by the positive moisture anomaly at this location. Although the SE-BR region presents a more stable environment (negative anomalies) this region is conditionally unstable in the summer and has a neutral environment in the winter. The reason why these cyclones show a less unstable environment at the time of genesis could be justified by the presence of previous convection, further evidences can be found through cyclone composites analysis in section 4.3. Over the ocean, including the SE-SAO region, the genesis environment is less stable than the climatology in both seasons.

The potential vorticity and jet velocity were used to analyze the upper-level genesis properties of the cyclones. The distributions of potential vorticity at $300 \mathrm{hPa}$ at the time of genesis in the summer and winter are presented in Figs $4.10 \mathrm{a}$ and $\mathrm{b}$. The PV values are multiplied by $\times-1 P V U$, so that the higher the PV, the more cyclonic it is. Despite the higher values of PV in the summer, the distribution at the time of genesis is similar to the climatology. In the winter, a PV intrusion at the time of genesis occurs especially at some locations over the South American coast, including the LA PLATA and SE-BR region. Campetella and Possia (2007) and Reboita et al. (2010) showed that the center of Argentina and Southern Brazil are areas of cut-off low genesis, which may influence the cyclogenesis in South America (e.g. Funatsu et al., 2004; Iwabe and da Rocha, 2009). At the time of maximum intensity (Figs 4.10 c and d) the PV is anomalously cyclonic over the whole domain, particularly between $40^{\circ} \mathrm{S}$ and $60^{\circ} \mathrm{S}$. The associated stratospheric intrusion is expected to be higher at the time of maximum intensity of cyclones indicating a possible 

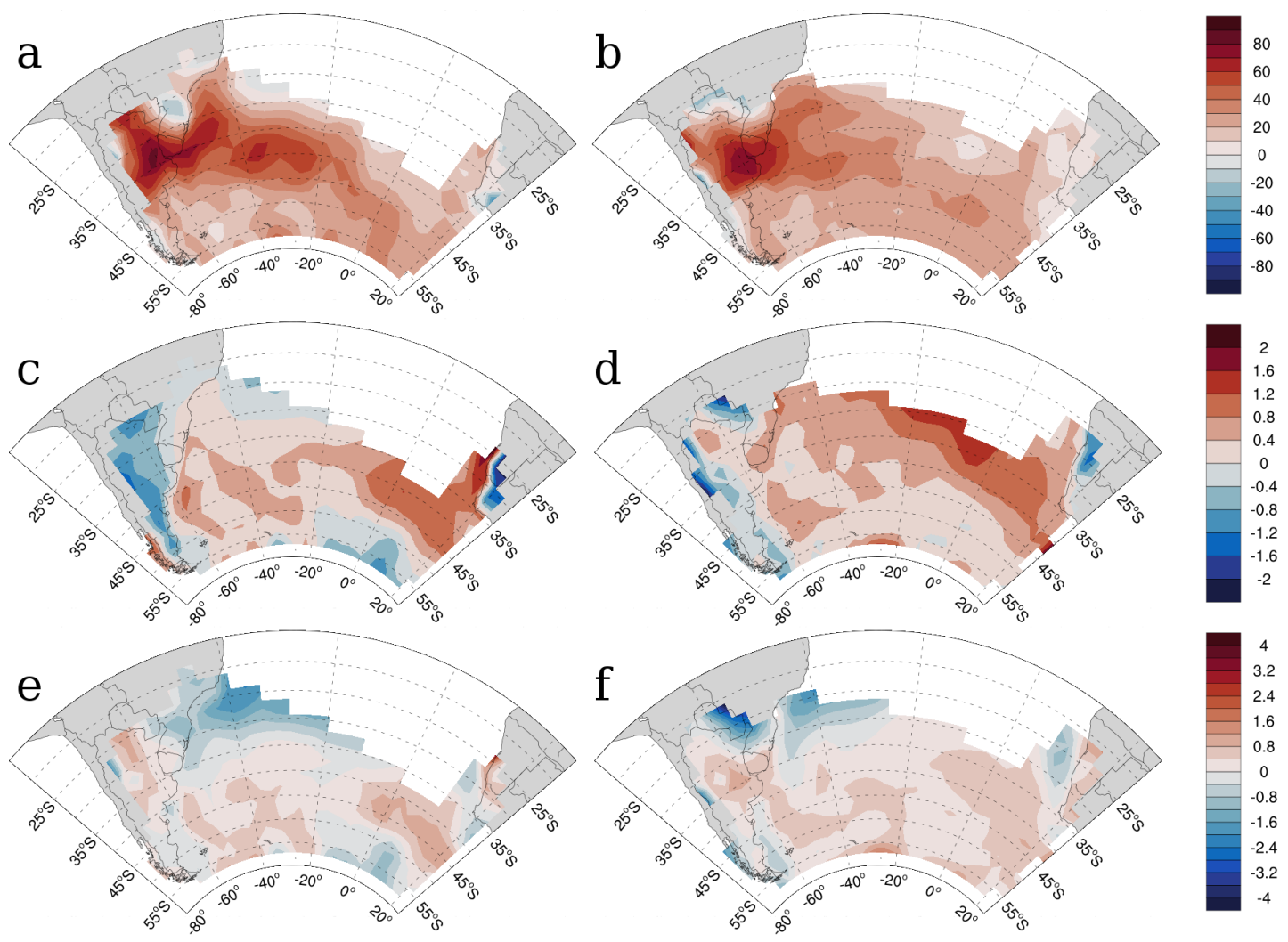

Figure 4.9: Spatial distribution of anomalies at the time of genesis of the integrated humidity at lower-level $\left(\mathrm{kg} \mathrm{kg}^{-1}\right)$ in (a) austral summer and (b) winter; $\partial \theta / \partial p\left(10^{-2} \mathrm{KhPa}^{-1}\right)$ in (c) summer and (d) winter, and; $\partial \theta_{e} / \partial p\left(10^{-2} K h \mathrm{~Pa}^{-1}\right)$ in (e) summer and (f) winter. The anomalies are computed using the season climatology and the fields are not plotted where genesis density $<0.2$ cyclones $\left(10^{6} \mathrm{~km}^{2}\right)^{-1} \mathrm{month}^{-1}$. 

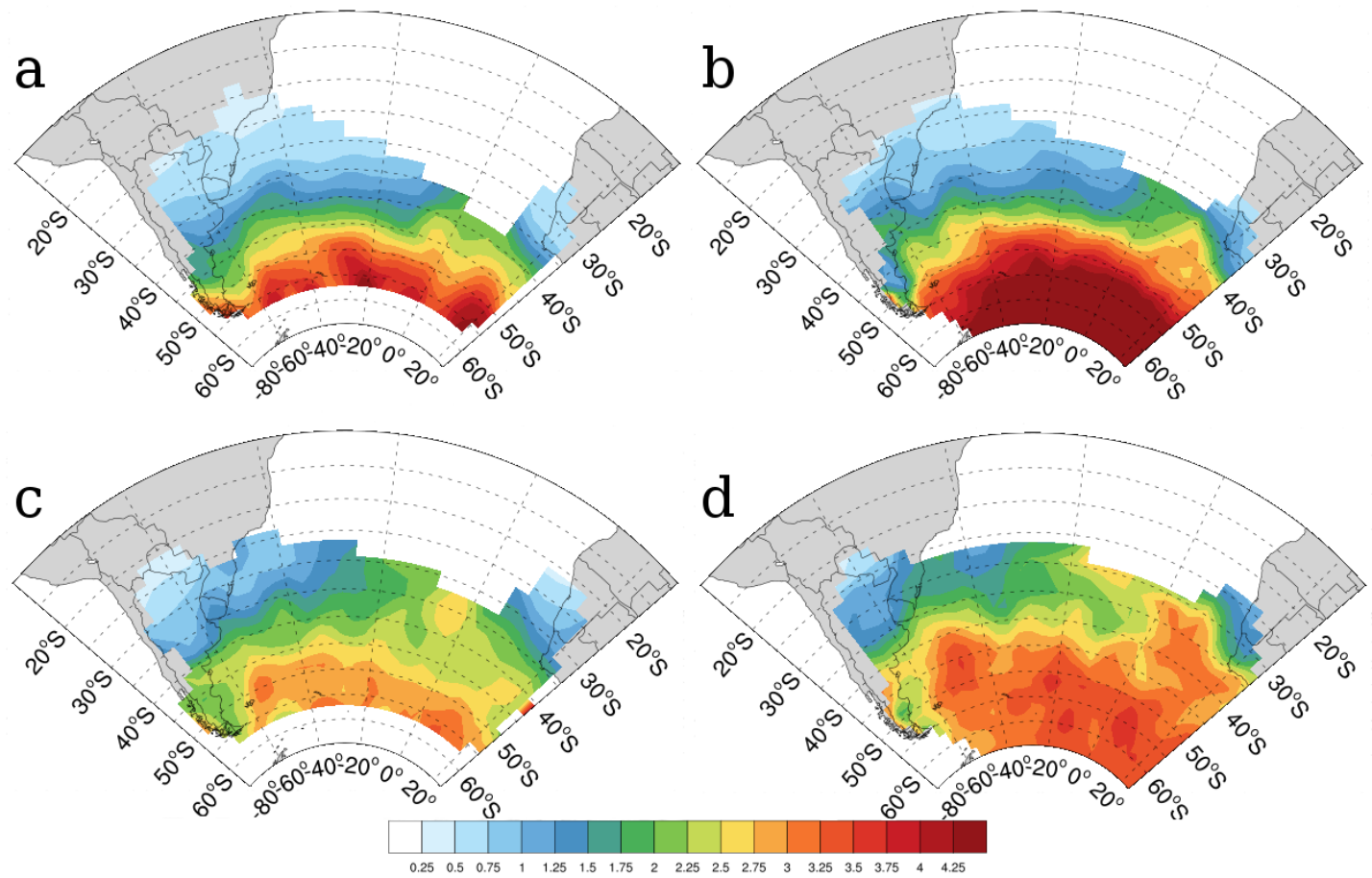

Figure 4.10: Spatial distribution of potential vorticity at $300 \mathrm{hPa}(\times-1 P V U)$ at genesis time and maximum intensity time in the austral $(\mathrm{a}, \mathrm{b})$ summer and $(\mathrm{c}, \mathrm{d})$ winter, respectively. The field distribution at genesis and at the maximum intensity are not plotted where genesis and track density $<0.2$ cyclones $\left(10^{6} \mathrm{~km}^{2}\right)^{-1}$ month $^{-1}$ and $<0.5$ cyclones $\left(10^{6} \mathrm{~km}^{2}\right)^{-1}$ month $^{-1}$, respectively.

displacement of the upper-level maximum cyclonic PV toward the cyclone center.

Finally, the distributions of the upper-level jet velocity at the time of genesis are shown in Figs 4.11 and b. Cyclones tend to develop for upper-level jets which tend to be more intense at the time of genesis than in the mean climatology. The anomalies of upper-level jet velocity are higher in the SE-SAO region (more than $10 \mathrm{~m} \mathrm{~s}^{-1}$ ) than on the South American coast $\left(2-5 \mathrm{~m} \mathrm{~s}^{-1}\right)$. The only exception is the cyclones that form over the SEBR in the summer, that show a genesis environment with a weak upper-level jet, similar to the mean climatology. A weak upper-level jet may suggest that vertical wind shear is not strong in this region.

\subsection{Cyclones structure}

In this section, the cyclone composites are presented to understand the cyclogenesis precursors of each defined genesis region. An intensity threshold was used to select the 


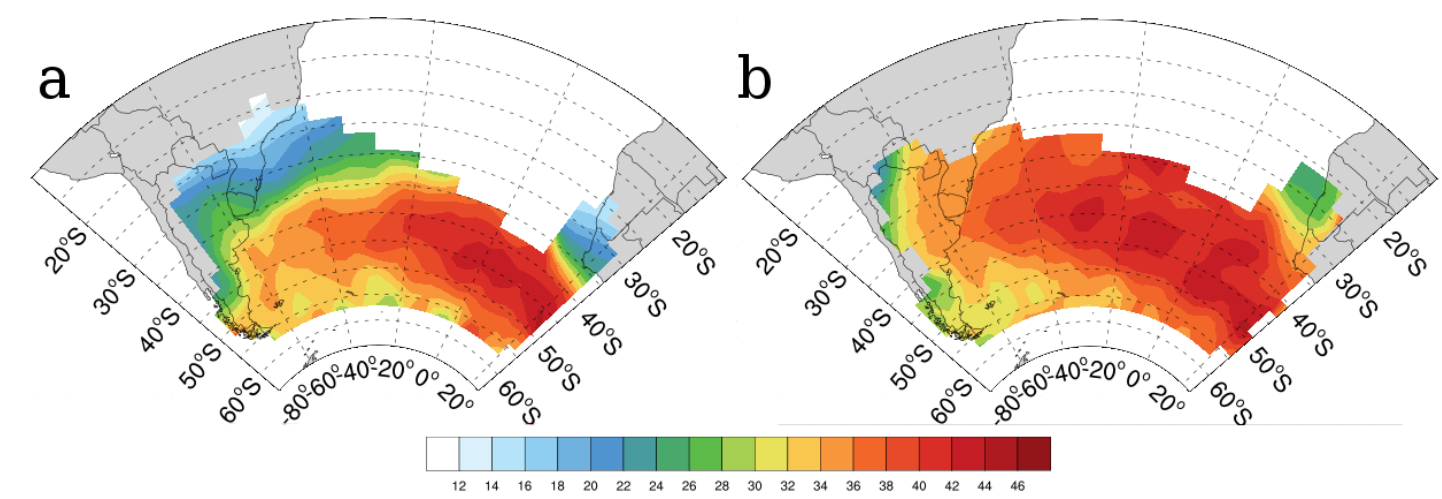

Figure 4.11: Spatial distribution of upper-level jet $\left(\mathrm{m} \mathrm{s}^{-2}\right)$ in austral (a) summer and (b) winter at the time of genesis. The field distribution at genesis is not plotted where genesis density $<0.2$ cyclones $\left(10^{6} \mathrm{~km}^{2}\right)^{-1} \mathrm{month}^{-1}$.

Table 4.3 - Intensity threshold (scaled by $-1 \times 10^{-5} s^{-1}$ ) applied to the selection of $30 \%$ most intense cyclone of each defined genesis region in summer and winter and the number of cyclones used to compute the each composites.

\begin{tabular}{ccccc}
\hline \hline & \multicolumn{2}{c}{ DJF } & \multicolumn{2}{c}{ JJA } \\
\hline & threshold & number & threshold & number \\
SE-BR & 7.1 & 61 & 8.8 & 44 \\
LA PLATA & 8.8 & 63 & 10.5 & 92 \\
ARG & 8.2 & 197 & 8.6 & 169 \\
SE-SAO & 8.9 & 167 & 10.0 & 221 \\
\hline \hline
\end{tabular}

$30 \%$ most strong systems of each region in each season. The threshold for each region and season changes according to its maximum intensity. Table 4.3 shows the limits adopted in each case and the number of systems used in each composite.

First, an overview of the cyclone structure for each genesis region is examined to explore the general extratropical cyclone features at the time of genesis. The cyclone structure for each region will be shown separately for composites of time steps before and after the time of genesis. For clarity, only composites at $12 \mathrm{~h}$ before, at the time of genesis and $24 \mathrm{~h}$ after it will be shown. The discussion of the intensification of the precursors is based on the thermal advection at $850 \mathrm{hPa}$, geopotential height at $500 \mathrm{hPa}$, vertical velocity, vertically integrated moisture transport and moisture flux convergence $(925 \mathrm{hPa}-700 \mathrm{hPa})$ and upper-level divergence and geopotential height at $200 \mathrm{hPa}$. 

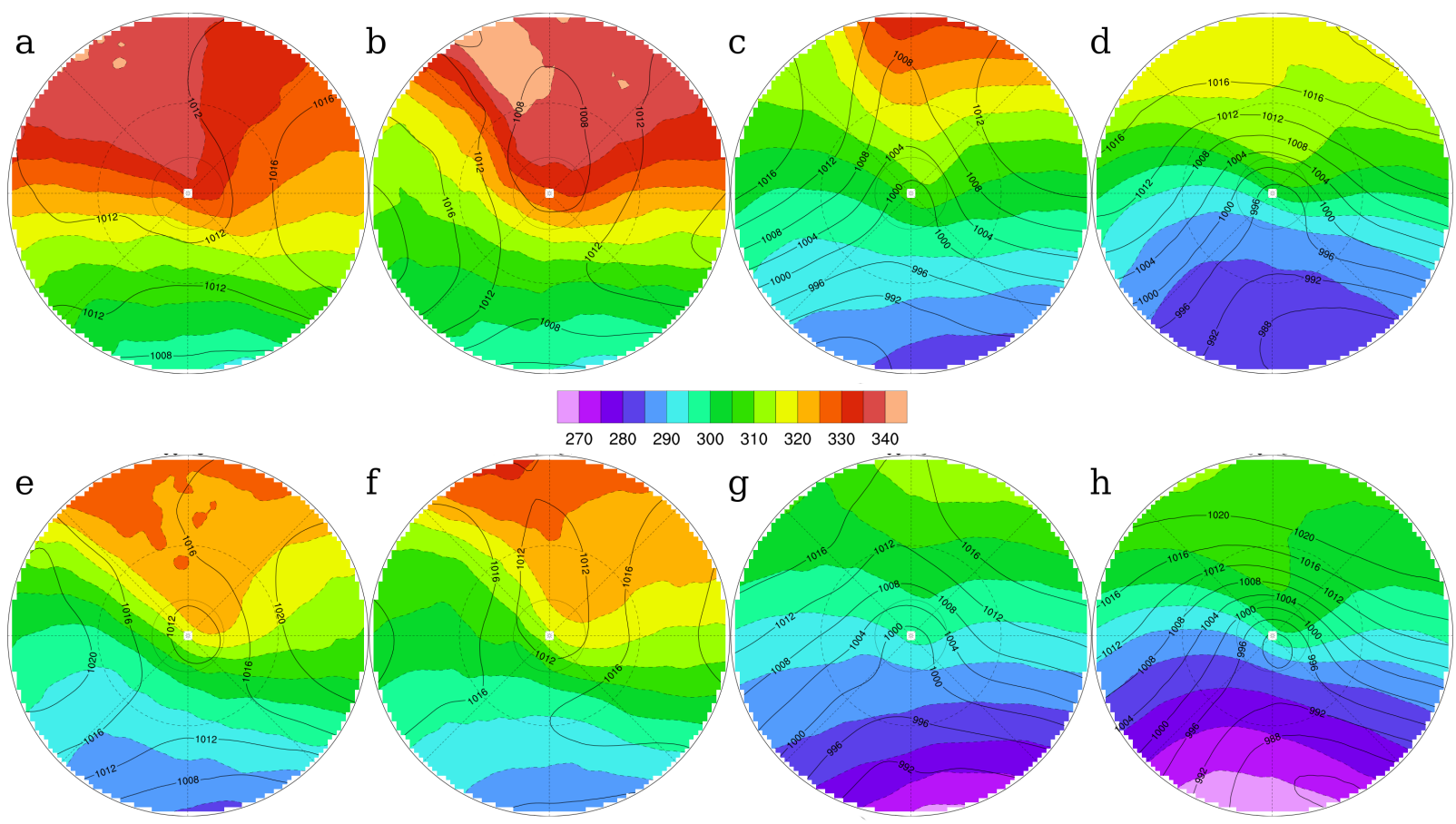

Figure 4.12: Composites of mean equivalent potential temperature $\left(\theta_{e}\right)$ at $925 \mathrm{hPa}(\mathrm{K}$; shaded) and MSLP (hPa; black line) from different genesis regions in the (a-d) summer and (f-g) winter : (a,e) SE-BR, (b,f) LA PLATA, $(c, g)$ ARG and $(\mathrm{d}, \mathrm{h})$ SE-SAO.

\subsubsection{General structure of cyclone genesis}

The composite structure of temperature $\left(\theta_{e}\right)$ at $925 \mathrm{hPa}$ and MSLP at the time of genesis are shown in Fig 4.12. The cyclones from all genesis regions tend to form in a temperature gradient zone with the warm isotherms folding towards the center, following the conceptual models of Bjerknes et al. (1922) and Shapiro and Keyser (1990). As discussed before, the use of relative vorticity in the cyclone tracking allows the identification of cyclonic features without a closed isobar, as it is possible to see in most of the MSLP composites (Fig 4.12). The MSLP composite structure also retains the position of the SASH relative to the genesis region. In the SE-BR and LA PLATA regions, the SASH signature in the MSLP mean field is east-northeastward of the cyclone center.

Figure 4.13 shows the composites of $\mathrm{RH}$ and $\mathrm{PV}$ at $300 \mathrm{hPa}$, and mean temperature $\left(\theta_{e}\right)$ at $925 \mathrm{hPa}$ at the time of genesis. The $\mathrm{RH}$ structure in some composites shows a horizontal elongated cloud band across the center. The presence of this cloud band is usually related to a strong thermal gradient at the surface, indicating frontal cloud. In general, this cloud band structure within an extratropical cyclone is called polar front cloud 

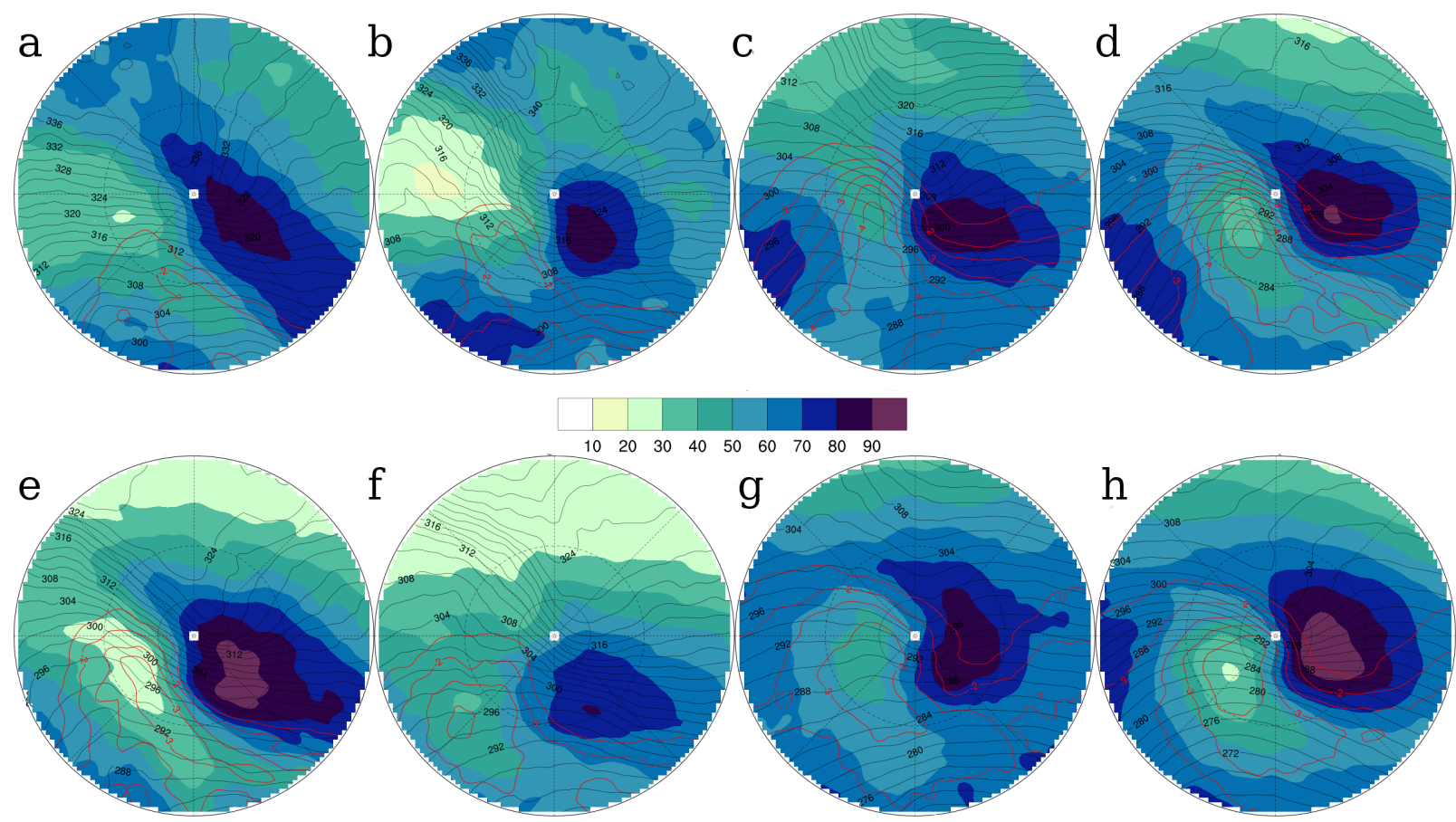

Figure 4.13: Composites of mean equivalent potential temperature $\left(\theta_{e}\right)$ at $925 \mathrm{hPa}(\mathrm{K}$; black lines), RH (\%; shaded) and PV at $300 \mathrm{hPa}$ (PVU; red line) from different genesis regions in the (a-d) summer and (f-g) winter : (a,e) SE-BR, (b,f) LA PLATA, (c,g) ARG and $(d, h)$ SE-SAO.

and is associated with a high baroclinic environment (Streten and Troup, 1973; Browning and Roberts, 1994). The presence of a more pronounced cloud band at the time of genesis could be an evidence of secondary cyclogenesis (Dacre et al., 2012) and it is observed in SE-BR cyclones in the summer and in both seasons in SE-SAO cyclones. The composite of $\mathrm{PV}$ at $300 \mathrm{hPa}$ shows an upper-level trough upstream of the cyclone center in all cyclones. The only exception is the SE-BR cyclones in the summer, where the upper-level trough seems to be weak. The PV values of -2 PVU $\left(1 \mathrm{PVU}=1 \times 10^{-6} s^{-1}\right)$ indicate a stratospheric intrusion upstream of the cyclone development center, in the Southern Hemisphere. The PV values are higher in cyclogenesis that occurs poleward due to the lower tropopause.

\subsubsection{Cyclone structure evolution during genesis}

Figure 4.14 shows the composite of the mean surface temperature advection, winds at $850 \mathrm{hPa}$ and geopotential height at $500 \mathrm{hPa}$ for the SE-BR cyclones. In the summer, the temperature advection is very weak before the time of genesis, increasing slowly after genesis, and showing no evidence of strong frontal characteristics. The winter composites 

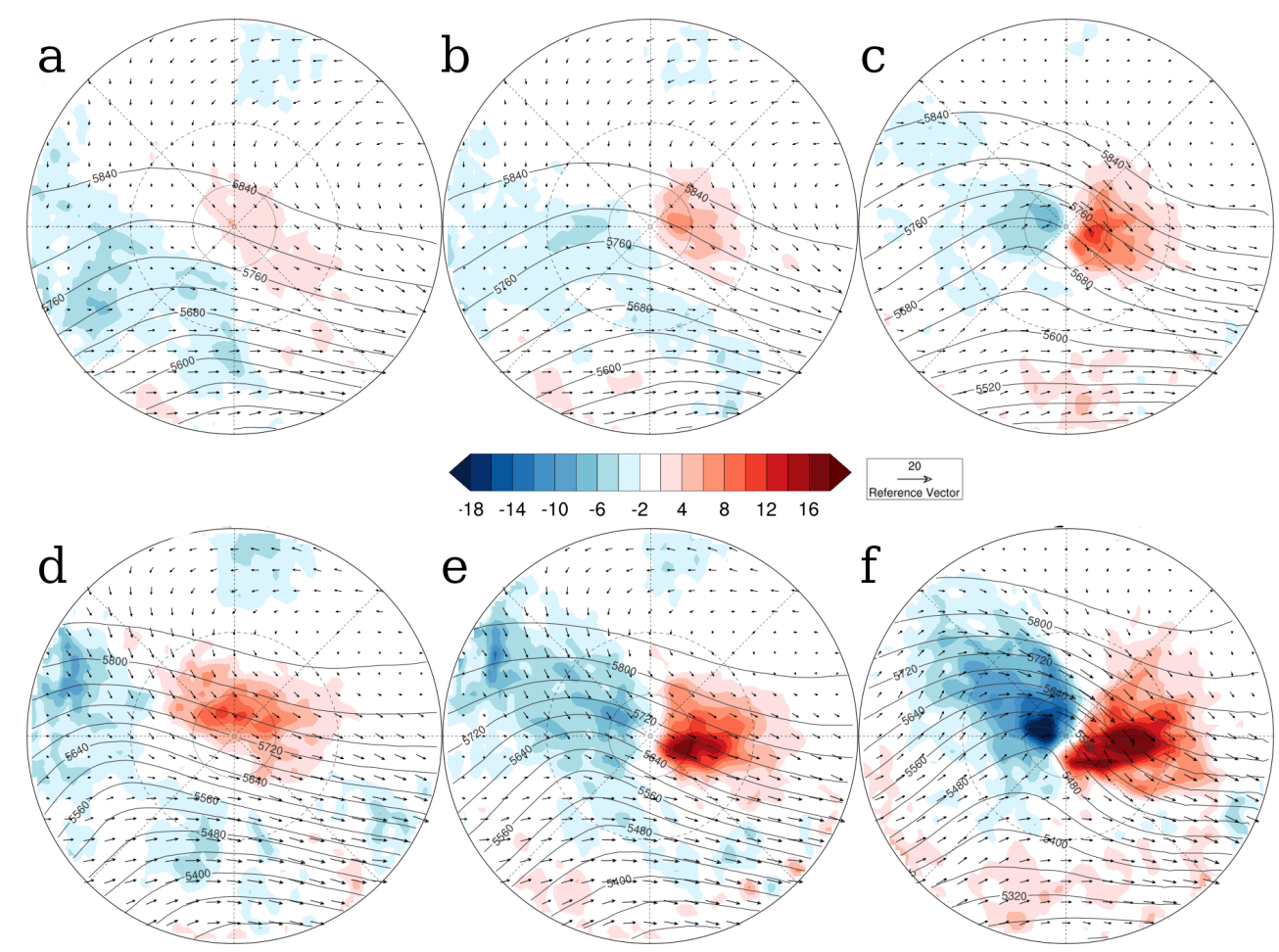

Figure 4.14: Composites of SE-BR cyclones temperature advection at $850 \mathrm{hPa}\left(10^{-5} \mathrm{~K}^{-1}\right.$; shaded), geopotential height at $500 \mathrm{hPa}$ (gpm; black line) and winds at $850 \mathrm{hPa}(\mathrm{m}$ $s^{-1}$ ) in the (a-c) summer and (d-f) winter: (a,d) at 12 hours before time of genesis; $(\mathrm{b}, \mathrm{e})$ at time of genesis, and; $(\mathrm{c}, \mathrm{f})$ at 24 hours after genesis.

show strong warm advection before genesis and a rapid increase of cold and warm advection after the genesis time.

The low-level wind structure and MSLP at the time of genesis (Fig 4.12 and e) show the southwestern path of the SASH in the upper-east side of the composites. The SASH is located northeastward of its main position during the winter, which may reflect the stronger warm advection before genesis. Moreover, there is strong low-level baroclinicity in the SE-BR region due to the northward shift of the BMC and STSF in the winter. The thermal advection associated with the ocean heat and moisture fluxes can act to decrease the low-level stability contributing to the cyclone development. In both seasons there is a mid-level trough moving to the east that is located westward of the cyclone center at the time of the genesis giving support to the cyclone development.

The vertical velocity at $700 \mathrm{hPa}$, the integrated moist flux convergence and transport is shown in Fig 4.15. In the summer, there is a narrow band of upward motion and moisture convergence with a NW-SE orientation before the time of genesis. This feature 
in the summer composites may indicate the presence of an "old" front, possibly generated by a "parent" cyclone located southeastward from the genesis area. This can explain the structure analogous of the "polar front cloud" observed for the RH at $300 \mathrm{hPa}$ at the genesis time for the SE-BR summer composites (Fig 4.13a). The existence of this convergence strip associated with a cloud band at $300 \mathrm{hPa}$ may be indicative of secondary cyclogenesis. However, the relatively weak thermal advection leads us to believe that this type of secondary development occurs due to the effects of moist deformation strain acting to decrease the frontal temperature gradient of a preexisting front (e.g., Renfrew et al., 1997; Dacre and Gray, 2006). Following the summer cyclone development, the mid-level trough position seems to enhance the vertical movement. However, the proximity of its axis to the cyclone center reveals a small tilt of the system, which does not totally explain the enhancement of the vertical movement. Figure 4.16 shows the divergence of the winds and geopotential at $200 \mathrm{hPa}$. The summer composites show the weak upper-level trough that intensifies during the genesis process (Fig $4.16 \mathrm{~b}$ ). The upper-level divergence is due to a diffluent flow and gives support to the development of the cyclone at low level, enhancing vertical velocity upwards and organizing the small cores of moisture convergence to a larger region at the center of the cyclone at the time of the genesis (Figs $4.14 \mathrm{~b}$ and $4.15 \mathrm{~b}$ ).

In the winter, the existence of a trailing front is not evident. Despite the presence of upward movement and low-level convergence, they seem to be promoted by the mid-level trough even before genesis (Figs $4.14 \mathrm{~d}, \mathrm{e}$ ). The upper-level trough at $200 \mathrm{hPa}$ promotes divergence downstream at the same location where there is low-level convergence and midlevel upward motion, showing the coupling of the system even before genesis (Figs 4.15 d,e and $4.16 \mathrm{~d}, \mathrm{e})$. When the trough moves towards the low-level warm advection, the genesis occurs, probably due to the consequent reduction of vertical stability. This sequence of events in the SE-BR winter genesis is defined as type B development by Petterssen and Smebye (1971).

It is important to note that, in the summer, the weak upper-level jet along with strong moisture convergence at low levels and the diffluent flow at upper levels are typical of subtropical cyclone development (Gozzo et al., 2014; Dutra et al., 2017). Subtropical cyclones in the South Atlantic develop mainly in SE-BR region (Gozzo et al., 2014), and they may have been included in the composite process since no distinction between subtropical and extratropical cyclones were made. 

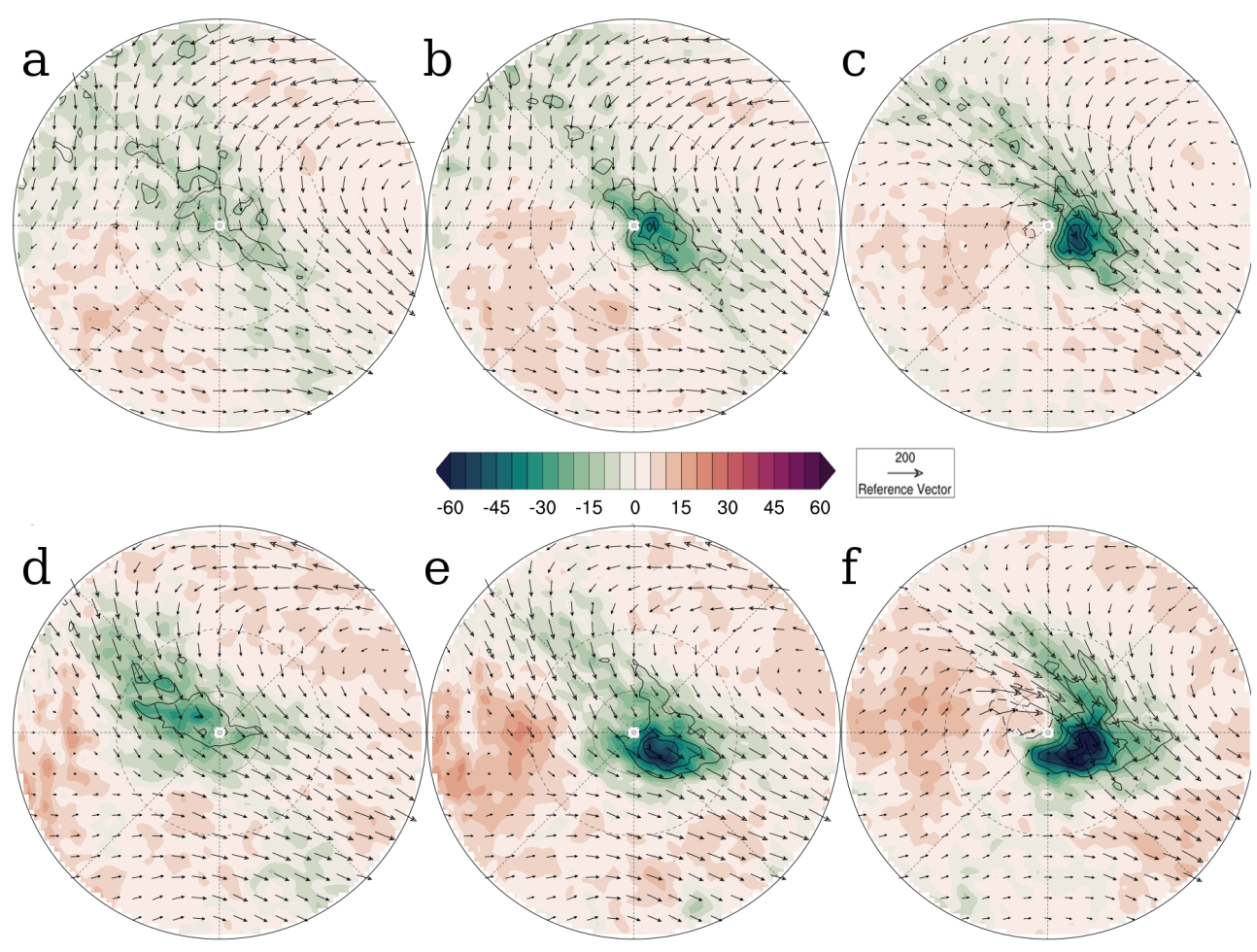

Figure 4.15: Composites of SE-BR cyclones omega at $700 \mathrm{hPa}\left(10^{-2} \mathrm{~Pa} s^{-1}\right.$; shaded), vertically integrated moisture transport $\left(\mathrm{kg} \mathrm{m}^{-1} \mathrm{~s}^{-1}\right.$; arrows) and moisture flux convergence $\left(10^{-3} \mathrm{~kg} \mathrm{~m} \mathrm{~m}^{-2} \mathrm{~s}-1\right.$; contour) at low level $(925-700 \mathrm{hPa})$ in the (a-c) summer and (d-f) winter: (a,d) at 12 hours before time of genesis; (b,e) at time of genesis, and; $(\mathrm{c}, \mathrm{f})$ at 24 hours after genesis. The vertical velocity is contoured every $0.2 \times 10^{-3} \mathrm{~kg}$ $m^{-2} s-1$, without the zero line and negative values (downward movement) are in dashed line. 

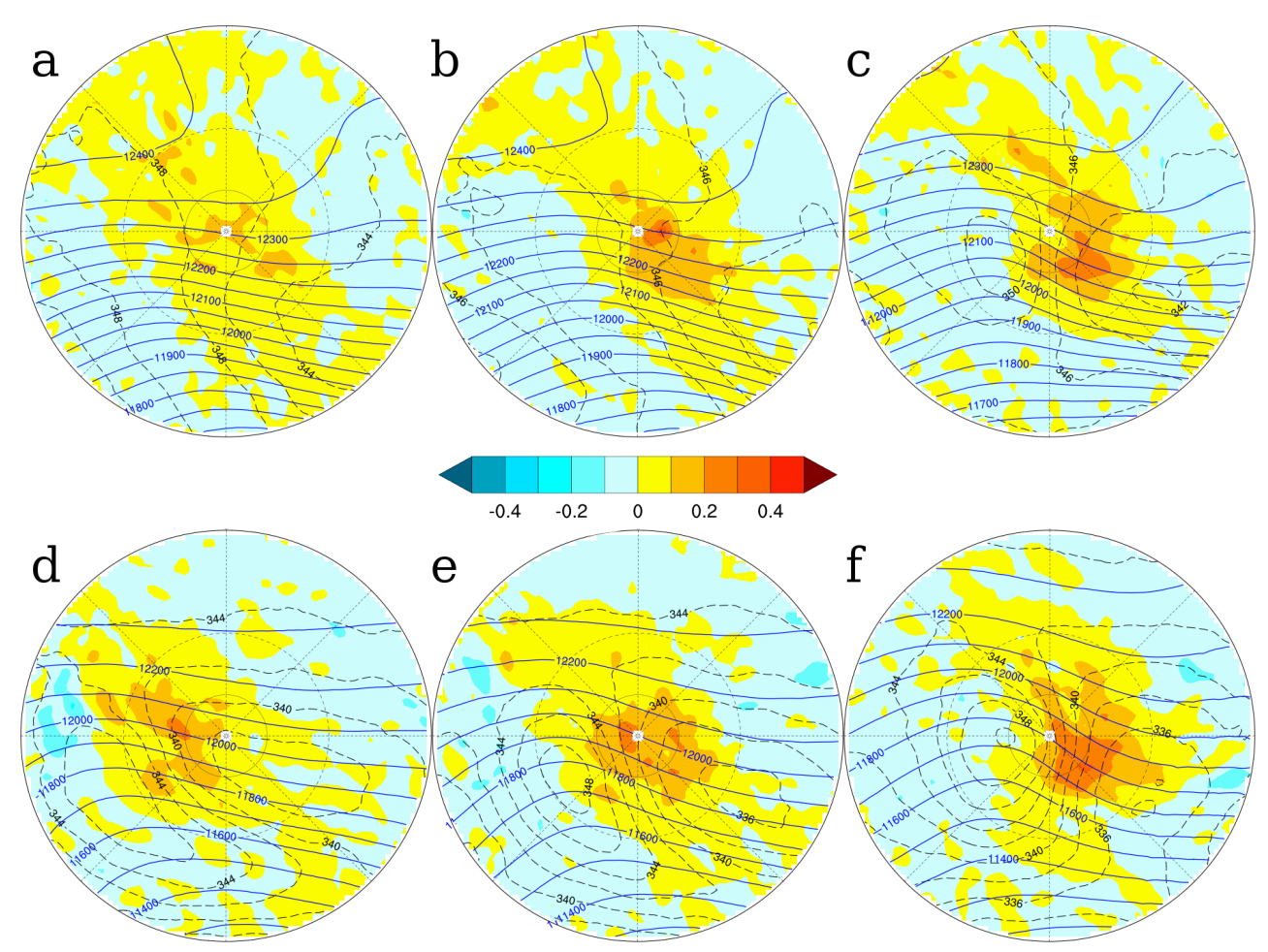

Figure 4.16: Composites of SE-BR cyclones potential temperature ( $K$; black line), geopotential height (gpm; blue line) and divergence of mass $\left(s^{-1}\right.$; shaded) at $200 \mathrm{hPa}$ in the (a-c) summer and (d-f) winter: (a,d) at 12 hours before time of genesis; (b,e) at time of genesis, and; (c,f) at 24 hours after genesis. 


\section{La Plata region (LA PLATA)}

The composites of mean thermal advection and winds at $850 \mathrm{hPa}$, and geopotential height at $500 \mathrm{hPa}$ before and after genesis, for cyclones from LA PLATA region, are shown in Figs 4.17 a-c. Only the winter composites are shown, as this season has more cyclogenesis than summer, but the composites produced are similar for both seasons. The differences between summer and winter composites will be discussed along the text. The signature of the Andes Cordillera, particularly in the composites before genesis time and at genesis, is apparent. This signal appears as a thin meridional strip of cold advection. A warm advection exists at the center of the cyclone before genesis time in the winter composites, while it starts only at the time of genesis in the summer composites. This warm advection in the winter composite seems to be intensified by the anticyclonic circulation southeastward from the cyclone center, which may be the effect of the SASH westward position and intensity in this season. In both seasons the intensification of the warm and cold advection around the cyclone center is faster after genesis time. Although the LA PLATA cyclones start over the continent, they move eastward over the ocean very quickly due to the narrow shape of South America. In this way, they may be already over the ocean at 12 to 24 hours after the genesis time, where surface fluxes can be intense. In fact, the more intense temperature advection in the winter after genesis can be understood in terms of the northward shift of BMC. Figures 4.17d-f show the vertical velocity at $700 \mathrm{hPa}$, and the integrated moist convergence flux and transport. In the winter, it is possible to see subsidence in a meridional strip promoted by descending air from the Andes Cordillera.

The lee effect is responsible for the development of a low-pressure center observed in composites at the genesis time (Figs $4.12 \mathrm{~b}$ and $\mathrm{f}$ ). The elongated shape of the low observed in composites at the genesis time (Figs 4.12b and $\mathrm{f}$ ) makes us believe that it is an influence of the thermal-orographic lows called Northwestern Argentina Low (NAL, Seluchi et al., 2003) and the Chaco Low (CL, Saulo et al., 2004). The NAL is thermally induced in summer due to surface fluxes above a desert region and orographically induced in winter by forced subsidence during an upper-level trough occurrence and is usually located around $30^{\circ} \mathrm{S}$ close to the Andes lee slope. The CL is basically thermally induced and is located southward around $20^{\circ} \mathrm{S}$ above Paraguay and Bolivia (Seluchi and Saulo, 2012). The southward low level circulation combined by CL and NAL allows a well-organized 
low-level northerly current. The presence of the SASH westward of its main position linked with the CL and NAL southward circulation in the winter may be responsible for the intensified warm advection before genesis. In the summer, the CL intensifies the transport of humidity to the LA PLATA region (Saulo et al., 2004), that may help the genesis. The tracking algorithm used here identifies the earlier stages of the cyclones that intensify further eastward, near the Southeastern South American coast and where using MSLP would first identify them. This fact reinforces the argument for the influence of thermal-orographic lows in the cyclogenesis in the LA PLATA region in both seasons, enhancing the moisture transport and warm advection. Ribeiro et al. (2016) show that development of warm fronts in this region are related to the eastern edge of the CL and NAL northwesterly flow and, most of the time, are followed by cyclogenesis. Also, Seluchi et al. (2003) and Seluchi and Saulo (1998) highlight the role of NAL formation in the reduction of static stability before genesis time due to warm and moist advection. The upper-level pattern of the LA PLATA cyclone composites (Figs 4.17g-i) is similar to the SE-BR cyclones. In the summer, the presence of a diffluent flow promotes divergence that enhances and organizes the low-level convergence at the genesis time (not shown), similar to the SE-BR composites. In the winter LA PLATA composites, there is an upper-level perturbation moving eastward reinforcing the low-level system.

\section{Argentina region $(A R G)$}

Although composites for the ARG cyclones were produced for summer and winter, only summer composites are presented here. Very few aspects are different between the summer and winter composites and are discussed in the text. Figures $4.18 \mathrm{a}-\mathrm{c}$ show the composite of the mean temperature advection and winds at $850 \mathrm{hPa}$, and geopotential height at $500 \mathrm{hPa}$ of the ARG cyclones before, at and after genesis times for winter. In the ARG composites, as in the LA PLATA ones, the presence of the Andes Cordillera is observed through a meridional band of cold advection westward of the composite center. The mountain chain height at this latitude $\left(45^{\circ} \mathrm{S}\right)$ is lower than at $30^{\circ} \mathrm{S}$, and the lee effects are not so strong as in the LA PLATA region. However, it is possible to see a moving trough at $500 \mathrm{hPa}$ that intensifies due to its interaction with the Andes stationary trough (Gan and Rao, 1994) from $-12 \mathrm{~h}$ to genesis time. In the ARG cyclone composites, the cold advection is stronger at the time of genesis, particularly in the summer. This strong cold advection occurs above 

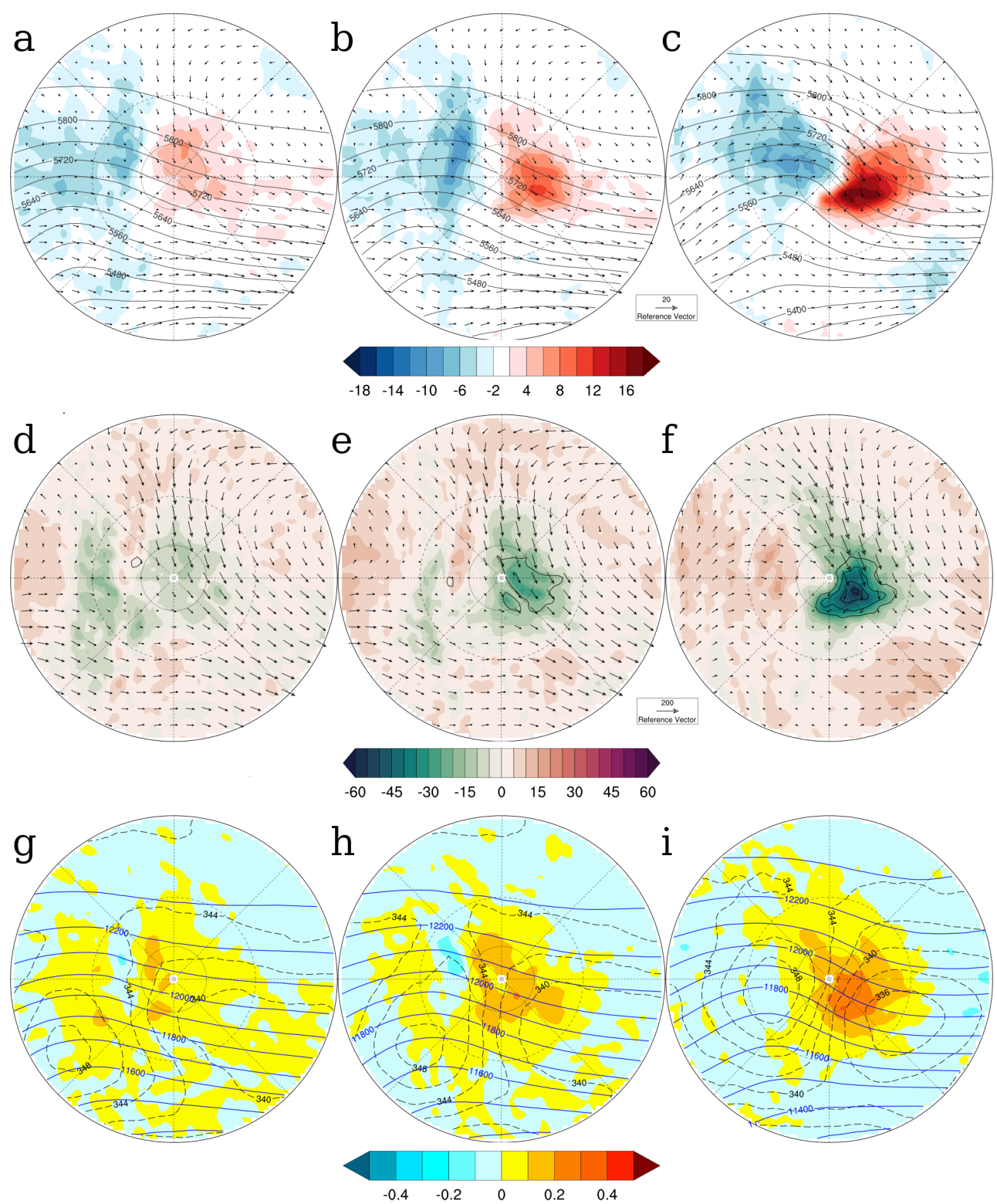

Figure 4.17: Composites of LA PLATA cyclones in the winter: (a-c) temperature advection at $850 \mathrm{hPa}\left(10^{-5} \mathrm{~K} \mathrm{~s}^{-1}\right.$; shaded), geopotential height at $500 \mathrm{hPa}$ (gpm; black line) and winds at $850 \mathrm{hPa}\left(\mathrm{m} \mathrm{s}^{-1}\right)$; (d-f) omega at $700 \mathrm{hPa}\left(10^{-2} \mathrm{~Pa} \mathrm{~s}^{-1}\right.$; shaded), vertically integrated moisture transport $\left(\mathrm{kg} \mathrm{m}^{-1} \mathrm{~s}^{-1}\right.$; arrows $)$ and moisture flux convergence $\left(10^{-3} \mathrm{~kg} \mathrm{~m}^{-2} \mathrm{~s}-1\right.$; contour) at low level $(925-700 \mathrm{hPa})$, and; (g-i) potential temperature ( $K$; black line), geopotential height (gpm; blue line) and divergence of mass $\left(s^{-1}\right.$; shaded) at $200 \mathrm{hPa}$. Composites $(\mathrm{a}, \mathrm{d}, \mathrm{g})$ at 12 hours before the time of genesis; $(\mathrm{b}, \mathrm{e}, \mathrm{h})$ at the time of genesis, and; (c,f,i) at 24 hours after the time of genesis. The vertical velocity is contoured every $0.2 \times 10^{-3} \mathrm{~kg} \mathrm{~m}^{-2} \mathrm{~s}-1$, without the zero line and negative values (downward movement) are in dashed line. 
the land surface, that is warmer than the upper air temperature in the summer, decreasing the static stability at the low level. In the winter, the reduction of static stability is lower as the cold advection in less intense. When compared with the SE-BR and LA PLATA cyclones, the ARG cyclone temperature advection intensifies rapidly in the $12 \mathrm{~h}$ interval after genesis time (not shown). Figures 4.18d-f present the vertical velocity at $700 \mathrm{hPa}$, and the integrated moist convergence flux and transport and Figs $4.18 \mathrm{~b}$-i show the upper level geopotential $(200 \mathrm{hPa})$ and the divergence of winds at $200 \mathrm{hPa}$. It is possible to see the $500 \mathrm{hPa}$ geopotential trough westward of the composite cyclone center inducing upward vertical motion. This baroclinic system is reinforced by an upper-level trough (Fig $4.18 \mathrm{~h}$ ). There is no strong influence of horizontal moisture transport and convergence in ARG region genesis process.

\section{Southeastern South Atlantic Ocean (SE-SAO)}

Only cyclone composites from winter are shown for the SE-SAO region, for clarity. Again, differences between summer and winter composites are highlighted in the text. The winter composites of the mean temperature advection and winds at $850 \mathrm{hPa}$, and geopotential height at $500 \mathrm{hPa}$ before and after genesis are presented in Figs $4.19 \mathrm{a}$-c. There is a strong warm advection 12 hours before genesis in the center of the composite along with a cold advection westward. This cold advection at lower levels seems to be associated with the mid-level trough at $12 \mathrm{~h}$ before genesis. The cold and warm advections increase rapidly after genesis time, being slightly stronger in the winter. The vertical velocity, vertically integrated moist transport and moist flux convergence are shown in Figs $4.19 \mathrm{~d}-\mathrm{f}$. There is a convergence of moisture near the cyclone center $12 \mathrm{~h}$ before the genesis time associated with a strong upward movement at $700 \mathrm{hPa}$. At the time of genesis, the $500 \mathrm{hPa}$ trough moves eastward into the low-level warm advection region and reinforces the upward motion of moist and warm air. The SE-SAO cyclones seem to develop northwestward of another cyclone as it is possible to see through the curvature of the geopotential field at $500 \mathrm{hPa}$ (Fig 4.19 $\mathrm{b}$ ) and MSLP structure at the time of genesis (Figs 4.12 $\mathrm{d}$ and $\mathrm{h}$ ). This secondary development occurs on the cold side of the parent cyclone. Some authors have related the secondary development in the cold sector to the intrusion of dry stratospheric air (e.g., Browning et al., 1997; Iwabe and da Rocha, 2009). In fact, at the time of genesis, SE-SAO cyclones present a dry slot associated with cyclonic PV at $300 \mathrm{hPa}$ in the cold sector close 

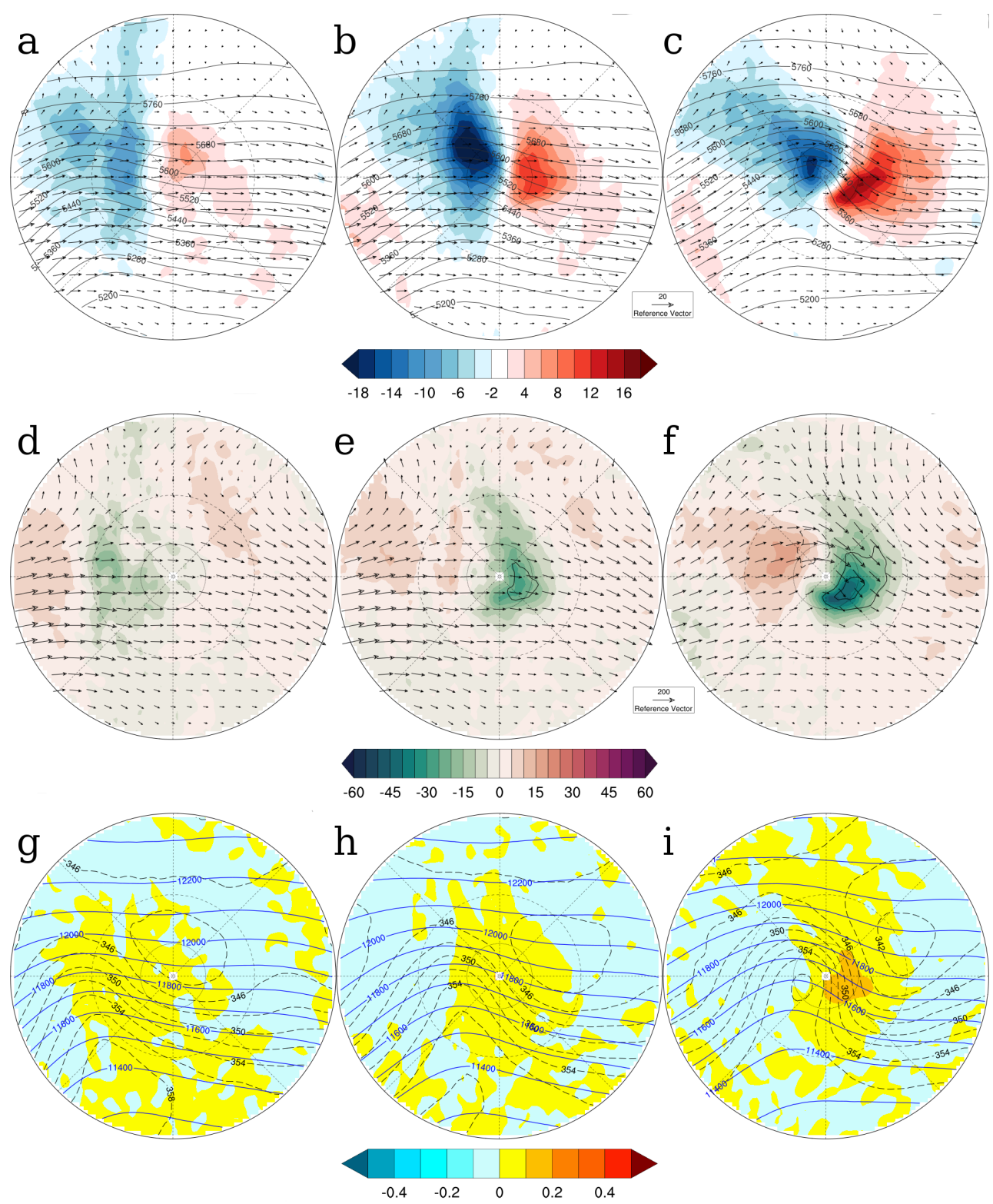

Figure 4.18: As in Fig 4.17 but for the composites of ARG cyclones in the summer. 
to their center (Figs $4.13 \mathrm{~d}$ and $\mathrm{h}$ ).

\subsection{Discussion and Conclusions}

The cyclone climatology presented in this Chapter, in general, agrees with past works that had found a main South Atlantic storm track between $40^{\circ} \mathrm{S}$ and $55^{\circ} \mathrm{S}$ and a subtropical path coming from Uruguay $\left(35^{\circ} \mathrm{S}\right)$ and the Southern Brazilian coast $\left(30^{\circ} \mathrm{S}\right)$. The genesis density statistic indicates three main cyclogenesis regions on the South American coast: one on the Southern Brazilian coast (SE-BR, $30^{\circ} \mathrm{S}$ ), a second above the continent near the La Plata river discharge region (LA PLATA, $35^{\circ} \mathrm{S}$ ) and a third on the southeastern coast of Argentina (ARG, $\left.40^{\circ} \mathrm{S}-55^{\circ} \mathrm{S}\right)$. A fourth genesis region was found centered at $55^{\circ} \mathrm{S}$ and $10^{\circ} \mathrm{W}$ in the Southeastern South Atlantic (SE-SAO). The adjustment of the tracking constraints, performed to avoid tracking issues over South America, improved the identification of genesis, particularly in the ARG and SE-BR.

The pattern of track density and its variability throughout the year correspond to those found in other studies (e.g., Taljaard, 1967; Sinclair, 1994; Hoskins and Hodges, 2005). However, some differences are seen between studies based on relative vorticity from others based on MSLP. For example, Simmonds and Keay (2000a) found that in the South Atlantic Ocean sector the highest track density was around $60^{\circ} \mathrm{S}$ with no clear evidence of a subtropical storm track in their results. These differences are related to the use of MSLP to perform the cyclone tracking, once the cyclones in the sub-tropics are weak and fast moving, and often do not have a closed isobar in their early stages due to the strong background pressure gradient at this location (Sinclair, 1994, 1995, 1997; Hoskins and Hodges, 2005).

The genesis density maps show that the SE-BR and ARG regions are more active in the summer (DJF) while the LA PLATA and SE-SAO regions are more active in the winter, as reported by Hoskins and Hodges (2005) and Reboita et al. (2010a). However, the seasonal variability is not evident for the SE-BR and ARG regions according to the numbers of cyclones per regions. Regarding the differences in cyclone identification and tracking methods described above, it is difficult to compare the seasonal variability of genesis in specific regions because other studies have used different boundaries to compute such variability (e.g., Reboita et al., 2010a). 

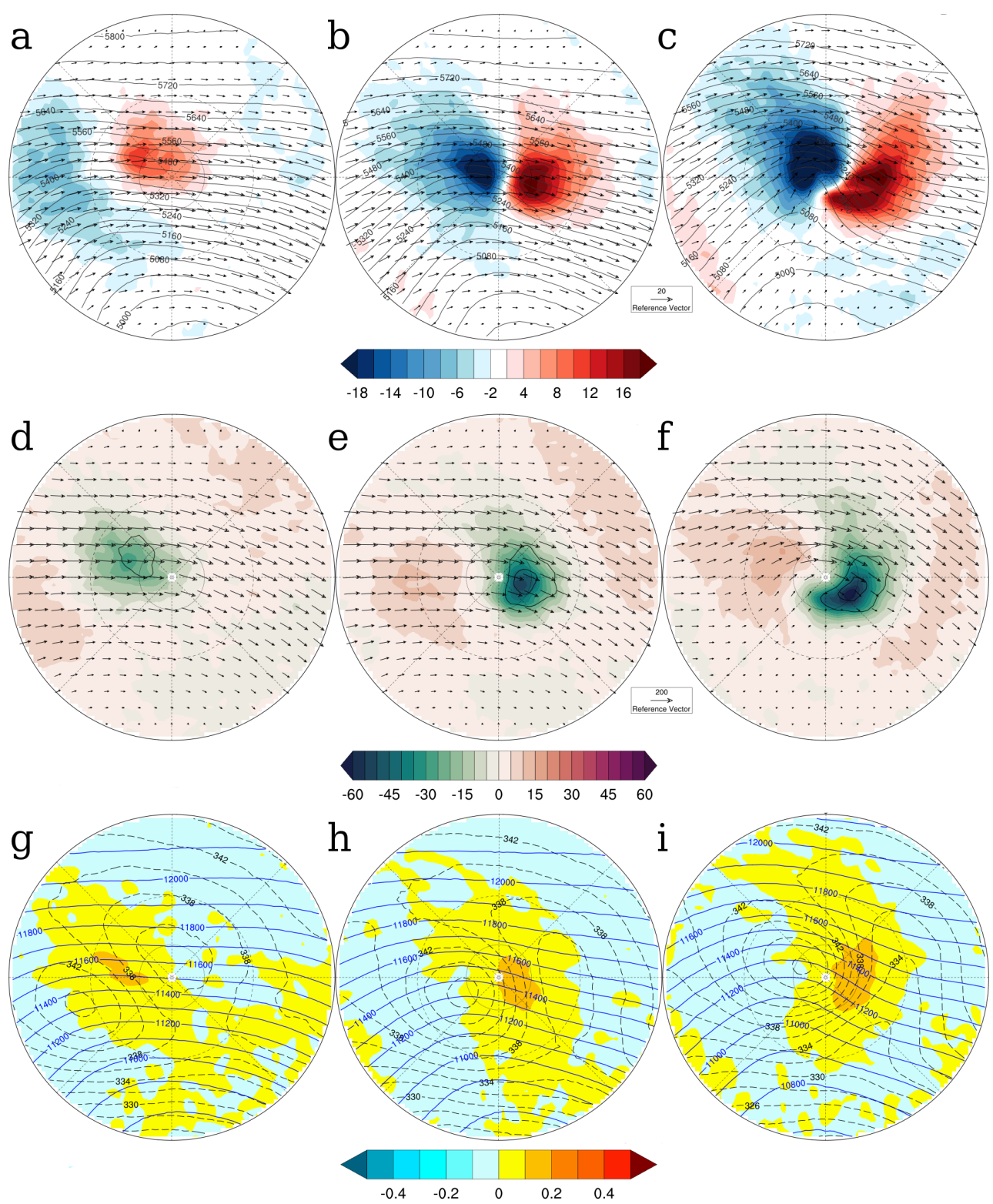

Figure 4.19: As in Fig 4.17 but for the composites of SE-SAO cyclones in the winter. 
The differences in the magnitudes of genesis between this work and some previous studies (e.g., Gan and Rao, 1991; Sinclair, 1994, 1995; Hoskins and Hodges, 2005; Reboita et al., 2010a; Mendes et al., 2010) can be generally explained by: the field used to perform the tracking, the feature identification thresholds (e.g., lifetime, minimum intensity), the method used to compute the statistics and even the resolution of the data used. Gan and Rao (1991) and Mendes et al. (2010) produced genesis density maps based on cyclone identification using the MSLP with manual and automated tracking methods, respectively. Both of them found two main cyclogenesis regions on the South American coast equivalent to the LA PLATA and ARG genesis region of this work. Sinclair (1995) and Hoskins and Hodges (2005) found a third region at $25^{\circ} \mathrm{S}$ using methods based on relative vorticity, suggesting that cyclones developed in the SE-BR region were weak systems that may not be detected by using MSLP as discussed earlier.

There are also differences between studies based on vorticity computed from winds at a tropospheric level above the boundary layer, e.g., $850 \mathrm{hPa}$ (this study, Hoskins and Hodges, 2005) and those from $1000 \mathrm{hPa}$ geopotential or MSLP (e.g., geostrophic vorticity Sinclair, 1994, 1995). Although weak and fast moving systems from subtropical latitudes are presented in the cyclogenesis distribution maps of Sinclair (1994, 1995), there is an underestimation when compared with this work and other studies based on relative vorticity from winds (Hoskins and Hodges, 2005; Reboita et al., 2010a). Reboita et al. (2010a) used vorticity from winds at $10 \mathrm{~m}$, an intensity threshold of $-1.5 \times 10^{-5} \mathrm{~s}^{-1}$ and considered only cyclones with the first time step of the track above the ocean. These authors found three genesis regions along the South American coast, similar to our finding, although the regions above the continent (LA PLATA) appears shifted to the coast at $35^{\circ} \mathrm{S}$.

The comparison between Hoskins and Hodges (2005) and this study shows higher correspondence, probably due to the same tracking method based on relative vorticity of winds at $850 \mathrm{hPa}$. However, here, the mean genesis density is higher in some locations when compared with Hoskins and Hodges (2005). The genesis magnitude is much higher on the Argentina coast and it is slightly higher in the SE-BR region for both seasons. The shorter lifetime threshold is the main reason for these differences. While we are using 24 hours, Hoskins and Hodges (2005) considered tracks that last at least more than 48 hours. However, the newly applied tracking constraints are also responsible for the accumulation of genesis densities. Comparing genesis density computed for cyclones that last at least 
more than $48 \mathrm{~h}$ (not shown), it is also possible to see an increase of genesis in SE-BR and ARG region, particularly in the summer.

The spatial distribution maps of the cyclone characteristics and radial composites of cyclone structure showed differences in the genesis environment of the South Atlantic domain. The intense cyclones of all regions are influenced by mid and upper-level troughs giving dynamical support to the genesis. In the summer, upper-level divergence plays an important role to genesis, particularly in the SE-BR and LA PLATA regions. Northward of $35^{\circ} \mathrm{S}$, two distinct processes support the genesis in the summer and winter. In the summer, low-level forcing are more critical in the genesis process, primarily associated with tropical moisture transport from the SALLJ and SSAH (Vera et al., 2002; Campetella and Vera, 2002; Mendes et al., 2007). During cyclone development these warm and humid fluxes, allied to the ocean interaction, feed the cyclone, providing low-level instability (Vera et al. 2002; Piva et al., 2008; Mendes et al., 2010). The SE-BR cyclones seems to develop on trailing fronts of pre-existing cyclones in the summer, in the absence of a strong low-level baroclinicity (e.g., Dacre and Gray, 2006). In the winter, a more baroclinic environment takes place, i.e., stronger upper-level jet and SST gradient, due to the northward shift of BMC and STSF (Olson et al., 1988; Piola et al., 2000). However, the influence of moisture transport and convergence at low-level remain, which may explain the intense cyclones generated in LA PLATA and SE-BR regions during the winter. The development of the orographic low, called NAL, on the lee side of Andes reinforces the warm and moist advection in LA PLATA region, decreasing the low-level stability during cyclonegenesis (Seluchi and Saulo, 1998, Seluchi et al., 2003, Ribeiro et al., 2016). Moreover, stratospheric PV intrusions also affect genesis and cyclone intensification in this area, as seen in distribution maps and reported by Iwabe and da Rocha (2009) and Funatsu et al. (2004).

Southward of $35^{\circ} \mathrm{S}$, cyclones develop in a high baroclinic environment (e.g., Gan and Rao, 1991; Hoskins and Hodges, 2005). The small influence of low-level humidity makes us believe that the reduction of vertical stability is related to the thermal advection and adiabatic heating, the latter acting only in the ARG region. In fact, the adiabatic heating due to subsidence of air on the lee side of Andes may be responsible for the lower static stability observed in the ARG region at the time of genesis, which along with the local vertical wind shear, results in a high cyclonic growth rate (see Eq.2.1). The SE-SAO cyclones develop in a high-baroclinic zone in the cold sector of a parent cyclone, associated 
with the intrusion of dry stratospheric air (i.e., cyclonic PV intrusion; e.g., Browning et al., 1997; Iwabe and da Rocha, 2009). 
Chapter 5

\section{HadGEM2-ES evaluation}

\subsection{Genesis and track density biases}

The historical experiment from the global climate model HadGEM2-ES is compared with the NCEP-CFSR to evaluate its ability to represent cyclone climatology in South Atlantic Ocean. The common period between these two datasets is from 1980 to 2005, totalling a climatology of 26 years. Figure 5.1 shows the NCEP-CFSR genesis and track densities for the winter and summer computed for 1980 - 2005 period. The patterns of genesis and track density distributions are the same observed for a climatology of 31 years (Fig. 4.1).

Table 5.1 shows the number of cyclones tracked for the South Atlantic Basin and separately within each genesis region defined in Chapter 4, for NCEP-CFSR and HadGEM2-ES between 1980 and 2005. The percentage in parentheses in the third column indicates how much HadGEM2-ES underestimated (negative) or overestimated (positive) NCEPCFSR. Generally, the HadGEM2-ES uses to underestimate the cyclones over South Atlantic, mainly due to the coarser resolution of the climate model. The data resolution still affects cyclone detection even after a previous truncation of relative vorticity field. Pinto et al. (2005) showed that weak systems are less identified with the reduction of spatial resolution. Besides this, a coarser resolution also impacts the orographic representation in the model, leading to fewer cyclogenesis in South America once Andes Cordillera is vital to cyclone development, particularly in LA PLATA region. The ARG genesis region seems to be an exception, presenting more cyclones in HadGEM2-ES both in the summer and winter. There is also an overestimation of $25 \%$ of cyclones in the SE-BR region in the winter. According to the NCEP-CFSR results, winter is the season which SE-BR region 


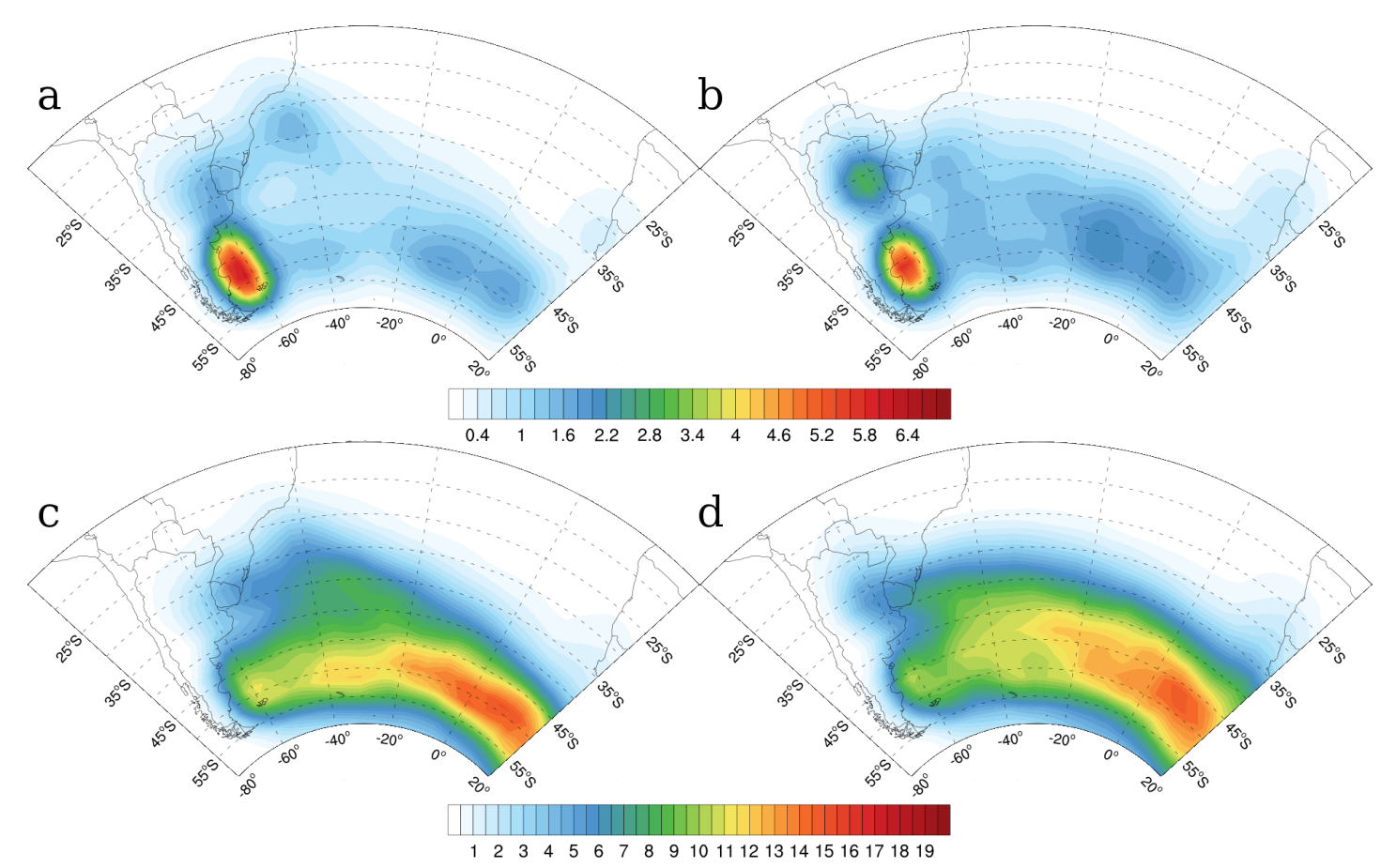

Figure 5.1: NCEP-CFSR genesis density for 1980-2005 period in the (a) summer and (b) winter, and track density in the (c) summer and (d) winter for South Atlantic domain. The density unit is cyclone per $10^{6} \mathrm{~km}^{2}$ per month.

used to be less active especially in its northern portion (Chapter 4). The LA PLATA and SE-SAO regions are underestimated in HadGEM2-ES.

Figure 5.2 shows the HadGEM2-ES cyclogenesis density and its biases related to NCEPCFSR, for the summer and winter. As it is seemed in total numbers (Table 5.1), the HadGEM2-ES overestimates the genesis of ARG region in summer, with a bias of more than three cyclones per $10^{6} \mathrm{~km}^{2}$ per month (Fig. 5.2 k). This overestimation in density is also addressed to the spatial range of cyclogenesis occurrence as long as density is a measure of cyclones per area. While in the NCEP-CFSR the higher genesis density $(>5$ cyclones per $10^{6} \mathrm{~km}^{2}$ per month) within the ARG region has an elongated pattern between $42.5^{\circ} \mathrm{S}$ and $52.5^{\circ} \mathrm{S}$ (Fig $5.1 \mathrm{a}$ ), in the HadGEM2-ES it is more concentrated in $42.5^{\circ} \mathrm{S}-50^{\circ} \mathrm{S}$ latitude range (Fig. 5.2 ). The small area of genesis in HadGEM2-ES influences the genesis density computation, causing the negative biases around the positive biases spot in the ARG region. The genesis density in the LA PLATA, SE-BR, and SE-SAO regions are underestimated in the HadGEM2-ES historical in summer.

The HadGEM2-ES winter genesis density also presents a positive bias within ARG region (Fig. $5.2 \mathrm{~d}$ ), but lower than in the summer. The LA PLATA region has a negative 
Table 5.1 - Total number of cyclones, annual mean and standard deviation for South Atlantic domain $\left(15^{\circ} \mathrm{S}-55^{\circ} \mathrm{S}, 75^{\circ} \mathrm{W}-20^{\circ} \mathrm{E}\right)$ and for each defined cyclogenesis region within the domain. The values were computed for the 1980-2005 period and divided in summer (DJF) and winter (JJA). The number in parentheses at the third column is the percentage of the HadGEM2-ES total relative to NCEP-CFSR.

\begin{tabular}{rcccc}
\hline \hline \multicolumn{5}{c}{ DJF } \\
\hline region & NCEP-CFSR & HadGEM2-ES (\%) & NCEP-CFSR & HadGEM2-ES \\
\hline \hline South Atlantic & 2488 & $2268(-8.8)$ & $95.7 \pm 6.4$ & $87.2 \pm 7.5$ \\
SE-BR & 185 & $163(-11.9)$ & $7.1 \pm 1.9$ & $6.3 \pm 2.0$ \\
LA PLATA & 198 & $164(-17.2)$ & $7.6 \pm 2.1$ & $6.3 \pm 2.6$ \\
ARG & 689 & $708(2.8)$ & $26.5 \pm 4.2$ & $27.2 \pm 4.9$ \\
SE-SAO & 702 & $535(-23.8)$ & $27.0 \pm 3.5$ & $20.6 \pm 3.4$ \\
\hline \hline & \multicolumn{5}{c}{ JJA } \\
region & NCEP-CFSR & HadGEM2-ES $(\%)$ & NCEP-CFSR & HadGEM2-ES \\
\hline \hline South Atlantic & 2922 & $2834(-3.0)$ & $112.4 \pm 7.8$ & $109.0 \pm 6.1$ \\
SE-BR & 167 & $209(25.1)$ & $6.4 \pm 2.3$ & $8.0 \pm 3.0$ \\
LA PLATA & 290 & $248(-14.5)$ & $11.2 \pm 2.9$ & $9.5 \pm 2.1$ \\
ARG & 601 & $637(6.0)$ & $23.1 \pm 4.3$ & $24.5 \pm 3.9$ \\
SE-SAO & 921 & $816(-11.4)$ & $35.4 \pm 5.7$ & $31.4 \pm 4.1$ \\
\hline
\end{tabular}



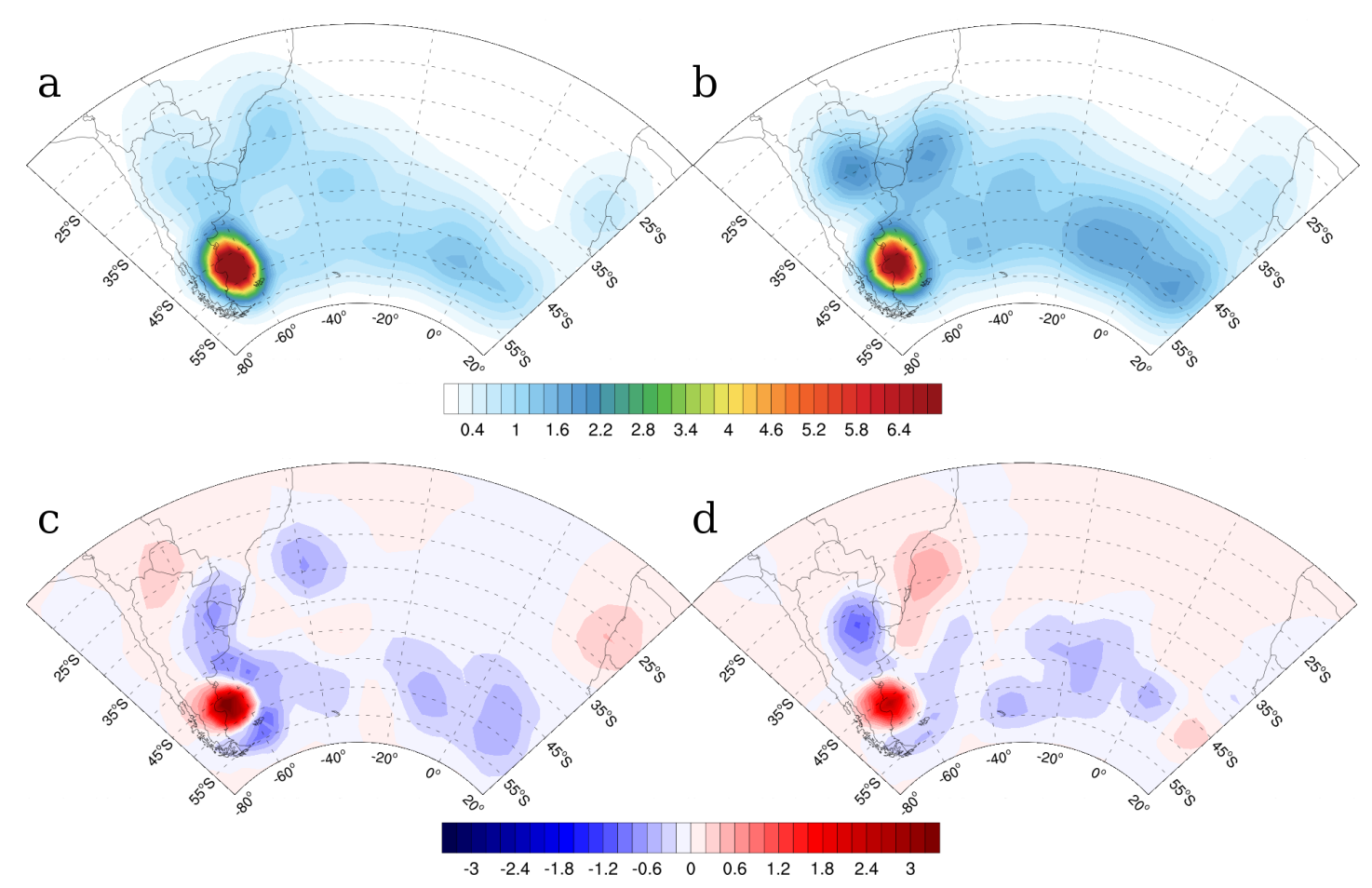

Figure 5.2: HadGEM2-ES genesis density in the (a) summer and (b) winter and the associated biases in the (c) summer and (d) winter. Unit for the bias and genesis density is cyclone per $10^{6} \mathrm{~km}^{2}$ per month.

bias in the HadGEM2-ES (> 1 cyclones per $10^{6} \mathrm{~km}^{2}$ per month). At the same latitude $\left(30^{\circ} \mathrm{S}\right)$, in the SE-BR region, there is a positive bias. We can hypothesize that the dipole between these two regions may be a consequence of the inadequate representation of orography due to a coarse resolution. In Chapter 4 it was discussed the importance of the Andes Cordillera in lee development in the LA PLATA through the formation of the NAL as a precursor of cyclogenesis. Cyclones from the SE-SAO region are underestimated in HadGEM2-ES historical in winter.

Krüger et al. (2012), studying a smaller domain over Southeastern South Atlantic Ocean, also found fewer cyclones using HadAM3 historical experiment. These authors confirm that the resolution and the inappropriate orography representation compromise the cyclone identification, which can be improved using regional downscaling. However, it is important to remember that HadAM3 does not have ocean coupling, what can harm the cyclone representation in the model (e.g., Ulbrich et al., 2009, Lee, 2014). Reboita et al. (2018) compared HadGEM2-ES with NCEP-CFSR and tracked more cyclones in the former. On the other hand, they used a more restricted domain not considering cyclones 
over the continent and eastward of $20^{\circ} \mathrm{W}$ and, consequently, did not include the two regions which present the most negative bias in the present study: LA PLATA and SE-SAO.

The storm track density performed to the HadGEM2-ES historical and its bias related to NCEP-CFSR in the summer and winter are presented in Fig. 5.3. In the summer, there is a positive bias southward of $50^{\circ} \mathrm{S}$ and a negative northward of it, probably as a consequence of the overestimated genesis in the ARG region. Another factor that contributes to the negative bias observed northward of $40^{\circ} \mathrm{S}$ during summer is the underestimated genesis in the LA PLATA and SE-BR regions. It can be noted a positive cyclogenesis bias east of Andes centered at $25^{\circ} \mathrm{S}$ (Fig. 5.2 a).

The magnitude of track density biases in the winter is smaller than in summer (Fig. $5.3 \mathrm{~d})$. However, there is also a positive bias caused by the overestimated cyclogenesis in ARG region and a negative bias at $40^{\circ} \mathrm{S}$ due to the underestimation of genesis in the LA PLATA region (Fig. 5.3.). The positive genesis bias in the SE-BR region may promote the positive bias of track density northward of $35^{\circ} \mathrm{S}$. In both seasons there is a negative genesis density in the SE-SAO region and, as consequence, there is a lower track density between $40^{\circ} \mathrm{S}$ and $50^{\circ} \mathrm{S}$, eastward of $20^{\circ} \mathrm{E}$.

\subsection{Intensity and other aspects}

Figure 5.4 shows the maximum relative vorticity at $850 \mathrm{hPa}$ within South Atlantic domain for the cyclones from each genesis region, in the summer and winter. Both NCEPCFSR and HadGEM2-ES historical histograms are plotted for comparison. According to the maximum vorticity, HadGEM2-ES uses to underestimate the intensity of the cyclones, as it is seen in the right tail of the distributions. However, the HadGEM2-ES seems to generate more medium-to-high intense cyclones, between -5 and $-9 \times 10^{-5} s^{-1}$, than weaker systems, specially in the ARG and SE-BR regions. In fact, in the summer, the SE$\mathrm{BR}$ region presents a group of high-intensity systems $\left(\leq-12 \times 10^{-5} \mathrm{~s}^{-1}\right)$. The two peaks observed in the winter histogram for the LA PLATA region, in NCEP-CFSR, are not evident in HadGEM2-ES. The systems from the less intense peak $\left(-3\right.$ and $\left.-6 \times 10^{-5} s^{-1}\right)$ seem to prevail in the LA PLATA region from HadGEM2-ES. However, the second peak of more intense cyclones is defined in the winter histogram from SE-BR, what reinforces that perturbations that use to develop in the LA PLATA region are being shifted eastward 

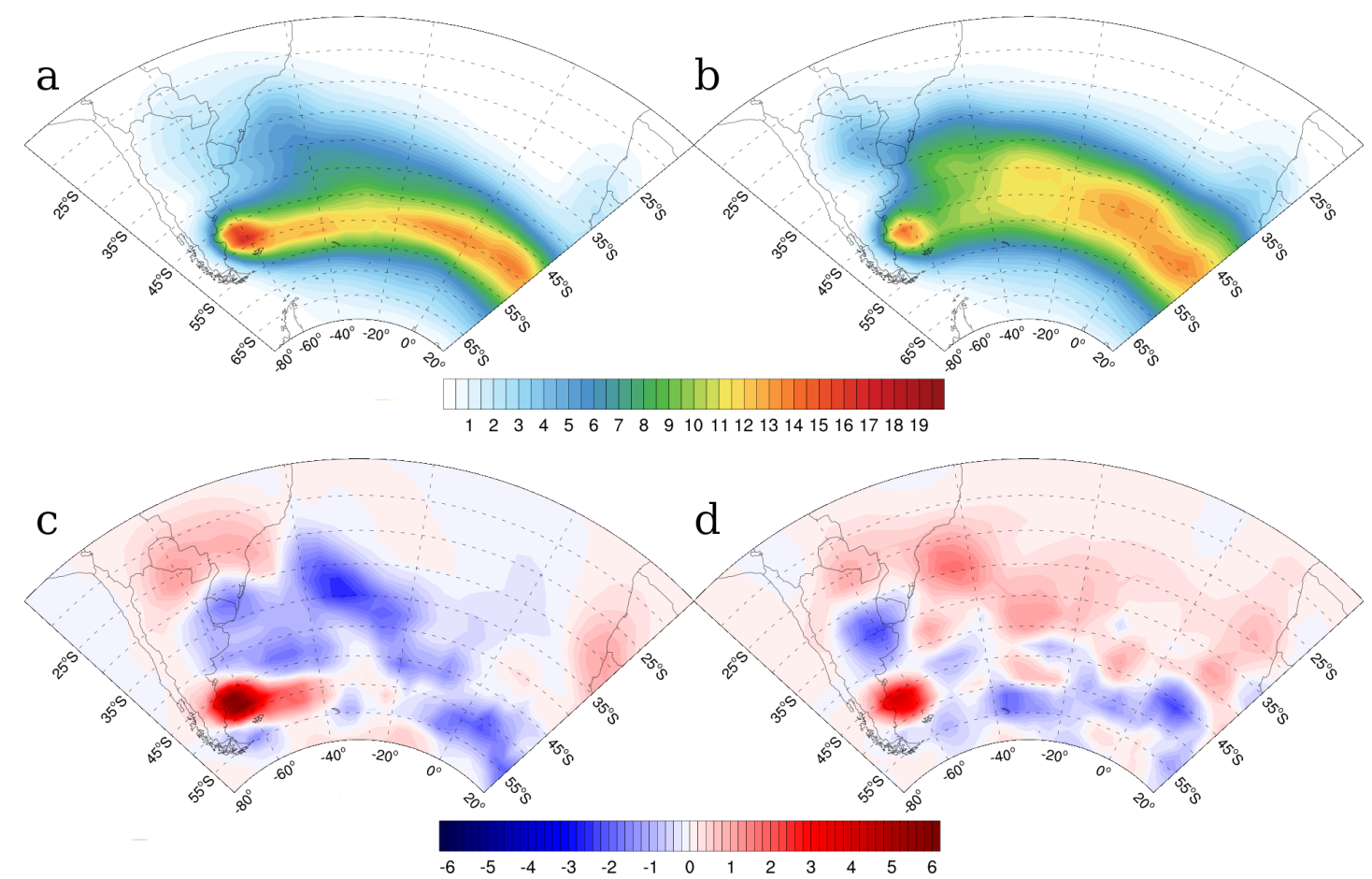

Figure 5.3: HadGEM2-ES track density in the (a) summer and (b) winter and the associated biases in the (c) summer and (d) winter. Unit for the bias and track density unit is cyclone per $10^{6} \mathrm{~km}^{2}$ per month.

due to the coarse orographic representation. Both the histograms of minimum MSLP and maximum wind speed at $925 \mathrm{hPa}$ show a lower occurrence of high-intensity cyclones in all regions (Figs. B.1 and B.2). However, SE-BR presents a strong group of cyclones according to MSLP ( $\leq 980 \mathrm{hPa}$ ). The HadGEM2-ES wind speed histograms are shifted to the left, showing lower wind speed associated with the cyclones when compared to NCEP-CFSR histograms.

Table 5.2 contains the mean relative vorticity at genesis time, mean lifetime and mean cyclone displacement speed in each defined genesis region computed for all period, and separately for summer and winter. Regarding these three parameters, the HadGEM2-ES represents the South Atlantic cyclones behavior: they last longer and move slower in the summer than in winter. The ARG and SE-SAO regions present the highest displacement speed, and the initial vorticity is higher in SE-SAO region, as reported in NCEP-CFSR analysis. Despite that, HadGEM2-ES cyclones generally present a longer mean lifetime and are slower than the ones from NCEP-CFSR.

Figure 5.5 shows the spatial distribution of the mean growth rate, which is high between 

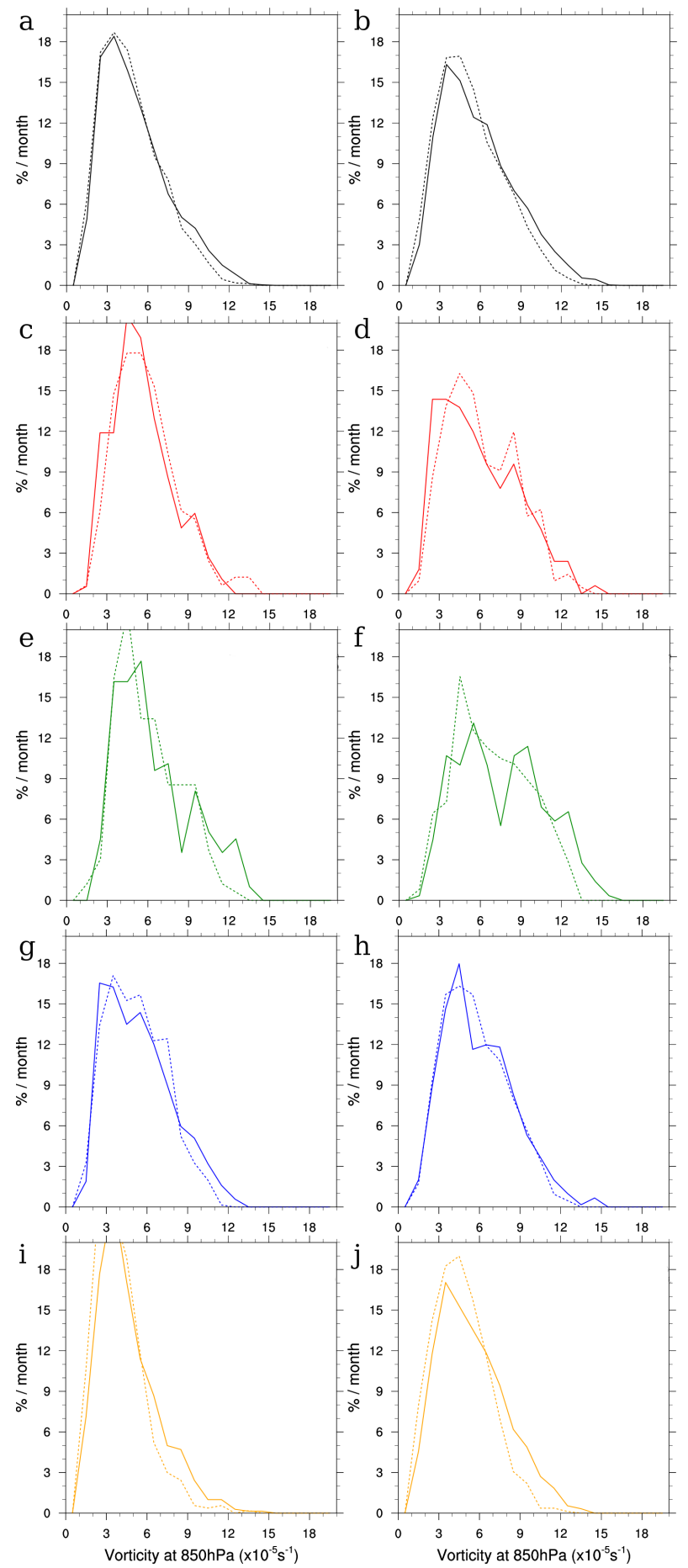

Figure 5.4: HadGEM2-ES historical (dashed line) and NCEP-CFSR (solid line) histograms of the maximum filtered vorticity at $850 \mathrm{hPa}$ in the summer (left) and winter (right) for (a,b) South Atlantic, (c,d) SE-BR, (e,f) LA PLATA, (g,h) ARG, and (i,j) SE-SAO regions. The vorticity is scaled by $-1 \times 10^{-5} s^{-1}$. The intensity histograms were produced for cyclones originated in each genesis region separately. The percentage was computed based on the mean cyclones per month for each region. 
Table 5.2 - The mean $850 \mathrm{hPa}$ relative vorticity at genesis time $\left(-1 \times 10^{-5} s^{-1}\right)$, mean lifetime (days), mean cyclone displacement speed $\left(m s^{-1}\right)$ and standards deviations computed within South Atlantic domain $\left(15^{\circ} \mathrm{S}-55^{\circ} \mathrm{S}, 75^{\circ} \mathrm{W}-20^{\circ} \mathrm{E}\right)$ and within each defined genesis region. The means were calculated for the HadGEM2-ES historical (1980-2005) for the summer (DJF) and winter (JJA).

\begin{tabular}{rccc}
\hline \hline \multicolumn{4}{c}{ DJF } \\
region & initial vort. & lifetime & speed \\
\hline \hline South Atlantic & $2.6 \pm 1.2$ & $4.8 \pm 3.2$ & $13.2 \pm 4.8$ \\
SE-BR & $3.0 \pm 1.1$ & $6.1 \pm 3.5$ & $10.7 \pm 4.1$ \\
LA PLATA & $2.5 \pm 1.0$ & $6.4 \pm 4.3$ & $11.0 \pm 4.6$ \\
ARG & $2.3 \pm 1.0$ & $4.6 \pm 3.0$ & $13.5 \pm 4.0$ \\
SE-SAO & $3.0 \pm 1.4$ & $4.1 \pm 2.6$ & $15.3 \pm 4.7$ \\
\hline \multicolumn{4}{c}{ JJA } \\
region & initial vort. & lifetime & speed \\
\hline \hline South Atlantic & $3.1 \pm 1.4$ & $4.3 \pm 2.9$ & $14.3 \pm 5.0$ \\
SE-BR & $3.2 \pm 1.4$ & $4.5 \pm 2.9$ & $13.1 \pm 4.7$ \\
LA PLATA & $2.9 \pm 1.1$ & $5.2 \pm 3.2$ & $11.6 \pm 4.1$ \\
ARG & $2.7 \pm 1.2$ & $4.4 \pm 2.7$ & $13.7 \pm 4.1$ \\
SE-SAO & $3.6 \pm 1.5$ & $3.9 \pm 3.0$ & $16.4 \pm 4.8$ \\
\hline
\end{tabular}




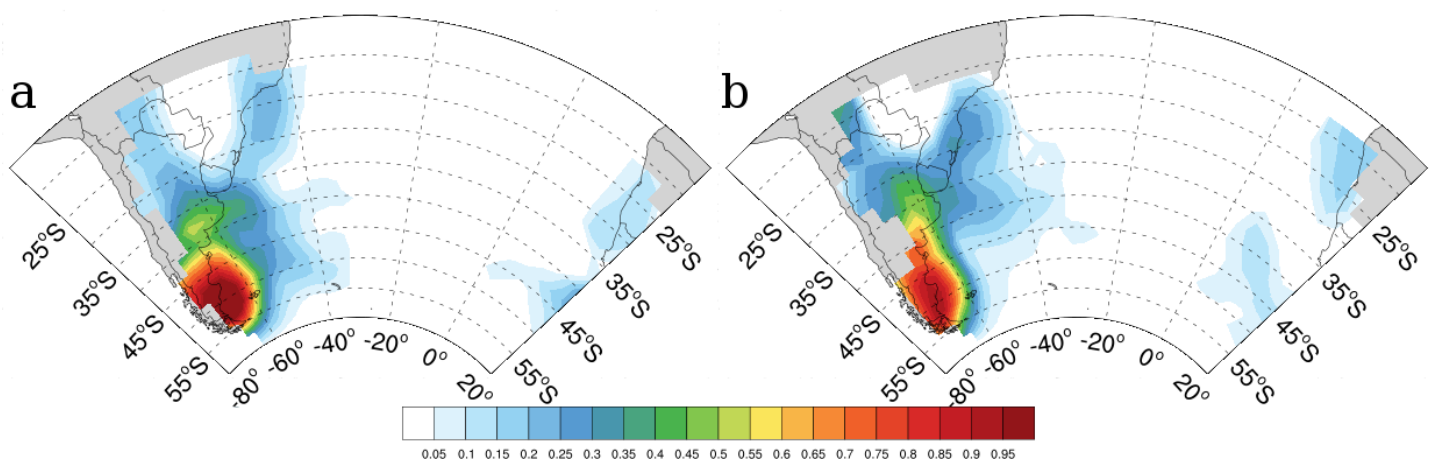

Figure 5.5: Spatial distribution of the mean growth rate $\left(-1 \times 10^{-5} s^{-1} d a y^{-1}\right)$ in the (a) summer and (b) winter. The fields are not plotted where track density $<0.3$ cyclones $\left(10^{6} \mathrm{~km}^{2}\right)^{-1}$ mont $^{-1}$.

$45^{\circ} \mathrm{S}$ and $55^{\circ} \mathrm{S}$ above the continent (ARG region) in the summer. In the winter, the growth rate in HadGEM2-ES is higher than in NCEP-CFSR distribution (Fig 4.7d). During the winter the mean growth rate extends northward but, in HadGEM2-ES, the high rates are more concentrated in the ARG region. The Brazilian coast presents moderate growth rate in HadGEM2-ES $\left(\geq 2 \times 10^{-5} s^{-1} d a y^{-1}\right)$ both in summer and winter, although during the winter it is larger than the observed in the NCEP-CFSR analysis.

\subsection{Spatial distribution of cyclone properties}

The spatial distribution of the SST gradient at the time of genesis and its climatological pattern are displayed in Fig. 5.6. The climatological maximum SST gradient is located in Southwestern and Southeastern South Atlantic, between $35^{\circ} \mathrm{S}$ and $45^{\circ} \mathrm{S}$, as observed in NCEP-CFSR (Fig. 5.6. and d). The seasonal pattern is also in agreement with the reference: the SST gradient is stronger and shifts northward during the winter. Although the ocean fronts are correctly placed, the climate model is not able to represent their intensity. In the BMC, the subtropical front (northern front) is restricted to west of $10^{\circ} \mathrm{W}$, and the polar front (southern front) is weaker in HadGEM2-ES. The STSF is weaker than in the NCEP-CFSR, especially in winter. In fact, the SST gradient at the time of genesis, in the winter, does not present high values in the Southern Brazilian coast, as shown in the NCEP-CFSR analysis (Fig 5.6p). Moreover, the SST gradient distributions at the time of genesis, in the summer and winter, are weaker than in the reanalysis, especially in $45^{\circ} \mathrm{S}$.

Figures $5.7 \mathrm{a}$ and $\mathrm{b}$ show the low-level integrated humidity at the time of genesis in 

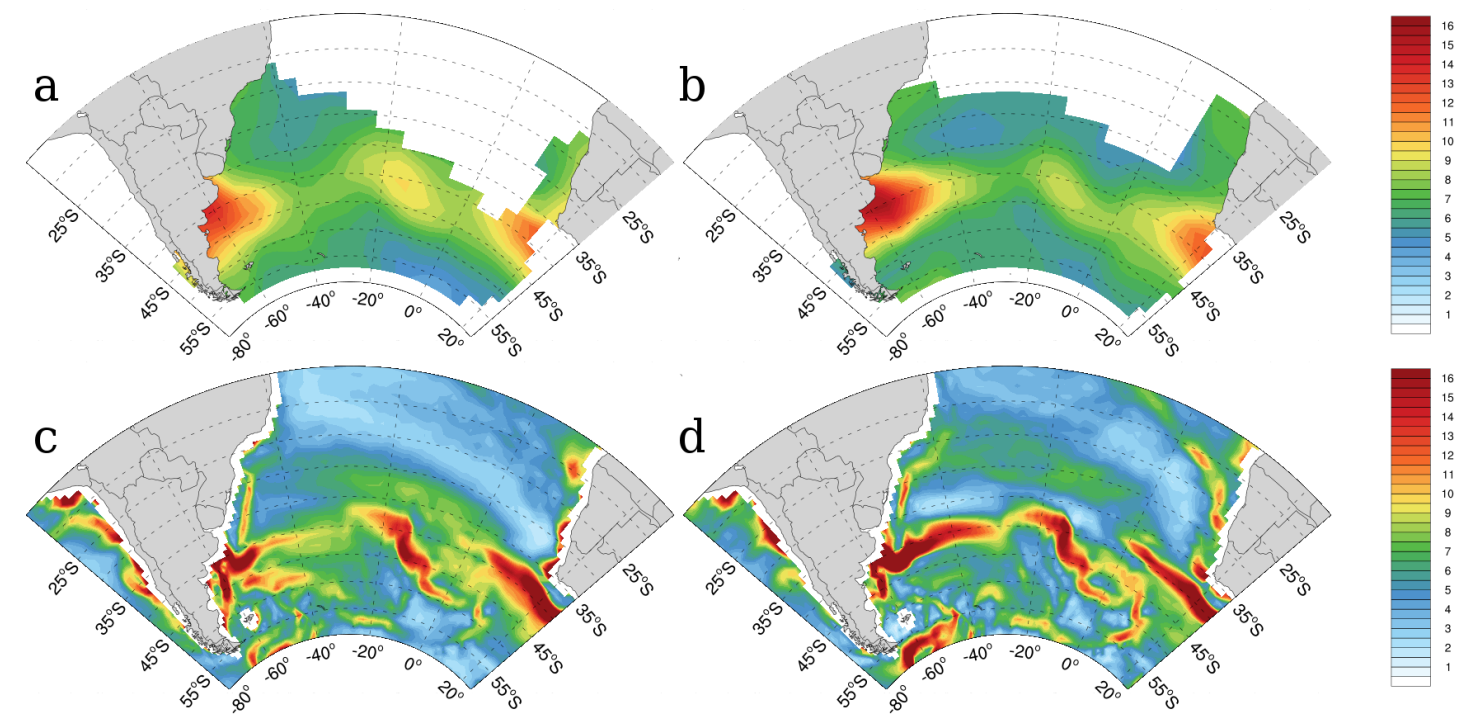

Figure 5.6: Spatial distribution of SST gradient at the time of genesis in the (a) summer and (b) winter. Sea surface temperature (SST) gradient in South Atlantic Ocean in the austral (c) summer and (d) winter. The gradient unit is $10^{-3} \mathrm{~K} \mathrm{~km}^{-1}$. The fields are not plotted where genesis density $<$ 0.2 cyclones $\left(10^{6} \mathrm{~km}^{2}\right)^{-1}$ month $^{-1}$.

the summer and winter. The HadGEM2-ES generally presents more low-level moisture than NCEP-CFSR in both seasons (not shown). For this reason, the genesis environment between $30^{\circ} \mathrm{S}$ and $40^{\circ} \mathrm{S}$ in the summer, and $25^{\circ} \mathrm{S}$ and $35^{\circ} \mathrm{S}$ in the winter present higher moist than in the NCEP-CFSR analysis.

Figures 5.7k and $\mathrm{d}$ show the mean static stability $(\partial \theta / \partial p)$ and Figs. 5.7p and $\mathrm{f}$ the mean conditional stability $\left(\partial \theta_{e} / \partial p\right)$ for HadGEM2-ES historical. Both static and conditional stabilities are well represented in the HadGEM2-ES model in spatial and seasonal points of view. The differences are larger in the static stability of eastern South America coast, between $60^{\circ} \mathrm{W}$ and $40^{\circ} \mathrm{W}$. In the summer, this region is more statically stable in the HadGEM2-ES experiment when compared with NCEP-CFSR, particularly in Southeastern coast. In the winter, the HadGEM2-ES presents higher $\partial \theta / \partial p$ southward of $40^{\circ} \mathrm{W}$, in the ARG and SE-SAO regions. At the time of genesis, the ARG region cyclones present lower static stability in the HadGEM2-ES when compared with NCEP-CFSR, both in the summer and winter. Moreover, a less stable area in HadGEM2-ES distribution map is confined in $45^{\circ} \mathrm{S}$. The LA PLATA region, in the winter, presents a more stable genesis environment than NCEP-CFSR, what may explain the lower number of cyclone development. The conditional stability at the time of genesis is similar to those observed in the 

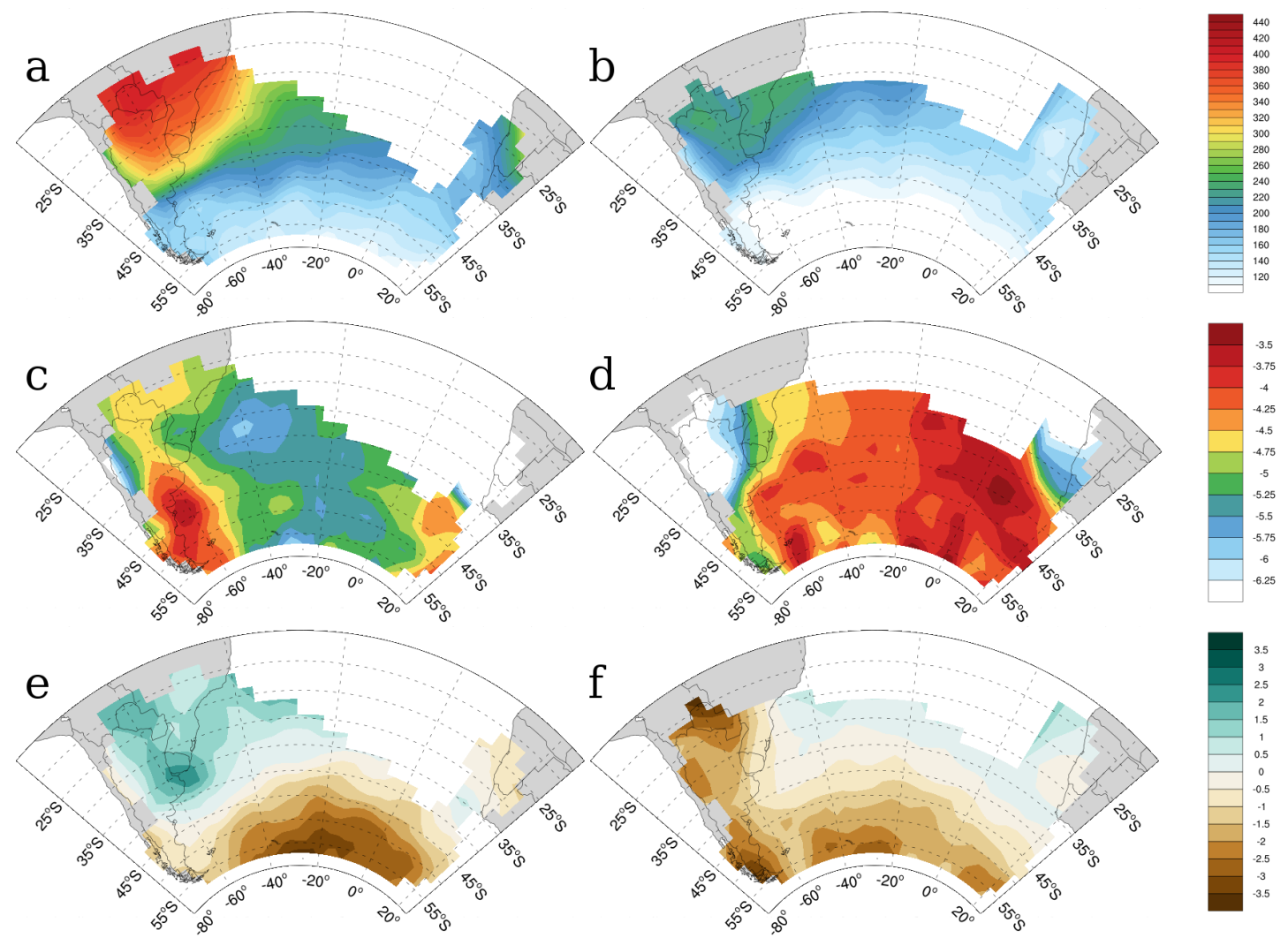

Figure 5.7: Spatial distribution of the integrated humidity at lower-level $\left(\mathrm{kg} \mathrm{kg}^{-1}\right)$ at genesis time in the austral (a) summer and (b) winter; $\partial \theta / \partial p\left(10^{-2} K h P a^{-1}\right)$ at genesis time in the (c) summer and (d) winter, and; $\partial \theta_{e} / \partial p\left(10^{-2} K h \mathrm{~Pa}^{-1}\right)$ at genesis time in the (e) summer and (f) winter. The fields are not plotted where genesis density $<$ 0.2 cyclones $\left(10^{6} \mathrm{~km}^{2}\right)^{-1}$ month $^{-1}$.

NCEP-CFSR analysis. However, there is a more neutral to unstable genesis environment in the ARG (both seasons) and SE-BR (winter) regions.

In the jet velocity distribution at the time of genesis (Figs. 5.8 a and b), LA PLATA and SE-BR regions present a slower jet velocity, even in the winter - when the subtropical jet shifts northward affecting the surrounding areas (Chap. 4). A weaker upper-level jet may lead to a decrease in the wind shear at this location, that combined with the moisture availability at lower levels, may result in a genesis environment similar to the observed during the summer in the SE-BR region, in the NCEP-CFSR analysis. The underestimated jet velocity also affects the development of SE-SAO cyclones and may be associated with the negative genesis bias in this region. The upper-level jet speed is underestimated in HadGEM2-ES when compared with the NCEP-CFSR climatology, in both seasons (Figs B.4c and d). In the summer, the jet pattern is similar to the observed 

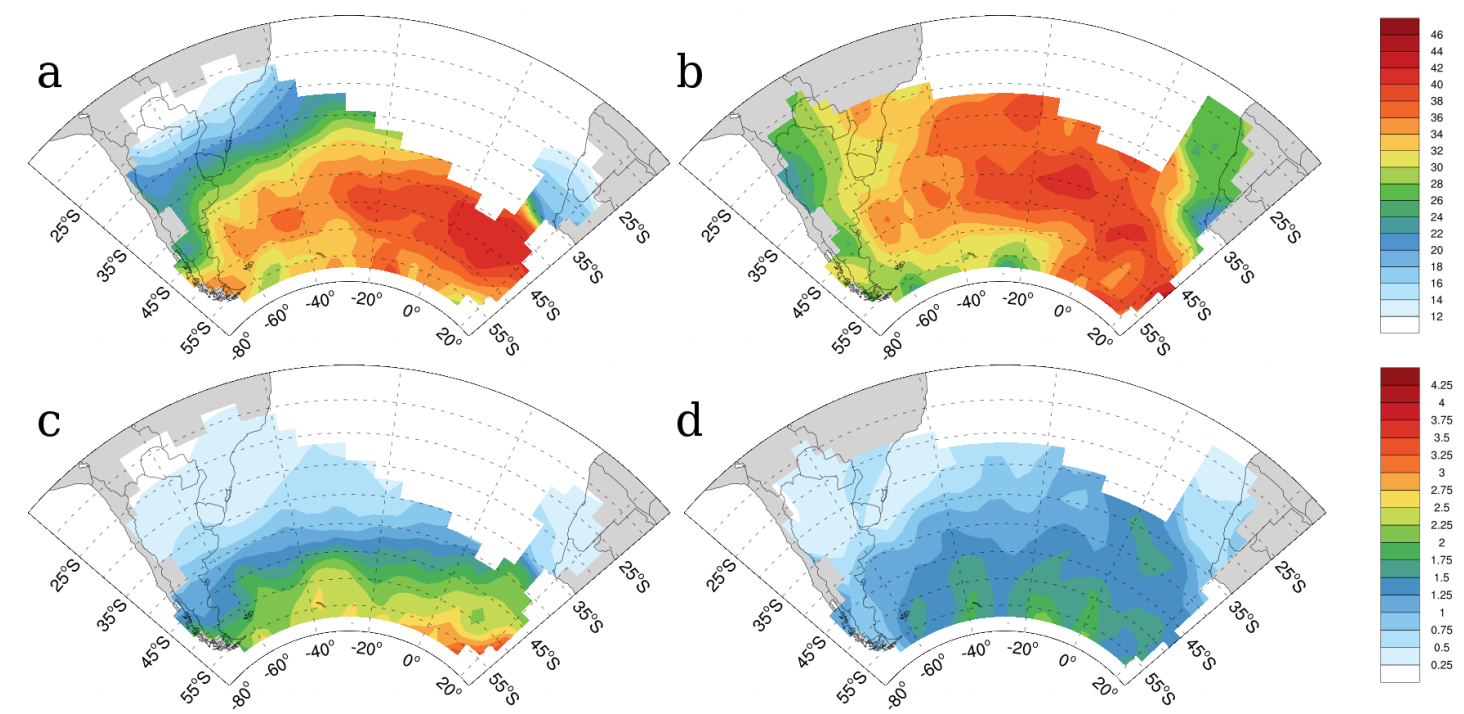

Figure 5.8: Spatial distribution of upper-level jet $\left(\mathrm{m} \mathrm{s}^{-1}\right)$ in the austral (a) summer and (b) winter; and the potential vorticity at $300 \mathrm{hPa}(\times-1 P V U)$ in the $(\mathrm{c})$ summer and (d) winter at the time of genesis. The field distribution at genesis and at the maximum intensity are not plotted where genesis and track density $<0.2$ cyclones $\left(10^{6} \mathrm{~km}^{2}\right)^{-1}$ mont $h^{-1}$ and $<0.5$ cyclones $\left(10^{6} \mathrm{~km}^{2}\right)^{-1}$ mont $^{-1}$, respectively.

in NCEP-CFSR, with its core centered at $45^{\circ} \mathrm{S}$ above the ocean, although the velocities are about 2 to $4 \mathrm{~m} \mathrm{~s}^{-1}$ below the mean climatology. In the winter, the underestimation is more significant, reaching more than $6 \mathrm{~m} \mathrm{~s}^{-1}$ above the continent at $30^{\circ} \mathrm{S}$. The jet core above South American coast ranges from $30^{\circ} \mathrm{S}$ to $40^{\circ} \mathrm{S}$ in the NCEP-CFSR climatology against a narrow jet between $45^{\circ} \mathrm{S}$ to $55^{\circ} \mathrm{S}$ in HadGEM2-ES.

The spatial distribution of $\mathrm{PV}$ at $300 \mathrm{hPa}$ at the time of genesis is shown in Figs. $5.8 \mathrm{c}$ and $d$, respectively. Although there is a general proper representation of season variation of $\mathrm{PV}$ at $300 \mathrm{hPa}$, with higher values in the summer than in the winter, the HadGEM2-ES underestimates the values in almost 1 PVU in some regions. Differently from NCEP-CFSR distributions in the winter (Fig. 4.10 b), a stratospheric intrusion does not seem to affect the genesis northward of $40^{\circ} \mathrm{S}$ in HadGEM2-ES, what could imply in less genesis being produced in the LA PLATA region. The PV values in the spatial distribution at the genesis time and in the climatology (Figs. B.4 and b) indicate that there are some issues in the representation of stratosphere-troposphere interactions in HadGEM2-ES. 
Table 5.3 - Intensity threshold (multiplied by $-1 \times 10^{-5}$ ) applied to select the $30 \%$ most intense cyclones of each defined genesis region in the summer and winter, and the number of cyclones used to compute each composite in the HadGEM2-ES analysis.

\begin{tabular}{ccccc}
\hline \hline & \multicolumn{2}{c}{ DJF } & \multicolumn{2}{c}{ JJA } \\
\hline & threshold & number & threshold & number \\
SE-BR & 7.2 & 49 & 8.6 & 54 \\
LA PLATA & 7.6 & 47 & 9.0 & 68 \\
ARG & 7.7 & 175 & 8.0 & 165 \\
SE-ESAO & 7.8 & 124 & 8.8 & 175 \\
\hline \hline
\end{tabular}

\subsection{Cyclones structure}

In this section, the cyclone composites of HadGEM2-ES historical experiment are presented. The intensity threshold used to select the $30 \%$ strongest systems of each region in each season is shown in Table 5.3. The LA PLATA region presents the highest threshold when compared with other genesis regions, which is in agreement with the observed intensity histograms (Fig. 5.4).

This section contains an approach analogous to Section 4.3; an overview of the cyclone structure for each genesis region at, before and after the genesis time. For clarity, only composites at $12 \mathrm{~h}$ before and $24 \mathrm{~h}$ after the time of genesis will be shown. The discussion of the intensification of the precursors is considered using the same fields used in Section 4.3 , except for the vertical velocity. However, as is seen in Figs. 4.15, 4.17d-f, 4.18d-f and $4.19 \mathrm{~d}-\mathrm{f}$, the VIMFC field can be used as a proxy of vertical velocity as long as regions with positive (negative) VIMFC have negative (positive) omega.

\subsubsection{General structure of cyclone genesis}

Figure 5.9 shows the composite structure of equivalent potential temperature at 925 $\mathrm{hPa}\left(\theta_{e} 925\right)$ and MSLP at the time of genesis for all regions in the summer and winter. Both the $\theta_{e} 925$ and MSLP structures are similar to the ones found in the NCEP-CFSR cyclones compositing (Fig 4.12). Some key features discussed in Section 4.3 are presented: the temperature gradient zone with the warm isotherms folding towards the center (Bjerknes et al., 1922; Shapiro and Keyser, 1990), the elongated MSLP structure in the lower lefthand quadrant (Catto et al., 2010), and the SASH signature, particularly in the SE-BR 

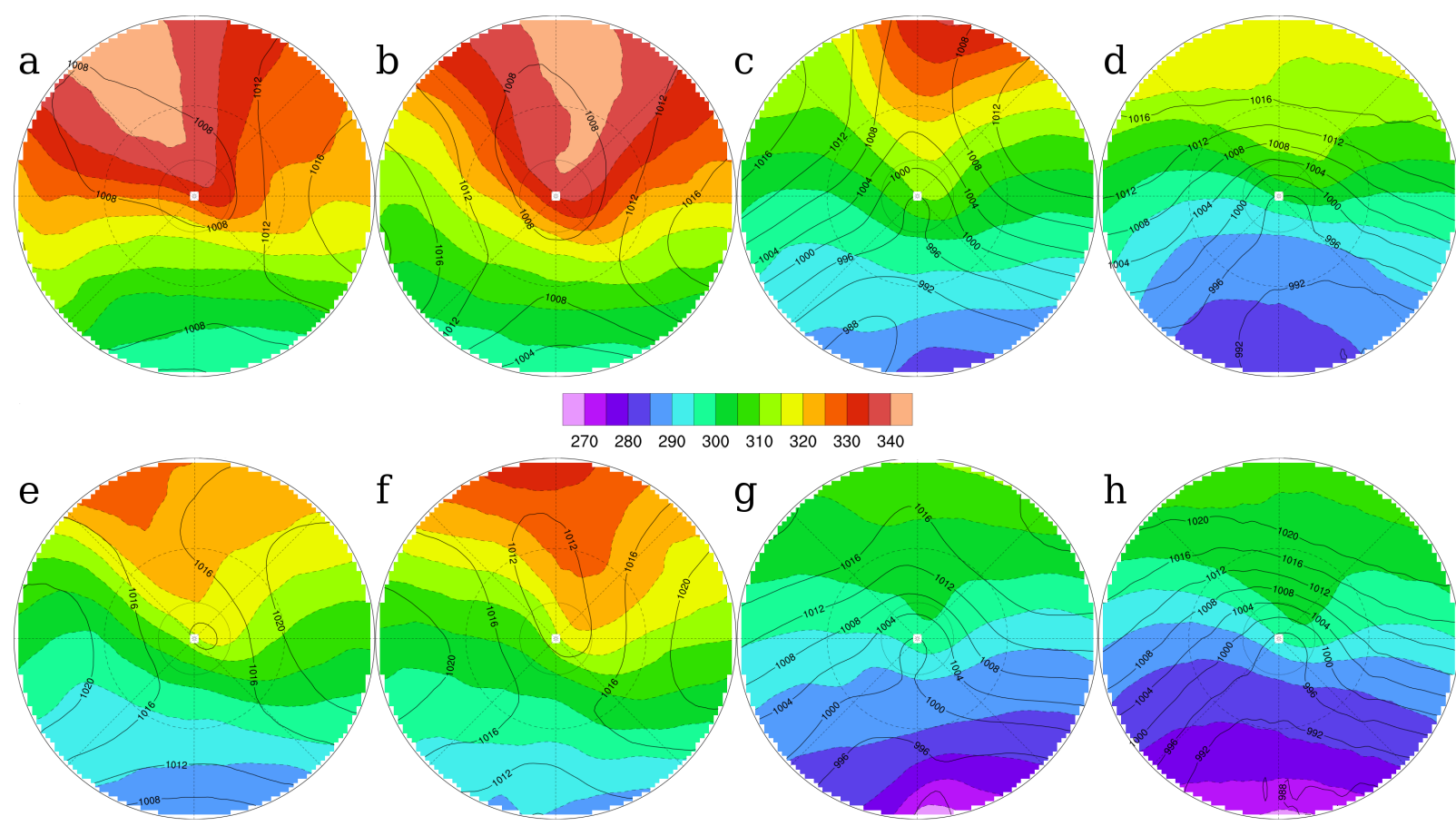

Figure 5.9: Composites of mean equivalent potential temperature $\left(\theta_{e}\right)$ at $925 \mathrm{hPa}$ (K; shaded) and MSLP (hPa; black line) from different genesis regions in the (a-d) summer and (f-g) winter : (a,e) SE-BR, (b,f) LA PLATA, (c,g) ARG and (d,h) SE-SAO.

and LA PLATA regions.

The composites of $\mathrm{RH}$ and $\mathrm{PV}$ at $300 \mathrm{hPa}$ at the time of genesis are presented in Fig 5.10, Again, the main observed RH and PV cyclone structures are similar to the ones found in the NCEP-CFSR cyclones compositing (Fig. 4.13) for both seasons. The frontal cloud band indicated by high values of $\mathrm{RH}$ at $300 \mathrm{hPa}$, are observed in the SE-BR and SE-SAO cyclones, only in the summer and in both seasons, respectively. As discussed in Section 4.3, the presence of these cloud bands at the time of genesis may be an evidence of secondary cyclogenesis in SE-BR and SE-SAO, and they are also observed in HadGEM2ES composites. Although the composite structure of PV at $300 \mathrm{hPa}$ shows an upper-level trough upstream of the cyclone center, as seen in NCEP-CFSR cyclones, the trough seems to be less intense in HadGEM2-ES. The low PV values affect mostly the cyclones from the SE-BR and LA PLATA regions, particularly in the summer. Cyclones from HadGEM2-ES present similar PV values for the ARG region and lower PV values in the summer for SE-SAO when compared to NCEP-CFSR. The PV composite is in agreement with the $\mathrm{PV}$ at $300 \mathrm{hPa}$ spatial distributions, which indicates that the stratospheric intrusions in HadGEM2-ES are underestimated, especially northward of $40^{\circ} \mathrm{S}$. 

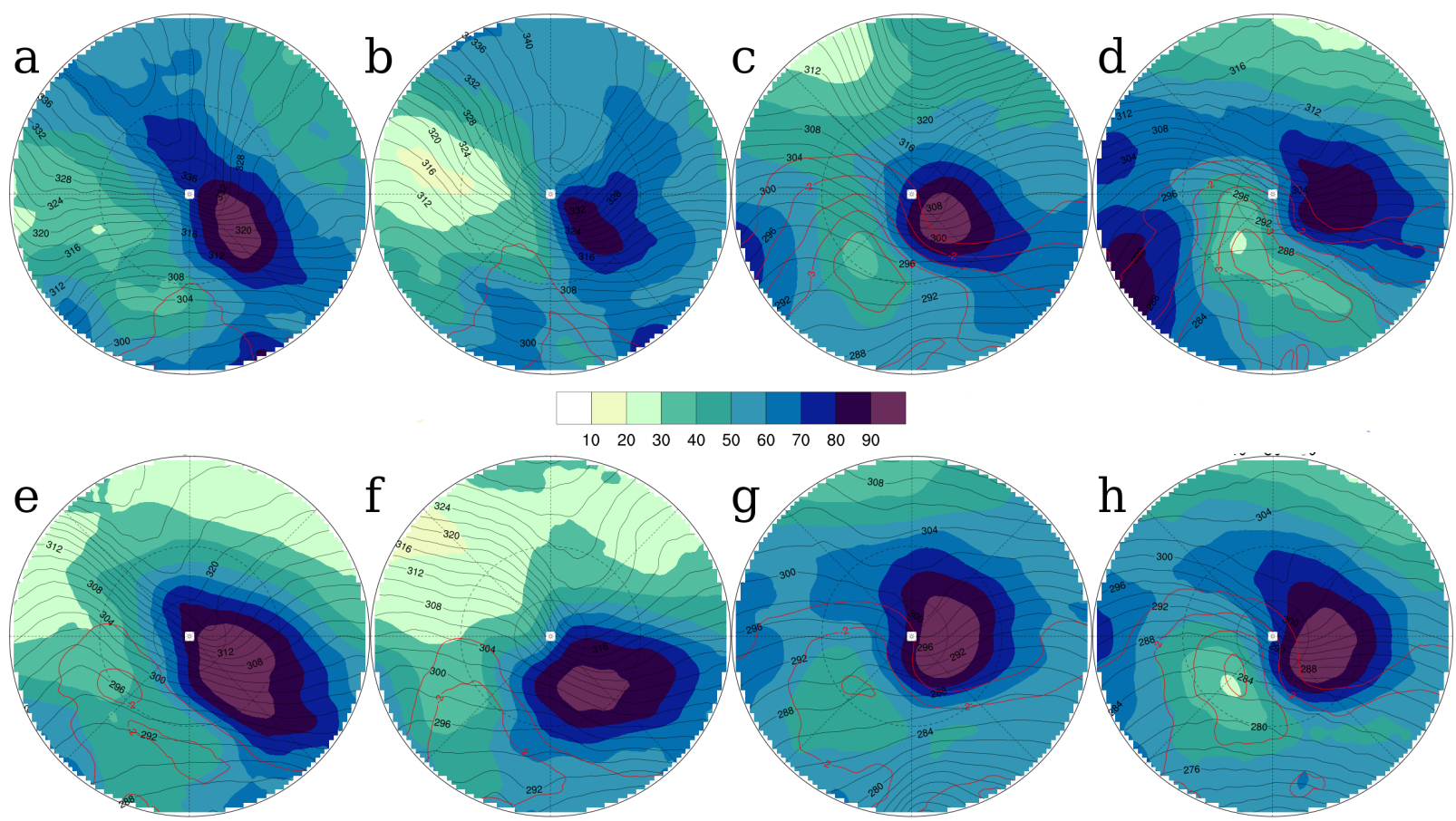

Figure 5.10: Composites of mean equivalent potential temperature $\left(\theta_{e}\right)$ at $925 \mathrm{hPa}(\mathrm{K}$; black lines), $\mathrm{RH}$ (\%; shaded) and $\mathrm{PV}$ at $300 \mathrm{hPa}$ (PVU; red line) from different genesis regions in the (a-d) summer and (f-g) winter : (a,e) SE-BR, (b,f) LA PLATA, (c,g) ARG and $(\mathrm{d}, \mathrm{h})$ SE-SAO.

\subsubsection{Cyclone structure evolution during genesis}

The composites structure in HadGEM2-ES and NCEP-CFSR are similar, and adding all the HadGEM2-ES cyclone composites in this section would be repetitive. For this reason, only the most relevant composites are shown here. This section evaluates the ability of HadGEM2-ES in representing the main cyclogenesis structures in each region (discussed in section 4.3.2).

\section{Southeastern Brazilian Coast (SE-BR)}

Figure 5.11 shows the composite of the mean surface temperature advection and winds at $850 \mathrm{hPa}$, and geopotential height at $500 \mathrm{hPa}$ for the SE-BR cyclones. Both summer and winter present a weak advection of warm temperature before the time of genesis, increasing gradually during the genesis. The temperature advection is slightly stronger in the winter than the summer compositing only at 24 hours after the time of genesis. In the NCEPCFSR composites of SE-BR cyclones in the winter, there is a warm temperature advection before genesis and a rapid increase of cold and warm advection after the genesis time (Figs. 


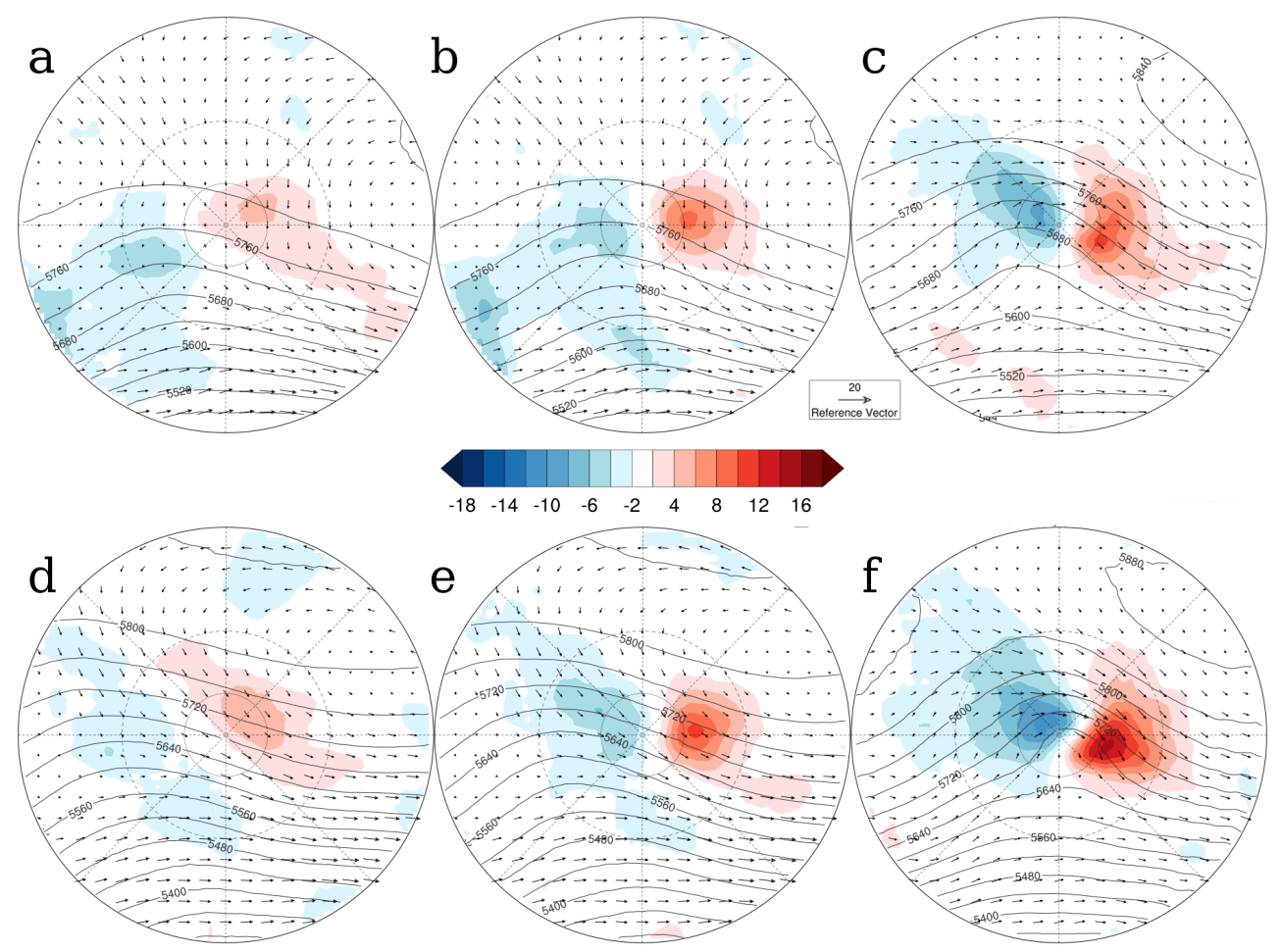

Figure 5.11: Composites of temperature advection at $850 \mathrm{hPa}\left(10^{-5} \mathrm{~K} \mathrm{~s}^{-1}\right.$; shaded), geopotential height at $500 \mathrm{hPa}$ (gpm; black line) and winds at $850 \mathrm{hPa}\left(\mathrm{m} \mathrm{s}^{-1}\right)$ for SE-BR cyclones in the (a-c) summer and (d-f) winter: $(\mathrm{a}, \mathrm{d})$ at 12 hours before the time of genesis; $(\mathrm{b}, \mathrm{e})$ at the time of genesis, and; (c,f) at 24 hours after genesis.

5.11d-f). The temperature advection structure in HadGEM2-ES is weaker than in NCEPCFSR and may have been influenced by the coarser resolution of the former. However, the differences between summer and winter in NCEP-CFSR composites are not observed in HadGEM2-ES composites. The weak thermal advection seen in SE-BR cyclones in the winter may have been led by the absence of a strong SST gradient at southern Brazilian coast, promoting less low-level baroclinicity for the cyclone development. In this way, the difference between summer and winter genesis environment in the SE-BR region, observed in the NCEP-CFSR analysis, are not evident in HadGEM2-ES.

The low-level wind structure is similar to NCEP-CFSR compositing both in summer and winter. It is possible to observe an anticyclonic circulation eastward and northeastward of the cyclone center in the summer and winter, respectively, which is the western/southwestern path of the SASH (also in MSLP field, Figs. 5.9 a and e). Although the westward and southward shift of the SASH is present in the SE-BR cyclones compositing, they do not enhance the warm advection as discussed in section 4.3 .2 , not even before the 
time of genesis where the warm advection may contribute to the decrease of the static stability.

The geopotential height at $500 \mathrm{hPa}$ structure shows the same pattern from the observed in NCEP-CFSR. However, in the winter, the perturbation from mid-level composites seems smaller and shallower than the trough found in the NCEP-CFSR composite. The difference may be addressed to the absence of a more intense temperature advection to amplify the mid-level wave. The wind structure at $200 \mathrm{hPa}$ shows an anticyclone in the upper-left side of the composite (not shown). The same upper-level feature is observed in the NCEPCFSR composites, as well as a divergence at $200 \mathrm{hPa}$. This divergence is associated with a diffluent flow (only in the summer) and an upper-level wave propagation that amplifies while moves toward the low-level cyclone, enhancing the upward movement throughout the atmospheric column (also observed in NCEP-CFSR, Figs.4.16a-c). The VIMFC and VIMT are shown in Fig 5.12, and both patterns and values are similar to the NCEP-CFSR composites. In the summer, there is a narrow band of moisture convergence with a NW-SE orientation that, as discussed in section 4.3.2, may indicate an "old" front.

The structure patterns observed in HadGEM2-ES composites are similar to the ones seen in NCEP-CFSR for the SE-BR cyclones, except by the weaker thermal advection and geopotential height in the winter. The overestimated mass divergence, thermal advection and VIMFC may have been affected by the data resolution due to the finite difference method. Even taking in account these issues, HadGEM2-ES presents less frontal cyclones in the winter for the SE-BR region, with a mid-level perturbation of shorter scale when compared to NCEP-CFSR.

\section{La Plata region (LA PLATA)}

The composites of temperature advection, winds at $850 \mathrm{hPa}$ and geopotential height at $500 \mathrm{hPa}$ before and after genesis, for cyclones from LA PLATA region, are shown in Figs $5.13 \mathrm{a}$-c. Only the winter composites are shown as this season has more cyclogenesis than summer, but the composites produced are similar for both seasons. The differences between the summer and winter composites are discussed throughout the text. In Fig. $5.13 \mathrm{a}$ is observed a warm advection before the time of genesis in the winter. In the summer, as reported in the NCEP-CFSR composites (section 4.3.2), the warm advection starts only at the time of genesis. It is intensified in the winter by the presence of an anticyclonic 


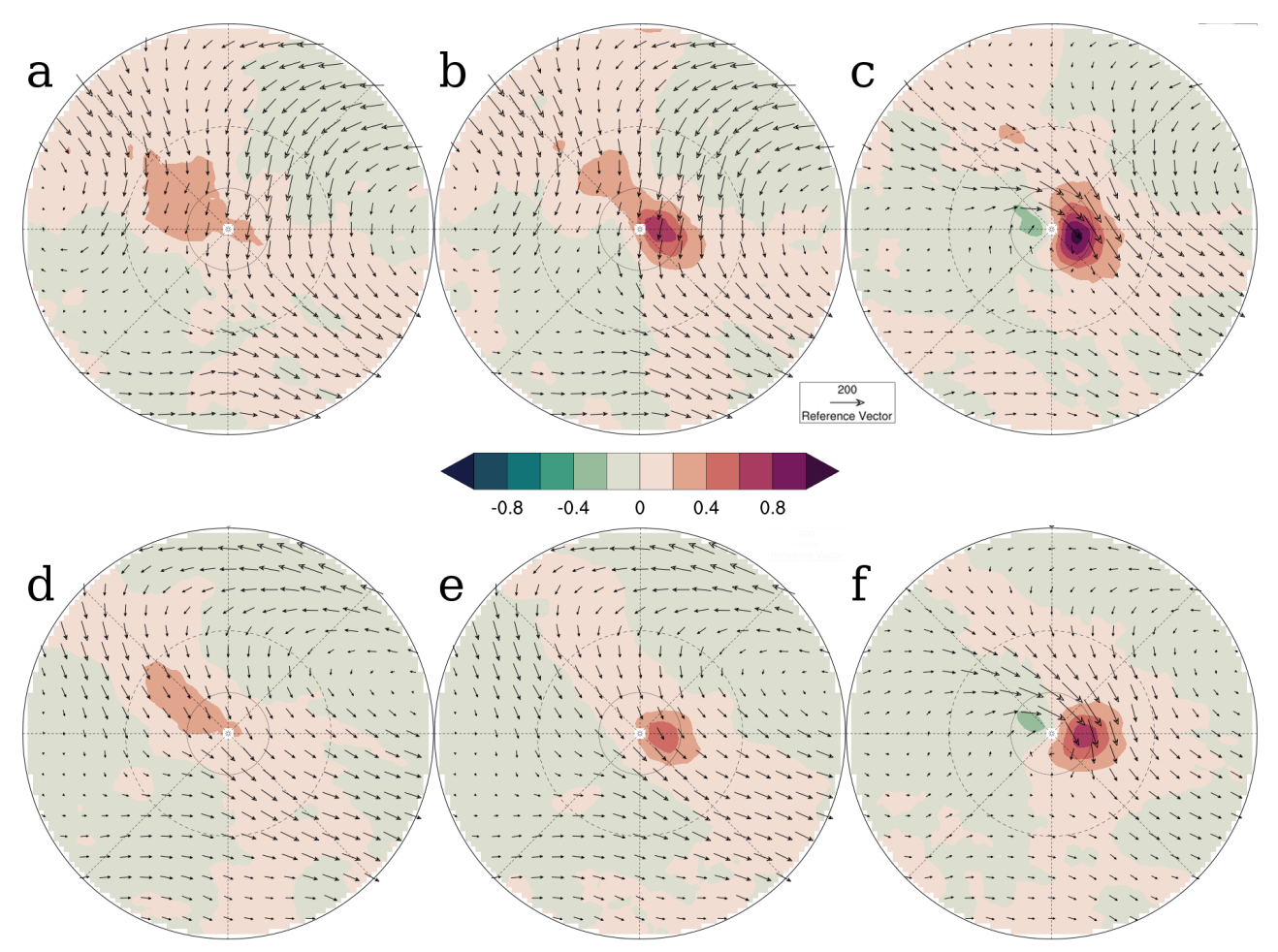

Figure 5.12: Composites of vertically integrated moisture flux convergence $\left(10^{-3} \mathrm{~kg} \mathrm{~m}^{-2} \mathrm{~s}-1\right.$; shaded) and moisture transport $\left(\mathrm{kg} \mathrm{m}^{-1} \mathrm{~s}^{-1}\right.$; arrows) at low levels $(925-700 \mathrm{hPa})$ for SE-BR cyclones in the (a-c) summer and (d-f) winter: (a,d) at 12 hours before the time of genesis; (b,e) at the time of genesis, and (c,f) at 24 hours after genesis. 
circulation Southeast of the cyclone center, which may be the SASH signature in the composite allied to the NAL South/Southeastern circulation (at the time of genesis, Fig. 5.9 ). The thermal advection (i.e., cold and warm advection) becomes intense after the time of genesis, probably due to the cyclone displacement to the ocean. However, the northward shift of the BMC system is not well represented in HadGEM2-ES (Fig 5.6 d), what may interfere in the intensification of LA PLATA cyclones. The signature of the Andes Cordillera in the thermal structure is not evident in HadGEM2-ES as it is in NCEPCFSR. However, there is a perturbation in geopotential height at $500 \mathrm{hPa}$ that is probably related to the interaction with the orography. This interaction is more evident in the winter composites and generates a short mid-level wave that intensifies the warm advection at $850 \mathrm{hPa}$. As it is seen in the $\mathrm{SE}-\mathrm{BR}$ composites, the mid-level wave in the winter is shorter than the observed in the NCEP-CFSR composites.

Figures $5.13 \mathrm{~d}-\mathrm{f}$ show the VIMFC and VIMT. Both in summer and winter, there is a moisture transport south/southeastward of the cyclone center, induced by the SASH. In the summer, the VIMT is stronger due to more moisture availability and the presence of the SALLJ. However, the winter composites also present a strong VIMFC, almost equal to the summer. The only difference is that, in the summer, the moisture convergence begins $24 \mathrm{~h}$ before genesis time (not shown) and in the winter, it starts only at the time of genesis.

The upper-level pattern of the LA PLATA cyclone composites (not shown) in HadGEM2ES is similar to the structure found in the NCEP-CFSR analysis. There is an upper-level trough that promotes divergence downstream, above the cyclone center at the time of genesis. In the summer, a diffluent flow caused by an anticyclone in the upper-left side of the composite, intensifies the divergence. As discussed in section 4.3.2, the divergence at upper-level reinforces the low-level system.

Argentina region $(A R G)$

Only cyclone composites from the summer are shown here for the ARG region, for clarity. Again, differences between summer and winter composites will be highlighted in the text. The summer composites of the mean temperature advection and winds at 850 $\mathrm{hPa}$ and geopotential height at $500 \mathrm{hPa}$ before and after genesis are presented in Fig. 5.14 . There is a warm advection at the cyclone center in both seasons. A strip of cold advection is found in the Andes relative to the time of genesis (e.i., westward of cyclone center). 


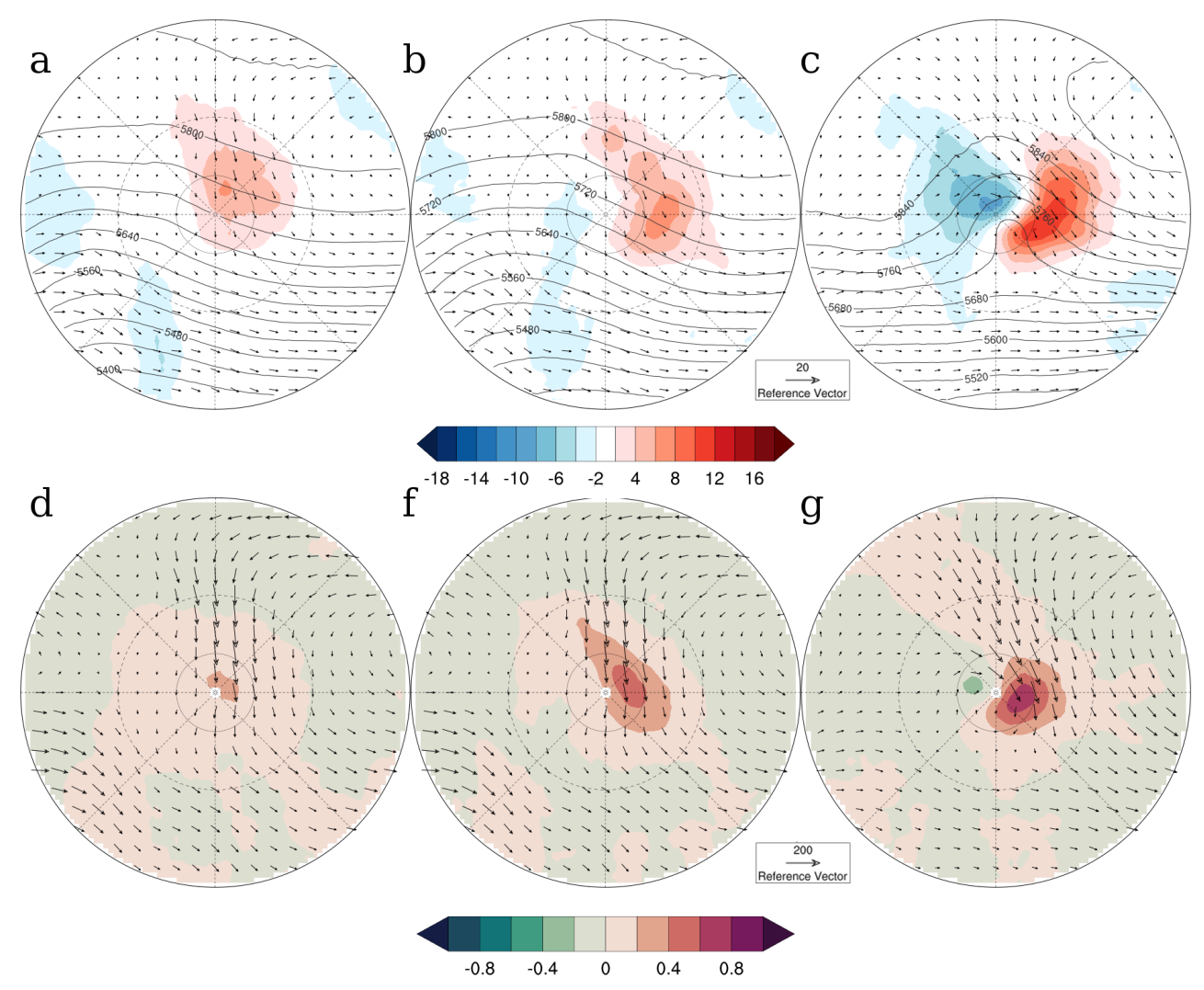

Figure 5.13: Winter composites of (a-c) temperature advection at $850 \mathrm{hPa}\left(10^{-5} \mathrm{~K} \mathrm{~s}^{-1}\right.$; shaded), geopotential height at $500 \mathrm{hPa}$ (gpm; black line) and winds at $850 \mathrm{hPa}\left(\mathrm{m} \mathrm{s}^{-1}\right)$; and (d-f) vertically integrated moisture flux convergence $\left(10^{-3} \mathrm{~kg} \mathrm{~m}^{-2} \mathrm{~s}-1\right.$; shaded) and moisture transport $\left(\mathrm{kg} \mathrm{m}^{-1} \mathrm{~s}^{-1}\right.$; arrows) at low levels $(925-700 \mathrm{hPa})$ for LA PLATA cyclones: $(\mathrm{a}, \mathrm{d})$ at 12 hours before the time of genesis; (b,e) at the time of genesis, and; (c,f) at 24 hours after genesis. 


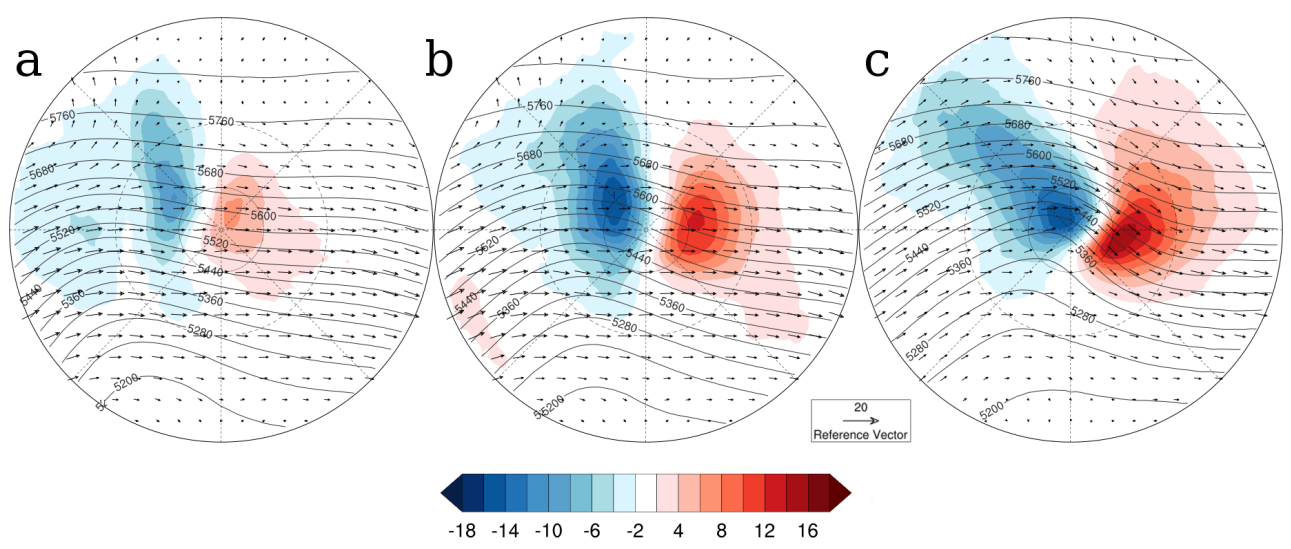

Figure 5.14: Composites of temperature advection at $850 \mathrm{hPa}\left(10^{-5} \mathrm{~K} \mathrm{~s}^{-1}\right.$; shaded), geopotential height at $500 \mathrm{hPa}$ (gpm; black line) and winds at $850 \mathrm{hPa}\left(\mathrm{m} \mathrm{s}^{-1}\right)$ for ARG cyclones in the summer: (a) at 12 hours before the time of genesis; (b) at the time of genesis, and; (c) at 24 hours after genesis.

However, it is possible to observe that the Andes signature in ARG cyclone composites is weaker when compared with the NCEP-CFSR composites. The warm advection intensity is well-compared with NCEP-CFSR in both seasons but is slightly weaker in the winter. The cold advection is underestimated in both seasons, particularly in the winter. As seen in NCEP-CFSR, the moisture processes may not be essential to genesis in ARG cyclones. The VIMFC is weak and only takes place at the cyclone center after the time of genesis (not shown). The upper-level composites show an upper-level trough moving toward the cyclone center at the surface and, after the time of genesis, the upper divergence eastward of the trough may give support to the cyclone development (not shown).

\section{Southeastern South Atlantic Ocean (SE-SAO)}

Figure 5.15 shows the composite of the mean temperature advection and winds at 850 $\mathrm{hPa}$ and geopotential height at $500 \mathrm{hPa}$ of the SE-SAO cyclones before, at and after genesis times. Only winter composites are presented because few aspects are different when compared to the summer, and they are discussed in the text. There is a strong warm advection 12 hours before the genesis in the center of the composite along with a cold advection westward, as reported in NCEP-CFSR composites. The cold and warm advection increases rapidly after the genesis time. However, the HadGEM2-ES considerably underestimates the temperature advection. The weak thermal advection may be due to the underestimated SST gradient zone in the South Atlantic Ocean (Fig 5.6). The MSLP 


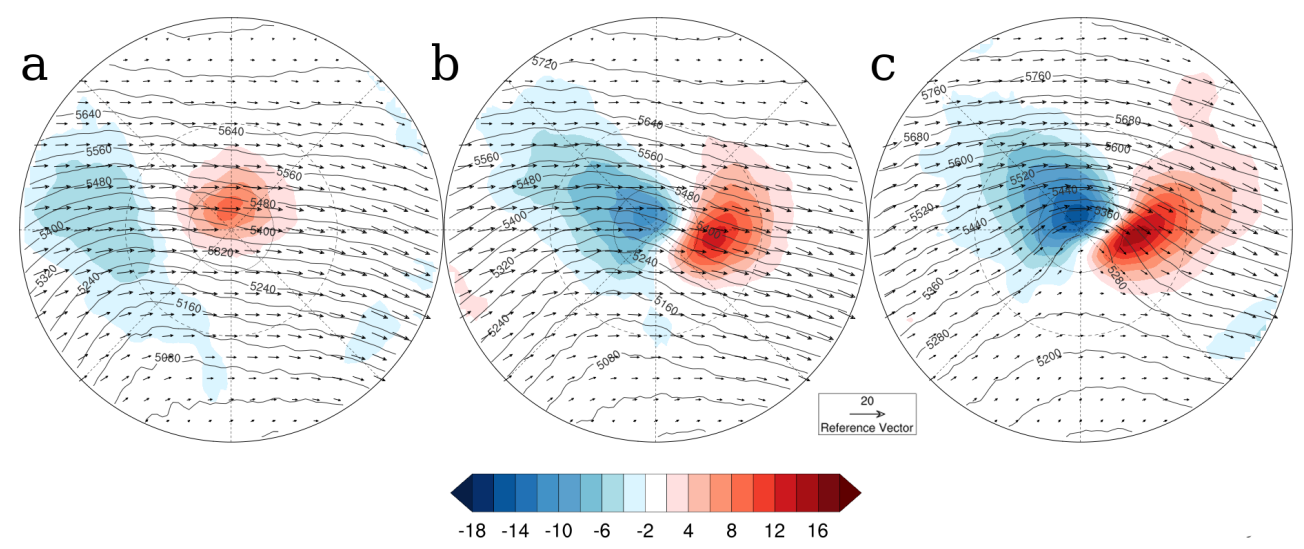

Figure 5.15: As in Fig 5.14 but for the composites of SE-SAO cyclones in the winter.

(Figs. $5.9 \mathrm{~d}$ and $\mathrm{h}$ ) and the geopotential height at $500 \mathrm{hPa}$ structures show "parental" cyclones located southeastward of the developing cyclone. As discussed in section 4.3.2, the SE-SAO cyclones present a secondary development on the cold side of the parent cyclone, as reported by Browning et al. (1997) and Iwabe and da Rocha (2009). However, the stratospheric intrusion, which is important for this type of genesis, may have not been properly represented in HadGEM2-ES, what also can justify the underestimation of cyclones in this region.

\subsection{Discussion and Conclusions}

This Chapter evaluated the ability of HadGEM2-ES to represent the characteristics of South Atlantic Cyclones considering some spatial statistics and structural aspects. It is possible to identify the four main genesis regions in HadGEM2-ES and their associated storm tracks. However, the HadGEM2-ES presented a positive genesis bias in the ARG region both in the summer and winter, what promoted a high track density between $45^{\circ} \mathrm{S}$ and $55^{\circ} \mathrm{S}$. Moreover, the HadGEM2-ES underestimated the genesis in the LA PLATA region in both seasons. This issue may be addressed to the poor orographic representation of the GCM due to the coarse resolution. Lee (2014) also found a reduction of genesis at this location and proposed that the transients may have been just passing directly over the mountain range, rather than "dying and being re-born" as is seen in SH climatologies (Hoskins and Hodges, 2005). The coarse resolution may have also been responsible for the negative bias in SE-BR in the summer and the SE-SAO in both seasons. The resolution of the HadGEM2-ES is not enough to secondary cyclone solving, as long as those systems 
develop in a frontal region where mesoscale and sub-grid processes (e.g., latent heat release) play an essential role. In the winter, the SE-BR region presented a positive bias in genesis density (and more than $25 \%$ in cyclone number) which may be related to a perturbation that comes from Pacific and, instead of growing in LA PLATA supported by lee effects, developed in Brazilian coast where the air-sea surface fluxes are intense. The HadGEM2ES cyclones lasted less and were slower than NCEP-CFSR cyclones, probably due to the lower negative bias from upper-level jet speed.

Although the SE-BR region presented a positive bias in the winter, the SST gradient and upper-level jet velocity at the time of genesis did not reveal a strong baroclinicity in this region. Chap. 4 discussed the importance of STSF and BMC northward shift in the baroclinic development in SE-BR in the winter, associated with the subtropical upper-level jet. It seems that the low-level moisture content and neutral conditional stability are able to play an essential role in this positive bias. In Eq. 2.1 the baroclinicity is measured by the vertical wind shear (associated mainly to the SST gradient) and the static stability. However, the Eady growth equation does not consider the diabatic process, which is vital to the SE-BR region. The moisture role may be decisive to the winter genesis bias from SE-BR once the upper and mid-level perturbations from Pacific, instead of interacting with the stationary Andes trough promoting genesis in the LA PLATA region, may keep moving eastward due to the bad orographic representation. Once the mid-level wave is above a conditionally neutral and moist environment it growths, enhanced by the upperlevel forcing. In this way, following the Eq. 2.1, the vertical stability term compensates the vertical wind shear term in the baroclinic growth process.

The SST gradient seems to be decisive in modulating the storm track position (e.g., Sanders and Gyakum, 1980; Hoskins and Hodges, 2005), as well as developing and intensifying cyclones in South American coast (e.g., Vera et al., 2002). In this way, the misrepresentation of the SST gradient field, both in intensity and variability, in HadGEM2-ES, may be a source of cyclogenesis bias that leads to track and lysis density biases. The oceanic fronts are complex features maintained by mesoscale processes in the ocean that may not be reproduced by the HadGEM2-ES resolution. According to Lee (2014), the zonal bias in the storm track observed in most of the CMIP5 models occurs mainly due to low atmospheric and oceanic model resolution, linked with the poor representation of orography and ocean front biases. The storm track bias is larger in the winter, as long as these models are not 
able to correctly represent the poleward latitudinal tilt of the tracks as the cyclones travel eastward (Ulbrich et al., 2009; Chang et al., 2012).

The larger number of weak cyclones is also a consequence of low resolution. Bengtsson et al. (2009) showed that a high-resolution version of ECHAM5 (T213) had represented extratropical cyclones with greater realism when compared to a lower resolution version (T63). The low-resolution models use to have the larger biases, regarding cyclogenesis and track densities, and intensity. The effect of the latent heat release in the cyclone development can also explain the low-intensity biases seen in Fig.5.4 (also in Figs. B.1 and B.2).

Despite the biases discussed above, it is remarkable how the HadGEM2-ES was able to represent South Atlantic cyclones structure during the genesis. These results are in agreement with Catto et al. (2010). HadGEM2-ES represented important features within the cyclone like the cloud front band (i.e., high RH at $300 \mathrm{hPa}$ ) and low-level VIMFC pattern at the genesis from SE-BR in the summer, and also the SE-SAO development at the cold sector of a 'parental' cyclone. However, there is some evidence that the climate model underestimates the stratosphere-troposphere interaction, as is seen through the distributions of PV at $300 \mathrm{hPa}$ at the time of genesis and in the composites. The underestimated thermal advection and divergence are related to the resolution, regarding the finite difference method applied to these computations. 
Chapter 6

\section{Cyclones in the HadGEM2-ES future projection}

\subsection{Genesis and track density}

The future projection of HadGEM2-ES for the RCP8.5 scenario was analyzed for the period from 2074 to 2099 , representing the last 26 years of the $21^{\text {th }}$ century. Table 6.1 shows the number of cyclones identified within the South Atlantic domain and in each genesis region defined in Chapter 4 (Fig 4.2) for the HadGEM2-ES RCP8.5 future projection. The percentage in parentheses at the third column indicates RCP8.5 projected increase (positive) or decrease (negative) in cyclone number. There is a general decrease in the cyclone number of $10 \%$ in the South Atlantic. The only exception is over the LA PLATA region, which increases in both seasons, particularly in the summer.

The RCP8.5 genesis density and its projected changes are presented in Fig. 6.1 for the summer and winter. Genesis decreases in the ARG region $\left(\sim 3\right.$ cyclones per $10^{6} \mathrm{~km}^{2}$ per month) both in summer and winter. The LA PLATA region presents an increase in cyclogenetic activity $\left(\sim 0.4\right.$ cyclones per $10^{6} \mathrm{~km}^{2}$ per month $)$ at $30^{\circ} \mathrm{S}$, both in summer and winter, as seen in Table 6.1. In the winter the increase extends further eastward along the northern portion of the SE-BR region. However, the SE-BR region presents a decrease in genesis density in the summer, its most active season according to the climatology. In the SE-SAO region the genesis density decreases in both seasons. Besides the increase in the genesis density in the La PLATA region, there is an increase in cyclogenetic activity eastward of ARG region (summer) and in Southeastern African coast (both seasons).

The track density and its future projected changes (Fig. 6.2) are mainly a response of the changes from genesis density. The storm track density decreases between $35^{\circ} \mathrm{S}$ and $55^{\circ} \mathrm{S}$ as a consequence of the decreased cyclogenetic activity in the ARG region and over 
Table 6.1 - Total number of cyclones, annual mean and standard deviation for South Atlantic domain $\left(15^{\circ} \mathrm{S}-55^{\circ} \mathrm{S}, 75^{\circ} \mathrm{W}-20^{\circ} \mathrm{E}\right)$ and for each defined cyclogenesis region within the domain. The values were computed for the 2074-2099 time period for the summer (DJF) and winter (JJA). The numbers in parentheses at the third column are the percentage of the HadGEM2-ES RCP8.5 total on the historical experiment total number.

\begin{tabular}{rcccc}
\hline \hline & \multicolumn{2}{c}{ DJF } & \multicolumn{2}{c}{ JJA } \\
\hline region & Total & Annual mean & Total & Annual mean \\
\hline \hline South Atlantic & $2038(-10.1)$ & $78.4 \pm 7.0$ & $2545(-10.2)$ & $97.9 \pm 7.1$ \\
SE-BR & $140(-14.1)$ & $5.4 \pm 2.2$ & $183(-12.4)$ & $7.0 \pm 2.2$ \\
LA PLATA & $174(6.1)$ & $6.7 \pm 2.7$ & $257(3.6)$ & $9.9 \pm 2.3$ \\
ARG & $627(-11.4)$ & $24.1 \pm 3.1$ & $520(-18.4)$ & $20.0 \pm 3.2$ \\
SE-SAO & $422(-21.1)$ & $16.2 \pm 4.2$ & $697(-14.6)$ & $26.8 \pm 4.1$ \\
\hline \hline
\end{tabular}
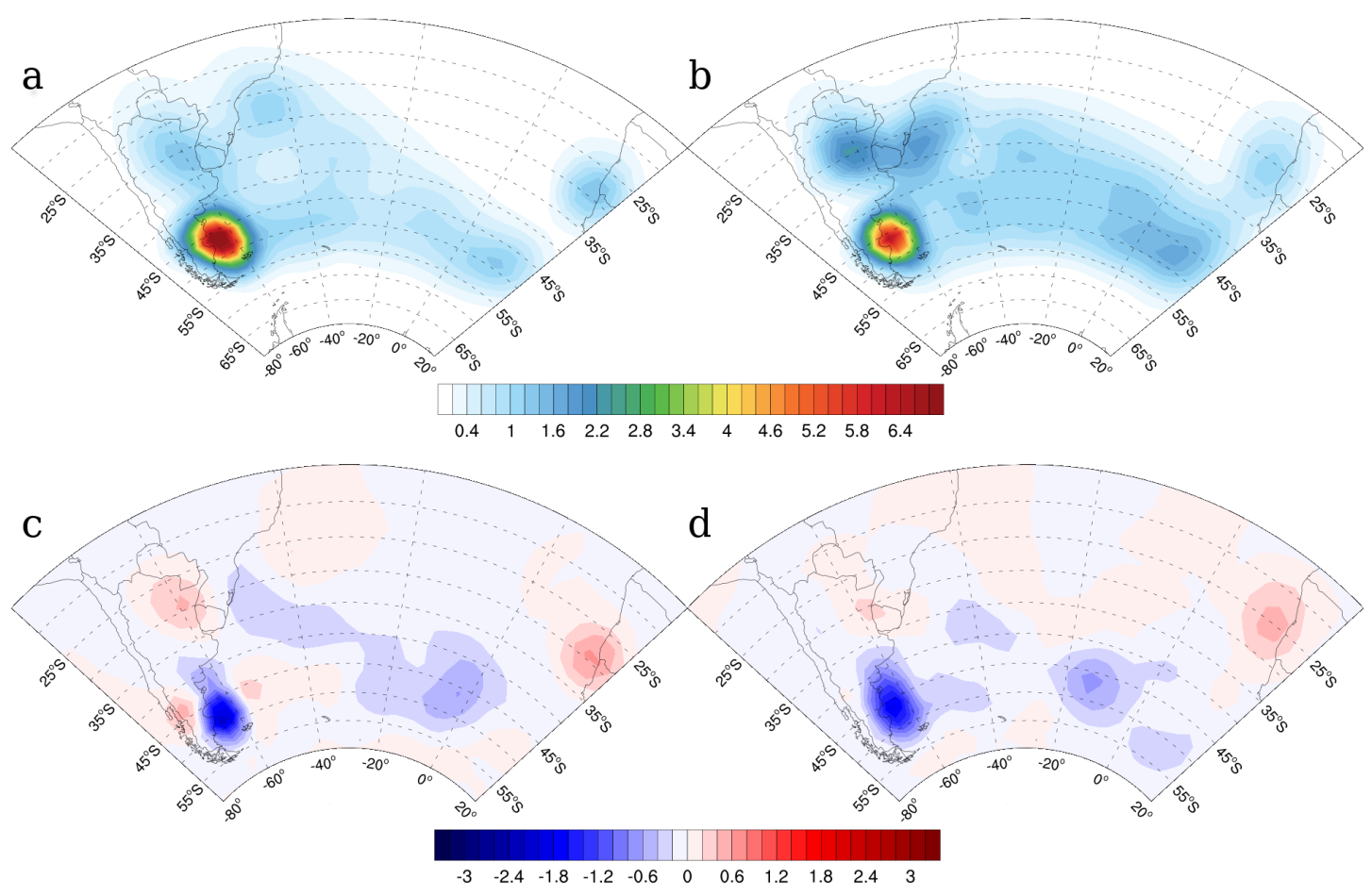

Figure 6.1: Genesis density in the austral (a) summer and (b) winter, and genesis density from RCP8.5 future projected changes for (c) summer and (d) winter. The density unit is cyclone per $10^{6} \mathrm{~km}^{2}$ per month. 
the ocean domain. The reduction in the frequency of cyclones is reported around the globe (e.g. Geng and Sugi, 2003; Bengtsson et al., 2006; Pinto et al., 2007; Ulbrich et al., 2009), in the SH (e.g. Simmonds and Keay, 2000b; Fyfe, 2003; Mizuta, 2012) and also in regional studies (Krüger et al., 2012; Reboita et al., 2018). The decrease in the number of cyclones within the South Atlantic domain may be partially addressed to the southward shift of the main storm-track. Although the considered cyclones were only those with timesteps inside the South Atlantic domain $\left(15^{\circ} \mathrm{S}-55^{\circ} \mathrm{S}, 75^{\circ} \mathrm{W}-20^{\circ} \mathrm{E}\right)$, the track density analysis extended further poleward in order to assess the storm track shift reported by several studies (e.g. Geng and Sugi, 2003; Bengtsson et al., 2006; Pinto et al., 2007; Ulbrich et al., 2009; Mizuta, 2012; Krüger et al., 2012; Reboita et al., 2018). In fact it is possible to observe an increase in the track density poleward of $65^{\circ} \mathrm{S}$, particularly in the summer.

The observed increase in genesis density in the LA PLATA region seems to affect only the track density in the Southeastern South America coast. This surely may affect directly the extreme events over Southern-Southeastern Brazilian coast and Uruguay. As seen in the historical evaluation, the poor representation of Andes Cordillera may affect the cyclogenesis in LA PLATA region (Figs. 5.2c and d). So, it is deducible that the increase observed in the projection is related to other forcing as long as orography representation did not change.

It is important to note that the magnitude of the changes observed in Figs. 6.1 and 6.2 is mostly smaller or equal to the biases seen in Figs. 5.2 -d and $5.3 \mathrm{c}$-d. However, the decrease of genesis density in the ARG region and the decrease in the track density northward of $55^{\circ} \mathrm{S}$ are larger than the biases for these same regions in the historical experiment.

\subsection{Intensity and other aspects}

Table C.1 shows that the mean values of initial vorticity, lifetime and speed of cyclones do not show significant changes.

Figure 6.3 shows the histogram of the maximum relative vorticity at $850 \mathrm{hPa}$ for the cyclones from each genesis region, in the summer and winter, including the HadGEM2-ES historical histogram. According to the maximum vorticity, the South Atlantic cyclone will be sightly stronger in the winter. However, the intensification of the cyclones is clearly observed in the two genesis regions equatorward. The SE-BR region presents in the future 

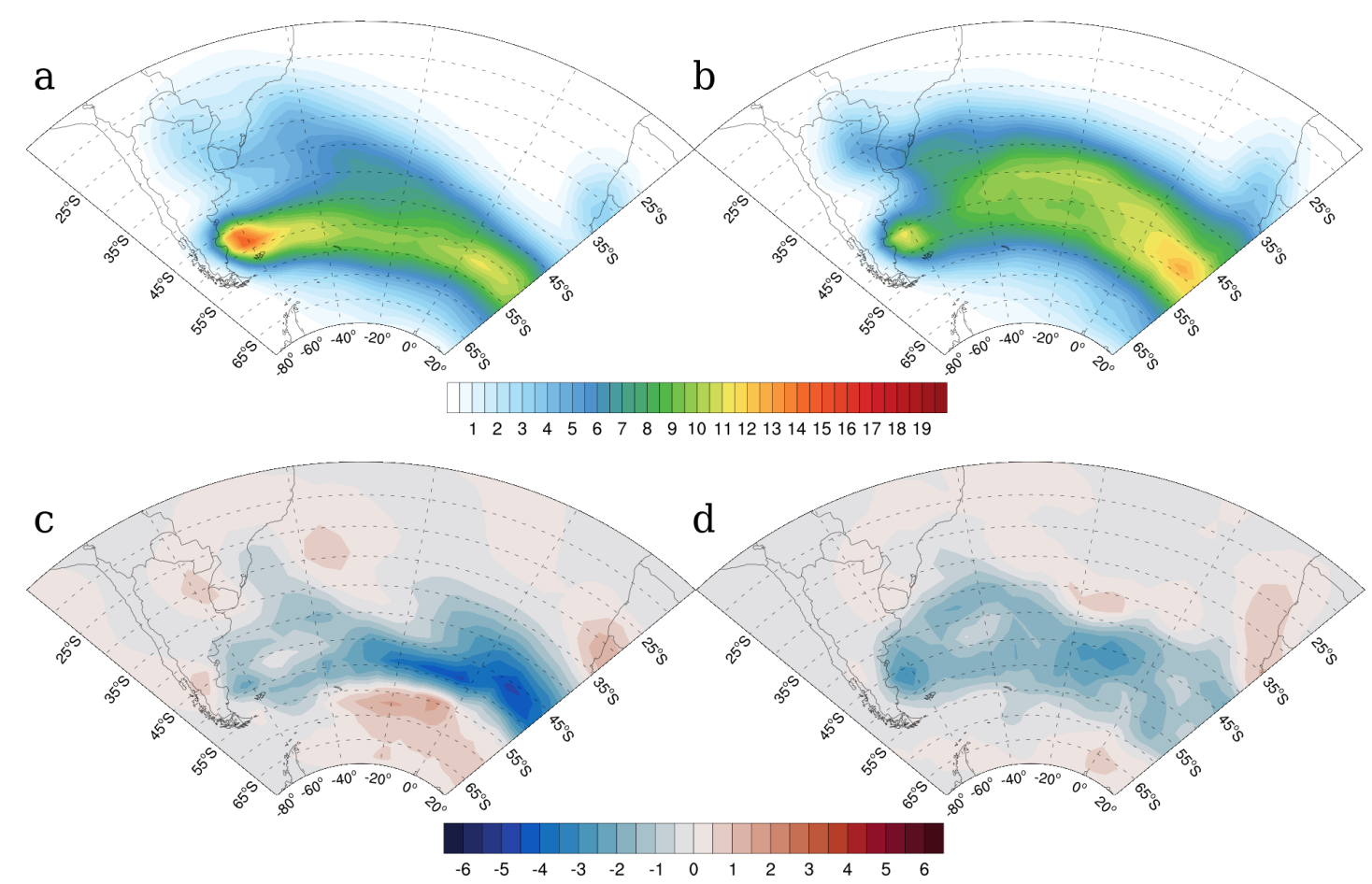

Figure 6.2: Track density in the austral (a) summer and (b) winter, and track density from RCP8.5 future projected changes for (c) summer and (d) winter. The density unit is cyclone per $10^{6} \mathrm{~km}^{2}$ per month.

projection a group of strong cyclones $\left(\zeta_{\max }=-9 \times 10^{-5} s^{-1}\right)$ in the summer, and stronger cyclones $\left(\zeta_{\max } \leq-9 \times 10^{-5} s^{-1}\right)$ followed by a reduction in weak-to-medium intensity systems in the winter. The LA PLATA cyclones also showed an intensification, shifting the histogram peak from -4 to $-6 \times 10^{-5} s^{-1}$ in the summer, and increasing the number of cyclones with $\zeta_{\max } \leq-8 \times 10^{-5} s^{-1}$ in the winter. The ARG and SE-SAO histograms present an increase in the occurrence of weak-to-medium intensity systems.

The intensification of the South Atlantic cyclones is more evident in the minimum MSLP histograms 6.4. In all distributions the left-tail increases, which reveals that the occurrence of cyclones with the $M S L P_{\min } \leq 980 \mathrm{hPa}$ also increases, particularly in the winter. Again, the SE-BR and LA PLATA cyclones showed the larger intensification.

The maximum wind speed histograms are shown in Fig. 6.5. There is an intensification observed in the right-tail of the distribution in the winter, more evident in the LA PLATA and SE-BR regions. However, the only distribution that presents large changes is the SEBR region. The SE-BR histogram peak changes from $27 \mathrm{~ms}^{-1}$ to $35 \mathrm{~ms}^{-1}$ in the summer, and from $32 \mathrm{~ms}^{-1}$ to a band between 35 and $40 \mathrm{~ms}^{-1}$ in the winter. 

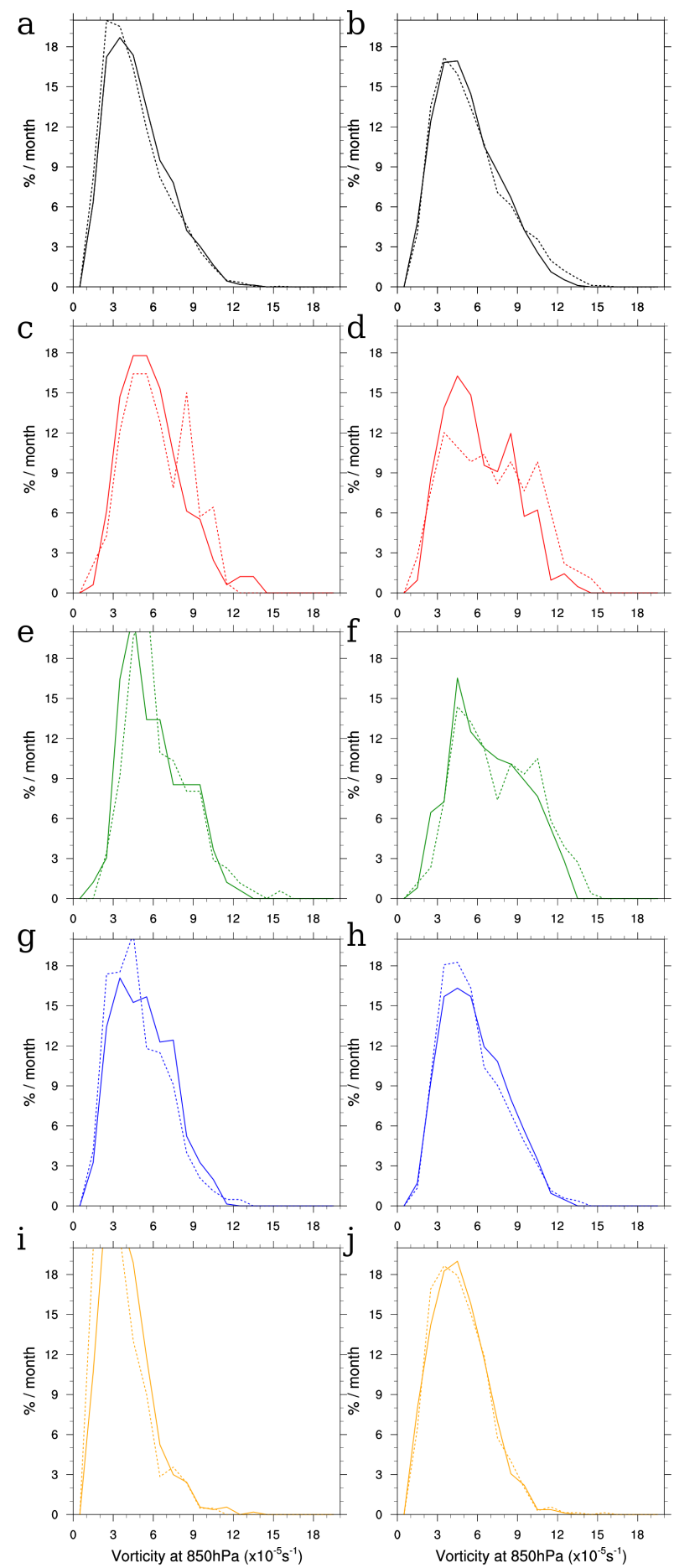

Figure 6.3: HadGEM2-ES RCP8.5 (dashed line) and historical (solid line) histograms of the maximum filtered vorticity at $850 \mathrm{hPa}$ in the (left) summer and (right) winter, for the regions: (a,b) South Atlantic, (c,d) SE-BR, (e,f) LA PLATA, $(\mathrm{g}, \mathrm{h})$ ARG, and (i,j) SE-SAO. The vorticity is scaled by $-1 \times$ $10^{-5} s^{-1}$. The intensity histograms were produced for cyclones originated in each genesis region separately. The percentage was computed based on the mean cyclones per month for each region. 

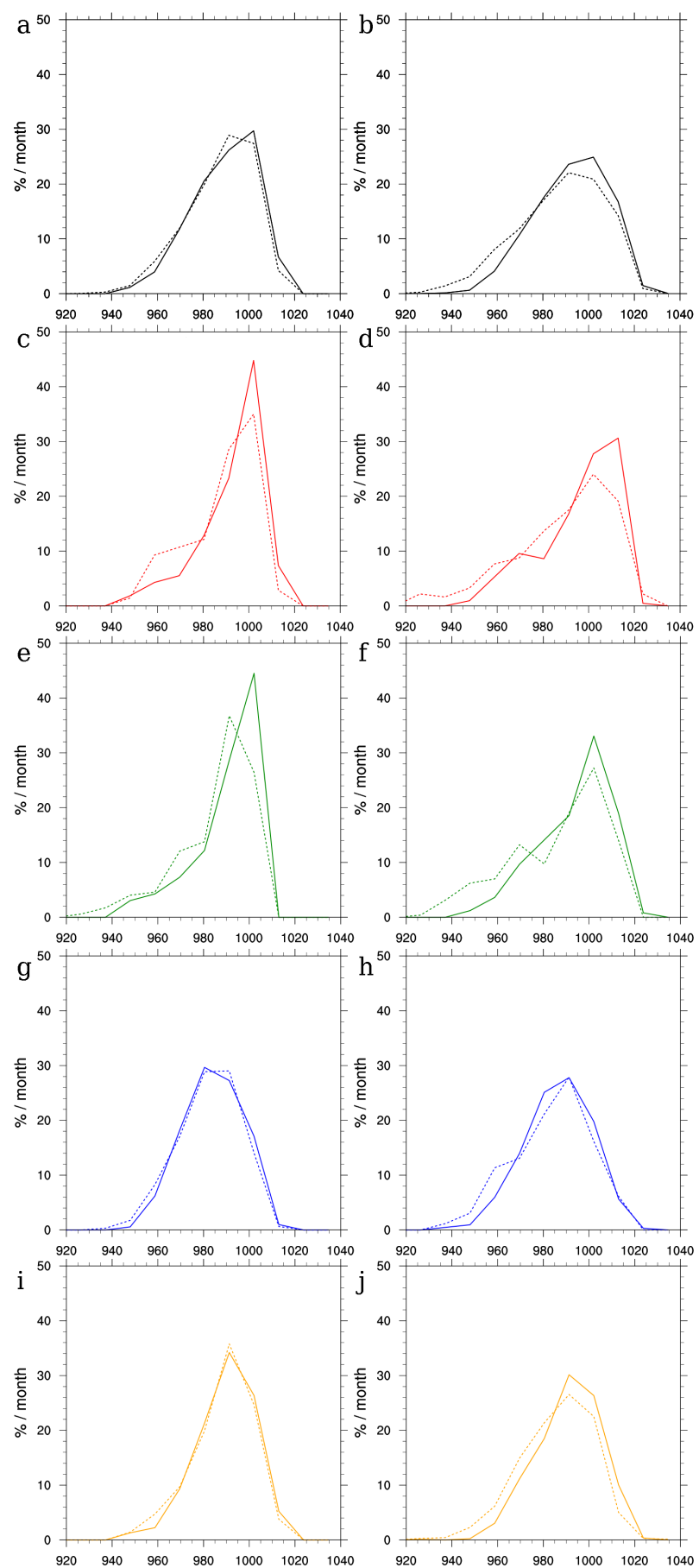

Figure 6.4: HadGEM2-ES RCP8.5 (dashed line) and historical (solid line) histograms of the minimum MSLP (hPa) in the (left) summer and (right) winter, for the regions: (a,f) South Atlantic, (b,g) SE-BR, (c,h) LA PLATA, (d,i) $\mathrm{ARG}$, and $(\mathrm{e}, \mathrm{j}) \mathrm{SE}-\mathrm{SAO}$. The minimum MSLP was searched within $5^{\circ}$ radius from the center of the cyclone. The intensity histograms were produced for cyclones originated in each genesis region separately. The percentage was computed based on the mean cyclones per month for each region. 

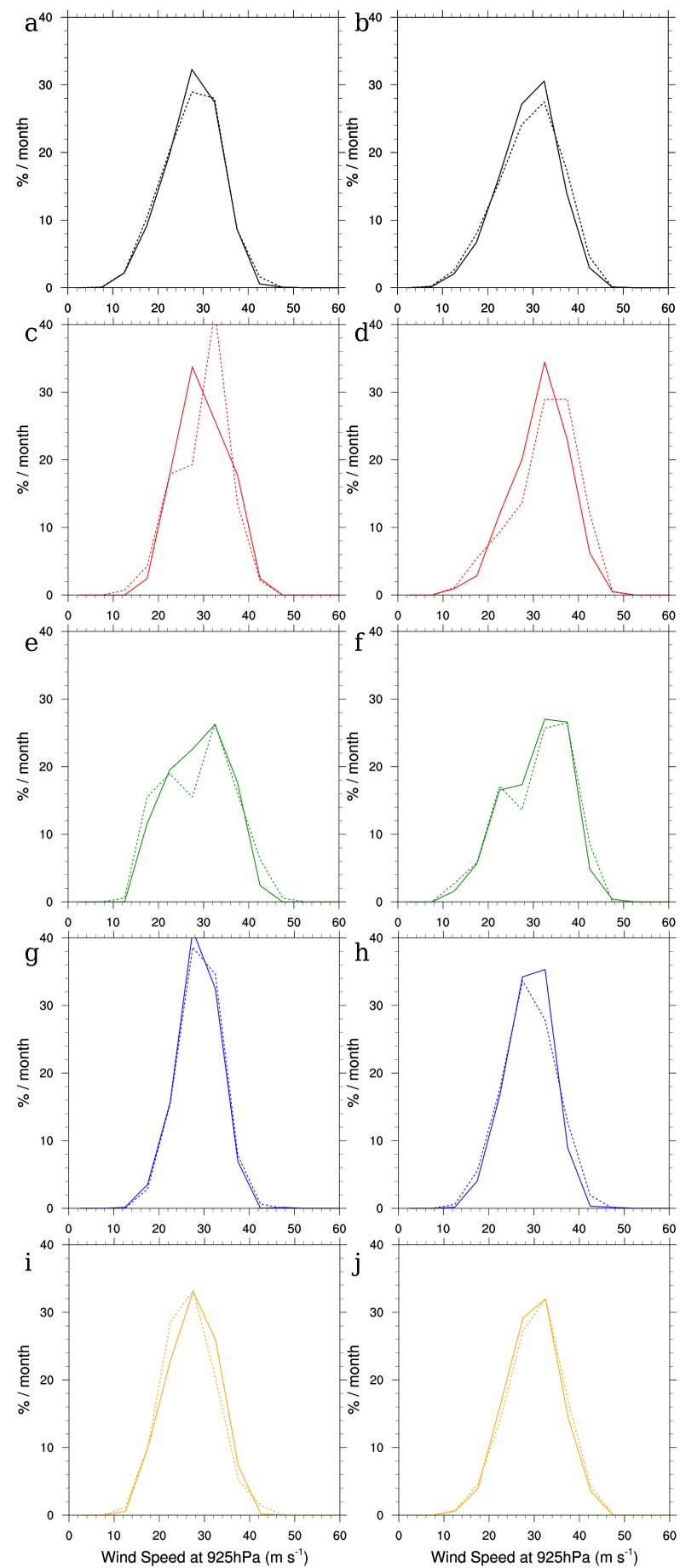

Figure 6.5: HadGEM2-ES RCP8.5 (dashed line) and historical (solid line) histograms of the maximum wind speed at $925 \mathrm{hPa}\left(\mathrm{m} \mathrm{s}^{-1}\right)$ in the (left) summer and (right) winter for the regions: (a,f) South Atlantic, (b,g) SE-BR, (c,h) LA PLATA, (d,i) ARG, and (e,j) SE-SAO. The maximum wind speed was searched within $6^{\circ}$ radius from the center of the cyclone. The intensity histograms were produced for cyclones originated in each genesis region separately. The percentage was computed based on the mean cyclones per month for each region. 
The results showed in this section are in agreement with previous studies that show an intensification of cyclones in the future projections (e.g. Geng and Sugi, 2003; Lambert and Fyfe, 2006; Bengtsson et al., 2009). However, a special attention may be given to the use of MSLP as a measure of intensification. While the vorticity and wind speed have shown an intensification restricted to some location and seasons, the MSLP has shown a general increase in cyclone intensity. The use of MSLP to assess the changes in cyclone intensity may be biased by potential changes in its background (Bengtsson et al., 2006), making this field more sensitive to climate change.

Figures 6.6 and b show the RCP8.5 future projected changes in the cyclone displacement speed in the summer and winter, respectively. Although there is no significant change in the mean speed for each region (Table C.1), the spatial changes in the distribution of the mean speed present another point of view. In the summer, the speed of cyclones increases poleward of $50^{\circ} \mathrm{S}$ while there is a decrease of cyclone speed in the Southeastern South Atlantic sector. However, in the Southwestern South Atlantic the cyclone mean speed increases, particularly in the LA PLATA and SE-BR regions. The changes in the pattern in the winter are not so clear, showing a general increase in cyclone speeds in most of the domain, including the SE-BR region, and a decrease in the LA PLATA and ARG regions. These changes may not be significant as long as their values are equal to or lower than the standard deviation in Table C.1.

Figures 6.6. and d show the RCP8.5 future projected changes in the mean growth rate for the summer and winter. There is an increase in the growth rate in the LA PLATA region and some locations of SE-BR region in the summer. In the winter, the SE-BR region and Southeastern South Atlantic present an increase in growth rate.

\subsection{Spatial distribution of cyclone properties}

Figure 6.7 shows the future changes in the SST gradient distribution at the time of genesis, for summer and winter. There is a poleward shift of the maximum SST gradient associated with the cyclone development in the western portion of the domain in both seasons. The southward shift of the BMC has been reported during the last decade in studies using observational and satellite data (e.g., Lumpkin and Garzoli, 2011; Goni et al. 2011), in numerical simulations (e.g., Gramcianinov, 2013; Combes and Matano, 2014) and 


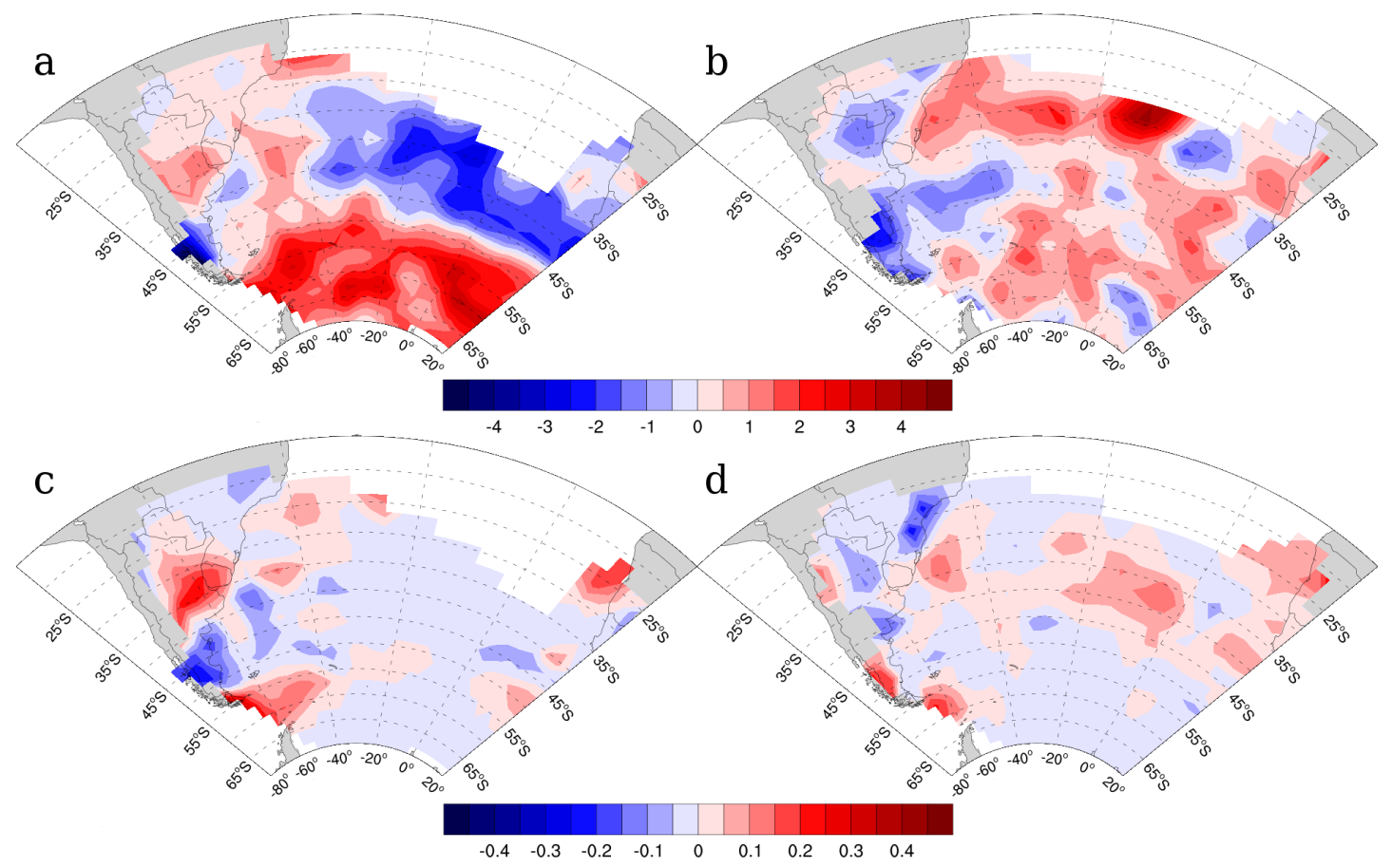

Figure 6.6: RCP8.5 future projected changes in the spatial distribution of the mean speed $(\mathrm{a}, \mathrm{b})$ and mean growth rate $(\mathrm{c}, \mathrm{d})$ in the $(\mathrm{a}, \mathrm{c})$ summer and $(\mathrm{b}, \mathrm{d})$ winter. The units are $m s^{-1}$ for the speed and $-1 \times 10^{-5} s^{-1} d a y^{-1}$ for the growth rate. The fields are not plotted where HadGEM2-ES RCP8.5 track density $<0.3$ cyclones $\left(10^{6} \mathrm{~km}^{2}\right)^{-1}$ month $^{-1}$. 

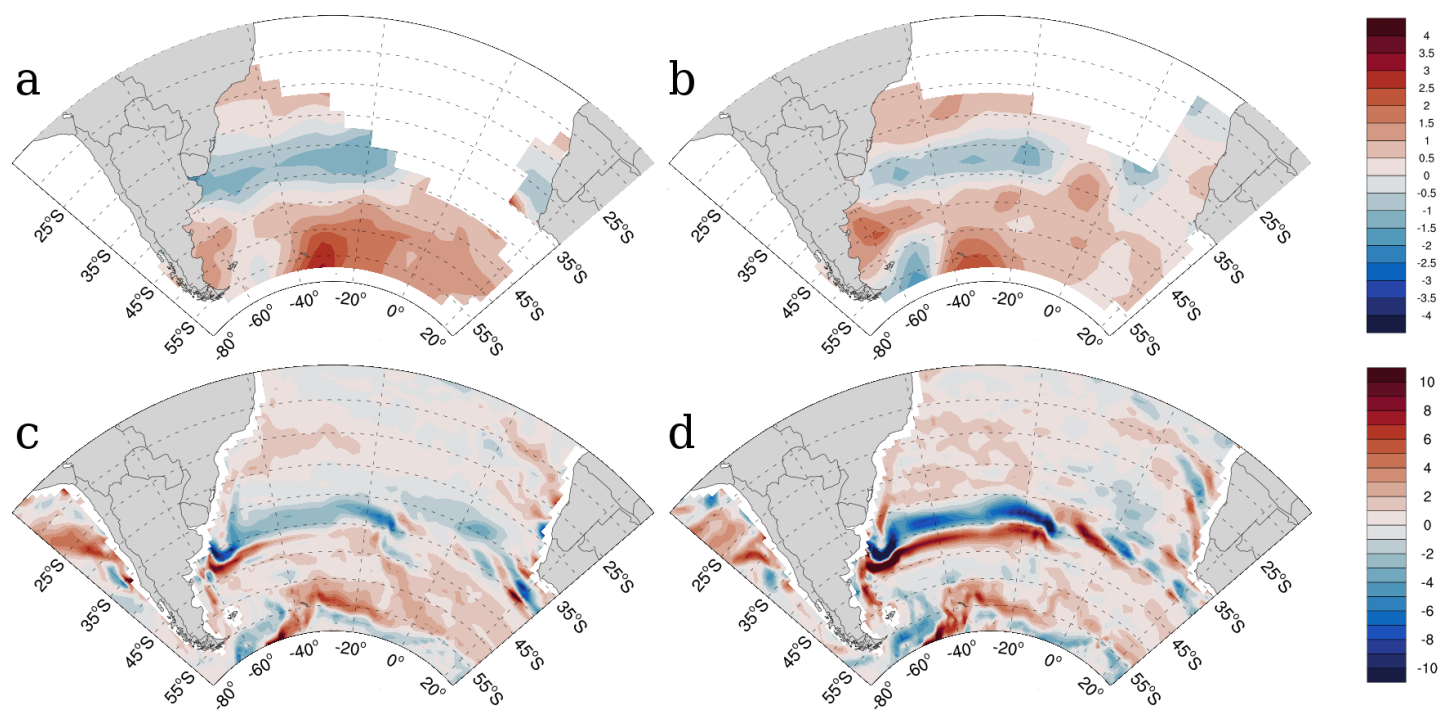

Figure 6.7: RCP8.5 future projected changes in the spatial distribution of SST gradient at genesis time in the (a) summer and (b) winter, and the changes in the mean SST gradient field in the (c) summer and (d) winter. The gradient unit is $10^{-3} \mathrm{~K} \mathrm{~km}^{-1}$ and the field is not plotted where genesis density $<0.2$ cyclones $\left(10^{6} \mathrm{~km}^{2}\right)^{-1}$ month $^{-1}$.

also in future projections (e.g., Grieger et al., 2014, Pontes et al., 2016). However, the drift of the South Atlantic SST gradient does not explain completely the observed changes in genesis and track density in the South Atlantic, as also found by Reboita et al. (2018).

Changes in the distribution of low-level parameters at the time of genesis are shown in Fig 6.8. Low-level integrated humidity presents a general increase in all South Atlantic domain, particularly equatorward of $35^{\circ} \mathrm{S}$ (Figs $6.8 \mathrm{a}$ and b). There is a large positive anomaly of humidity associated to the development of cyclones in the LA PLATA region in the summer. In the winter, there is also a positive humidity anomaly in the LA PLATA and SE-BR regions. The increase in the low-level humidity in the future projection could be related to the positive genesis anomalies in the LA PLATA region, although this response is not observed in SE-BR region, where the low-level moisture also increases. It is more probable that the changes in low-level humidity are related to the intensification of the LA PLATA and SE-BR cyclones, through latent heat release (Held and Soden, 2006).

The static stability distribution at the time of genesis shows an overall pattern of increase in the future projection (not shown), as also reported by other studies (Geng and Sugi, 2003; O'Gorman, 2010). However, the conditional stability distribution at the time of genesis presents a decrease of stability in the LA PLATA region in the summer, which 

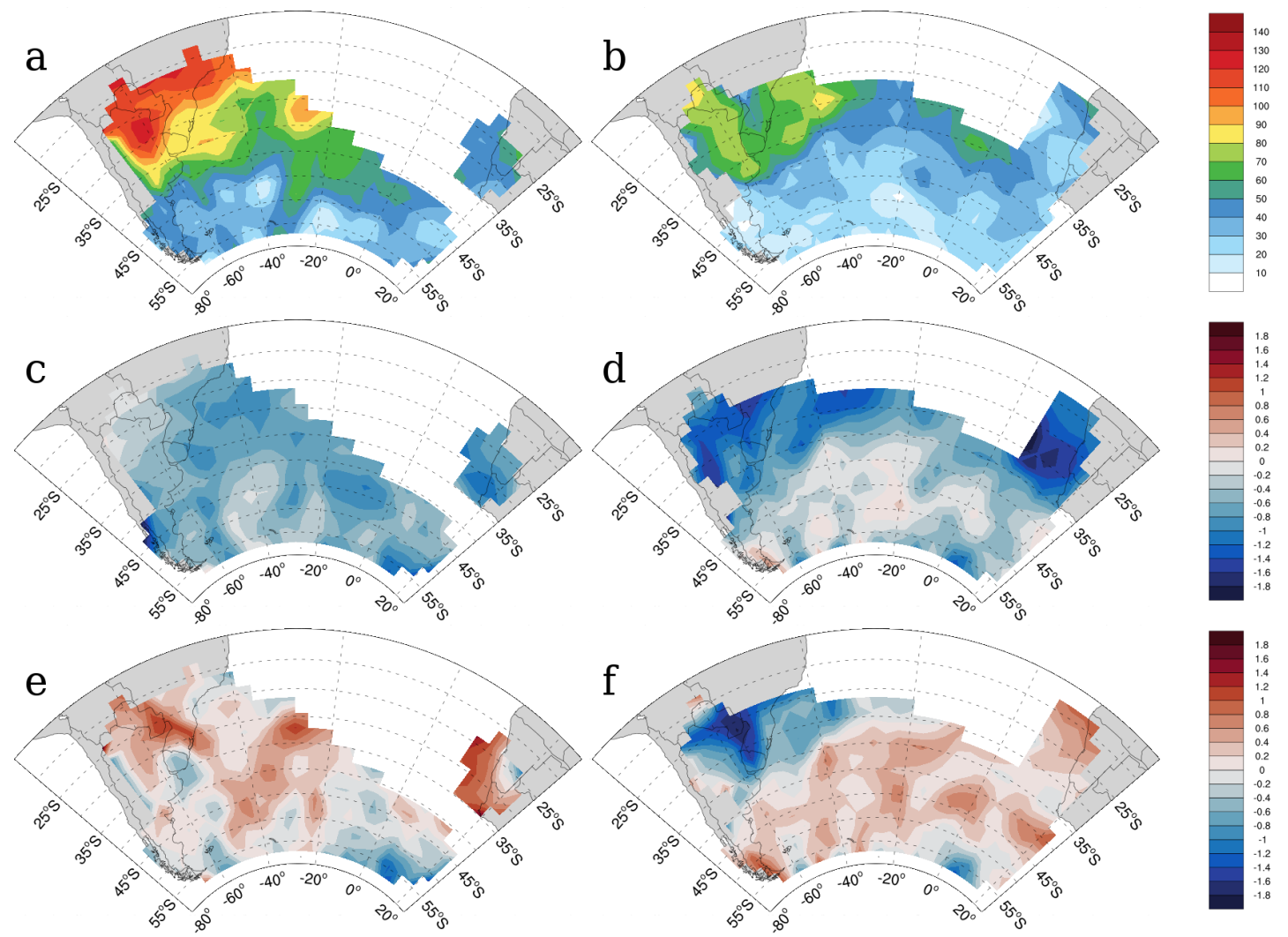

Figure 6.8: RCP8.5 future projected changes in the spatial distribution of the integrated humidity at lower-level $\left(\mathrm{kg} \mathrm{kg}^{-1}\right)$ at the genesis time in the (a) austral summer and (b) winter; $\partial \theta / \partial p\left(10^{-2} \mathrm{KhPa}^{-1}\right)$ at the genesis time in the (c) summer and (d) winter, and; $\partial \theta_{e} / \partial p\left(10^{-2} K h \mathrm{~Pa}^{-1}\right)$ at the genesis time in the (e) summer and (f) winter. The fields are not plotted where genesis density $<0.2$ cyclones $\left(10^{6} \mathrm{~km}^{2}\right)^{-1} \mathrm{month}^{-1}$.

may be related to the increase of low-level moisture (Fig $6.8 \mathrm{a}$ ) and to the increase in the genesis at this location.

Figures $6.9 \mathrm{a}$ and $\mathrm{b}$ show the changes of the upper-level jet speed distribution at the time of genesis in the summer and winter, respectively. There is an increase in the speed of the jet stream in the LA PLATA and SE-BR regions in both seasons. An intense upper-level jet is more restricted to the LA PLATA region in the summer, while during the winter it also affects the SE-BR region. Over the ARG region, the jet seems to slow down, what may be a consequence of the poleward shift of the polar upper-level jet (Kidston and Gerber, 2010; Simpson and Polvani, 2016). The RCP8.5 projects an upperlevel jet shift to the south, and a strengthening of the subtropical jet, particularly in the winter (Fig 6.10 b). Climatologically, the upper-level jet is centered between $50^{\circ} \mathrm{S}$ and $40^{\circ} \mathrm{S}$ in the summer, without strong speeds above South America between $40^{\circ} \mathrm{S}$ and $30^{\circ} \mathrm{S}$, 
in NCEP-CFSR (not shown) and also in HadGEM2-ES historical experiment (Fig B.4c). HadGEM2-ES RCP8.5 projets an intensification of the equatorward flank of the jet between $40^{\circ} \mathrm{S}$ and $30^{\circ} \mathrm{S}$ along with a southward shift of the poleward flank. Lee (2014) also found an intensified subtropical jet in the South Atlantic sector in the summer as well as in the South Pacific. Although Lee (2014) discussed that the split jet pattern in the summer may be led by the GCM biases, other works using multi-model means also found the occurrence of a summer split jet in future projections. In the winter, there is a strengthening of the upper-level jet in the subtropical latitudes that may be a consequence of broadening (Simpson et al., 2014; Simpson and Polvani, 2016).

The PV at $300 \mathrm{hPa}$ associated with cyclogenesis is presented in Figs 6.9 and d, for the summer and winter. As long as the PV values are multiplied by -1 , positive values mean cyclonic anomalies. In the summer, there is an increase in the PV at $300 \mathrm{hPa}$ associated with cyclogenesis equatorward of $40^{\circ} \mathrm{S}$. In the winter, there is a general increase in the PV. The changes in the PV distribution are also observed in the HadGEM2-ES RCP8.5 mean. The PV gradient in the summer presents a poleward shift, but with an increase equatorward of $45^{\circ} \mathrm{S}$. The poleward shift can be explain by the shift in the meridional temperature gradient whereas the increase in the PV northward can be a consequence of the enhanced warming in the upper-levels of the tropospere, which is larger close to the tropics (e.g. Held, 1993; Wilcox et al., 2012). In the winter, as with the summer, there is a poleward shift in the PV gradient at $300 \mathrm{hPa}$. However, changes in the mean PV at 300 $\mathrm{hPa}$ in the future projection do not explain the increase of cyclonic PV associated with the genesis.

\subsection{Cyclones structure}

In this section, the cyclone composites of HadGEM2-ES RCP8.5 experiment are presented. The intensity threshold used to select the $30 \%$ strongest systems of each region in each season is shown in Table 6.2. The threshold increased for the LA PLATA and SE-BR regions, in agreement with the intensification observed in Fig 6.3 .

Analogously to sections 4.3.1 and 5.4, the composites before, at the time of genesis and after it were performed to the fields of MSLP, $\theta_{e}$ at $925 \mathrm{hPa}, \mathrm{RH}$ and $\mathrm{PV}$ at $300 \mathrm{hPa}$, temperature advection and wind at $850 \mathrm{hPa}$, geopotential height at $500 \mathrm{hPa}$, VIMT and 

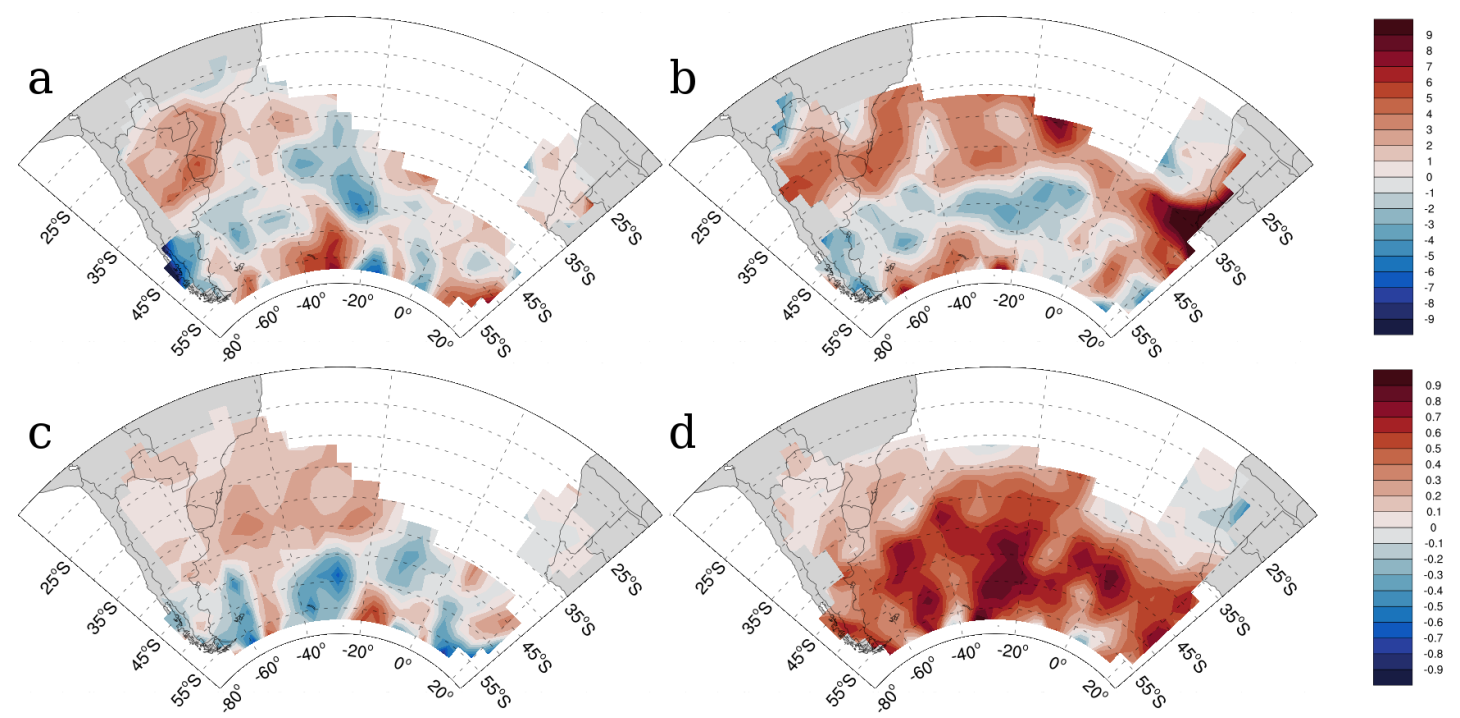

Figure 6.9: RCP8.5 future projected changes in the spatial distribution of upper-level jet $\left(\mathrm{m} \mathrm{s}^{-1}\right)$ in the austral (a) summer and (b) winter; and the potential vorticity at $300 \mathrm{hPa}(\times-1$ $P V U)$ in the (c) summer and (d) winter at the time of genesis. The field distribution at genesis and at the maximum intensity are not plotted where genesis and track density were $<0.2$ cyclones $\left(10^{6} \mathrm{~km}^{2}\right)^{-1} \mathrm{month}^{-1}$ and $<0.5$ cyclones $\left(10^{6} \mathrm{~km}^{2}\right)^{-1}$ month ${ }^{-1}$, respectively.
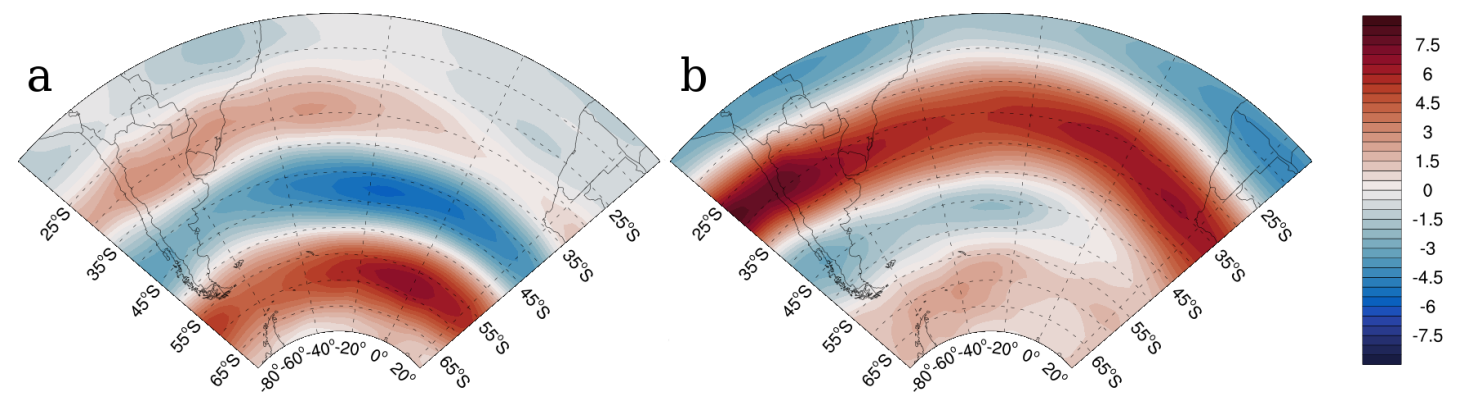

Figure 6.10: RCP8.5 future projected changes in mean upper-level jet speed $\left(\mathrm{m} \mathrm{s}^{-1}\right)$ in the austral (a) summer and (b) winter.

Table 6.2 - Intensity threshold (scaled by $-1 \times 10^{-5}$ ) applied to select the $30 \%$ most intense cyclones of each defined genesis region in the summer and winter and the number of cyclones used to compute each composite in the HadGEM2-ES RCP8.5 analysis.

\begin{tabular}{ccccc}
\hline \hline & \multicolumn{2}{c}{ DJF } & \multicolumn{2}{c}{ JJA } \\
\hline & threshold & number & threshold & number \\
SE-BR & 8.2 & 41 & 10.0 & 45 \\
LA PLATA & 8.3 & 50 & 9.8 & 70 \\
ARG & 7.7 & 149 & 8.1 & 126 \\
SE-ESAO & 8.0 & 90 & 8.9 & 150 \\
\hline \hline
\end{tabular}



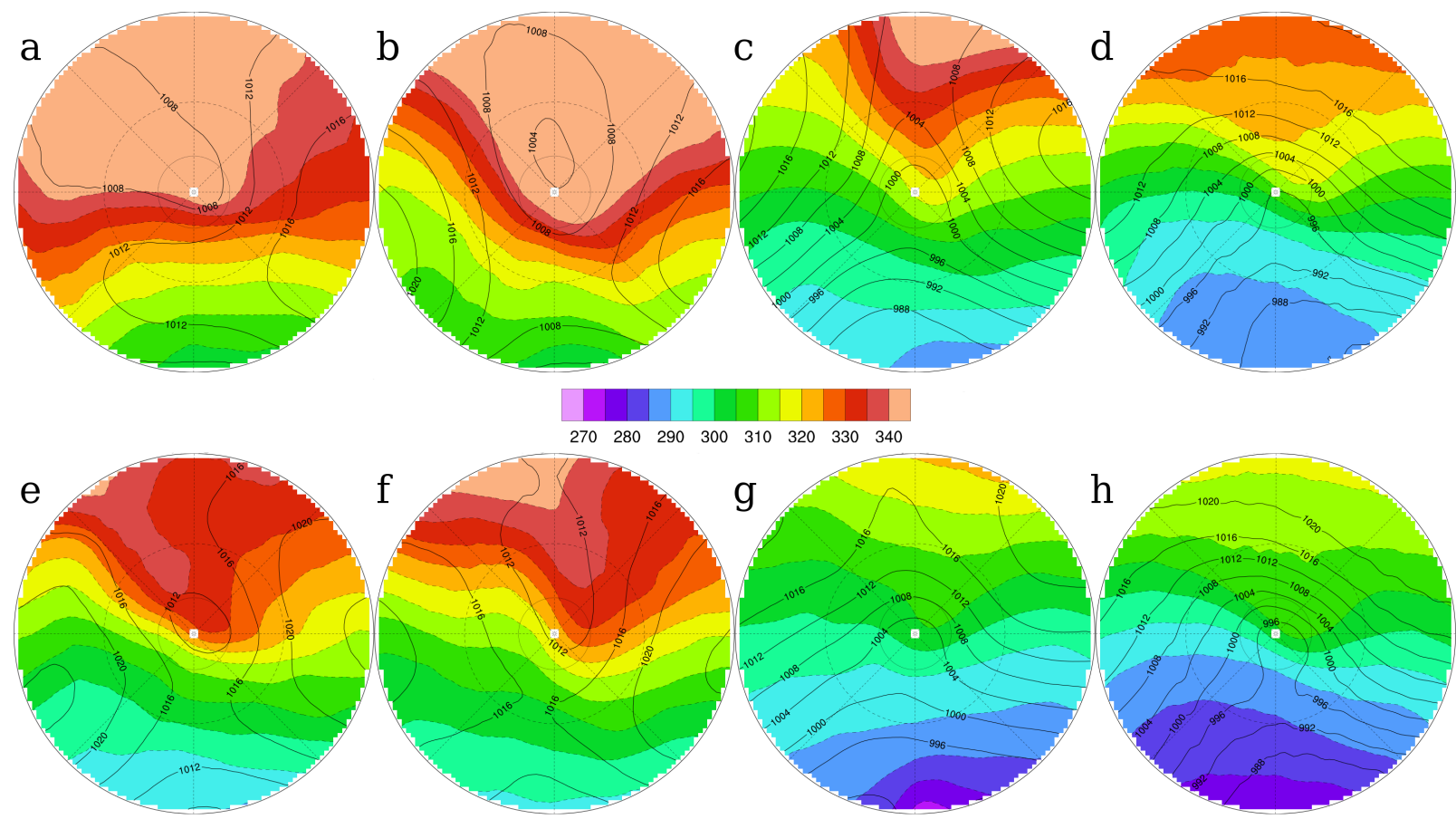

Figure 6.11: Composites of mean equivalent potential temperature $\left(\theta_{e}\right)$ at $925 \mathrm{hPa}(\mathrm{K}$; shaded) and MSLP ( $\mathrm{hPa}$; black line) from different genesis regions in the (a-d) summer and (f-g) winter : (a,e) SE-BR, (b,f) LA PLATA, $(c, g)$ ARG and (d,h) SE-SAO.

VIMFC $(925 \mathrm{hPa}-700 \mathrm{hPa})$, and upper-level divergence and geopotential at $200 \mathrm{hPa}$. In order to not be repetitive, the discussion is focused in the cyclone structure changes between the future projection and historical periods.

\subsubsection{General structure of cyclone genesis}

The composite structures of $\theta_{e}$ at $925 \mathrm{hPa}$ and MSLP at the time of genesis are shown in Fig 6.11. In all composites there is an increase in $\theta_{e}$ as consequence of a warmer and moister low-level troposphere in the future projection (Held, 1993; Held and Soden, 2006). This promotes a warmer air flowing at the warm sector of the cyclone. However, the temperature and MSLP structures are the same obtained for the HadGEM2-ES historical period, as well as the RH and PV at the $300 \mathrm{hPa}$ structure (Fig,C.1).

\subsubsection{Cyclone structure evolution during the genesis}

Figures $6.12 \mathrm{a}-\mathrm{c}$ show the temperature advection and winds at $850 \mathrm{hPa}$, and the geopotential height at $500 \mathrm{hPa}$ for the SE-BR cyclones in the winter. The SE-BR cyclone presents larger changes in the winter composite than in the summer, thus only this season 
is shown here (the summer composites are available in Appendix C, Fig C.2. The SE-BR cyclone presents a stronger warm advection before the genesis time and both warm and cold advections increase during the genesis (Figs $6.12 \mathrm{~b}$ and c) when compared to historical composites. In the winter, the geopotential wave at $500 \mathrm{hPa}$ is longer than in the historical composite, probably due to the thermal advection at low-level and the enhance of divergence at upper-level (Figs 6.12s-i). This coupling between upper and low levels mechanisms enhance the VIMFC, which is larger in the winter and exists since the time before genesis (Figs.6.12d-f). The summer composites also present a large VIMFC, although the winter composites present more changes when compared with the historical ones (Figs C.2d-f).

Figure 6.13 shows the cyclone composites for the LA PLATA region in the summer, when there is an increase in the genesis density (Fig.6.1k) and the cyclone structure presents larger changes in relation to the historical period (the winter composites are available in Appendix C, Fig C.3).. As with the SE-BR composites, the LA PLATA cyclones show a strong low-level thermal advection and upper-level divergence in both seasons (Figs.6.13 and 6.12). As with SE-BR winter cyclones, the geopotential wavelength is larger in the winter when compared to the historical composites. However, large differences for the LA PLATA cyclones remain in the summer composites, where the VIMT structure shows a moisture transport from the north toward the cyclone center, and an enhanced VIMFC at $12 \mathrm{~h}$ after the time of genesis (Figs 6.13). This feature may indicate a strong warm conveyor belt, giving support to the intensification of the cyclone. The warm conveyor belt is associated with the precipitation within the cyclone (Browning and Roberts, 1996).

The ARG and SE-SAO cyclone composites do not present significant changes when compared to historical, despite an increase in the thermal advection in both seasons. In fact, the thermal advection is stronger in RCP8.5 future projection for all genesis regions, particularly the warm advection. The composites not presented in this Chapter are in Appendix C.

\subsection{Discussion and Conclusion}

HadGEM2-ES RCP8.5 future projection shows a general decrease of approximately $10 \%$ of cyclogenesis in the South Atlantic domain in both seasons. The only genesis region that presents a slight increase is the LA PLATA (6.1 and 3.6\%, in the summer and winter, 

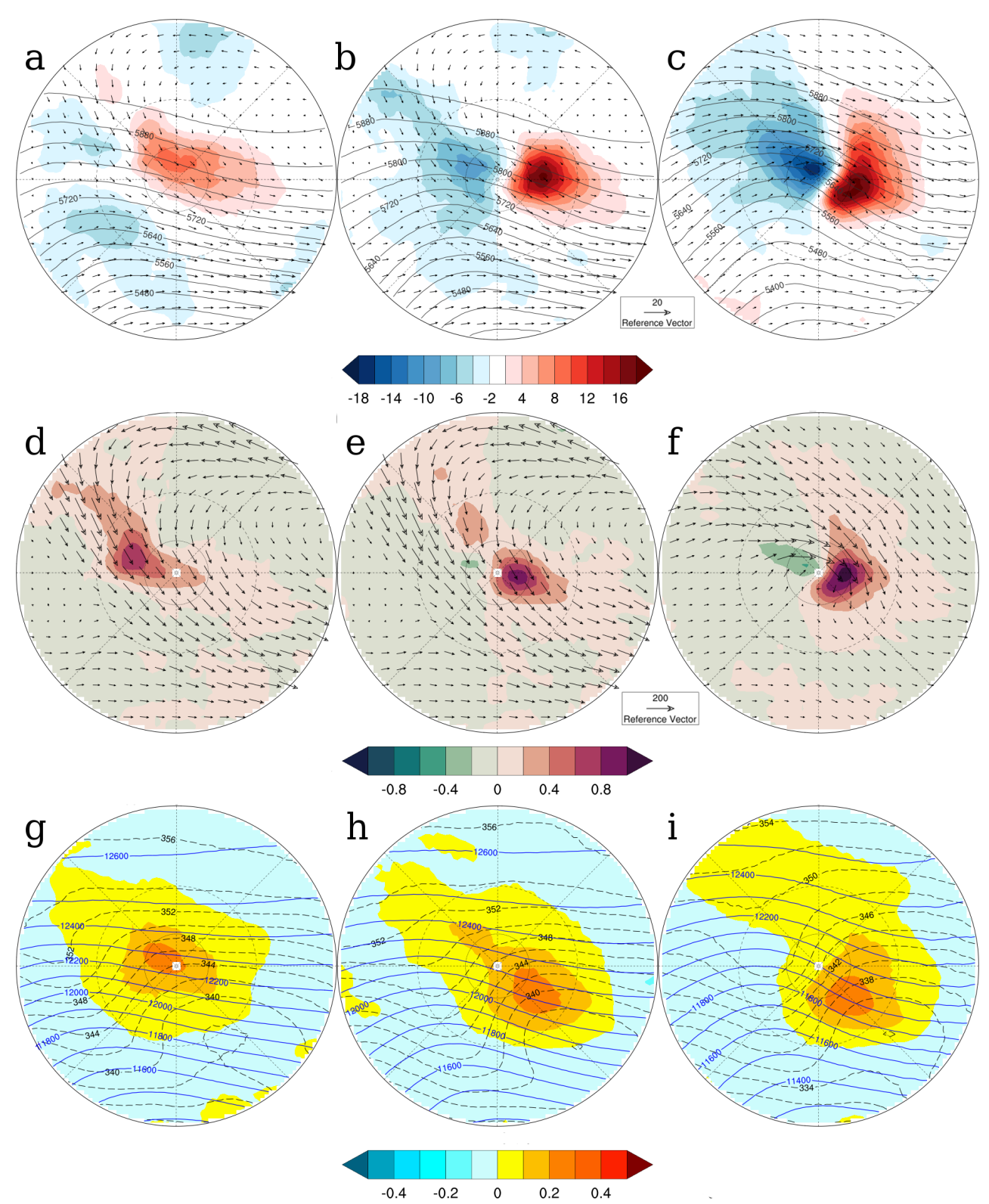

Figure 6.12: Composites of the SE-BR cyclones in the winter, for the fields: (a-c) temperature advection at $850 \mathrm{hPa}\left(10^{-5} \mathrm{~K} \mathrm{~s}^{-1}\right.$; shaded), geopotential height at $500 \mathrm{hPa}$ (gpm; black line) and winds at $850 \mathrm{hPa}\left(\mathrm{m} \mathrm{s}^{-1}\right)$; (d-f) vertically integrated moisture flux convergence $\left(10^{-3} \mathrm{~kg} \mathrm{~m}^{-2} \mathrm{~s}-1\right.$; shaded $)$ and moisture transport $\left(\mathrm{kg} \mathrm{m}^{-1} \mathrm{~s}^{-1}\right.$; arrows $)$ and at low level (925 - $700 \mathrm{hPa})$, and; (g-i) potential temperature ( $K$; black line), geopotential height (gpm; blue line) and divergence of mass $\left(s^{-1}\right.$; shaded) at 200 $\mathrm{hPa}$. Composites $(\mathrm{a}, \mathrm{d}, \mathrm{g})$ at 12 hours before the time of genesis; $(\mathrm{b}, \mathrm{e}, \mathrm{h})$ at the time of genesis, and; (c,f,i) at 24 hours after the time of genesis. 

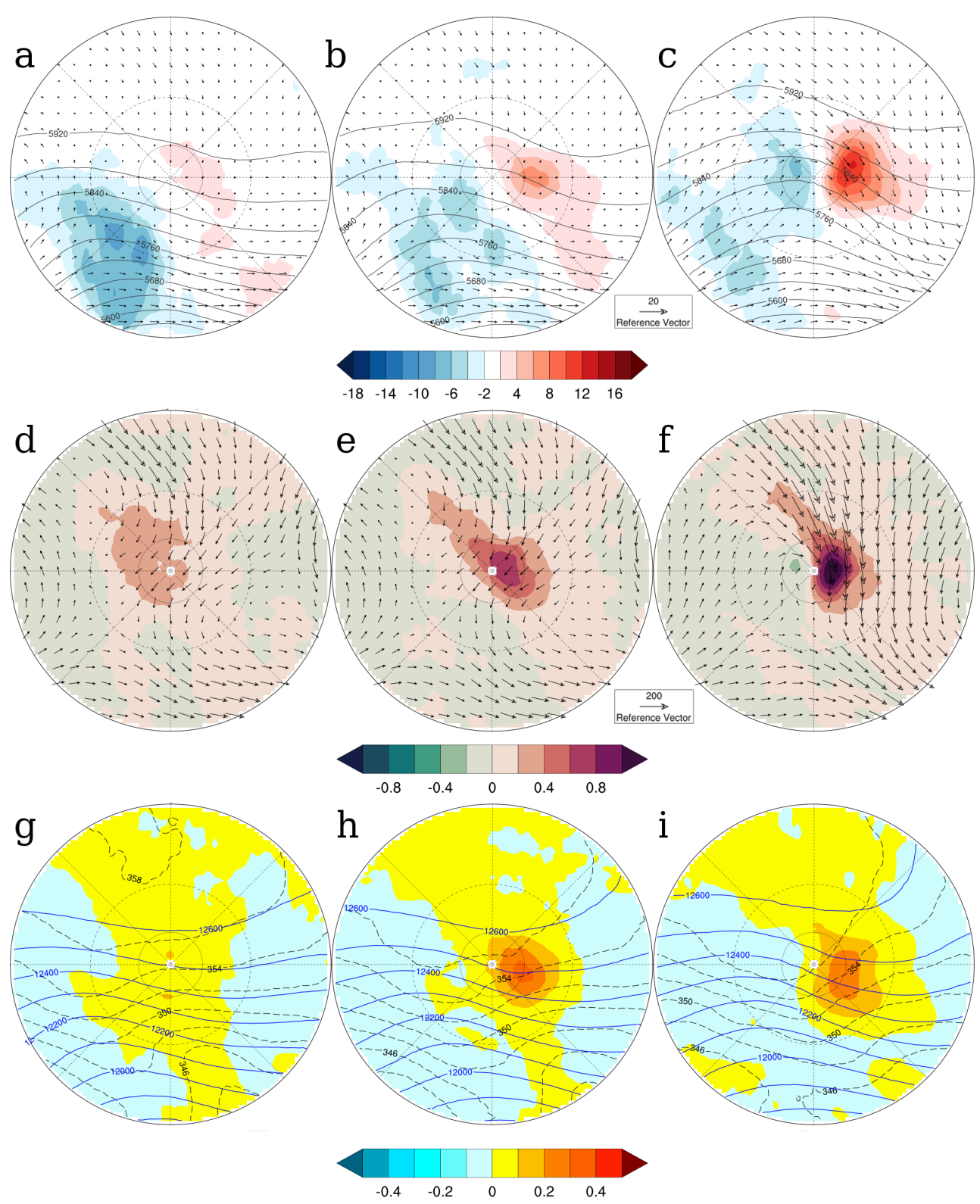

Figure 6.13: As in Fig 6.12 but for the composites of LA PLATA cyclones in the summer. 
respectively). In agreement with previous studies, there is a poleward shift of the storm track indicated by a reduction of track density between $35^{\circ} \mathrm{S}$ and $55^{\circ} \mathrm{S}$ and an increase southward of this zone (Figs 6.2 and $\mathrm{d}$ ). However, it is important to look at future changes in the genesis and track densities with caution, since for some locations they are, sometimes, smaller than the biases. In the case of increased cyclogenesis in the LA PLATA region, only changes in the summer are larger than the bias.

The decrease in the number of cyclones and the poleward shift of the storm track are well documented (Geng and Sugi, 2003; Bengtsson et al., 2006; Pinto et al., 2007; Ulbrich et al., 2009; Fyfe, 2003, Mizuta, 2012). Reboita et al. (2018) found a reduction of $10.4 \%$ over the Southwestern Atlantic Ocean, using the HadGEM2-ES RCP8.5 (2070-2098). The reduction of cyclone frequency is related to the poleward shift of the storm track, once the increase in high-latitudes covers a smaller area than the mid-latitudes (Bengtsson et al. 2006; Lee, 2014).

Many studies have tried to explain the poleward shift of the storm track and upperlevel jet due to climate change (e.g., Geng and Sugi, 2003; Wittman et al., 2007; Wilcox et al. 2012). The called "expansion of the tropics" may be a response of the mean zonal circulation to the global warming (Lu et al., 2008). According to these authors, the increase in the static stability in the subtropics and mid-latitudes suppresses the baroclinic eddy growth in the equatorward flank of the polar jet and pushes the transient activity poleward. The shift in the eddy activity, in turns, pushes the polar jet (eddy-driven) southward, resulting in the expansion of the Hadley Cell and the southward shift of the mid-latitude jet.

The stratospheric circulation and ozone also have a large impact in the tropospheric upper-level position (e.g., Wittman et al., 2007; Wilcox et al., 2012). Wilcox et al. (2012) showed that the increase in the stratospheric wind shear can induce a poleward shift of the upper-level jet in the troposphere. The stratosphere wind shear may increase with the strengthening of the meridional temperature gradient due to the warming in the tropical upper-troposphere and cooling in the polar low-stratosphere (Mizuta, 2012). This mechanism may be associated with the increase of Rossby Wave Breaking in mid-latitudes in future projections (Wittman et al., 2007; Wilcox et al., 2012; Ndarana et al., 2012).

The poleward shift pattern is better defined in the summer, with an increase in the track density southward of $55^{\circ} \mathrm{S}$ (Figs 6.2 c). The most interesting change in this season is 
the genesis increase (larger than model bias) in the LA PLATA region. This change may be addressed, at first, to the increase in the warm and moist advection from the tropics. There is evidence of an intensification of the thermal advection and moisture transport in the cyclone composites (Figs 6.13a-f). Also, the spatial distribution of low-level humidity at the time of genesis reveals a large amount of moisture above the continent, at $30^{\circ} \mathrm{S}$ (Figs.6.8 ). These factors may influence the cyclone development in two ways: decreasing the vertical stability before genesis, and providing heating fluxes, such as latent heat release, during the cyclone development and intensification (e.g., Vera et al., 2002).

Also, the increase in the upper-level jet at $30^{\circ} \mathrm{S}$ may increase the baroclinicity, reflecting in the increased mean growth rate in this location (Fig 6.6 $)$. The thermal wind balance shows that the wind shear is inversely correlated with the Coriolis parameter, thus the meridional temperature gradient does not need to be as intense as in higher latitudes to promote large wind shear. The strengthening of the equatorward flank of the upper-level jet between $40^{\circ} \mathrm{S}$ and $30^{\circ} \mathrm{S}(\mathrm{Fig}, 6.9 \mathrm{a})$ may be a consequence of the increased meridional temperature gradient at the tropopause by the troposphere (stratosphere) warming (cooling), as discussed above (Mizuta, 2012).

The defined subtropical jet acting over South America may also be a consequence of a future projected split in the summer jet (Fig, 6.10a). Some works have shown an increase in the occurrence of the split jet in the Southern Hemisphere in all seasons (Bengtsson et al., 2006; Simpson et al. 2014; Lee, 2014), whereas in the present climate it usually happens only in the winter (e.g., Hoskins and Hodges, 2005). However, GCMs present problems in representing the split jet mechanism in the current climate and, thus, may also present some issues simulating it in the future projections (Lee, 2014).

The cyclogenesis increasing in the LA PLATA region could be linked with the increase in the austral precipitation over Southern Brazil, Northern Argentina and Uruguay in the future projections, already reported by several studies (Vera et al., 2006; Marengo et al., 2010; Seth et al., 2010; Jones and Carvalho, 2013; IPCC, 2013). Seth et al. (2010), using 9 GCM (CMIP3), studied the changes in the South American Monsoon System (SAMS) and found a southward shift of the SACZ and SASH in the summer. These authors also found a strengthening in the SALLJ, supplying moisture into the farther south of South American continent during the summer. The increase in the low-level southward transport of moisture and warm is in agreement with our results. 
Chapter

\section{Dynamical Downscaling}

\subsection{NCEP-CFSR simulation}

The "control" simulation using the NCEP-CFSR (ExpCFSR, hereafter) is evaluated in order to assess the ability of the regional model in representing the cyclones in the South Atlantic. For large-scale fields and precipitation, the evaluation was performed using NASA-MERRA and GCPC, besides the NCEP-CFSR. The cyclone representation was evaluated using the tracking and cyclone diagnostics from the NCEP-CFSR. However, the reanalysis was interpolated to the same grid of the regional experiment to avoid differences regarding the tracking domain and the filter method. ExpCFSR simulated a period of 15 years, from 1991 to 2005.

\subsubsection{Evaluation}

The evaluation of the ExpCFSR was held using the mean temperature at $2 \mathrm{~m}$ above the ground, winds at 250 and $850 \mathrm{hPa}$ and precipitation, for the summer and winter. Some of the other fields are found in the Appendix $\mathrm{D}$.

In the summer, the ExpCFSR presents high surface temperatures on the continent, northward of $30^{\circ} \mathrm{S}$, with a maximum over Paraguay (Fig.7.1). This high temperature center is also presented in the NCEP-CFSR and NASA-MERRA, and is reported in other studies (e.g., Solman et al., 2013). However, it is stronger in the ExpCFSR and NASAMERRA rather than in the NCEP-CFSR. The temperature in the northern portion of the domain is less intense in the NCEP-CFSR than in the ExpCFSR. In Central Argentina, however, the ExpCFSR presents lower temperatures than the reanalysis, especially NASAMERRA. On the ocean, ExpCFSR has lower temperature, probably due to the absence of 
ocean-atmosphere coupling. In the winter, the ExpCFSR still simulates high temperatures in the tropics, but lower than the NASA-MERRA ones (Fig.7.2). Still in the winter, the mean surface temperature field from ExpCFSR is closer to the NCEP-CFSR one.

The ExpCFSR is able to represent the mean precipitation pattern over South America (Fig.7.3 and 7.4). In the summer, although the regional model overestimates the tropical precipitation $\left(20^{\circ} \mathrm{S}\right)$ when compared to NCEP-CFSR, it is in agreement with GPCP. The latter is a product derived only from satellite and observed data, and thus, it is more likely to represent reliable precipitation than the reanalysis. In this sense, the similarities between the ExpCFSR and GPCP summer tropical precipitation is an evidence that the regional model is "better" (closer to reality) simulating the precipitation than NCEP-CFSR in this season. However, there is a general underestimation on the ocean, particularly in the SACZ region. The misrepresentation of the oceanic sector of SACZ was reported by da Silva (2018), who showed that most of the microphysics and cumulus parametrizations in WRF were not able to simulate the SACZ precipitation over the ocean. In the winter, there is an underestimation along Uruguayan and Southeastern Argentinian coast related only to GPCP, indicating that it must be a result of the large-scale input rather than regional parametrizations.

The ExpCFSR simulates a weaker SALLJ in the summer than NCEP-CFSR and NASA-MERRA, as one can see through the meridional wind speed at $850 \mathrm{hPa}$ in Fig. 7.5. It can explain the negative temperature biases observed in the ExpCFSR in Central Argentina, as long as the SALLJ transports tropical warm air southward. In the winter, the ExpCFSR presents a SALLJ structure closer to reanalysis, but slightly stronger (Fig. 7.6.).

The regions along the Andes Cordillera present large biases in some locations for all the fields used in the evaluation. At first, ExpCFSR and NCEP-CFSR have distinct topography source, which results in differences up to $500 \mathrm{~m}$ (Fig.7.7 d). It implies in differences in representing mountain peaks over a mountain chain, that can disrupt and shift the circulation. Secondly, differences in cumulus and microphysics parametrizations between the models result in a distinct representation of orographic precipitation. Usually, regional models have problems representing topographically-induced rainfall over the Andes, what directly affects the temperature distribution over South America (e.g., Chou et al., 2012; Solman et al., 2008). 

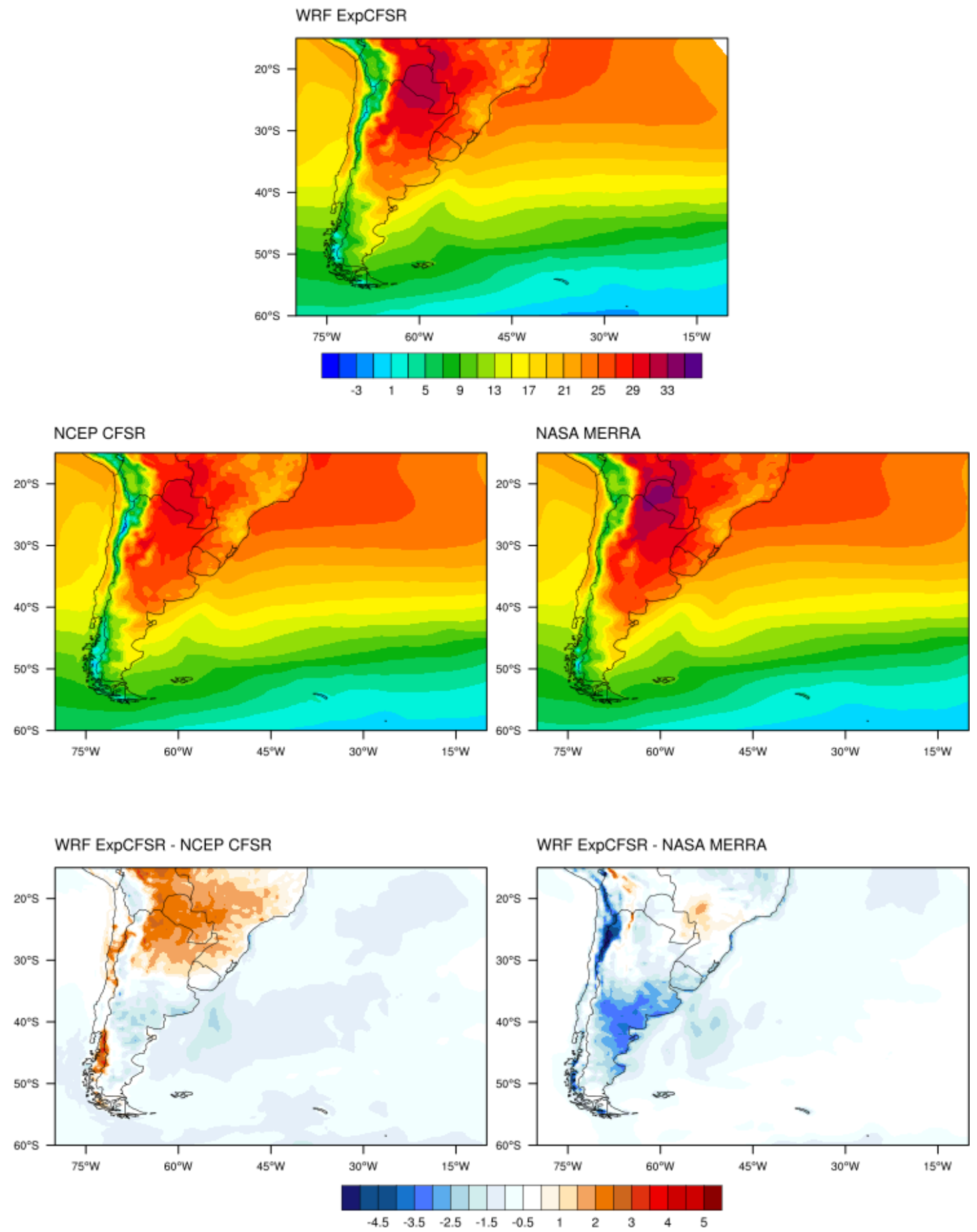

Figure 7.1: Mean temperature at $2 \mathrm{~m}\left({ }^{\circ} \mathrm{C}\right)$ distribution in austral summer for the ExpCFSR, NCEP-CFSR, NASA-MERRA; and the differences ExpCFSR - NCEP-CFSR and ExpCFSR - NASA-MERRA. The climatological mean comprises the 1991-2005 period. 

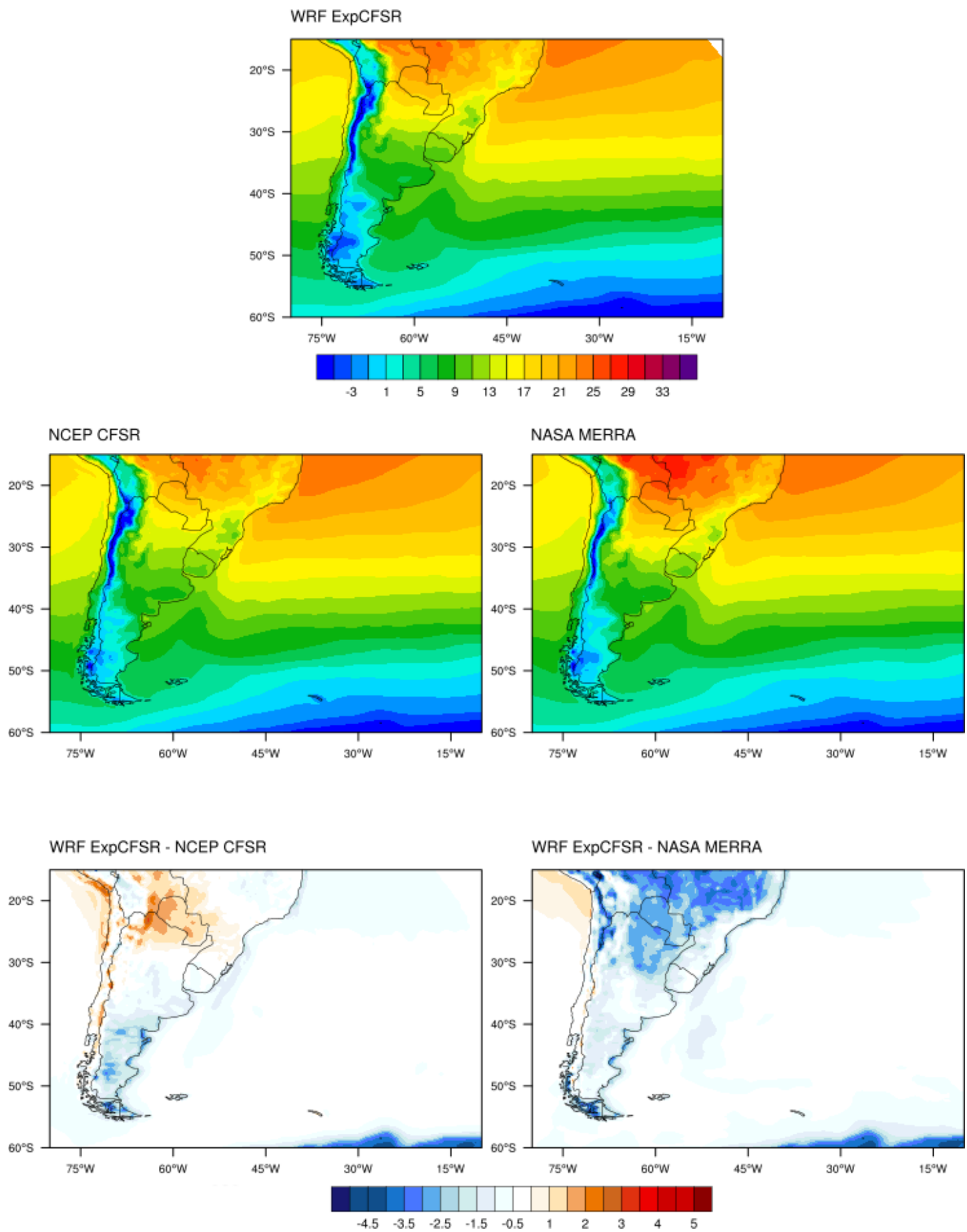

Figure 7.2: As in Fig, 7.1 but for the winter. 

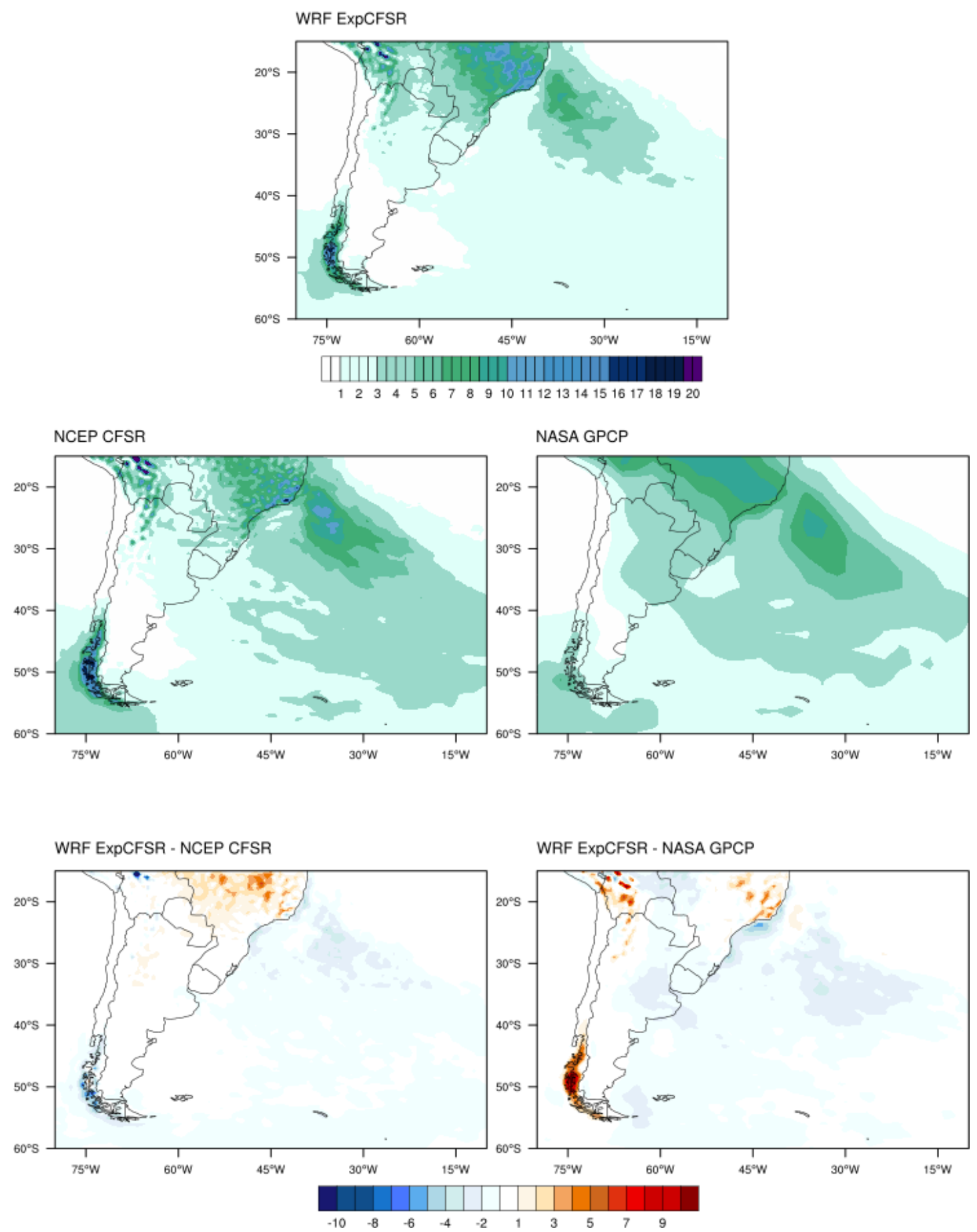

WRF ExpCFSR - NASA GPCP

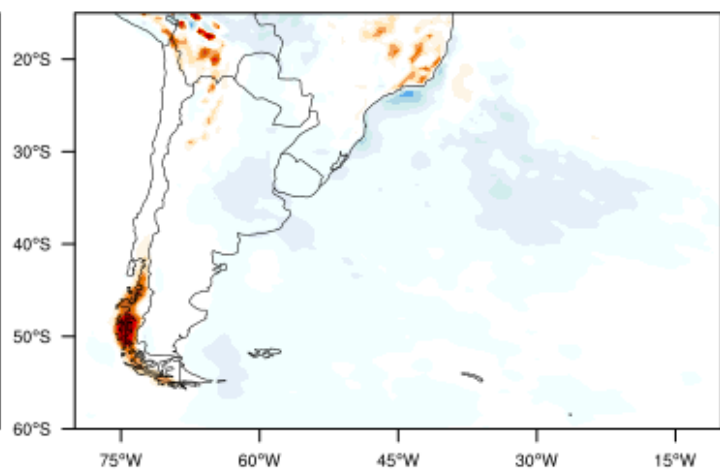

Figure 7.3: As in Fig.7.1 but for the mean precipitation $\left(m m d a y^{-1}\right)$ distribution in the austral summer. 

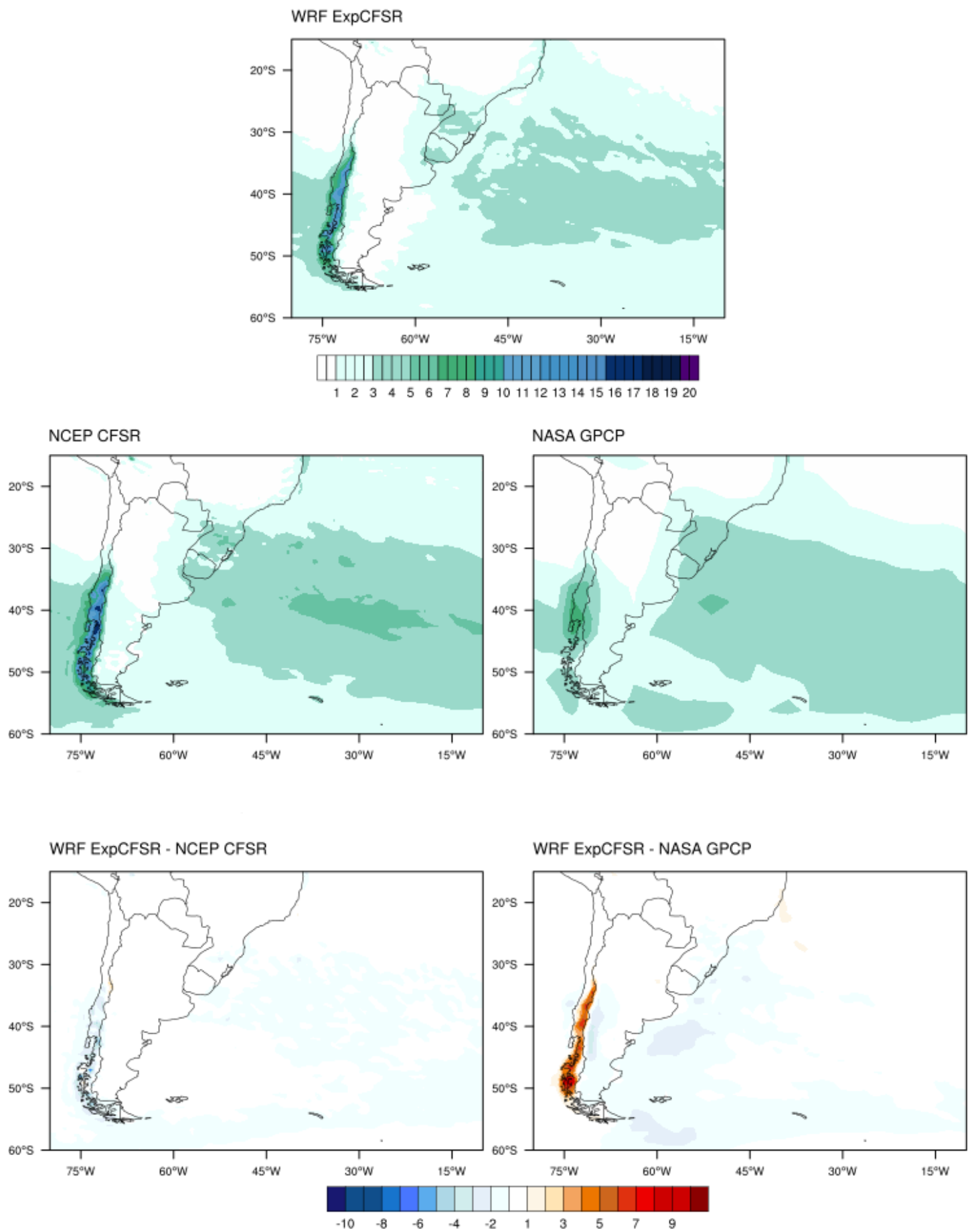

Figure 7.4: As in Fig 7.1 but for the mean precipitation $\left(m m d a y^{-1}\right)$ distribution in the winter. 

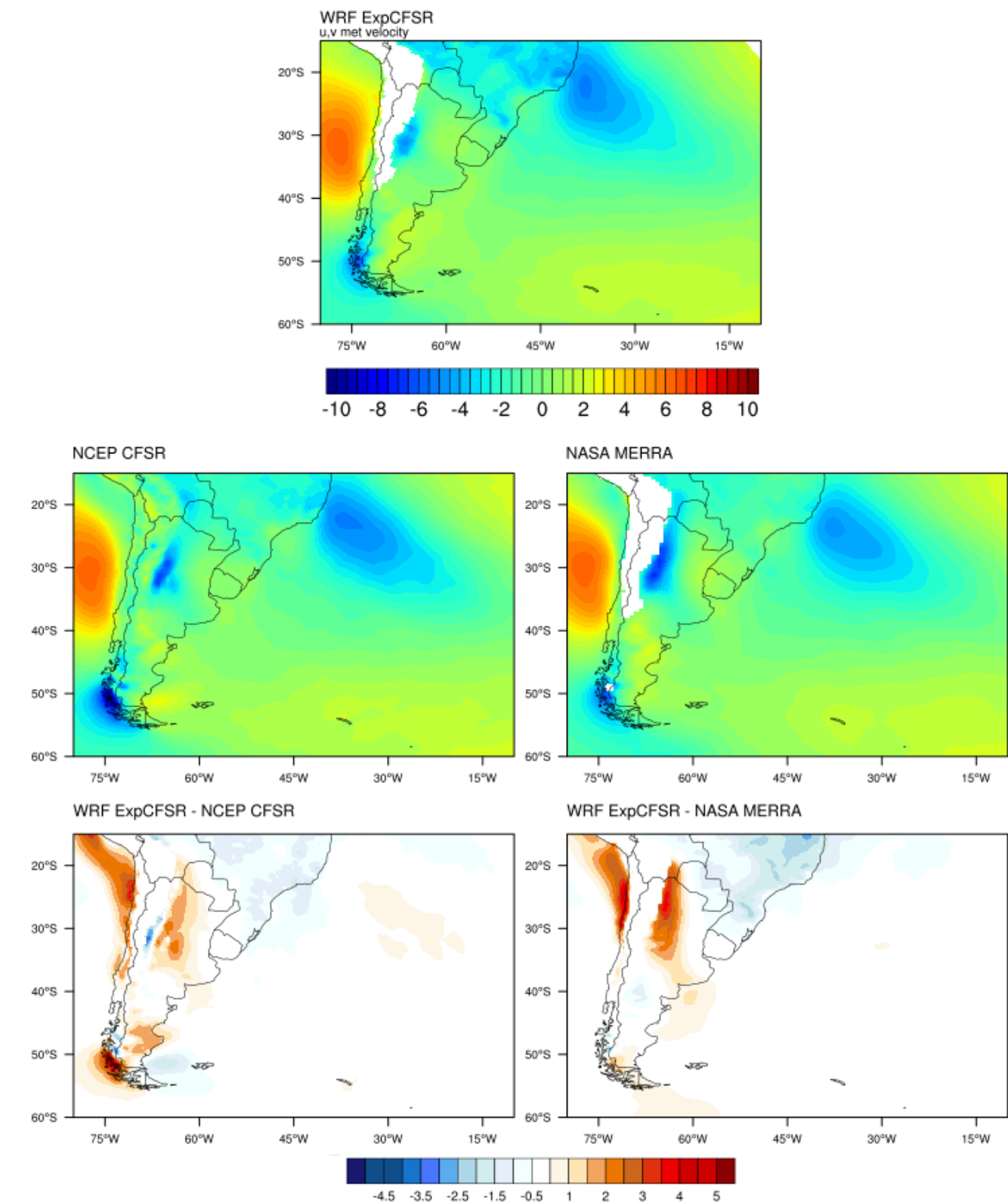

WRF EXPCFSR - NASA MERRA

Figure 7.5: As in Fig 7.1 but for the mean meridional wind speed at $850 \mathrm{hPa}\left(\mathrm{ms}^{-1}\right)$ in the austral summer. 

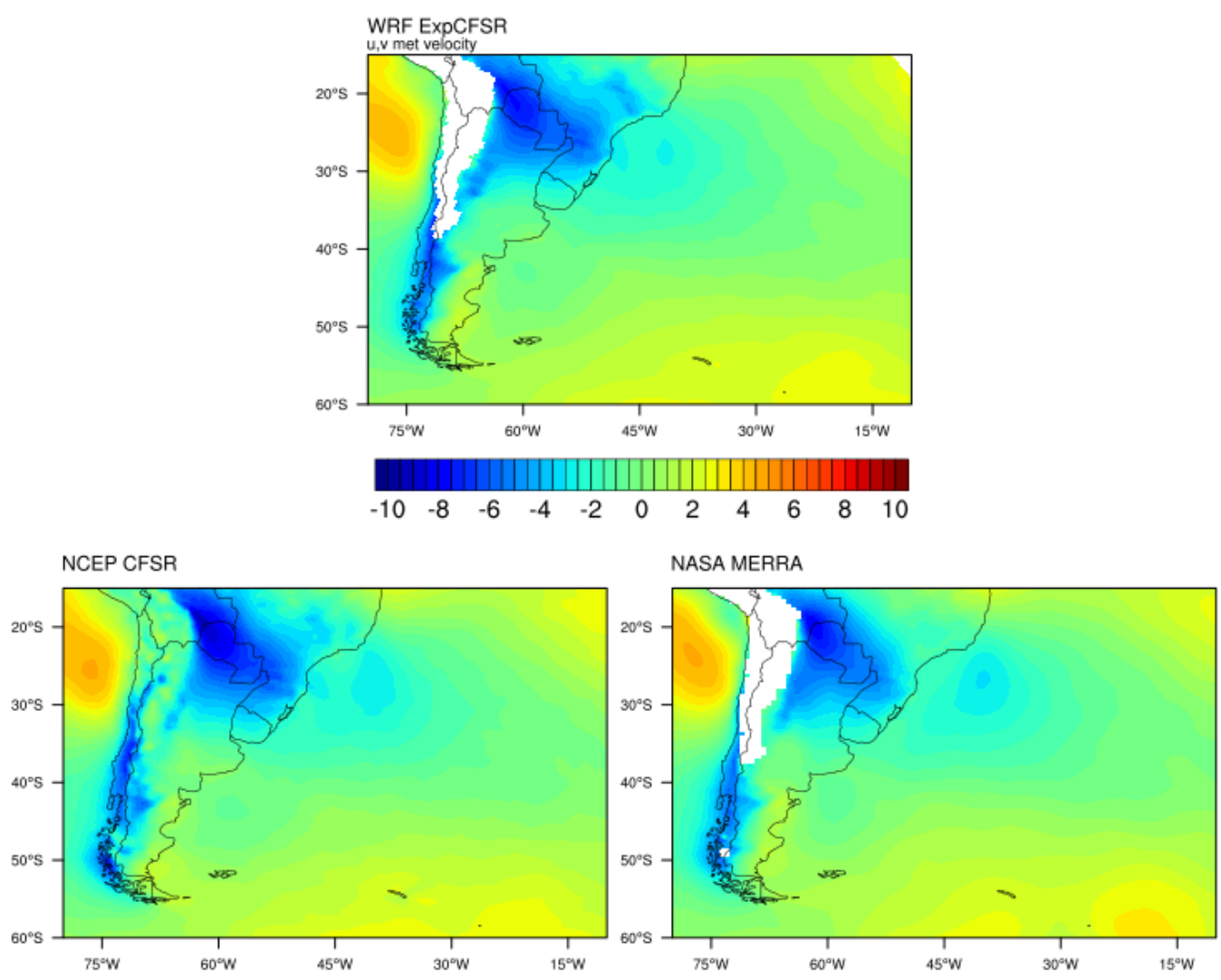

WRF ExpCFSR - NCEP CFSR

WRF EXPCFSR - NASA MERRA
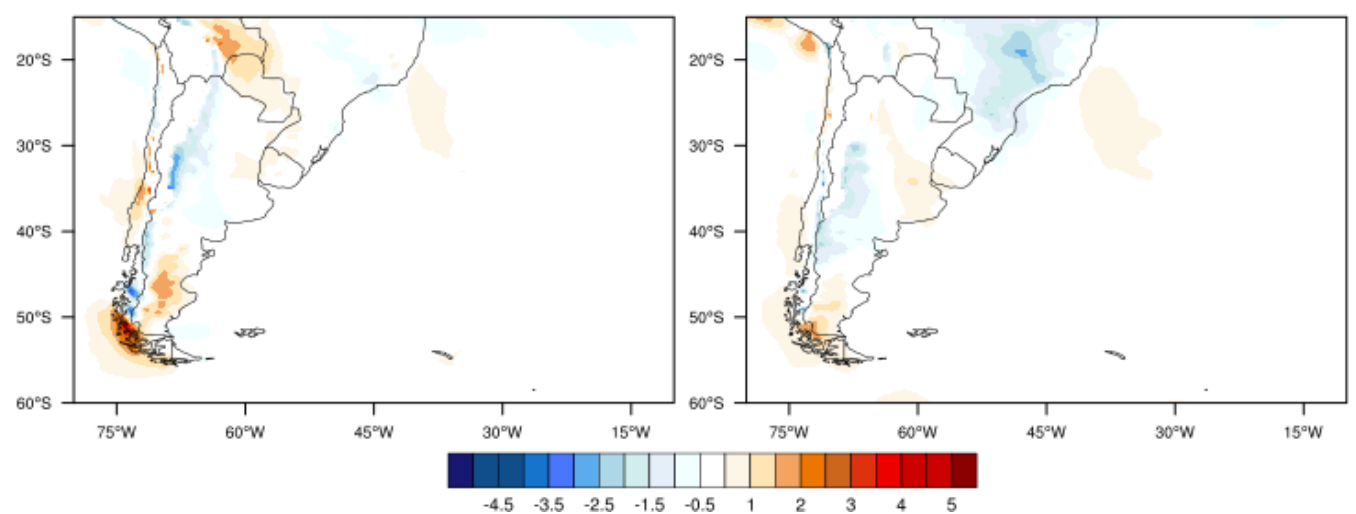

Figure 7.6: As in Fig 7.1 but for the mean meridional wind speed at $850 \mathrm{hPa}\left(\mathrm{ms}^{-1}\right)$ in the winter. 

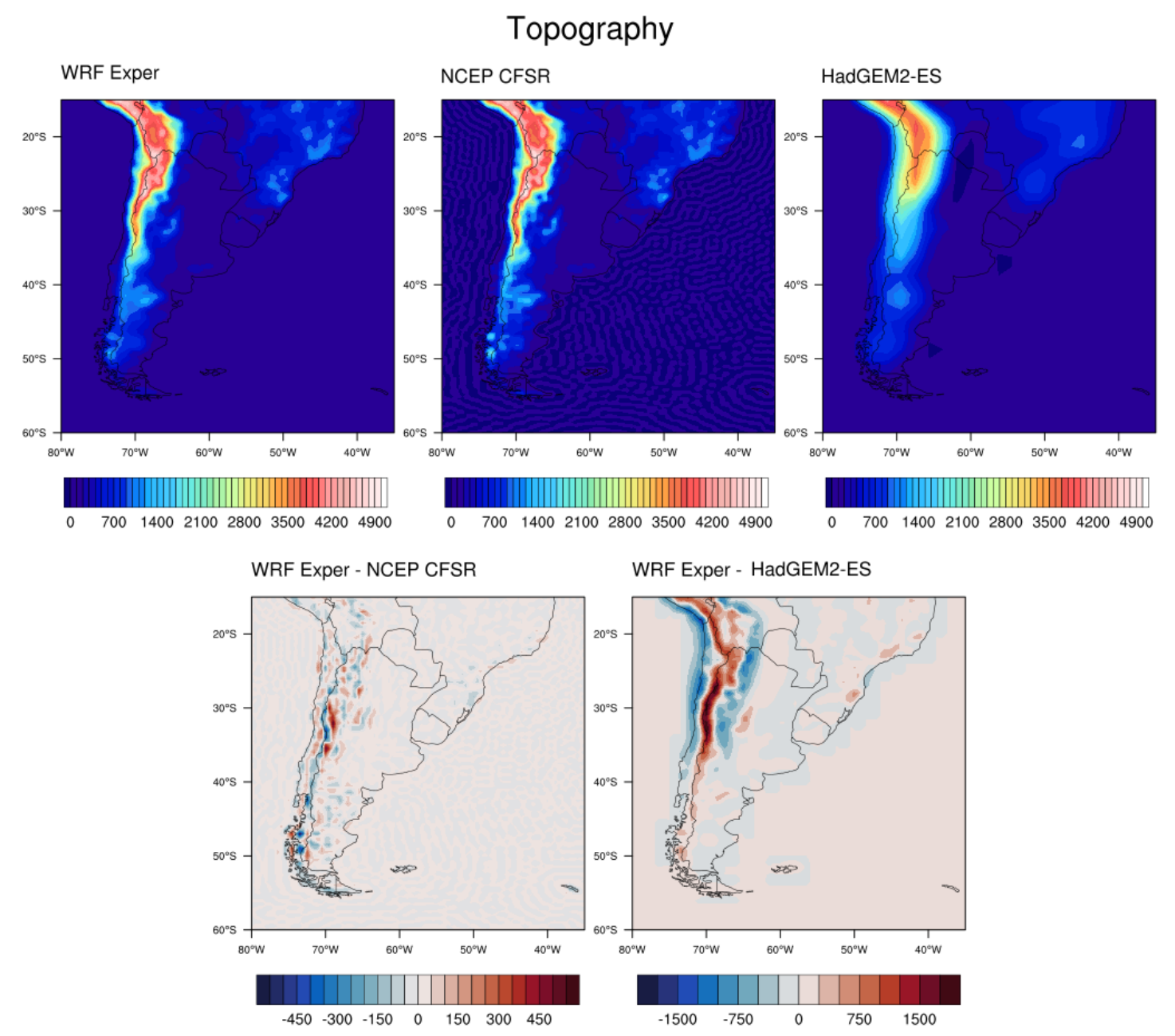

Figure 7.7: Orographic representation (m) in the (a) ExpCFSR, (b) NCEP-CFSR and (c) HadGEM2-ES; and the differences (d) ExpCFSR - NCEP-CFSR and (e) ExpCFSR - HadGEM2-ES. 
Table 7.1 - Total number, annual mean and standard deviation of cyclones in South Atlantic domain (model grid) and in each defined cyclogenesis region within the domain. The values were computed for the 1991-2005 in the summer (DJF) and winter (JJA). The number in parentheses at the third column is the percentage of the ExpCFSR total relative to NCEP-CFSR.

\begin{tabular}{rcccc}
\hline \hline \multicolumn{5}{c}{ DJF } \\
\hline region & NCEP-CFSR & ExpCFSR (\%) & NCEP-CFSR & ExpCFSR \\
\hline \hline South Atlantic & 1712 & $1136(-33.6)$ & $114.1 \pm 8.8$ & $75.7 \pm 8.0$ \\
SE-BR & 132 & $86(-34.8)$ & $8.8 \pm 2.2$ & $5.7 \pm 1.2$ \\
LA PLATA & 197 & $95(-30.7)$ & $9.1 \pm 3.3$ & $6.3 \pm 2.3$ \\
ARG & 503 & $414(-17.7)$ & $33.5 \pm 3.4$ & $27.6 \pm 3.3$ \\
\hline \hline \multicolumn{5}{c}{ JJA } \\
\hline \multicolumn{5}{c}{ Total } \\
region & NCEP-CFSR & ExpCFSR (\%) & NCEP-CFSR & ExpCFSR \\
\hline \hline South Atlantic & 1804 & $1377(-23.7)$ & $120.3 \pm 10.6$ & $91.8 \pm 10.1$ \\
SE-BR & 138 & $96(-30.4)$ & $9.2 \pm 2.8$ & $6.4 \pm 2.4$ \\
LA PLATA & 183 & $187(-2.1)$ & $12.5 \pm 3.3$ & $12.2 \pm 3.1$ \\
ARG & 448 & $355(-20.8)$ & $29.9 \pm 3.4$ & $23.7 \pm 5.8$ \\
\hline \multicolumn{5}{c}{}
\end{tabular}

\subsubsection{Cyclones representation}

Table 7.1 shows the total number, annual mean and standard deviation of cyclones in the South Atlantic grid. It is possible to see that the ExpCFSR simulated fewer cyclones than NCEP-CFSR for all regions. The most considerable differences are in the SE-BR and LA PLATA regions in the summer and SE-BR and ARG regions in the winter. The LA PLATA cyclogenesis in the winter has a small negative bias of $2.1 \%$, indicating that the regional model processes may play an important role in the genesis at this location.

Figure 7.8 shows the cyclone genesis density simulated by ExpCFSR and its difference concerning the NCEP-CFSR, in the summer and winter. The ExpCFSR can simulate the three main genesis regions along South America: SE-BR, LA PLATA, and ARG. However, it is essential to clarify that the low genesis density found in the Eastern South Atlantic, and consequently in the SE-SAO region, is a result of the proximity of the eastern and northern boundaries. Cyclones generated close to the border may not achieve the minimum 


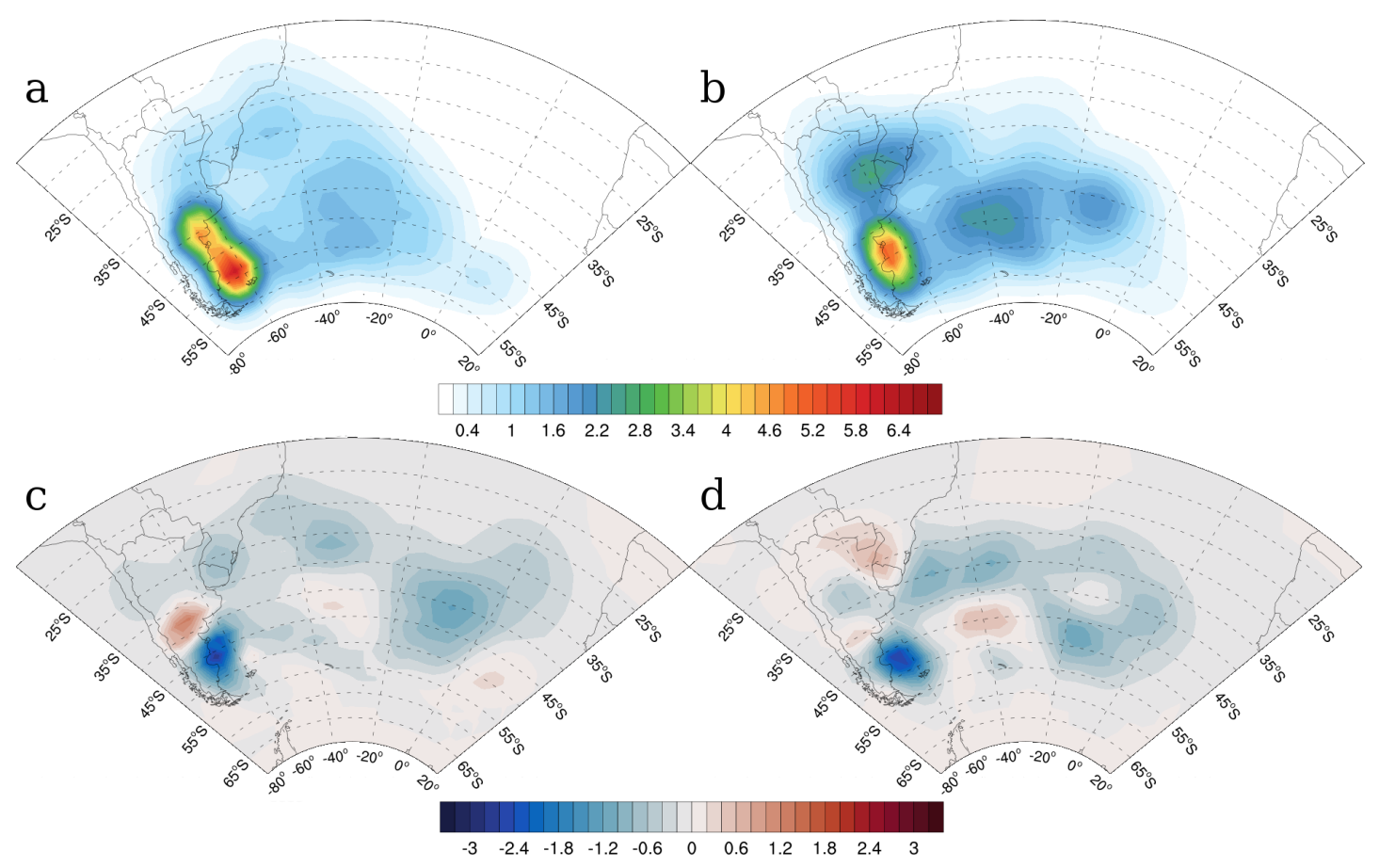

Figure 7.8: ExpCFSR genesis density in the (a) summer and (b) winter and the differences (ExpCFSR - NCEP-CFSR) in the (c) summer and (d) winter. The units for the genesis density and the differences are cyclone per $10^{6} \mathrm{~km}^{2}$ per month.

lifetime and displacement threshold to be counted as a cyclone. In this way, the cyclones from the SE-SAO region are not analyzed in this Chapter, and their study in the future should comprise a larger domain.

The limited area tracking also brings some other issues in the cyclone distribution by shifting some genesis regions due to the spatial filter distortion along the latitude axis. In Appendix D (Fig.D.3) is possible to see a comparison between the genesis density from a tracking performed in the NCEP-CFSR T42 (global) and the NCEP-CFSR interpolated for the ExpCFSR grid with the spatial filter. The cyclones from SE-BR, which are small in their early stages, are only identified by the algorithm later, in a region centered in $30^{\circ} \mathrm{S}, 35^{\circ} \mathrm{W}$. The ARG region presents higher genesis density as long as the smaller features are found in higher latitudes by using a fixed spatial threshold than a spectral filter.

However, even using the same tracking method in both NCEP-CFSR and ExpCFSR, the last simulates less cyclones (Table 7.1, Figs. 7.8p and d). Reboita et al. (2010a) showed that a single complex low-pressure area can contain more than one vortex and this type of feature is not always represented in regional model results. Looking at the filtered vorticity 


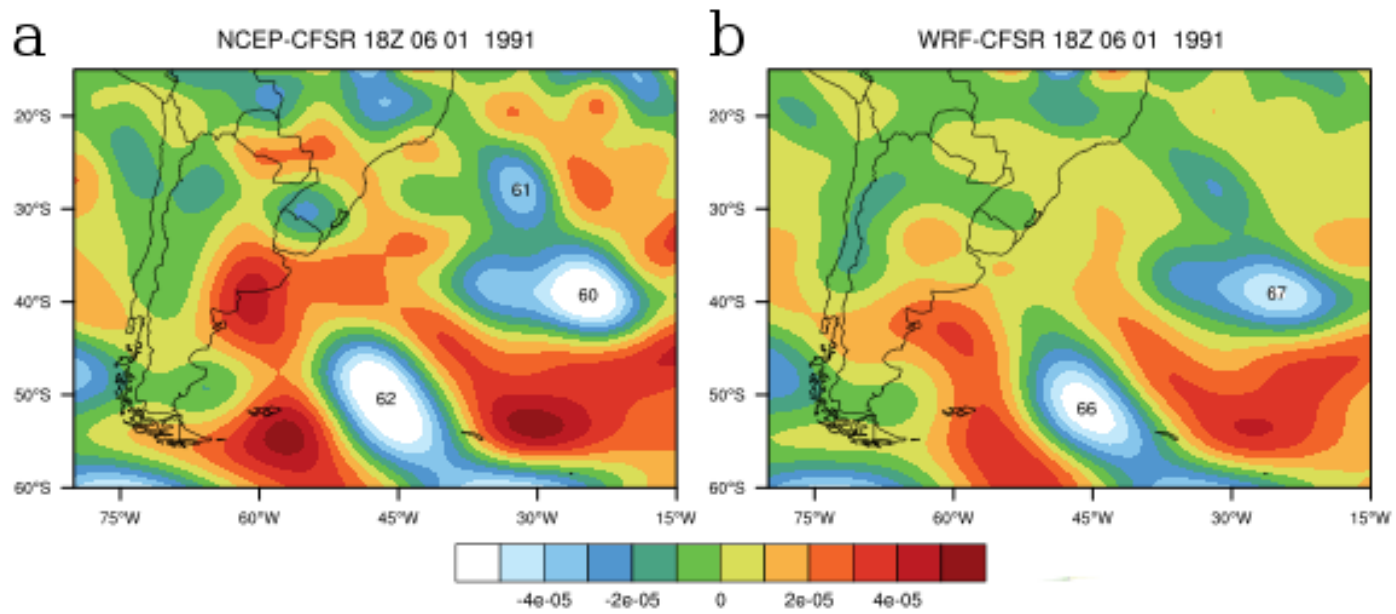

Figure 7.9: Example of the filtered relative vorticity field (at $850 \mathrm{hPa}$ ) in a given time step for the (a) NCEP-CFSR and (b) ExpCFSR. Each number indicates a tracking identification label in the algorithm. The vorticity unit is $\left(s^{-1}\right)$.

fields in Fig. 7.9, it is possible to see an example: the algorithm identifies two cyclones in a negative vorticity stripe in the NCEP-CFSR $(60,61)$ while only one is detected in ExpCFSR (67). Although there is a negative vorticity core northwestward of the cyclone $\mathrm{n}^{\circ} 67$, the vorticity field in the regional model is weaker than in the reanalysis. In this way, the cyclonic features in ExpCFSR are detected between 6 and $12 \mathrm{~h}$ later than in the reanalysis and thus, may not fulfill the minimum thresholds to be added in the tracking analysis. The same issues were observed by Reboita (2008) and Reboita et al. (2010a). Although Reboita et al. (2010a) found only 1\% of underestimation in RegCM3 compared to NCEP-CFSR, they showed that the regional model was less capable to reproduce initially strong systems $\left(\zeta_{10 m} \leq-2.5 \times 10^{-5} s^{-1}\right)$.

Cyclogenesis increases in three locations: the Northern ARG (summer) and Eastern LA PLATA (winter) regions, and an area centered in $45^{\circ} \mathrm{S}, 40^{\circ} \mathrm{W}$ (winter). As long as there are no differences between the filtering and tracking methods applied in NCEP-CFSR and ExpCFSR in this case, the observed biases are due to the regional model characteristics. As discussed above, the difference between ExpCFSR and NCEP-CFSR can be addressed to the inability of the regional model to represent complex low vorticity cores that may cause discrepancies in cyclone lifecycles, both in intensity and lifetime. However, the observed biases in Fig.7.8 may also be related to the regional model features, e.g., the slightly stronger winter SALLJ in the ExpCFSR when compared to the NCEP-CFSR. 
The ExpCFSR presents a more statically unstable (stable) environment over the continent (ocean) which can be a consequence of a model overestimation (underestimation) of the surface temperature (Figs.7.1 and 7.2). The lower static stability seems to be associated with the positive genesis anomaly in the LA PLATA region in the winter, which can be seen in Fig. 7.10b. Although the mean low-level integrated moisture does not present differences in comparison to NCEP-CFSR (not showed), the moisture content associated to the genesis time is larger in the LA PLATA region, where the genesis density is higher (Fig $7.10 \mathrm{~d})$. The increase in cyclogenetic activity centered in $45^{\circ} \mathrm{S}, 40^{\circ} \mathrm{W}$, in the winter, seems to be associated with the reduced static stability at this location.

The genesis density in the ARG region is more elongated north-south in the ExpCFSR compared to the reanalysis, what may explain the positive anomaly of genesis density between $35^{\circ} \mathrm{S}$ and $40^{\circ} \mathrm{S}$ (Fig $7.8 \mathrm{c}$ ). The mechanisms responsible for that may be associated with the equatorward shift of the perturbation when it moves from Pacific through the mountain chain, once the orography is better represented in the regional model rather than in reanalysis. The perturbation coming from Pacific is deformed while crossing the Andes and a high anomaly of geopotential is generated equatorward of the "old" disturbance on the lee side, as described by Gan and Rao (1994).

The track density and its differences related to NCEP-CFSR are presented in Fig. 7.11 for the summer and winter. The track anomalies are associated with the ones from genesis density. In this way, there is a general decrease in the track density over the domain in the ExpCFSR, with positive anomalies corresponding to the regions with positive genesis anomaly.

Figure 7.12 shows the intensity histograms computed with the filtered relative vorticity $(850 \mathrm{hPa})$. The histograms of minimum MSLP and maximum wind speed at $925 \mathrm{hPa}$ were also computed and are available in Appendix D (Figs.D.4 and D.5). The ExpCFSR presents less intense cyclones than NCEP-CFSR regarding the vorticity, both in the summer and winter. Although the intensity underestimation can be related to the misrepresentation of the SE-SAO cyclones in the ExpCFSR, less intense cyclones are also observed in the histograms computed for SE-BR, LA PLATA and ARG regions. The histograms of minimum MSLP and maximum wind speed also show less intense cyclones in the ExpCFSR, although the differences are not so evident as seen in the vorticity ones. It is important to note that due to the short analyzed period (15 years), the intensity distributions showed 

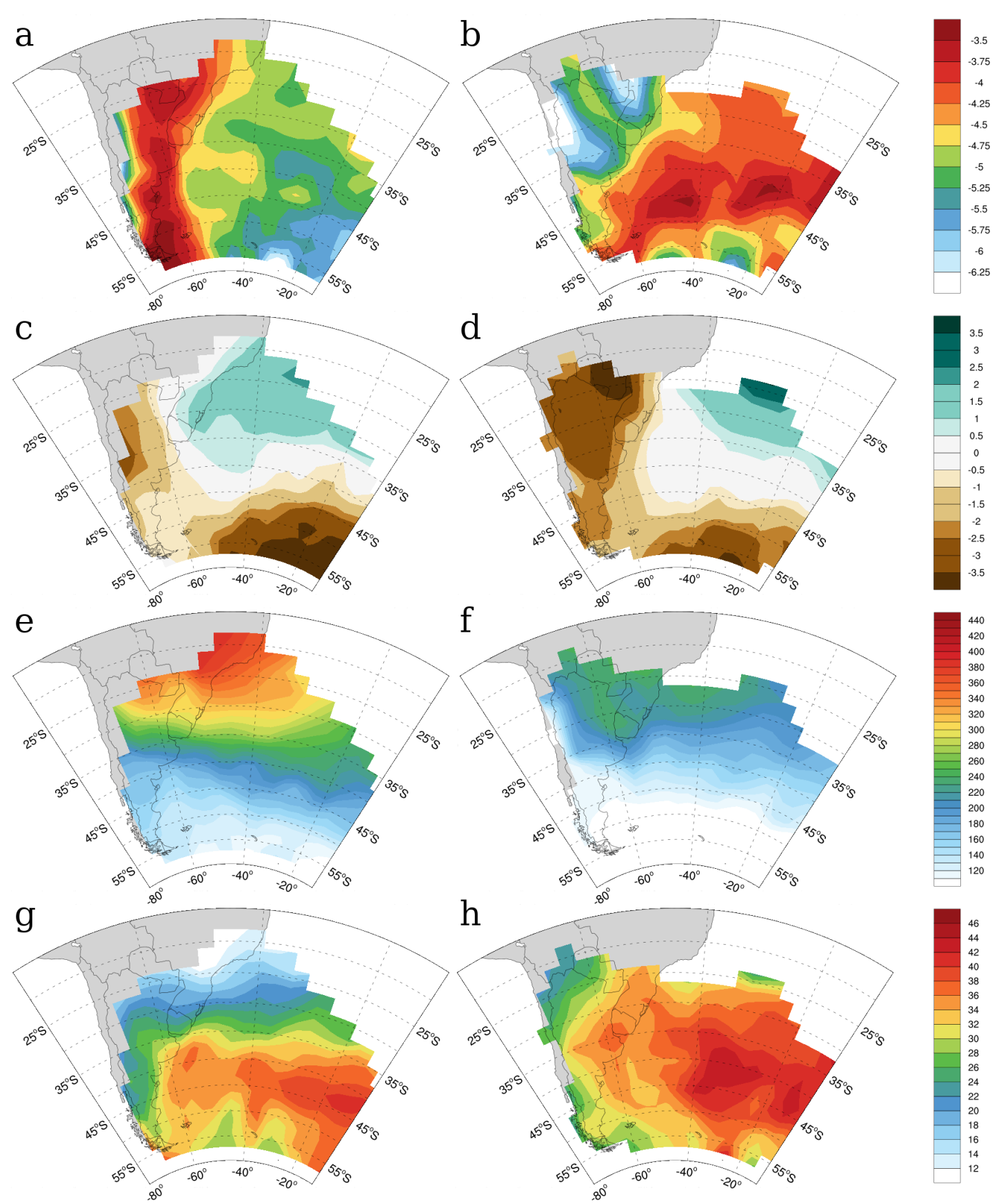

Figure 7.10: Spatial distribution of the integrated humidity at lower-level $\left(\mathrm{kg} \mathrm{kg}^{-1}\right)$, $\partial \theta / \partial p\left(10^{-2} K h P a^{-1}\right), \partial \theta_{e} / \partial p\left(10^{-2} K h P a^{-1}\right)$ and the upper-level jet $\left(m s^{-1}\right)$ for ExpCFSR, at the genesis time in the austral summer (a, c, e and $\mathrm{g}$, respectively) and winter ( $\mathrm{b}, \mathrm{d}, \mathrm{f}$ and $\mathrm{h}$, respectively). The fields are not plotted where genesis density $<0.2$ cyclones $\left(10^{6} \mathrm{~km}^{2}\right)^{-1} \mathrm{month}^{-1}$. 


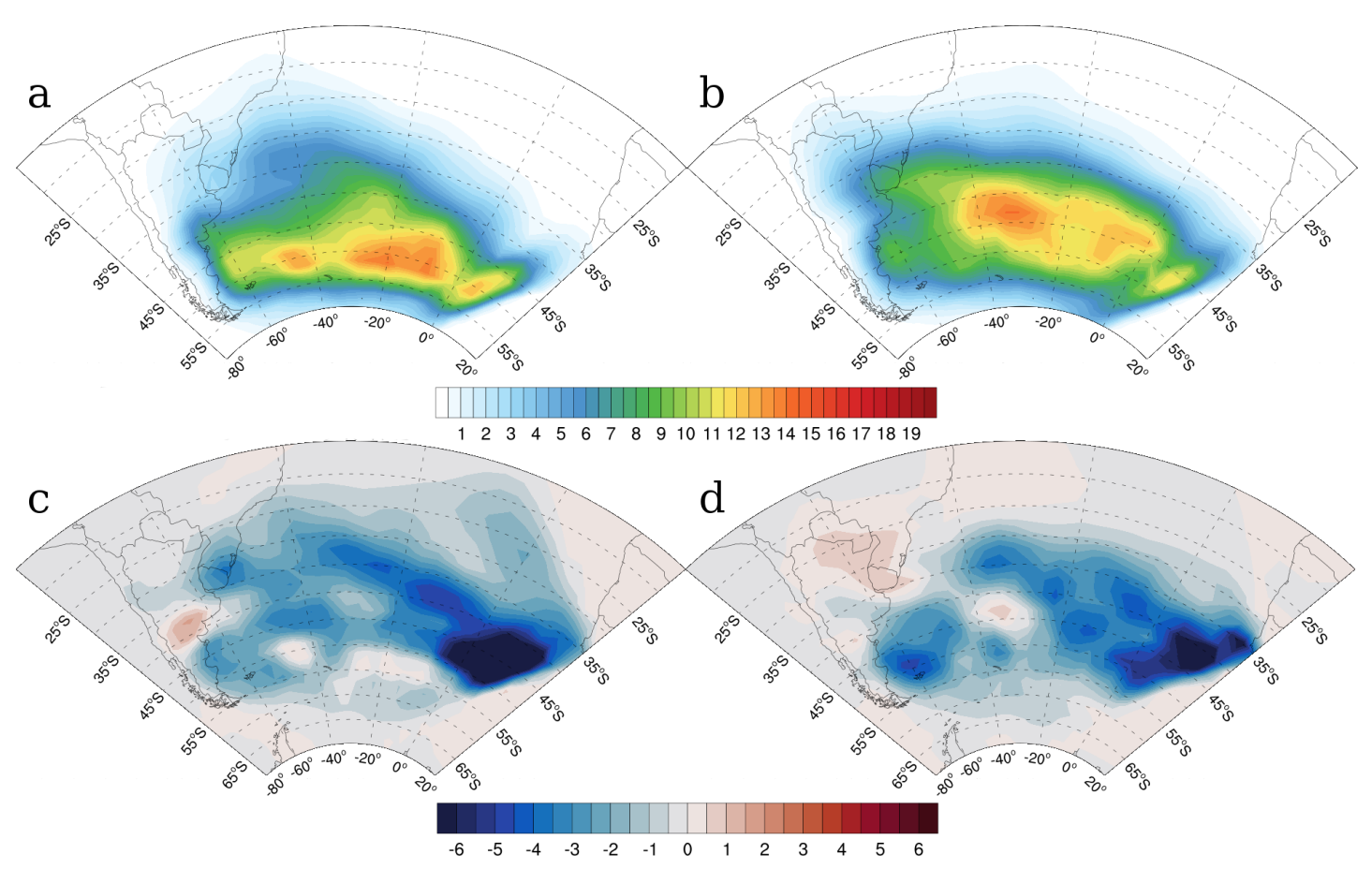

Figure 7.11: ExpCFSR track density in the (a) summer and (b) winter and the differences (ExpCFSR - NCEP-CFSR) in the (c) summer and (d) winter. The units for the track density and the differences are track per $10^{6} \mathrm{~km}^{2}$ per month.

in this Chapter are less smoothed than the others, that used a longer period (32 years, Chap. 4. 27 years, Chap. 5 and 6), due to the lower number of samples (cyclones).

\subsection{HadGEM2-ES simulations}

The "present" climate simulation using the HadGEM-ES historical (ExpHad-Hist, hereafter) is analyzed in this section regarding its improvements and biases in relation to HadGEM2-ES and the reference (ExpCFSR). Also, the "future" climate simulation using the HadGEM2-ES RCP8.5 (ExpHad-RCP85) is accessed focusing in the differences in relation to ExpHad-Hist. Both ExpHad-Hist and ExpHad-RCP85 present a simulated period of 15 years, from 1991 to 2005 and 2085-2099, respectively.

\subsubsection{Present climate}

Table 7.2 shows the total number of cyclones identified in the HadGEM2-ES historical downscaling (ExpHad-Hist) and Fig. 7.13 shows its genesis density and biases (relative 

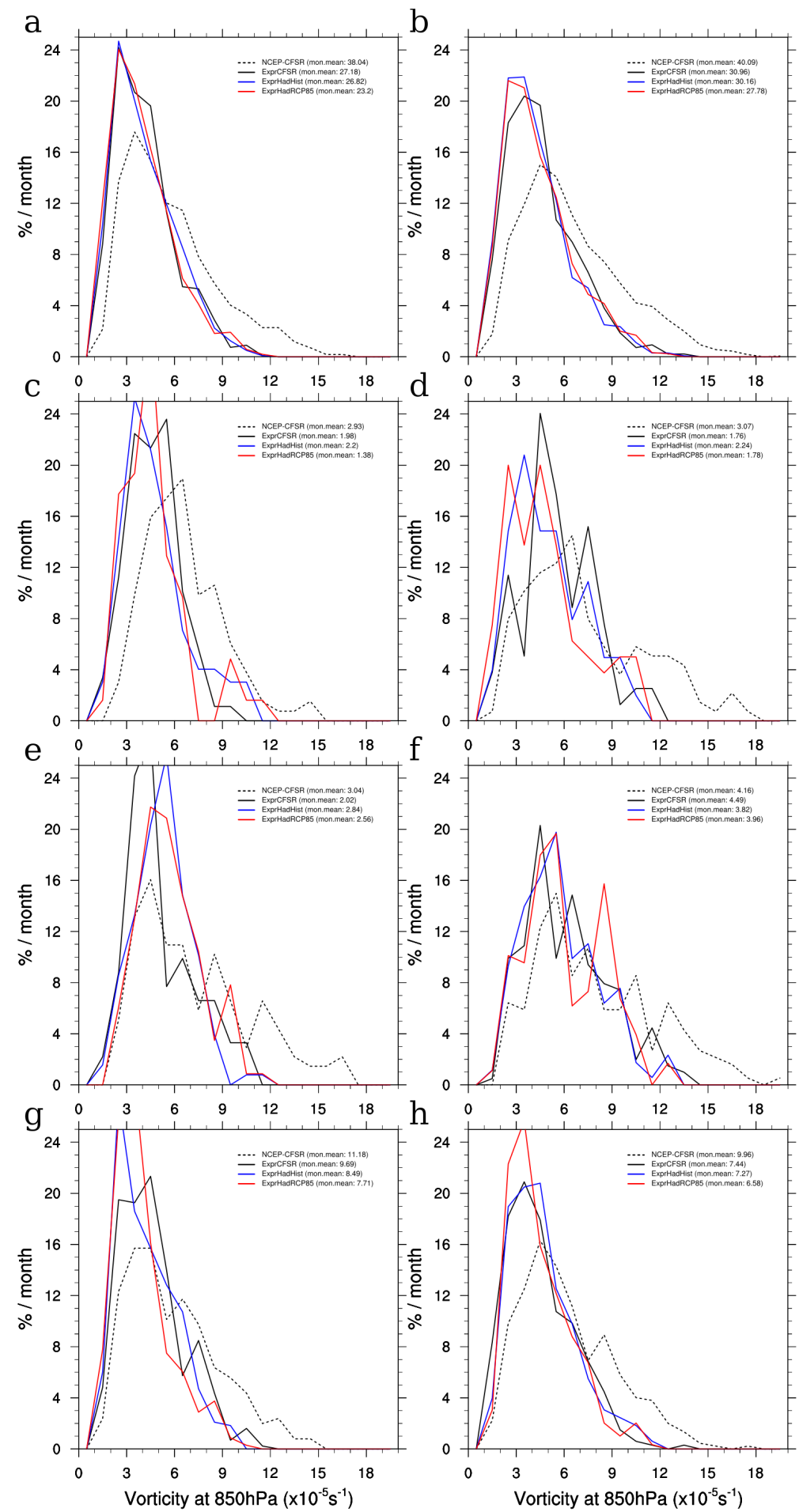

Figure 7.12: Histograms of the maximum filtered vorticity at $850 \mathrm{hPa}$ in the summer (left) and winter (right) for (a,b) South Atlantic, (c,d) SE-BR, (e,f) LA PLATA and $(\mathrm{g}, \mathrm{h})$ ARG. The NCEP-CFSR (dashed line), ExpCFSR (black solid line) and ExpHad-Hist (blue line) for 1991-2005, and ExpHadRCP85 (red line) for 2085-2099. The vorticity is scaled by $-1 \times 10^{-5} s^{-1}$. The intensity histograms were produced for cyclones originated in each genesis region separately. The percentage was computed based on the mean cyclones per month for each region. 
Table 7.2 - Total number, annual mean and standard deviation of cyclones for South Atlantic domain (model grid) and each defined cyclogenesis region within the domain. The values were computed for the 1991-2005 period in the summer (DJF) and winter (JJA). The number in parentheses at the second column is the percentage of the ExpHad-Hist total relative to ExpHad-RCP85.

\begin{tabular}{rcccc}
\hline \hline \multicolumn{5}{c}{ DJF } \\
\hline region & ExpHad-Hist & ExpHad-RCP85 $(\%)$ & ExpHad-Hist & ExpHad-RCP85 \\
\hline \hline South Atlantic & 1207 & $1046(-13.3)$ & $80.5 \pm 8.2$ & $69.7 \pm 4.7$ \\
SE-BR & 99 & $68(-31.3)$ & $6.6 \pm 2.1$ & $4.5 \pm 2.2$ \\
LA PLATA & 128 & $116(-9.4)$ & $8.5 \pm 3.2$ & $7.7 \pm 3.6$ \\
ARG & 382 & $345(-9.7)$ & $25.5 \pm 5.3$ & $23.0 \pm 2.4$ \\
\hline \hline region & ExpHad-Hist & ExpHad-RCP85 $(\%)$ & ExpHad-Hist & ExpHad-RCP85 \\
\hline \hline South Atlantic & 1357 & $1253(-7.7)$ & $90.5 \pm 9.2$ & $83.5 \pm 7.5$ \\
SE-BR & 101 & $89(-11.9)$ & $6.7 \pm 3.3$ & $5.9 \pm 3.1$ \\
LA PLATA & 172 & $173(0.6)$ & $11.5 \pm 3.0$ & $11.5 \pm 3.6$ \\
ARG & 327 & $287(-12.2)$ & $21.8 \pm 4.2$ & $19.1 \pm 3.7$ \\
\hline
\end{tabular}

to ExpCFSR). The ExpHad-Hist presents a total number of cyclones close to ExpCFSR, with slightly more cyclones in the summer (6.3\%) and fewer cyclones in the winter ($1.5 \%$ ). However, there is a positive bias in the equatorward genesis regions, between $20^{\circ} \mathrm{S}$ and $25^{\circ} \mathrm{S}$, and a negative bias in the ARG region in the summer. In the winter, there are small positive (negative) bias equatorward (poleward) of $25^{\circ} \mathrm{S}$. The ExpHad-Hist seems to increase the cyclogenetic activity in the equatorward flank of the storm track, which is the opposite of the observed biases in HadGEM2-ES historical.

The improved representation of the LA PLATA cyclogenesis may be addressed to the increase in resolution and better orographic representation. However, the genesis in this region in the winter is shifted equatorward when compared to the reference. The ExpHadHist also simulated more genesis in the LA PLATA region in the summer. The SE-BR region is active in the summer, although it presents a higher density in the ExpHad-Hist than in the reference. The genesis density in the ARG region is smaller in the ExpHad-Hist than in ExpCFSR, both in the summer and winter. 


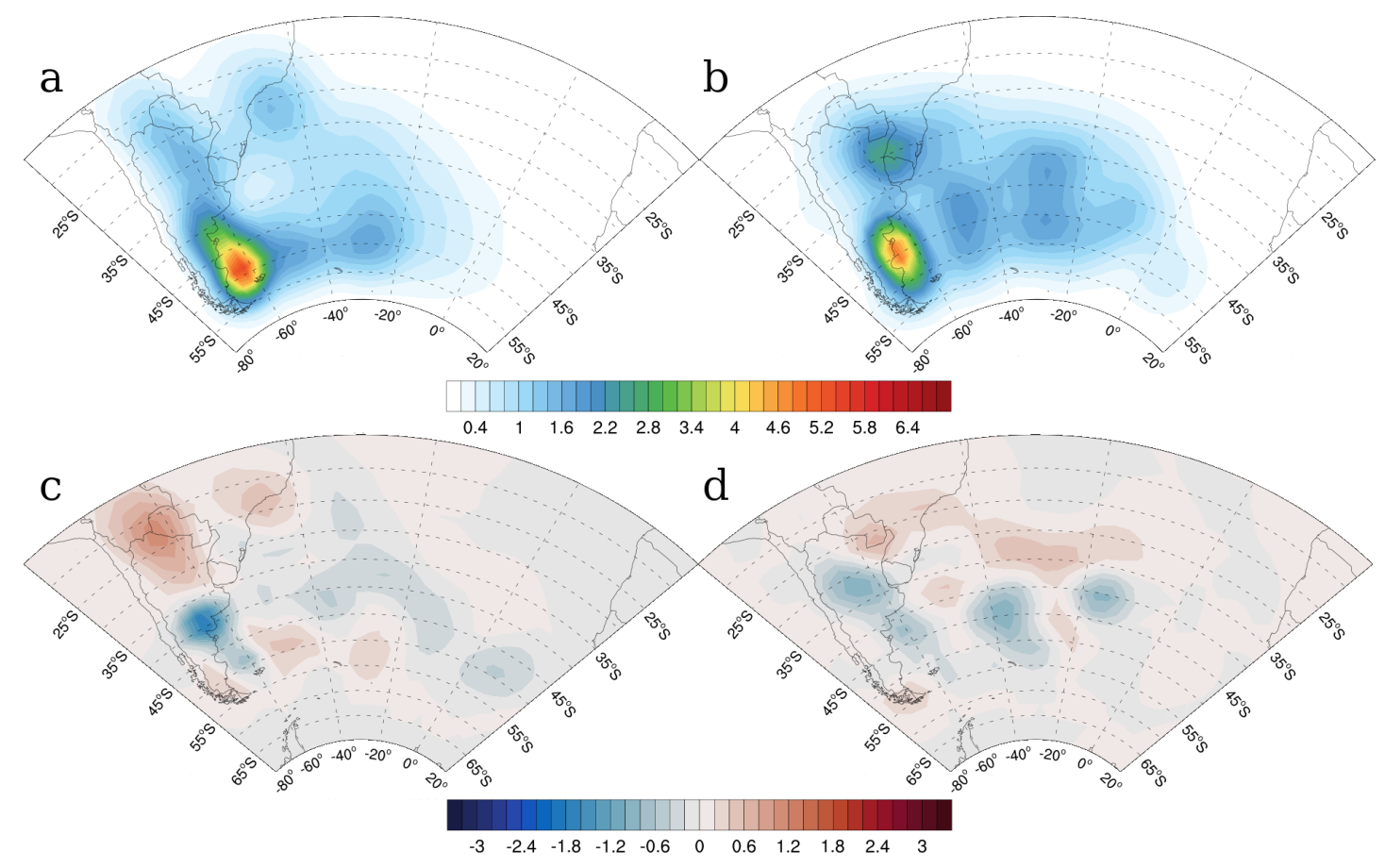

Figure 7.13: ExpHad-Hist genesis density in the (a) summer and (b) winter and the biases (ExpHad-Hist - ExpCFSR) in the (c) summer and (d) winter. The units for the genesis density and the differences are cyclone per $10^{6} \mathrm{~km}^{2}$ per month.

Most of the observed differences between ExpCFSR and ExpHad-Hist are associated with the low-level moisture and static and conditional stabilities. At first, ExpHad-Hist simulates a less statically stable low-level troposphere over South America due to a higher surface temperature (not shown). The spatial distributions of $\partial \theta / \partial p, \partial \theta_{e} / \partial p$ and lowlevel integrated moisture are presented in Fig 7.14, and show a less conditionally stable environment at the genesis time equatorward of $35^{\circ} \mathrm{S}$, both in the summer and winter. These factors together directly affect the cyclogenetic activity in the LA PLATA and SE$\mathrm{BR}$ regions, so that the former is more active in the winter and the latter in the summer, as reported in the climatology.

Figure 7.7? shows that the difference between HadGEM2-ES and the regional model topography is larger than $1500 \mathrm{~m}$ in some locations. In the regional model, the Andes Cordillera may be acting not only to generate and amplify perturbations but also to channel moisture and warm from the tropics to the mid-latitudes (Mendes et al., 2007).

The track density and bias are presented in Fig. 7.15 for the summer and winter. The track bias is a consequence of the genesis bias in Fig. 7.13. Thus, there is a positive bias in 

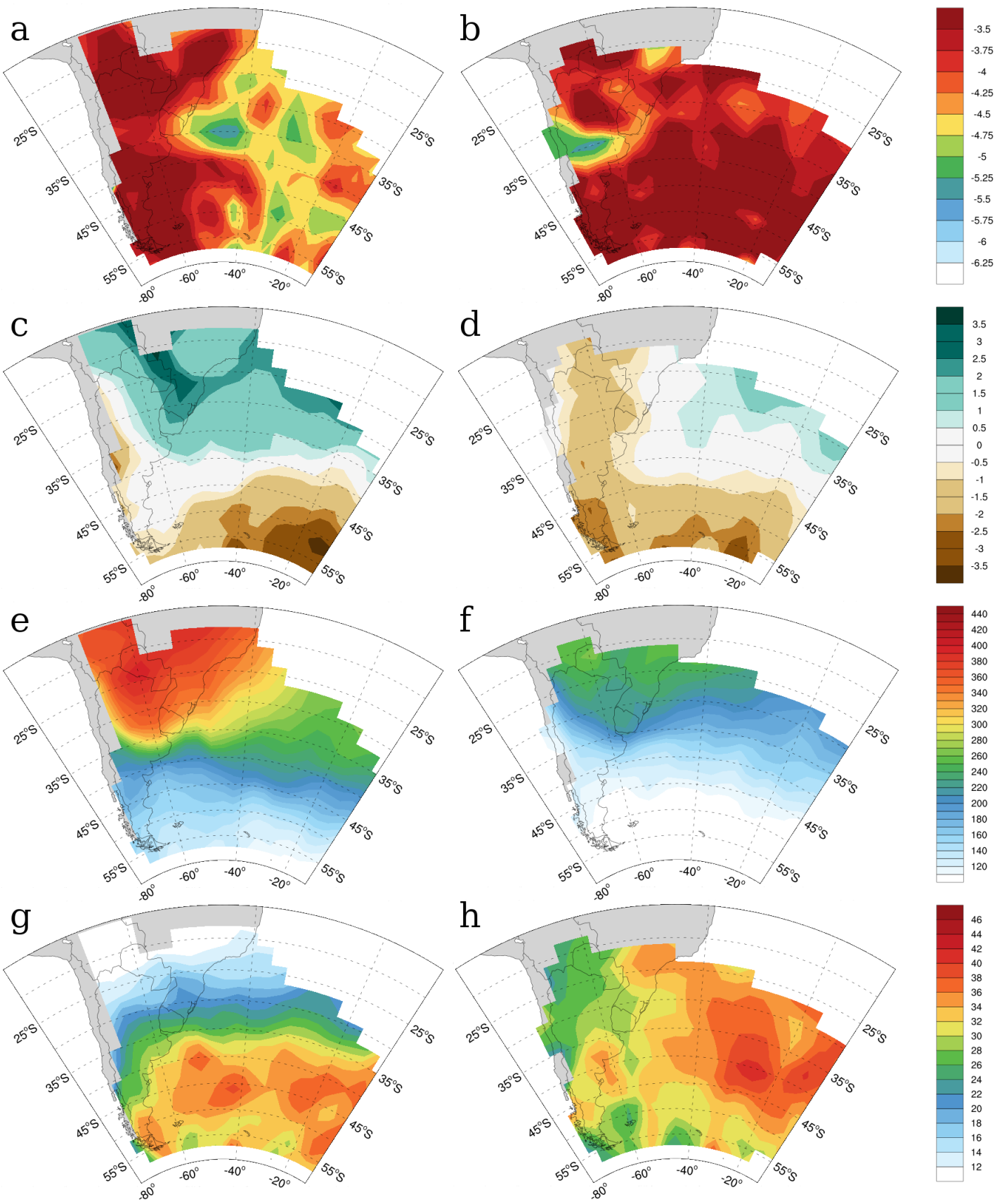

Figure 7.14: Spatial distribution of the integrated humidity at lower-level $\left(\mathrm{kg} \mathrm{kg}^{-1}\right)$, $\partial \theta / \partial p\left(10^{-2} K h P a^{-1}\right), \partial \theta_{e} / \partial p\left(10^{-2} K h \mathrm{~Pa}^{-1}\right)$ and the upper-level jet for ExpHad-Hist, at the genesis time in the austral summer (a, c, e and $\mathrm{g}$, respectively) and winter ( $\mathrm{b}, \mathrm{d}, \mathrm{f}$ and $\mathrm{h}$, respectively). The fields are not plotted where genesis density $<0.2$ cyclones $\left(10^{6} \mathrm{~km}^{2}\right)^{-1} \mathrm{month}^{-1}$. 


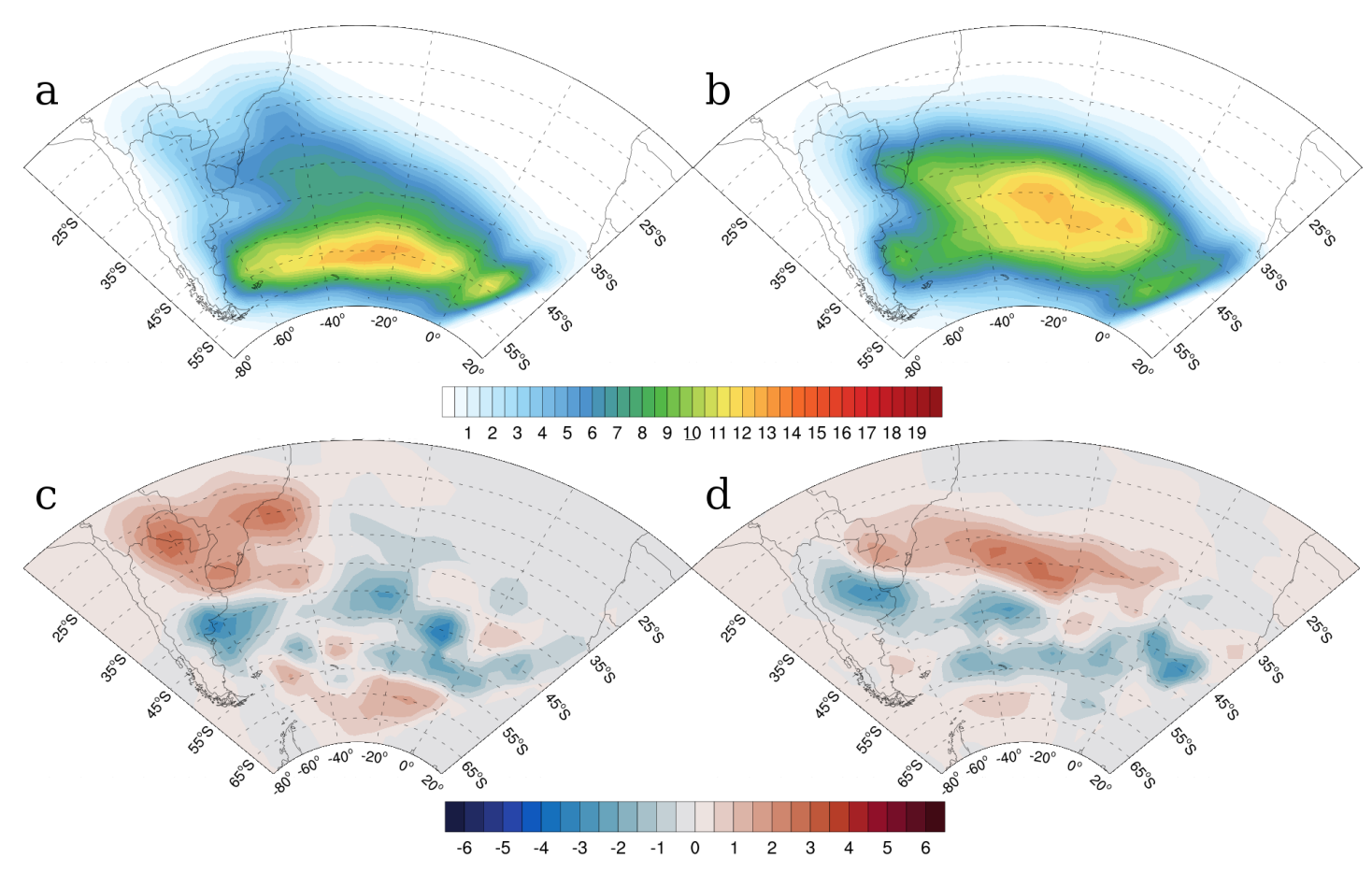

Figure 7.15: ExpHad-Hist track density in the (a) summer and (b) winter and biases (ExpHad-Hist - ExpCFSR) in the (c) summer and (d) winter. The units for the track density and the differences are cyclone per $10^{6} \mathrm{~km}^{2}$ per month.

the equatorward flank of the storm track, concentrated over the continent in the summer, and zonally spread in the winter.

\subsubsection{Future climate}

Table 7.2 shows the total number of cyclones identified in the HadGEM2-ES RCP85 downscaling (ExpHad-RCP85) and its computed percentage of ExpHad-Hist. Also, Fig. 7.16 shows the ExpHad-RCP85 genesis density and future changes. As observed in Chap. 6, there is a general decrease in the number of cyclones over the domain in the future simulation. However, in the ExpHad-RCP85, the decrease is larger in the summer than in the winter while in HadGEM2-ES RCP85 there was no significant difference between these seasons. It is possible to see a slight increase in the cyclogenesis density in the southeastern part of the LA PLATA region in the winter, although there are no significant changes in absolute numbers. In the summer, there is an increase in genesis density over the ARG region, between $40^{\circ} \mathrm{S}$ and $45^{\circ} \mathrm{S}$.

Figure 7.16 shows the ExpHad-RCP85 genesis density and projected changes in the 


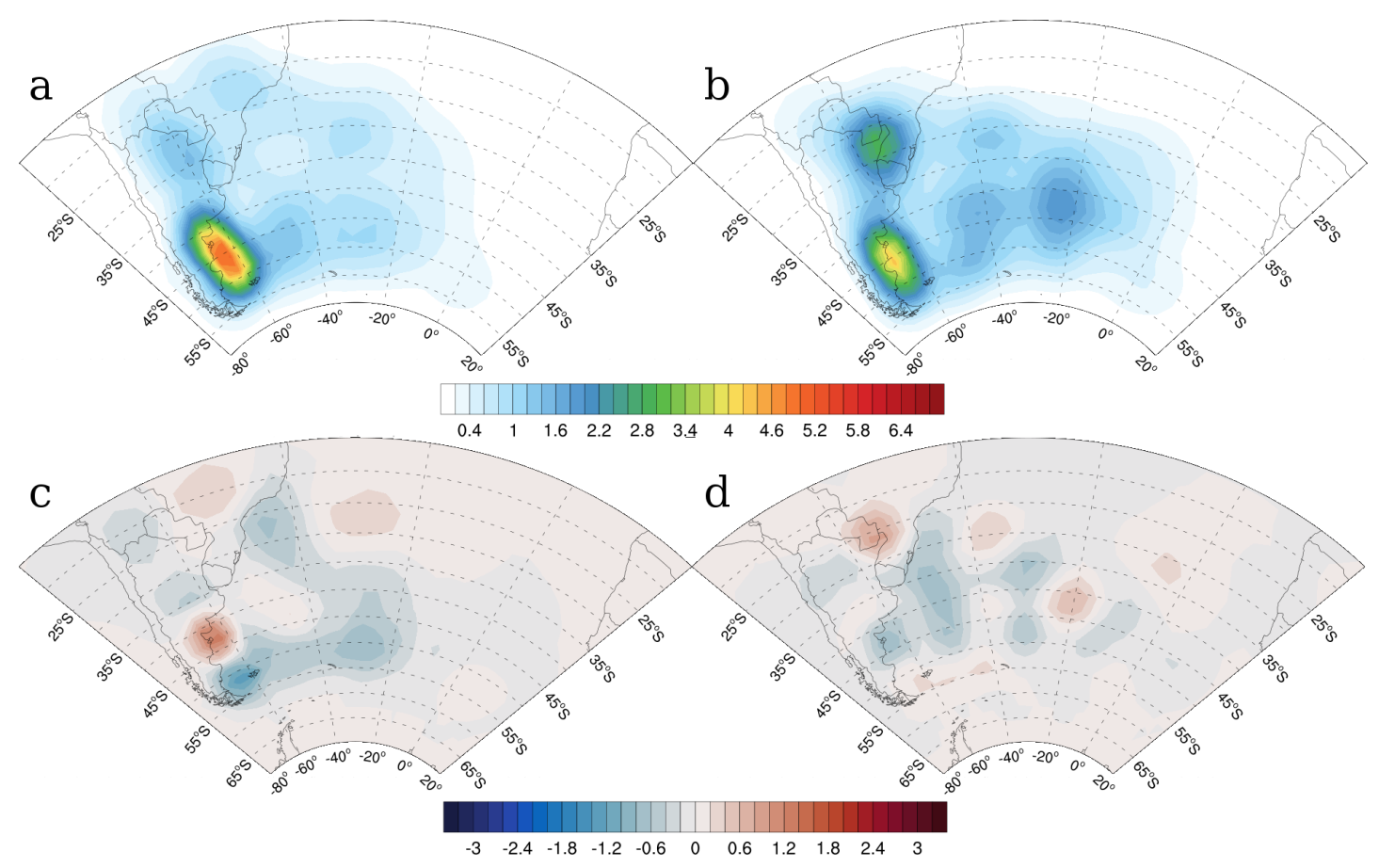

Figure 7.16: ExpHad-RCP85 genesis density in the (a) summer and (b) winter and the changes (ExpHad-RCP85 - ExpHad-Hist) in the (c) summer and (d) winter. The units for the genesis density and the changes are cyclones per $10^{6} \mathrm{~km}^{2}$ per month.

summer and winter. As discussed in Chap 6, the future changes in some locations are smaller than the biases. There is a general decrease in the genesis over the whole domain, followed by a reduction in the track density between $35^{\circ} \mathrm{S}$ and $55^{\circ} \mathrm{S}$. However, the downscaling presented different tendencies in the genesis activity over South America.

At first, there is an equatorward shift in the SE-BR genesis region in the summer, advancing toward the continent. There were no changes in this region in HadGEM2-ES RCP85. Moreover, the projected increase in the LA PLATA cyclogenesis in the same season is not simulated by the ExpHad-RCP85. There is an increase in genesis in the ARG region between $40^{\circ} \mathrm{S}$ and $45^{\circ} \mathrm{S}$ as a consequence of an equatorward elongation of the genesis density.

In the winter, the projected changes in genesis density are weaker than in the summer, what is in agreement with the results in Table 7.2. However, the increase in the genesis in the Eastern LA PLATA is larger than the bias and it is also observed in HadGEM2-ES RCP85 projection.

Looking at the spatial distributions of cyclone characteristics at the time of genesis, it 
is possible to see an increase in the static stability and low-level moisture over the domain, in both seasons (Fig 7.17 a and b). The low-level moisture is larger in the summer and may affect genesis poleward of $40^{\circ} \mathrm{S}$, what can explain the increase in the Northern ARG region (Fig.7.17). The increase of humidity also can explain the positive tendencies of genesis over $20^{\circ} \mathrm{S}$ in the summer and over the LA PLATA region in the winter (Fig 7.17f).

Changes in upper-level jet show an increase in its speed in both seasons. In the summer, the polar jet shifts poleward while the subtropical jet of South America is strengthened. The subtropical jet, allied with a conditionally unstable and moisten environment, may be responsible to the cyclone development over $20^{\circ} \mathrm{S}$. In the winter, as with HadGEM2-ES RCP8.5 projection, there is a strengthening in the equatorward flank of the upper-level jet, that, analogous to the summer case, may increase the cyclogenesis in the LA PLATA region. The cyclone intensity changes simulated by ExpHad-RCP85 do not show stronger cyclones over the entire domain. The intensity distributions of ExpHad-Hist and ExpHadRCP85 are similar. However, the histograms of the LA PLATA and SE-BR regions show an increase in the number of intense cyclones in both seasons $\left(\zeta_{\max }=-9 \times 10^{-5} s^{-1}\right)$. This intensification is not evident in the histograms of minimum MSLP and maximum wind speed at $925 \mathrm{hPa}$.

The ExpHad-RCP85 track density and the simulated changes are presented in Fig. 7.18 for the summer and winter. As with HadGEM2-ES projected changes, the ExpHad-RCP85 simulated a decrease in the track density due to the reduction of cyclones in mid-latitudes. The southern boundary impairs the observation of a possible poleward shift. However, it is possible to see a slight increase of the track density at $55^{\circ} \mathrm{S}$ in the summer. The increase of the equatorward flank of the storm track is more evident in ExpHad-RCP85 than in HadGEM2-ES.

\subsection{Discussion and Conclusions}

The ExpCFSR reproduces well the overall distribution of the mean surface temperature, precipitation and winds across the South American continent. However, there is a dipole pattern of biases between the subtropics and the mid-latitudes, which is related to the representation of the SALLJ by the ExpCFSR. The regional experiment simulates a weak SALLJ in the summer, when the warm and moisture advections from the tropics use to 

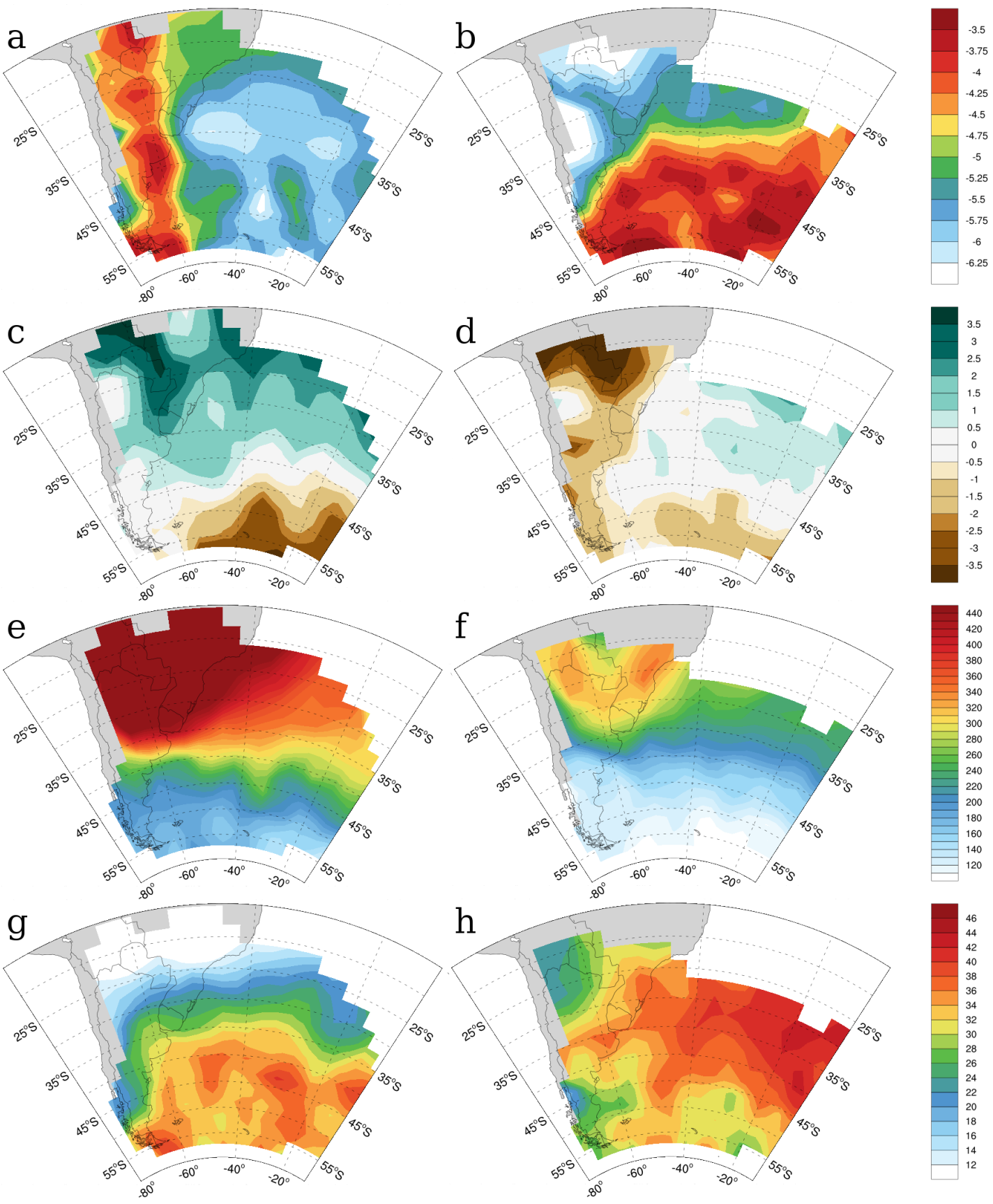

Figure 7.17: Spatial distribution of the integrated humidity at lower-level $\left(\mathrm{kg} \mathrm{kg}^{-1}\right)$, $\partial \theta / \partial p\left(10^{-2} K h P a^{-1}\right), \partial \theta_{e} / \partial p\left(10^{-2} K h P a^{-1}\right)$ and the upper-level jet $\left(m s^{-1}\right)$ for ExpHad-RCP85, at the genesis time in the austral summer (a, c, e and g, respectively) and winter (b, d, f and h, respectively). The fields are not plotted where genesis density $<0.2$ cyclones $\left(10^{6} \mathrm{~km}^{2}\right)^{-1}$ month $h^{-1}$. 


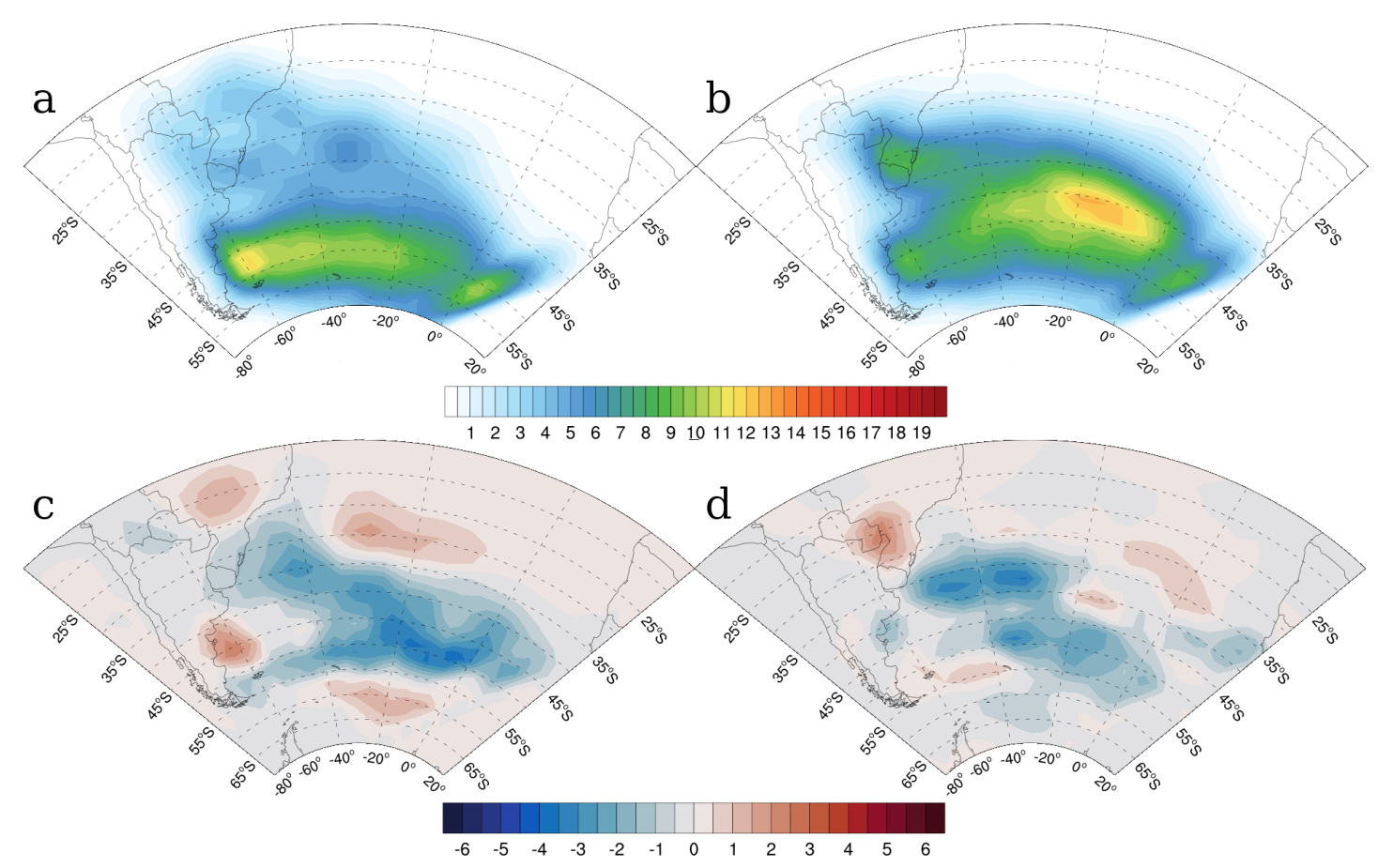

Figure 7.18: ExpHad-RCP85 track density in the (a) summer and (b) winter and the changes (ExpHad-RCP85 - ExpHad-Hist) in the (c) summer and (d) winter. The units for the track density and the changes are cyclone per $10^{6} \mathrm{~km}^{2}$ per month.

be enhanced (Marengo et al., 2002; Vera et al., 2006). The weakening of this transport in the ExpCFSR results in a negative bias of temperature poleward of $30^{\circ} \mathrm{S}$ in the summer. On the other hand, the ExpCFSR presents a stronger SALLJ in the winter.

The ExpCFSR simulated fewer cyclones than NCEP-CFSR for all regions. The region that presented lower negative bias was the LA PLATA $(2 \%)$, in the winter, probably due to an enhanced SALLJ in this season. The low-level jet brings warm and moist air, contributing to decrease the static stability over the continent around $30^{\circ} \mathrm{S}$, as is possible to observe in the spatial distributions (Figs 7.10). In this way, the regional model may improve the mechanisms associated with the LA PLATA cyclogenesis, which can be an indication of the dependence of mesoescale features in the genesis over this region (e.g., orographic low).

However, it was seen that the limited-area model could not be advantageous to study cyclones in an ocean basin domain. At first, the tracking thresholds adopted tend to exclude the cyclones close to the Southern and Eastern boundaries, as long as they move outside the domain without fulfilling the requested displacement $(1000 \mathrm{~km})$ and lifetime 
(1 day). Secondly, the regional model presents some issues in representing complex lowpressure systems, as also reported by Reboita et al. (2010a). The regional model also tends to simulate less intense vorticity fields, that delays the identification of the center of minimum vorticity and, along with the limited area, may also affect genesis and track density within the domain.

Moreover, some studies have shown that models without ocean-atmosphere coupling tend to simulate fewer cyclones (Lee, 2014). Prescribed SST in a sub-daily timestep guarantees the ocean-to-atmosphere forcing in a time scale relevant to synoptic system development, and it is essential to modulate the storm track (e.g. Brayshaw et al., 2011). Hayasaki et al. (2013) showed that the meandering nature of the western boundary currents as Kuroshio Current, generates surface heat fluxes that modifies the near-surface baroclinicity in the marine boundary layer. Similar results can be found in Brazil Current (e.g. Vianna et al. 2010), and the SST anomalies on regional scale have a potential to change the cyclone activity along the oceanic frontal zone. However, the regional model does not interact with the SST fields, and thus, there is no improvement in SST resolution in the regional model. Moreover, the non coupling may generate some SST bias associated with atmosphere-to-ocean forcing, such as cloud feedbacks, e.g., SST cooling by cloud covering.

The absence of interactions between cyclones and the ocean surface in the climate experiments presented here may also be responsible for some regional model issues, such as lower cyclone intensity, difficulties in representing the lifetime and complex negative vorticity centers. These biases can be addressed to the non-existence of positive and negative feedbacks between cyclone dynamics and SST, sea surface roughness and upperocean vertical mixing (e.g. Doyle, 1995; Ren et al., 2004; Vianna et al., 2010).

The ExpHad-Hist simulated the genesis density distribution according to the climatology. However, there was an increase in the genesis in the LA PLATA and SE-BR regions concerning the GCM. This increase can be addressed mainly to the improvement of the regional scale features, like moisture and warm temperature advections from the tropics and a better orographic representation. The fewer cyclone number observed poleward of $34^{\circ} \mathrm{S}$ when compared to the reference (ExpCFSR) may be related to the weak upper-level jet.

The ExpHad-RCP8.5 showed some other changes than the ones observed in HadGEM2ES 8.5 projection. In the summer, there is an increase in the genesis density centered in 
$20^{\circ} \mathrm{S}, 50^{\circ} \mathrm{W}$, in the northern edge of SE-BR, and in the ARG region, at $45^{\circ} \mathrm{S}$. In the winter, an increase in the genesis density in the LA PLATA region is observed, as in HadGEM2-ES RCP8.5 projection. However, in ExpHad-RCP8.5 the increasing signal is stronger, which can be an evidence of the improved representation of the genesis in this location.

The regional model also projected an increase in the static stability at mid-latitudes, as a consequence of the "expansion of the tropics" (Lu et al., 2008). The ExpHad-RCP8.5 simulated, as well, the subtropical jet strengthening in the summer and winter. However, there is a substantial increase in the low-level moisture content, affecting up to $45^{\circ} \mathrm{S}$ poleward in the summer. The increase in the low-level moisture is also observed in HadGEM2ES RCP8.5, although in the downscaling it is much larger. The low-level humidity and a conditionally unstable environment allied to the strong subtropical jet over South America $\left(25^{\circ} \mathrm{S}\right)$ can justify the increase in the genesis in this location. In the winter, the increase in the genesis in the LA PLATA region can be addressed to the strengthening of the equatorward flank of the upper-level jet, along with the enhance in the low-level moisture amount, also affecting the vertical stability of the low-level column. The large content of low-level moisture available in the future simulation can be firmly connected to the intensification of the cyclones in the SE-BR and LA PLATA regions. 
Chapter 8

\section{Conclusions}

The primary goal of this thesis was to access the future projected changes in the cyclones originated in the South Atlantic, focusing on their genesis and intensifying mechanisms. An automated tracking method was used based on the relative vorticity from winds at 850 $\mathrm{hPa}$. Besides that, the cyclone diagnostic was used to understand genesis and intensification mechanisms, using information sampled from individual features to build spatial distribution maps. Cyclone composites were also used to analyze cyclone structure at its development. Based on these methods we evaluated the ability of HadGEM2-ES to reproduce the main characteristics of the South Atlantic cyclones and access their future projected changes using the RCP8.5 scenario. Then, we performed a dynamical downscaling using the WRF model to improve the resolution of the climate model. The results were discussed in each Chapter, and the most important findings are highlighted here.

\subsection{Summary of key findings}

\section{Climatological aspects of South Atlantic cyclogenesis}

There are four cyclogenesis regions in the South Atlantic Ocean domain: the first on the Southern Brazilian coast (SE-BR, $\left.30^{\circ} \mathrm{S}\right)$; the second over the continent which comprises Northern Argentina, Uruguay and Southern Brazil (LA PLATA, 35ㅇ); the third on the southeastern and central coast of Argentina (ARG, $40^{\circ} \mathrm{S}-55^{\circ} \mathrm{S}$ ); and the fourth in the Southeastern South Atlantic (SE-SAO), centered at $55^{\circ} \mathrm{S}$ and $10^{\circ} \mathrm{W}$.

Northward of $35^{\circ} \mathrm{S}$, the low-level forcing is more critical in the genesis process, primarily associated with the reduction of the low-level stability due to the tropical warm and moisture transport from the SALLJ and SASH. In the LA PLATA region, the presence 
of an orographic low enhance the advection of warm and moisten air, particularly in the winter. Also, in the winter, the northward shift of SST gradients increase the baroclinicity at these locations. In the summer, there is some evidence that SE-BR cyclones are secondary systems which develop in a pre-existent front. Southward of $35^{\circ} \mathrm{S}$, ARG and SE-BR cyclones form themselves in a high baroclinic environment where the low-level humidity has a small influence. The reduction of static stability in the ARG region can be addressed to the thermal advection and adiabatic heating due to the subsidence of air on the lee side of Andes. The SE-SAO cyclones also present secondary development, on the cold side of "parental" cyclones.

\section{HadGEM2-ES biases}

The HadGEM2-ES can reproduce the four main cyclogenetic regions within South Atlantic and their associated storm tracks. However, this GMC presents a negative bias in the subtropical storm track, as a consequence of an underestimated genesis in the LA PLATA and SE-BR regions. The HadGEM2-ES also simulates less intense cyclones in all analyzed fields. Most of the biases observed in HadGEM2-ES can be addressed to its coarse resolution, which may affect mesoscale and latent heat release processes in the SE-BR and SE-SAO secondary developments and LA PLATA genesis. The bad orographic representation has a considerable impact on the LA PLATA genesis, decreasing the development in this location and shifting it eastward, to the SE-BR region, in the winter. The coarse resolution also impacts the SST gradient features associated with cyclone intensification over the South American coast and the intensity of upper-level jet.

\section{South Atlantic cyclone changes}

HadGEM2-ES RCP8.5 future projection shows a decrease of $10 \%$ in the number of cyclones over South Atlantic and a poleward shift of the main storm track linked to the larger reduction in mid than high latitudes. This result is in agreement with the most known literature, and is associated with the increase in static stability in the mid-latitudes and the consequent "tropical expansion". However, the equatorward flank of the South Atlantic storm track seems to become strengthened, both in the summer and winter. The LA PLATA cyclogenesis increases in the summer and winter, but mainly in the former, which may be related to the reported increase in the summer precipitation over this loca- 
tion. This increase in the cyclone activity at $30^{\circ} \mathrm{S}$ is mostly restricted to the continent and seems to be associated with the strengthening of the equatorward flank of the upper-level jet and the increase in the low-level moisture content.

\section{Downscaling}

A reference simulation using the NCEP-CFSR (ExpCFSR) was performed to evaluate the regional model set-up and its ability to simulate the South Atlantic climate. The ExpCFSR reproduces well the overall South American climatology. However, the ExpCFSR presents a weaker (stronger) SALLJ in the summer (winter) when compared to NCEP-CFSR, which can be an evidence of the misrepresentation of its seasonal variability. The ExpCFSR simulates fewer cyclones than the reanalysis for all genesis regions, what can be addressed to the inability of the regional model to simulate complex low-pressure systems and cyclone intensity - the vorticity field seems smoothed when compared to NCEP-CFSR. For this reason, the cyclonic feature is identified later and sometimes is not classified as a cyclone by the tracking algorithm once it does not fulfill the displacement (1000 km) and lifetime (1 day) thresholds. The limited-area enhances this issue because some cyclones may move outside the Eastern/Southern domain edge before reaching those tracking requirements. The region that presented lower negative bias was the LA PLATA in the winter $(2 \%)$, where the effects of an improved orography, mesoscale processes and strong SALLJ seems to reduce the static stability and support cyclone development.

The ExpHad-Hist simulated the genesis density distribution according to the reference (ExpCFSR). However, it presented more genesis in the LA PLATA and SE-BR regions when compared to HadGEM2-ES historical, what is associated with the improvement of the regional scale features, like moisture and warm temperature advections from the tropics and better orographic representation. The low-level moisture content related to the genesis at these locations is larger than the HadGEM2-ES, what indicates the effect of the orography (channeling the poleward moisture transport) and other regional processes.

The ExpHad-RCP8.5 shows a general decrease of cyclogenesis over the domain. Despite the domain boundaries, it is possible to see a poleward shift of the main storm track in the summer. The reduction and southward displacement of the cyclone occurrences can be addressed to the increase in the static stability at mid-latitudes. However, the increase in the moisture content at low levels seems to balance the effect of the static stability as long 
as there is an increase in the genesis in the equatorward genesis regions. The ExpHadRCP85 simulates a growth in the genesis in the northern edge of SE-BR $\left(20^{\circ} \mathrm{S}, 50^{\circ} \mathrm{W}\right)$ and ARG $\left(45^{\circ} \mathrm{S}\right)$ regions, in the summer, and the LA PLATA region in the winter. This change in the winter in genesis density is also observed in HadGEM2-ES RCP8.5, but it presents a stronger signal in the regional model. The large increase in the low-level moisture and a strengthening of the equatorward flank of the upper-level jet could justify the increase in the genesis at these locations, competing with the increase in static stability. The large content of low-level moisture available in the future simulation can also be connected to the intensification of the cyclones in the SE-BR and LA PLATA regions.

\subsection{Final remarks and Recommendations for future work}

According to the HadGEM2-ES RCP8.5 projection and its downscaling, there is a decrease of cyclogenesis in the South Atlantic and a poleward shift of the storm track. Although several studies report these change patterns, their driven mechanisms are still not completely answered. In this work, it has been shown that the decrease in the number of cyclones may be strongly related to the increase in the static stability, following the $\mathrm{Lu}$ et al. (2008) explanation of a "tropical expansion". However, the main contribution of this work is that the cyclogenesis in some locations of South America is increasing, mainly due to the increase in the low-level moisture content and the strengthening of the equatorward flank of the upper-level jet. The cyclones in this locations will be slightly intense (between $20^{\circ}$ and $30^{\circ} \mathrm{S}$ ) and will affect a narrow area close to the South American coast.

These findings lead to other questions that are presented here as future work suggestions:

- Further analysis of the dynamical and thermodynamical changes in the cyclogenesis between $20^{\circ}$ and $30^{\circ} \mathrm{S}$ : analysis of energetic, such as the assessment of possible changes in the conversion terms (e.g. Dias Pinto and Da Rocha, 2011; Veiga et al., 2008; Pezza et al., 2010, 2014); classification of dynamical forcing mechanisms, like heightattributable quasi-geostrophic vertical motion diagnostic (Deveson et al., 2002, Dacre and Gray, 2006); vorticity budge (Dutra et al., 2017).

- Analysing cyclone changes in a large number of climate models to see whether other climate models represent the changes found in this work. However, the use of a fully 
ocean-coupled model is important, and stratospheric-coupled model is desirable. The assessment of these models can be done through the multi-model mean; however, recent studies have shown that due to the large spread between models results, this method may smooth the changes and be not good to dynamical analysis as long as different sorts of dynamical responses are mixing into a mean. In this way, the "storylines" approach suggested by Zappa and Shepherd (2017) seems to be a good choice as long as a multi-model mean is performed to GCM groups separated by different dynamical responses to warming climate.

- Assessing the impact of these changes not only in South America but also in the South Atlantic ocean. It is well known that changes in cyclones impact precipitation patterns directly over the continent and wave generation. However, cyclone changes affect the transport of heat and moisture poleward and the formation of water associated with the distribution of heat in the ocean, which may cause positive or negative feedbacks in the climate change. 


\section{Bibliography}

Adler, R., and Coauthors, 2003: The Version 2 Global Precipitation Climatology Project (GPCP) Monthly Precipitation Analysis (1979-Present). J. Hydrometeor., (4), 11471167.

Bengtsson, L., K. I. Hodges, M. Easch, N. Keenlyside, L. Kornblueh, J. J. Luo, and T. Yamagata, 2007: How may tropical cyclones change in a warmer climate? Tellus, 59A, 539-561, doi:10.1111/j.1600-0870.2007.00251.x.

Bengtsson, L., K. I. Hodges, and N. Keenlyside, 2009: Will extratropical storms intensify in a warmer climate? J. Climate, 22 (9), 2276-2301, doi:10.1175/2008JCLI2678.1.

Bengtsson, L., K. I. Hodges, and E. Roeckner, 2006: Storm tracks and climate change. J. Climate, 19 (15), 3518-3543, doi:10.1175/JCLI3815.1.

Bjerknes, J., , and H. Solberg, 1922: Life cycle of cyclones and the polar front theory of atmospheric circulation. Geofys. Publ., 3, 1-18.

Blackmon, M. L., 1976: A climatological spectral study of the 500 mb geopotential height of the Northern Hemisphere. J. Atmos. Sci., 33 (8), 1607-1623, doi: 10.1175/1520-0469(1976)033〈1607:ACSSOT $\rangle 2.0 . \mathrm{CO} ; 2$.

Blackmon, M. L., J. M. Wallace, N.-C. Lau, and S. L. Mullen, 1977: An observational study of the Northern Hemisphere wintertime circulation. J. Atmos. Sci., 34 (7), 1040-1053, doi:10.1175/1520-0469(1977)034〈1040:AOSOTN〉2.0.CO;2.

Bluestein, H., 1992: Synoptic-Dynamic Meteorology in Midlatitudes: Principles of Kinematics and Dynamics, Vol. 1. Oxford University Press, 448 p. pp. 
Bolton, D., 1980: The computation of equivalent potential temperature. Mon. Wea. Rev., 108, 1046-1053.

Brayshaw, D. J., B. Hoskins, and M. Blackburn, 2011: The basic ingredients of the North Atlantic storm track. Part II: Sea surface temperatures. J. Atmos. Sci., 68 (8), 17841805, doi:10.1175/2011JAS3674.1.

Browning, K. A., and N. M. Roberts, 1994: Structure of a frontal cyclone. Quart. J. Roy. Meteor. Soc., 120 (520), 1535-1557, doi:10.1002/qj.49712052006.

Browning, K. A., and N. M. Roberts, 1996: Variation of frontal and precipitation structure along a cold front. Quart. J. Roy. Meteor. Soc., 122 (November 1995), 1845-1872, doi:10.1002/qj.49712253606.

Browning, K. A., N. M. Roberts, and A. J. Illingworth, 1997: Mesoscale analysis of the activation of a cold front during cyclogenesis. Quart. J. Roy. Meteor. Soc., 123 (544), 2349-2374, doi:10.1002/qj.49712354410.

Buzzi, A., A. Speranza, S. Tibaldi, and E. Tosi, 1987: A unified theory of orographic influences upon cyclogenesis. Meteorology and Atmospheric Physics, 36 (1), 91-107, doi:10.1007/BF01045143.

Campetella, C. M., and N. E. Possia, 2007: Upper-level cut-off lows in southern south america. Meteorol. Atmos. Phys., 96 (1-2), 181-191, doi:10.1007/s00703-006-0227-2.

Campetella, C. M., and C. S. Vera, 2002: The influence of the Andes mountains on the South American low-level flow. Geophys. Res. Lett., 29 (17), 7, doi:10.1029/ 2002GL015451.

Campos, E. J. D., C. A. D. Lentini, J. L. Miller, and A. R. Piola, 1999: Interannual variability of the sea surface temperature in the South Brazil Bight. Geophys. Res. Lett., 26 (14), 2061-2064, doi:10.1029/1999GL900297.

Campos, R. M., C. E. Parente, and R. de Camargo, 2012: Extreme wave analysis in Campos Basin (Rio de Janeiro - Brazil) associated with extra-tropical cyclones and anticyclones. Proceedings of the ASME 2012 31st International Conference on Ocean, 
Offshore and Arctic Engineering. Volume 2: Structures, Safety and Reliability, Rio de Janeiro, Brazil, 71-80, doi:10.1115/OMAE2012-83117.

Catto, J. L., 2016: Extratropical cyclone classification and its use in climate studies. Rev. Geophys., 54 (2), 486-520, doi:10.1002/2016RG000519.

Catto, J. L., L. C. Shaffrey, and K. I. Hodges, 2010: Can climate models capture the structure of extratropical cyclones? J. Climate, 23 (7), 1621-1635, doi:10.1175/ 2009JCLI3318.1.

Chang, E. K. M., Y. Guo, and X. Xia, 2012: CMIP5 multimodel ensemble projection of storm track change under global warming. J. Geophys. Res.: Atmos., 117 (23), 1-19, doi:10.1029/2012JD018578.

Chang, E. K. M., S. Lee, and K. L. Swanson, 2002: Storm track dynamics. J. Climate, 15 (16), 2163-2183, doi:10.1175/1520-0442(2002)015〈02163:STD $\rangle 2.0 . C O ; 2$.

Charney, J. G., 1947: The dynamics of long waves in a baroclinic westerly current. Journal of Meteorology, 4 (5), 136-162, doi:10.1175/1520-0469(1947)004〈0136:TDOLWI $\rangle 2$. $0 . \mathrm{CO} ; 2$.

Chou, S. C., A. M. B. Nunes, and I. F. A. Cavalcanti, 2000: Extended range forecasts over South America using the regional eta model. Journal of Geophysical Research: Atmospheres, 105 (D8), 10 147-10 160, doi:10.1029/1999JD901137.

Chou, S. C., and Coauthors, 2012: Downscaling of South America present climate driven by 4-member HadCM3 runs. Climate Dyn., 38 (3), 635-653, doi:10.1007/ s00382-011-1002-8.

Coelho, C., and Coauthors, 2016: The 2014 southeast Brazil austral summer drought: regional scale mechanisms and teleconnections. Climate Dyn., 46 (11-12), 3737-3752, doi:10.1007/s00382-015-2800-1.

Collins, W. J., and Coauthors, 2011: Development and evaluation of an Earth-system model â HadGEM2. Geoscientific Model Development Discussions, 4 (2), 997-1062, doi:10.5194/gmdd-4-997-2011. 
Combes, V., and R. P. Matano, 2014: Trends in the brazil/malvinas confluence region. Geophys. Res. Lett., 41 (24), 8971-8977, doi:10.1002/2014GL062523.

Cox, P. M., 2001: Description of the "TRIFFID" Dynamic Global Vegetation Model. Hadley Centre technical note 24, Hadley Centre, Met Office, Berkshire, UK, 16 pp. January.

da Rocha, R. P., C. A. Morales, S. V. Cuadra, and T. Ambrizzi, 2009: Precipitation diurnal cycle and summer climatology assessment over south america: An evaluation of regional climate model version 3 simulations. Journal of Geophysical Research: Atmospheres, 114 (D10), doi:10.1029/2008JD010212.

da Rocha, R. P., S. Sugahara, and R. B. da Silveira, 2004: Sea waves generated by extratropical cyclones in the South Atlantic Ocean: Hindcast and validation against altimeter data. Wea. Forecasting, 19 (2), 398-410, doi:10.1175/1520-0434(2004)019/0398: SWGBEC $>2.0 . \mathrm{CO} ; 2$.

da Silva, N. P., 2018: Estudo dos Mecanismos Vinculados ao Estabelecimento de um Evento de ZCAS Através de Simulações com o Modelo WRF. Ph.D. thesis, Departamento de Ciências Atmosféricas do Instituto de Astronomia, Geofísica e Ciências Atmosféricas da Universidade de São Paulo, São Paulo, BR.

Dacre, H. F., and S. L. Gray, 2006: Life-cycle simulations of shallow frontal waves and the impact of deformation strain. Quart. J. Roy. Meteor. Soc., 132 (620), 2171-2190, doi:10.1256/qj.05.238.

Dacre, H. F., M. K. Hawcroft, M. A. Stringer, and K. I. Hodges, 2012: An Extratropical Cyclone Atlas: A tool for illustrating cyclone structure and evolution characteristics. Bull. Amer. Meteor. Soc., 93 (10), 1497-1502, doi:10.1175/BAMS-D-11-00164.1.

Deveson, A. C., K. A. Browning, and T. D. Hewson, 2002: A classification of FASTEX cyclones using a height-attributable quasi-geostrophic vertical-motion diagnostic. Quart. J. Roy. Meteor. Soc., 128 (579), 93-117, doi:10.1256/00359000260498806.

Dias Pinto, J. R., and R. P. Da Rocha, 2011: The energy cycle and structural evolution of cyclones over southeastern South America in three case studies. J. Geophys. Res.: Atmos., 116 (14), 1-17, doi:10.1029/2011JD016217. 
Dias Pinto, J. R., M. S. Reboita, and R. P. Da Rocha, 2013: Synoptic and dynamical analysis of subtropical cyclone Anita (2010) and its potential for tropical transition over the South Atlantic Ocean. J. Geophys. Res.: Atmos., 118 (19), 10870-10883, doi:10.1002/jgrd.50830.

Doyle, J. D., 1995: Coupled ocean wave/atmosphere mesoscale model simulations of cyclogenesis. Tellus A, 47 (5), 766-778, doi:10.1034/j.1600-0870.1995.00119.x.

Drumond, A., R. Nieto, L. Gimeno, and T. Ambrizzi, 2008: A Lagrangian identification of major sources of moisture over Central Brazil and La Plata Basin. J. Geophys. Res.: Atmos., 113 (D14), doi:10.1029/2007JD009547.

Dutra, L. M. M., R. P. da Rocha, R. W. Lee, J. R. R. Peres, and R. de Camargo, 2017: Structure and evolution of subtropical cyclone Anita as evaluated by heat and vorticity budgets. Quart. J. Roy. Meteor. Soc., 143 (704), 1539-1553, doi:10.1002/qj.3024.

Eady, E. T., 1949: Long waves and cyclone waves. Tellus, 1 (3), 33-52, doi:10.1111/j. 2153-3490.1949.tb01265.x.

Ek, M. B., K. E. Mitchell, Y. Lin, E. Rogers, P. Grunmann, V. Koren, G. Gayno, and J. D. Tarpley, 2003: Implementation of noah land surface model advances in the national centers for environmental prediction operational mesoscale eta model. J. Geophys. Res.: Atmos., 108 (D22), n/a-n/a, doi:10.1029/2002JD003296, 8851.

Evans, J. L., and A. Braun, 2012: A climatology of subtropical cyclones in the South Atlantic. J. Climate, 25 (21), 7328-7340, doi:10.1175/JCLI-D-11-00212.1.

Frederiksen, C. S., and J. S. Frederiksen, 1991: Flow over topography and instability on a sphere. J. Atmos. Sci., 48 (22), 2411-2419, doi:10.1175/1520-0469(1991)048/2411: FOTAIO $\rangle$ 2.0.CO;2.

Funatsu, B. M., M. A. Gan, and E. Caetano, 2004: A case study of orographic cyclogenesis over South America. Atmosfera, 17 (2), 91-113.

Fyfe, J. C., 2003: Extratropical southern hemisphere cyclones: Harbingers of climate change? Journal of Climate, 16 (17), 2802-2805, doi:10.1175/1520-0442(2003)016<2802: $\mathrm{ESHCHO}\rangle 2.0 . \mathrm{CO} ; 2$. 
Gan, M. A., and V. B. Rao, 1991: Surface Cyclogenesis over South America. Mon. Wea. Rev., 119, 1293-1302.

Gan, M. A., and V. B. Rao, 1994: The influence of the Andes Cordillera on transient disturbances. Mon. Wea. Rev., 122, 1141-1157, doi:10.1175/1520-0493(1994)122〈1141: TIOTAC $>2.0 . \mathrm{CO} ; 2$.

Geng, Q., and M. Sugi, 2003: Possible change of extratropical cyclone activity due to enhanced greenhouse gases and sulfate aerosols - Study with a high-resolution AGCM. J. Climate, 16 (13), 2262-2274, doi:10.1175/1520-0442(2003)16〈2262:PCOECA $>2.0 . C O ; 2$.

Giorgi, F., and L. O. Mearns, 1991: Approaches to the simulation of regional climate change: A review. Reviews of Geophysics, 29 (2), 191-216, doi:10.1029/90RG02636.

Goni, G. J., F. Bringas, and P. N. DiNezio, 2011: Observed low frequency variability of the Brazil Current front. JGR: Oceans, 116 (C10), doi:10.1029/2011JC007198.

Gordon, A. L., 1989: Brazil-Malvinas Confluence - 1984. Deep Sea Research Part A. Oceanographic Research Papers, 36 (3), 359 - 384, doi:https://doi.org/10.1016/ 0198-0149(89)90042-3.

Gozzo, L. F., and R. P. da Rocha, 2013: Air-sea interaction processes influencing the development of a Shapiro-Keyser type cyclone over the Subtropical South Atlantic Ocean. Pure and Applied Geophysics, 170 (5), 917-934, doi:10.1007/s00024-012-0584-3.

Gozzo, L. F., R. P. da Rocha, M. S. Reboita, and S. Sugahara, 2014: Subtropical cyclones over the southwestern South Atlantic: Climatological aspects and case study. J. Climate, 27 (22), 8543-8562, doi:10.1175/JCLI-D-14-00149.1.

Gramcianinov, C. B., 2013: Variabilidade da Corrente do Brasil na região da Confluência Brasil-Malvinas através de simulações numéricas. M.S. thesis, Departamento de Oceanografia Física, Química e Geológica do Instituto Oceanográfico da Universidade de São Paulo, São Paulo, Brazil.

Grieger, J., G. Leckebusch, M. Donat, M. Schuster, and U. Ulbrich, 2014: Southern Hemisphere winter cyclone activity under recent and future climate conditions in multimodel AOGCM simulations. Int. J. Climatol., 34 (12), 3400-3416, doi:10.1002/joc.3917. 
Griffies, S., M. J. Harrison, R. C. Pacanowski, and A. Rosati, 2004: A technical guide to MOM4. (5), 342 pp., version prepared on August 23, 2004.

Guishard, M. P., J. L. Evans, and R. E. Hart, 2009: Atlantic subtropical storms. part ii: Climatology. J. Climate, 22 (13), 3574-3594, doi:10.1175/2008JCLI2346.1.

Hadlock, R., and C. W. Kreitzberg, 1988: The Experiment on Rapidly Intensifying Cyclones over the Atlantic (ERICA) Field Study: Objectives and Plans. Bull. Amer. Meteor. Soc., 69 (11), 1309-1320, doi:10.1175/1520-0477(1988)069〈1309:TEORIC $\rangle 2.0 . C O ; 2$.

Hart, R. E., 2003: A cyclone phase space derived from thermal wind and thermal asymmetry. Mon. Wea. Rev., 131 (4), 585-616, doi:10.1175/1520-0493(2003)131<0585: ACPSDF $>2.0 . \mathrm{CO} ; 2$.

Hayasaki, M., R. Kawamura, M. Mori, and M. Watanabe, 2013: Response of extratropical cyclone activity to the Kuroshio large meander in northern winter. Geophys. Res. Lett., 40 (11), 2851-2855, doi:10.1002/grl.50546.

Held, I. M., 1993: Large-scale dynamics and global warming. Bull. Amer. Meteor. Soc., 74 (2), 228-242, doi:10.1175/1520-0477(1993)074〈0228:LSDAGW $\rangle 2.0 . C O ; 2$.

Held, I. M., and B. J. Soden, 2006: Robust responses of the hydrologic cycle to global warming. J. Climate, 19, 5686-5699, doi:10.1175/JCLI3990.1.

Hodges, K. I., 1994: A general-method for tracking analysis and its application to meteorological data. Mon. Wea. Rev., 122 (11), 2573-2586, doi:10.1175/1520-0493(1994) 122<2573:AGMFTA $\rangle 2.0 . \mathrm{CO} ; 2$.

Hodges, K. I., 1995: Feature tracking on the unit sphere. Mon. Wea. Rev., 123 (12), 3458-3465, doi:10.1175/1520-0493(1995)123〈3458:FTOTUS $\rangle 2.0 . C O ; 2$.

Hodges, K. I., 1996: Spherical nonparametric estimators applied to the UGAMP model integration for AMIP. Mon. Wea. Rev., 124 (12), 2914-2932, doi:10.1175/ 1520-0493(1996)124〈2914:SNEATT $\rangle$ 2.0.CO;2.

Hodges, K. I., 1999: Adaptative Constraints for Feature Tracking. Mon. Wea. Rev., 127, 1362-1373, doi:10.1175/1520-0493(1999)127〈1362:ACFFT $\rangle 2.0 . C O ; 2$. 
Hodges, K. I., R. W. Lee, and L. Bengtsson, 2011: A Comparison of Extratropical Cyclones in Recent Reanalyses ERA-Interim, NASA MERRA, NCEP CFSR, and JRA-25. J. Climate, 24, 4888-4906, doi:10.1175/2011JCLI4097.1.

Hong, S.-Y., J. Dudhia, and S.-H. Chen, 2004: A revised approach to ice microphysical processes for the bulk parameterization of clouds and precipitation. Mon. Wea. Rev., 132 (1), 103-120, doi:10.1175/1520-0493(2004)132〈0103:ARATIM $\rangle 2.0 . C O ; 2$.

Hong, S.-Y., Y. Noh, and J. Dudhia, 2006: A new vertical diffusion package with an explicit treatment of entrainment processes. Mon. Wea. Rev., 134 (9), 2318-2341, doi: 10.1175/MWR3199.1.

Hoskins, A., and K. I. Hodges, 2005: A New Perspective on the Southern Hemisphere Storm Tracks. J. Climate, 18, 4108-4129.

Hoskins, B. J., 1976: Baroclinic waves and frontogenesis part i: Introduction and eady waves. Quart. J. Roy. Meteor. Soc., 102 (431), 103-122, doi:10.1002/qj.49710243109.

Hoskins, B. J., and W. A. J. Heckley, 1981: Cold and warm fronts in baroclinic waves. Quart. J. Roy. Meteor. Soc., 107 (451), 79-90, doi:10.1002/qj.49710745105.

Hoskins, B. J., and K. I. Hodges, 2002: New Perspectives on the Northern Hemisphere Winter Storm Tracks. J. Atmos. Sci., 59, 1041-1061, doi:10.1175/1520-0469(2002)059〈1041: NPOTNH $>2.0 . \mathrm{CO} ; 2$.

Hoskins, B. J., M. E. McIntyre, and A. W. Robertson, 1985: On the use and significance of isentropic potential vorticity maps. Quart. J. Roy. Meteor. Soc., 111 (470), 877-946, doi:10.1002/qj.49711147002.

Hoskins, B. J., and P. J. Valdes, 1990: On the Existence of Storm-Tracks. J. Atmos. Sci., 47 (15), 1854-1864, doi:10.1175/1520-0469(1990)047〈1854:OTEOST $\rangle 2.0 . C O ; 2$.

Iacono, M. J., J. S. Delamere, E. J. Mlawer, M. W. Shephard, S. A. Clough, and W. D. Collins, 2008: Radiative forcing by long-lived greenhouse gases: Calculations with the AER radiative transfer models. J. Geophys. Res.: Atmos., 113 (D13), doi:10.1029/ 2008JD009944. 
Innocentini, V., and E. D. S. C. Neto, 1996: A case study of the 9 august 1988 South Atlantic storm: Numerical simulations of the wave activity. Wea. Forecasting, 11 (1), 78-88, doi:10.1175/1520-0434(1996)011<0078:ACSOTA〉2.0.CO;2.

IPCC, 2013: Climate Change 2013: The Physical Science Basis. Contribution of Working Group I to the Fifth Assessment Report of the Intergovernmental Panel on Climate Change. Cambridge University Press, Cambridge, United Kingdom and New York, NY, USA, $1535 \mathrm{pp}$.

Iwabe, C. M. N., and R. P. da Rocha, 2009: An event of stratospheric air intrusion and its associated secondary surface cyclogenesis over the south atlantic ocean. J. Geophys. Res.: Atmospheres, 114 (D9), doi:10.1029/2008JD011119, d09101.

Johns, T. C., and Coauthors, 2006: The new Hadley Centre Climate Model (HadGEM1): evaluation of coupled simulations. J. Climate, 19 (7), 1327-1353, doi:10.1175/JCLI3712. 1.

Joly, A., and Coauthors, 1997: The Fronts and Atlantic Storm-Track Experiment (FASTEX): Scientific objectives and experimental design. Bull. Amer. Meteor. Soc., 78 (9), 1917-1940, doi:10.1175/1520-0477(1997)078〈1917:TFAAST $\rangle 2.0 . C O ; 2$.

Jones, C., and L. M. V. Carvalho, 2013: Climate change in the South American Monsoon System: Present climate and CMIP5 projections. J. Climate, 26 (17), 6660-6678, doi: 10.1175/JCLI-D-12-00412.1.

Jones, D. A., and I. Simmonds, 1993: A climatology of Southern Hemisphere extratropical cyclones. Climate Dyn., 9 (3), 131â145, doi:10.1007/BF00209750.

Kain, J. S., 2004: The Kain-Fritsch convective parameterization: An update. J. Appl. Meteor., 43 (1), 170-181, doi:10.1175/1520-0450(2004)043〈0170:TKCPAU $\rangle 2.0 . C O ; 2$.

Kanamitsu, M., W. Ebisuzaki, J. Woollen, S.-K. Yang, J. J. Hnilo, M. Fiorino, and G. L. Potter, 2002: NCEPâDOE AMIP-II Reanalysis (R-2). Bull. Amer. Meteor. Soc., 83 (11), 1631-1644, doi:10.1175/BAMS-83-11-1631.

Keyser, D., B. D. Schmidt, and D. G. Duffy, 1989: A technique for representing threedimensional vertical circulations in baroclinic disturbances. Mon. Wea. Rev., 117 (11), 2463-2494, doi:10.1175/1520-0493(1989)117〈2463:ATFRTD $\rangle 2.0 . C O ; 2$. 
Kidston, J., and E. P. Gerber, 2010: Intermodel variability of the poleward shift of the austral jet stream in the CMIP3 integrations linked to biases in 20th century climatology. Geophys. Res. Lett., 37 (9), 1-5, doi:10.1029/2010GL042873.

Krüger, L. F., R. P. da Rocha, M. S. Reboita, and T. Ambrizzi, 2012: RegCM3 nested in HadAM3 scenarios A2 and B2: Projected changes in extratropical cyclogenesis, temperature and precipitation over the South Atlantic Ocean. Climatic Change, 113 (3-4), 599-621, doi:10.1007/s10584-011-0374-4.

Kuo, Y.-H., M. A. Shapiro, and E. G. Donall, 1991: The interaction between baroclinic and diabatic processes in a numerical simulation of a rapidly intensifying extratropical marine cyclone. Mon. Wea. Rev., 119 (2), 368-384, doi:10.1175/1520-0493(1991)119〈0368: TIBBAD $>2.0 . \mathrm{CO} ; 2$.

Lambert, S. J., and J. C. Fyfe, 2006: Changes in winter cyclone frequencies and strengths simulated in enhanced greenhouse warming experiments: Results from the models participating in the IPCC diagnostic exercise. Climate Dyn., 26 (7-8), 713-728, doi: 10.1007/s00382-006-0110-3.

Lee, R. W., 2014: Storm track biases and changes in a warming climate from an extratropical cyclone perspective using CMIP5. Ph.D. thesis, Department of Meteorology, University of Reading, Reading, UK.

Lim, E.-P., and I. Simmonds, 2002: Explosive Cyclone Development in the Southern Hemisphere and a Comparison with Northern Hemisphere Events. Mon. Wea. Rev., 130 (9), 2188-2209, doi:10.1175/1520-0493(2002)130〈2188:ECDITS $\rangle 2.0 . C O ; 2$.

Lu, J., G. Chen, and D. M. Frierson, 2008: Response of the zonal mean atmospheric circulation to El Niño versus global warming. J. Climate, 21 (22), 5835-5851, doi: 10.1175/2008JCLI2200.1.

Lumpkin, R., and S. Garzoli, 2011: Interannual to decadal changes in the western South Atlantic's surface circulation. J. Geophys. Res., 116 (C1), doi:10.1029/2010JC006285.

Marengo, J. A., M. W. Douglas, and P. L. S. Dias, 2002: The South American lowâlevel jet east of the Andes during the 1999 LBA-TRMM and LBA-WET AMC campaign. $J$. Geophys. Res.: Atmos., 107 (D20), LBA 47-1-LBA 47-11, doi:10.1029/2001JD001188. 
Marengo, J. A., W. R. Soares, C. Saulo, and M. Nicolini, 2004: Climatology of the low-level jet east of the Andes as derived from the NCEP-NCAR Reanalyses: Characteristics and temporal variability. J. Climate, 17 (12), 2261-2280, doi:10.1175/1520-0442(2004) 017<2261:COTLJE $\rangle$ 2.0.CO;2.

Marengo, J. A., and Coauthors, 2010: Future change of climate in South America in the late twenty-first century: Intercomparison of scenarios from three regional climate models. Climate Dyn., 35 (6), 1089-1113, doi:10.1007/s00382-009-0721-6.

Martin, G. M., and Coauthors, 2011: The HadGEM2 family of Met Office Unified Model climate configurations. Geoscientific Model Development, 4 (3), 723-757, doi:10.5194/ gmd-4-723-2011.

Mendes, D., E. P. Souza, J. Marengo, and M. C. D. Mendes, 2010: Climatology of extratropical cyclones over the South American-southern oceans sector. Theoretical and Applied Climatology, 100 (3), 239-250, doi:10.1007/s00704-009-0161-6.

Mendes, D., E. P. Souza, F. Trigo, Isabel, and P. M. A. Miranda, 2007: On precursors of South American cyclogenesis. Tellus, 59A, 114-121, doi:10.1111/j.1600-0870.2006. 00215.x.

Mizuta, R., 2012: Intensification of extratropical cyclones associated with the polar jet change in the CMIP5 global warming projections. Geophys. Res. Lett., 39 (19), 1-6, doi:10.1029/2012GL053032.

Mlawer, E. J., S. J. Taubman, P. D. Brown, M. J. Iacono, and S. A. Clough, 1997: Radiative transfer for inhomogeneous atmospheres: Rrtm, a validated correlated-k model for the longwave. J. Geophys. Res., 102 (D14), 16 663-16 682, doi:10.1029/97JD00237.

Murray, F. W., 1967: On the computation of saturation vapor pressure. J. Appl. Meteor., 6 (1), 203-204, doi:10.1175/1520-0450(1967)006〈0203:OTCOSV $\rangle$ 2.0.CO;2.

Murray, R. J., and I. Simmonds, 1991: A numerical scheme for tracking cyclone centres from digital data Part II: application to January and July general circulation model simulations. Australian Meteorological Magazine, 39, 167-180. 
NCL, 2018: The NCAR Command Language (Version 6.4.0). Boulder, Colorado: UCAR/NCAR/CISL/TDD, Software, doi:http://dx.doi.org/10.5065/D6WD3XH5.

Ndarana, T., D. W. Waugh, L. M. Polvani, G. J. P. Correa, and E. P. Gerber, 2012: Antarctic ozone depletion and trends in tropopause Rossby wave breaking. Atmospheric Science Letters, 13 (3), 164-168, doi:10.1002/asl.384.

Neiman, P. J., and M. A. Shapiro, 1993: The life cycle of an extratropical marine cyclone. Part I: frontal-cyclone evolution and thermodynamic air-sea interaction. Mon. Wea. Rev., 121 (8), 2153-2176, doi:10.1175/1520-0493(1993)121〈2153:TLCOAE〉2.0.CO;2.

Niu, G.-Y., and Coauthors, 2011: The community Noah land surface model with multiparameterization options (Noah-MP): 1. Model description and evaluation with local-scale measurements. J. Geophys. Res., 116 (D12), doi:10.1029/2010JD015139.

Nuss, W. A., and R. A. Anthes, 1987: A numerical investigation of low-level processes in rapid cyclogenesis. Mon. Wea. Rev., 115 (11), 2728-2743, doi:10.1175/1520-0493(1987) 115<2728:ANIOLL $>2.0 . \mathrm{CO} ; 2$.

O'Connor, F. M., and Coauthors, 2014: Evaluation of the new ukca climate-composition model â part 2: The troposphere. Geoscientific Model Development, 7 (1), 41-91, doi: 10.5194/gmd-7-41-2014.

O'Gorman, P. A., 2010: Understanding the varied response of the extratropical storm tracks to climate change. Proceedings of the National Academy of Sciences, 107 (45), $19176-19$ 180, doi:10.1073/pnas.1011547107.

Olson, D. B., G. P. Podest Â $i$, R. H. Evans, and O. B. Brown, 1988: Temporal variations in the separation of Brazil and Malvinas currents. Deep Sea Research Part A. Oceanographic Research Papers, 35 (12), 1971 - 1990, doi:https://doi.org/10.1016/ 0198-0149(88)90120-3.

Omrani, H., P. Drobinski, and T. Dubos, 2011: Investigation of indiscriminate nudging and predictability in a nested quasi-geostrophic model. Quart. J. Roy. Meteor. Soc., 138 (662), 158-169, doi:10.1002/qj.907. 
Omrani, H., P. Drobinski, and T. Dubos, 2015: Using nudging to improve global-regional dynamic consistency in limited-area climate modeling: What should we nudge? Climate Dyn., 44 (5), 1627-1644, doi:10.1007/s00382-014-2453-5.

Palmer, J., and I. Totterdell, 2001: Production and export in a global ocean ecosystem model. Deep Sea Research Part I: Oceanographic Research Papers, 48 (5), 1169 - 1198, doi:https://doi.org/10.1016/S0967-0637(00)00080-7.

Parise, C. K., L. J. Calliari, and N. Krusche, 2009: Extreme storm surges in the south of Brazil: atmospheric conditions and shore erosion. Braz. J. Oceanogr., 57, 175 - 188, doi:10.1590/S1679-87592009000300002.

Petterssen, S., and S. J. Smebye, 1971: On the development of extratropical cyclones. Quart. J. Roy. Meteor. Soc., 97 (414), 457-482, doi:10.1002/qj.49709741407.

Pezza, A. B., and T. Ambrizzi, 2003: Variability of Southern Hemisphere cyclone and anticyclone behavior: Further analysis. J. Climate, 16 (7), 1075-1083, doi:10.1175/ 1520-0442(2003)016〈1075:VOSHCA $>2.0 . \mathrm{CO} ; 2$.

Pezza, A. B., L. A. Garde, J. A. P. Veiga, and I. Simmonds, 2014: Large scale features and energetics of the hybrid subtropical low 'Duck' over the Tasman Sea. Climate Dyn., 42 (1-2), 453-466, doi:10.1007/s00382-013-1688-х.

Pezza, A. B., J. A. P. Veiga, I. Simmonds, K. Keay, and M. S. Mesquita, 2010: Environmental energetics of an exceptional high-latitude storm. Atmospheric Science Letters, 11 (1), 39-45, doi:10.1002/asl.253.

Pinto, J. G., T. Spangehl, U. Ulbrich, and P. Speth, 2005: Sensitivities of a cyclone detection and tracking algorithm: individual tracks and climatology. Meteorologische Zeitschrift, 14 (6), 823-838, doi:10.1127/0941-2948/2005/0068.

Pinto, J. G., U. Ulbrich, G. C. Leckebusch, T. Spangehl, M. Reyers, and S. Zacharias, 2007: Changes in storm track and cyclone activity in three SRES ensemble experiments with the ECHAM5/MPI-OM1 GCM. Climate Dyn., 29 (2-3), 195-210, doi:10.1007/ s00382-007-0230-4. 
Piola, A. R., E. J. D. Campos, O. O. Möller, M. Charo, and C. Martinez, 2000: Subtropical shelf front off eastern south america. J. Geophys. Res.: Oceans, 105 (C3), 6565-6578, doi:10.1029/1999JC000300.

Piola, A. R., O. O. Möller, R. A. Guerrero, and E. J. Campos, 2008: Variability of the subtropical shelf front off eastern South America: Winter 2003 and summer 2004. Continental Shelf Research, 28 (13), 1639-1648, doi:10.1016/j.csr.2008.03.013.

Piva, E. D., M. C. d. L. Moscati, and M. A. Gan, 2008: Papel dos fluxos de calor latente e sensível em superfície associado a um caso de ciclogênese na costa leste da América do Sul. Rev. Bras. Meteorol., 23 (4), 450-476.

Pontes, G. M., A. S. Gupta, and A. S. Taschetto, 2016: Projected changes to South Atlantic boundary currents and confluence region in the CMIP5 models: the role of wind and deep ocean changes. Environmental Research Letters, 11 (9), 094013.

Reboita, M. S., 2008: Ciclones extratropicais sobre o Atlântico Sul: Simulação Climática e Experimentos de Sensibilidade. Ph.D. thesis, Departamento de Ciências Atmosféricas do Instituto de Astronomia, Geofísica e Ciências Atmosféricas da Universidade de São Paulo, São Paulo, BR.

Reboita, M. S., T. Ambrizzi, and R. P. da Rocha, 2009: Relationship between the Southern Annular Mode and Southern Hemisphere atmospheric systems. Rev. Bras. Meteorol., 24, 48-55, doi:10.1590/S0102-77862009000100005.

Reboita, M. S., R. P. da Rocha, T. Ambrizzi, and E. S. Caetano, 2010: An assessment of the latent and sensible heat flux on the simulated regional climate over Southwestern South Atlantic Ocean. Climate Dyn., 34 (6), 873-889, doi:10.1007/s00382-009-0681-x.

Reboita, M. S., R. P. da Rocha, T. Ambrizzi, and C. D. Gouveia, 2015: Trend and teleconnection patterns in the climatology of extratropical cyclones over the Southern Hemisphere. Climate Dyn., 45 (7-8), 1929â1944, doi:10.1007/s00382-014-2447-3.

Reboita, M. S., R. P. da Rocha, T. Ambrizzi, and S. Sugahara, 2010a: South Atlantic Ocean cyclogenesis climatology simulated by regional climate model (RegCM3). Climate Dyn., 35 (7-8), 1331-1347, doi:10.1007/s00382-009-0668-7. 
Reboita, M. S., R. P. da Rocha, M. R. de Souza, and M. Llopart, 2018: Extratropical cyclones over the southwestern South Atlantic Ocean: HadGEM2-ES and RegCM4 projections. Int. J. Climatol., 0 (0), 1-14, doi:10.1002/joc.5468.

Reboita, M. S., M. A. Gan, R. P. da Rocha, and T. Ambrizzi, 2010b: Precipitation regimes in South America: a bibliography review. Rev. Bras. Meteorol., 25, 185 - 204, doi: 10.1590/S0102-77862010000200004.

Reboita, M. S., M. A. Gan, R. P. da Rocha, and I. S. Custódio, 2017: Ciclones em Superfície nas Latitudes Austrais: Parte I Revisão Bibliográfica. Rev. Bras. Meteorol., 32 (2), 171-186, doi:10.1590/0102-7786324002.

Reboita, M. S., R. Nieto, L. Gimeno, R. P. da Rocha, T. Ambrizzi, R. Garreaud, and L. F. Krüger, 2010: Climatological features of cutoff low systems in the Southern Hemisphere. J. Geophys. Res., 115 (D17), doi:10.1029/2009JD013251.

Reed, R. J., and A. J. Simmons, 1991: Numerical simulation of an explosively deepening cyclone over the north atlantic that was unaffected by concurrent surface energy fluxes. Wea. Forecasting, 6 (1), 117-122, doi:10.1175/1520-0434(1991)006〈0117:NSOAED $\rangle 2.0$. $\mathrm{CO} ; 2$.

Ren, X., W. Perrie, Z. Long, and J. Gyakum, 2004: Atmosphere â Ocean Coupled Dynamics of Cyclones in the Midlatitudes. Mon. Wea. Rev., 132, 2432-2451, doi: 10.1175/1520-0493(2004)132<2432.

Renfrew, I. A., A. J. Thorpe, and C. H. Bishop, 1997: The role of the environmental flow in the development of secondary frontal cyclones. Quart. J. Roy. Meteor. Soc., 123 (542), 1653-1675, doi:10.1002/qj.49712354210.

Riahi, K., and Coauthors, 2011: RCP 8.5 - A scenario of comparatively high greenhouse gas emissions. Climatic Change, 109, 33-37.

Ribeiro, B. Z., M. E. Seluchi, and S. C. Chou, 2016: Synoptic climatology of warm fronts in Southeastern South America. International Journal of Climatology, 36 (2), 644-655, doi:10.1002/joc. 4373 . 
Rienecker, M. M., and Coauthors, 2011: MERRA: NASAâs Modern-Era Retrospective Analysis for Research and Applications. J. Climate, 24 (14), 3624-3648, doi:10.1175/ JCLI-D-11-00015.1.

Rocha, L. N., 2017: Estudo de caso de Sting Jet num ciclone extratropical do tipo ShapiroKeyser no Atlântico Sul. M.S. thesis, Departamento de Ciências Atmosféricas do Instituto de Astronomia, Geofísica e Ciências Atmosféricas da Universidade de São Paulo, São Paulo, Brazil.

Saha, S., and Coauthors, 2010: The ncep climate forecast system reanalysis. Bull. Amer. Meteor. Soc., 91 (8), 1015-1058, doi:10.1175/2010BAMS3001.1.

Sanders, F., and J. R. Gyakum, 1980: Synoptic-dynamic climatology of the âbombâ. Mon. Wea. Rev., (10), 1589-1606, doi:10.1175/1520-0493(1980)108〈1589:SDCOT $\rangle 2.0 . C O ; 2$.

Sardeshmukh, P. D., and B. I. Hoskins, 1984: Spatial smoothing on the sphere. Mon. Wea. Rev., 112 (12), 2524-2529, doi:10.1175/1520-0493(1984)112〈2524:SSOTS $\rangle 2.0 . C O ; 2$.

Satyamurty, P., C. C. Ferreira, and M. A. Gan, 1990: Cyclonic vortices over South America. Tellus A, 42 (1), 194-201.

Saulo, A. C., M. E. Seluchi, and M. Nicolini, 2004: A case study of a Chaco Low-Level Jet event. Mon. Wea. Rev., 132 (11), 2669-2683, doi:10.1175/MWR2815.1.

Schultz, D. M., D. Keyser, and L. F. Bosart, 1998: The effect of large-scale flow on lowlevel frontal structure and evolution in midlatitude cyclones. Mon. Wea. Rev., 126 (7), 1767-1791, doi:10.1175/1520-0493(1998)126〈1767:TEOLSF $\rangle$ 2.0.CO;2.

Seluchi, M. E., and A. C. Saulo, 1998: Possible mechanisms yielding an explosive coastal cyclogenesis over South America: experiments using a limited area model. Aust. Meteor. Mag., 47, 309-320.

Seluchi, M. E., and A. C. Saulo, 2012: Baixa do Noroeste Argentino e Baixa do Chaco: caracterísitcas, diferenças e semelhanças. Rev. Bras. Meteorol., 27 (1), 49-60.

Seluchi, M. E., A. C. Saulo, M. Nicolini, and P. Satyamurty, 2003: The northwestern argentinean low: A study of two typical events. Mon. Wea. Rev., 131 (10), 2361-2378, doi:10.1175/1520-0493(2003)131〈2361:TNALAS $\rangle 2.0 . C O ; 2$. 
Semple, A. T., 2003: A review and unification of conceptual models of cyclogenesis. Meteor. Appl., 10 (1), 39-59, doi:10.1017/S135048270300505X.

Seth, A., M. Rojas, and S. A. Rauscher, 2010: CMIP3 projected changes in the annual cycle of the South American Monsoon. Climatic Change, 98 (3-4), 331-357, doi:10. 1007/s10584-009-9736-6.

Shapiro, M. A., and D. Keyser, 1990: Fronts, jet streams and the tropopause. Extratropical Cyclones, The Erik Palmen Memorial Volume, C. W. Newton, and E. O. Holopainen, Eds., Amer. Meteor. Soc., 167-191.

Simmonds, I., and K. Keay, 2000a: Mean southern hemisphere extratropical cyclone behavior in the 40-year NCEP-NCAR reanalysis. J. Climate, 13 (5), 873-885, doi: 10.1175/1520-0442(2000)013〈0873:MSHECB $\rangle 2.0 . \mathrm{CO} ; 2$.

Simmonds, I., and K. Keay, 2000b: Variability of Southern Hemisphere Extratropical Cyclone Behavior, 1958â97. J. Climate, 13, 550-561, doi:10.1175/1520-0442(2000) 013<0550:VOSHEC $\rangle 2.0 . \mathrm{CO} ; 2$.

Simpson, I. R., and L. M. Polvani, 2016: Revisiting the relationship between jet position, forced response, and annular mode variability in the southern midlatitudes. Geophys. Res. Lett., 43 (6), 2896-2903, doi:10.1002/2016GL067989.

Simpson, I. R., T. A. Shaw, and R. Seager, 2014: A diagnosis of the seasonally and longitudinally varying midlatitude circulation response to global warming. J. Atmos. Sci., 71 (7), 2489-2515, doi:10.1175/JAS-D-13-0325.1.

Sinclair, M. R., 1994: An objective cyclone climatology for the Southern Hemisphere. Mon. Wea. Rev., 122 (10), 2239-2256, doi:10.1175/1520-0493(1994)122〈2239:AOCCFT $\rangle 2.0$. $\mathrm{CO} ; 2$.

Sinclair, M. R., 1995: A climatology of cyclogenesis for the Southern Hemisphere. Mon. Wea. Rev., 123, 1601-1619.

Sinclair, M. R., 1997: Objective identification of cyclones and their circulation intensity, and climatology. Wea. Forecasting, 12 (3), 595-612, doi:10.1175/1520-0434(1997) 012<0595:OIOCAT $\rangle$ 2.0.CO;2. 
Skamarock, W. C., J. B. Klemp, J. Dudhia, D. O. Gill, D. M. Barker, M. G. Duda, W. W. X.-Y. Huang, and J. G. Powers, 2008: A Description of the Advanced Research WRF Version 3. Ncar technical note ncar/tn-475+str, 113 pp. doi:10.5065/D68S4MVH.

Solman, S. A., M. N. Nuñez, and M. F. Cabré, 2008: Regional climate change experiments over southern south america. i: present climate. Climate Dyn., 30 (5), 533-552, doi: 10.1007/s00382-007-0304-3.

Solman, S. A., and Coauthors, 2013: Evaluation of an ensemble of regional climate model simulations over South America driven by the ERA-Interim reanalysis: Model performance and uncertainties. Climate Dyn., 41 (5-6), 1139-1157, doi:10.1007/ s00382-013-1667-2.

Stauffer, D. R., and N. L. Seaman, 1990: Use of Four-Dimensional Data Assimilation in a Limited-Area Mesoscale Model. Part I: Experiments with Synoptic-Scale Data. Mon. Wea. Rev., 118 (6), 1250-1277, doi:10.1175/1520-0493(1990)118〈1250:UOFDDA $>2.0$. $\mathrm{CO} ; 2$.

Stopa, J. E., and K. F. Cheung, 2014: Intercomparison of wind and wave data from the ECMWF Reanalysis Interim and the NCEP Climate Forecast System Reanalysis. Ocean Modelling, 75, 65-83, doi:10.1016/j.ocemod.2013.12.006.

Streten, N. A., and A. J. Troup, 1973: A synoptic climatology of satellite observed cloud vortices over the southern hemisphere. Quart. J. Roy. Meteor. Soc., 99 (419), 56-72, doi:10.1002/qj.49709941906.

Taljaard, J. J., 1967: Development, distribution and movement of cyclones and anticyclones in the Southern Hemisphere during the IGY. J. Appl. Meteor., 6 (6), 973-987, doi:10.1175/1520-0450(1967)006〈0973:DDAMOC $\rangle$ 2.0.CO;2.

Taylor, K. E., R. J. Stouffer, and G. A. Meehl, 2012: An overview of CMIP5 and the experiment design. Bull. Amer. Meteor. Soc., 93 (4), 485-498, doi:10.1175/ BAMS-D-11-00094.1.

Thomson, A. M., and Coauthors, 2011: RCP4.5: A pathway for stabilization of radiative forcing by 2100. Climatic Change, 109 (1), 77-94, doi:10.1007/s10584-011-0151-4. 
Tibaldi, S., A. Buzzi, and P. Malguzzi, 1980: Orographically induced cyclogenesis: Analysis of numerical experiments. Mon. Wea. Rev., 108 (9), 1302-1314, doi:10.1175/ 1520-0493(1980)108〈1302:OICAON $\rangle 2.0 . \mathrm{CO} ; 2$.

Uccellini, L. W., R. A. Petersen, P. J. Kocin, K. F. Brill, and J. J. Tuccillo, 1987: Synergistic interactions between an upper-level jet streak and diabatic processes that influence the development of a low-level jet and a secondary coastal cyclone. Mon. Wea. Rev., 115 (10), 2227-2261, doi:10.1175/1520-0493(1987)115〈2227:SIBAUL $\rangle 2.0 . C O ; 2$.

Ulbrich, U., G. C. Leckebusch, and J. G. Pinto, 2009: Extra-tropical cyclones in the present and future climate: A review. Theoretical and Applied Climatology, 96 (1-2), 117-131, doi:10.1007/s00704-008-0083-8.

van Loon, H., 1965: A climatological Study of the Atmospheric Circulation in the Southern Hemisphere during the IGY, Part I: 1 July 1957â31 March 1958. J. Appl. Meteor., 4 (4), 479-491, doi:10.1175/1520-0450(1965)004〈0479:ACSOTA〉2.0.CO;2.

Veiga, J. A. P., A. B. Pezza, I. Simmonds, and P. L. Silva Dias, 2008: An analysis of the environmental energetics associated with the transition of the first South Atlantic hurricane. Geophys. Res. Lett., 35 (15), 1-6, doi:10.1029/2008GL034511.

Vera, C., and Coauthors, 2006: Toward a unified view of the American Monsoon Systems. J. Climate, 19 (20), 4977-5000, doi:10.1175/JCLI3896.1.

Vera, C. S., P. K. Vigliarolo, and E. H. Berbery, 2002: Cold season synoptic-scale waves over subtropical South America. Mon. Wea. Rev., 130 (3), 684-699, doi: 10.1175/1520-0493(2002)130<0684:CSSSWO $\rangle 2.0 . \mathrm{CO} ; 2$.

Vianna, M. L., V. V. Menezes, A. B. Pezza, and I. Simmonds, 2010: Interactions between Hurricane Catarina (2004) and warm core rings in the South Atlantic Ocean. J. Geophys. Res., 115 (7), 1-19, doi:10.1029/2009JC005974.

Wang, X. L., V. R. Swail, and F. W. Zwiers, 2006: Climatology and changes of extratropical cyclone activity: Comparison of ERA-40 with NCEP-NCAR reanalysis for 1958-2001. J. Climate, 19 (13), 3145-3166, doi:10.1175/JCLI3781.1. 
Warner, T. T., 2010: Numerical Weather and Climate Prediction. Cambridge University Press, doi:10.1017/CBO9780511763243.

Whitaker, J. S., and C. A. Davis, 1994: Cyclogenesis in a saturated environment. 51 (6), 889-908, doi:10.1175/1520-0469(1994)051〈0889:CIASE $\rangle$ 2.0.CO;2.

Wilcox, L. J., A. J. Charlton-Perez, and L. J. Gray, 2012: Trends in Austral jet position in ensembles of high- and low-top CMIP5 models. Journal of Geophysical Research Atmospheres, 117 (13), 1-10, doi:10.1029/2012JD017597.

Wittman, M. A. H., A. J. Charlton, and L. M. Polvani, 2007: The Effect of Lower Stratospheric Shear on Baroclinic Instability. J. Atmos. Sci., 64 (2), 479-496, doi: 10.1175/JAS3828.1.

Zappa, G., and T. G. Shepherd, 2017: Storylines of atmospheric circulation change for european regional climate impact assessment. J. Climate, 30 (16), 6561-6577, doi: 10.1175/JCLI-D-16-0807.1.

Zhang, D., and R. A. Anthes, 1982: A high-resolution model of the planetary boundary layer-sensitivity tests and comparisons with SESAME-79 data. J. Appl. Meteor., 21 (11), 1594-1609, doi:10.1175/1520-0450(1982)021〈1594:AHRMOT $\rangle$ 2.0.CO;2. 
Appendix 

Appendix A

Complementary figures of Chapter 4 

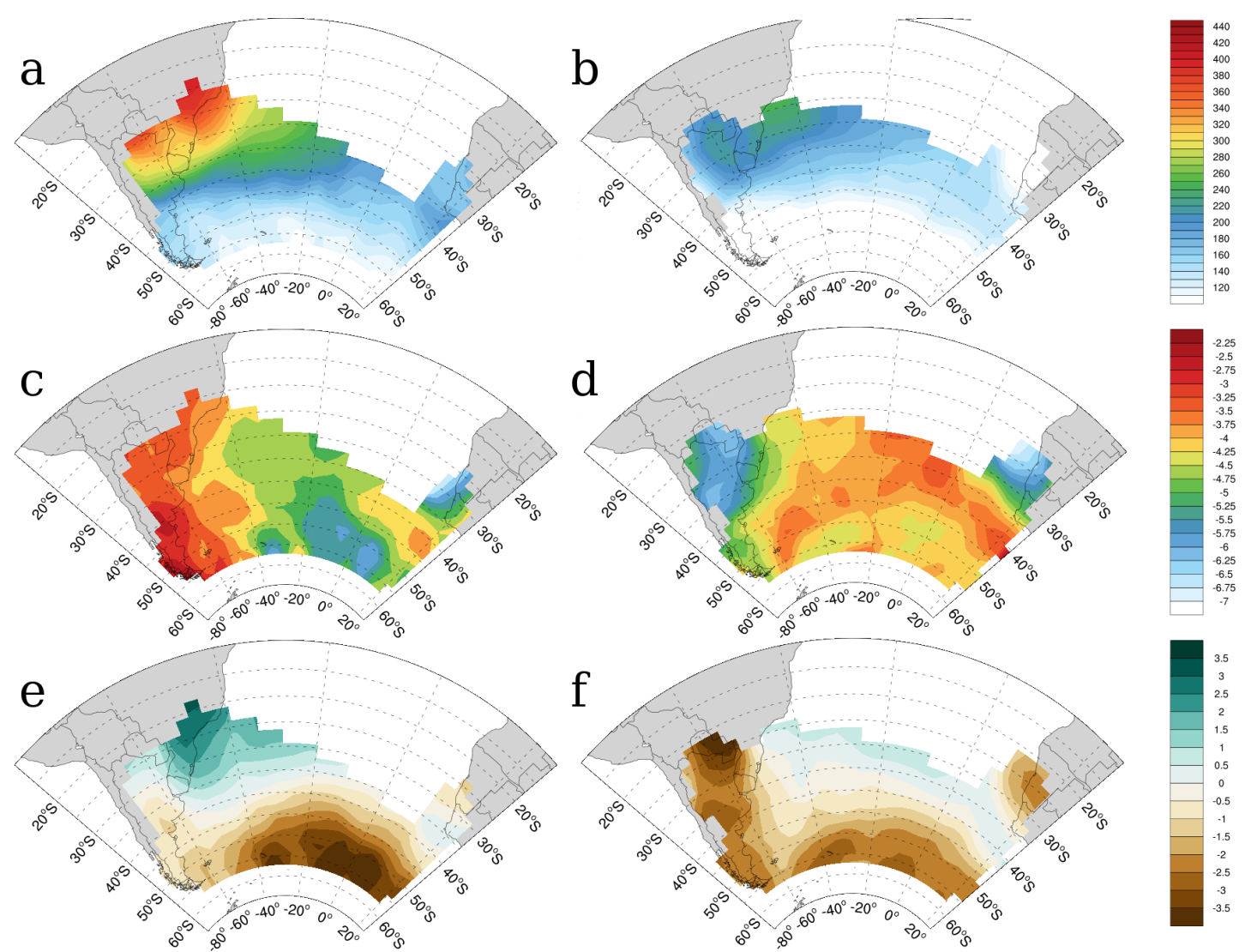

Figure A.1: Spatial distribution at the time of genesis of the integrated humidity at lower-level $(\mathrm{kg}$ $\left.\mathrm{kg}^{-1}\right)$ in (a) austral summer and (b) winter; $\partial \theta / \partial p\left(10^{-2} K h P a^{-1}\right)$ in (c) summer and (d) winter, and; $\partial \theta_{e} / \partial p\left(10^{-2} K h \mathrm{~Pa}^{-1}\right)$ in (e) summer and (f) winter. The fields are not plotted where genesis density $<0.2$ cyclones $\left(10^{6} \mathrm{~km}^{2}\right)^{-1} \mathrm{month}^{-1}$. 
Appendix B

Complementary figures of Chapter 5 


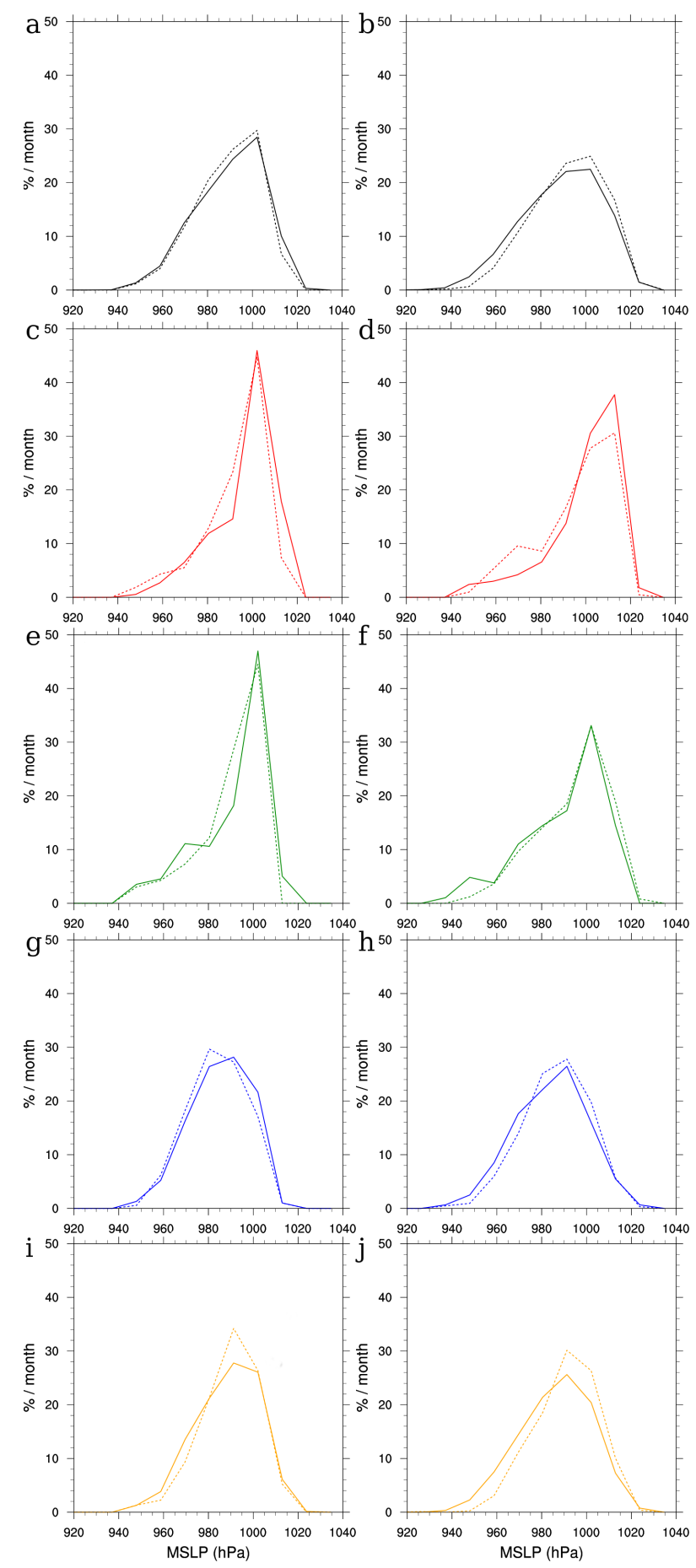

Figure B.1: HadGEM2-ES historical (dashed line) and NCEP-CFSR (solid line) histograms of the minimum MSLP (hPa) in the (upper) summer and (lower) winter; (a,f) South Atlantic, (b,g) SE-BR, (c,h) LA PLATA, (d,i) ARG, and $(e, j)$ SE-SAO regions. The minimum MSLP was searched within $5^{\circ}$ radius from the center of the cyclone. The intensity histograms were produced for cyclones originate in each genesis region separately. The percentage was computed based on the mean cyclones per month for each region. 

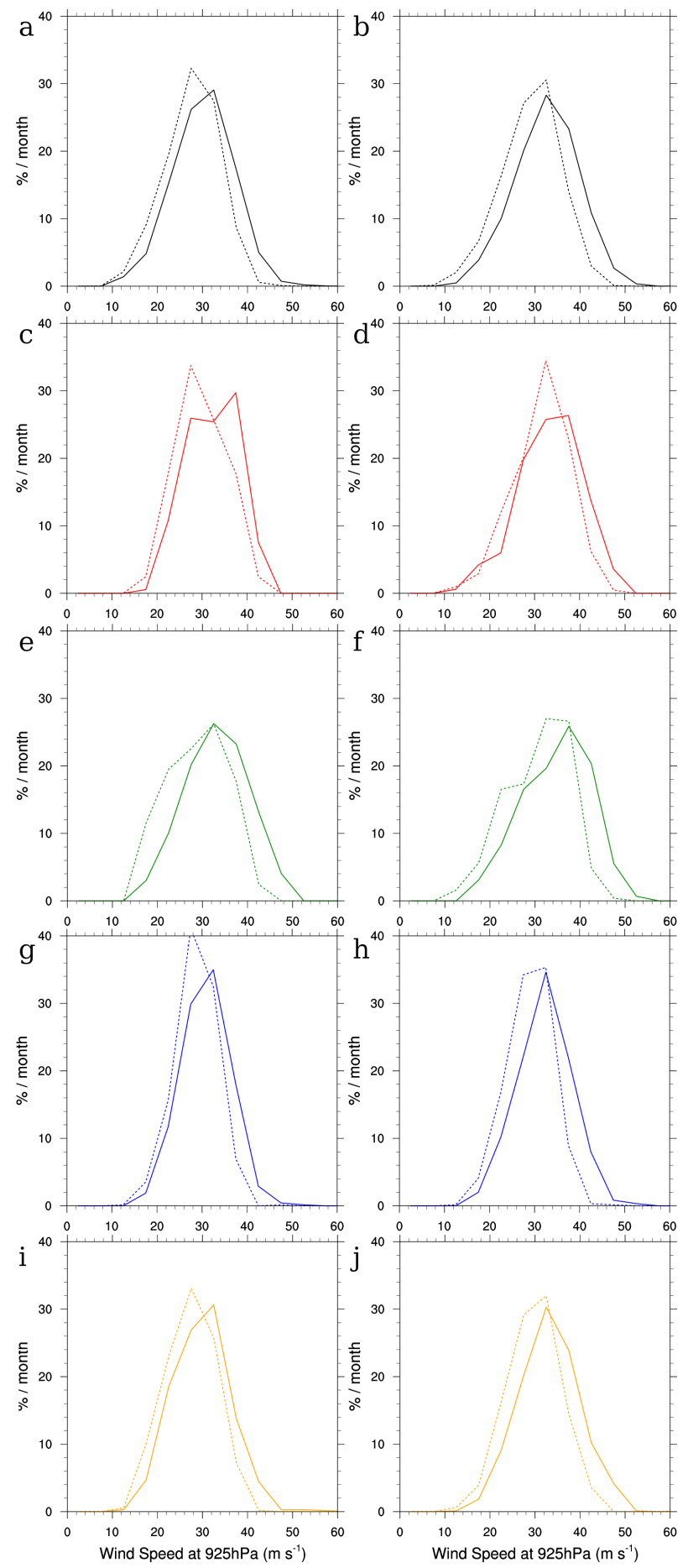

Figure B.2: HadGEM2-ES historical (dashed line) and NCEP-CFSR (solid line) histograms of the maximum wind speed at $925 \mathrm{hPa}\left(\mathrm{m} \mathrm{s}^{-1}\right)$ in the (upper) summer and (lower) winter; (a,f) South Atlantic, (b,g) SE-BR, (c,h) LA PLATA, (d,i) ARG, and (e,j) SE-SAO regions. The maximum wind speed was searched within $6^{\circ}$ radius from the center of the cyclone. The intensity histograms were produced for cyclones originate in each genesis region separately. The percentage was computed based on the mean cyclones per month for each region. 

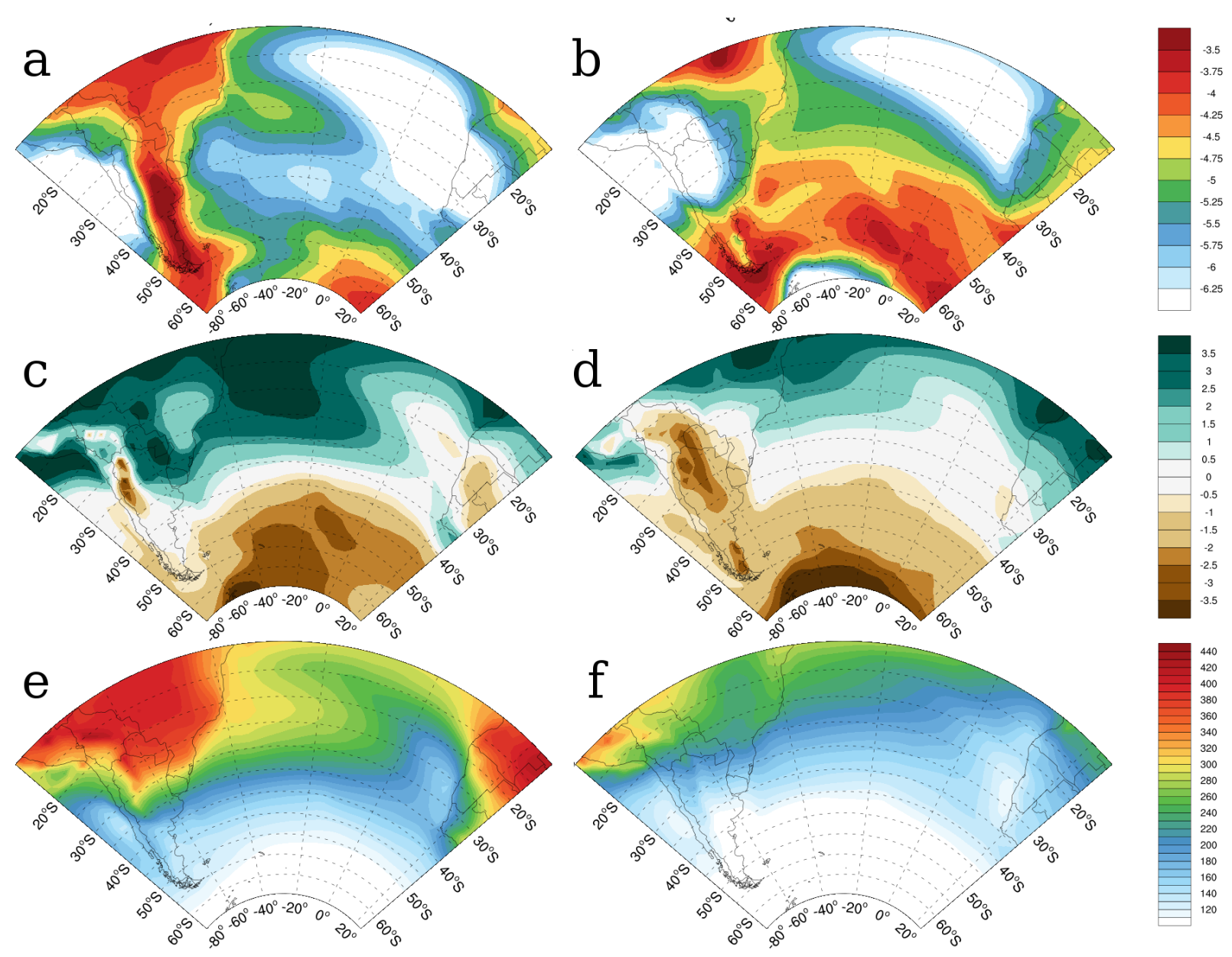

Figure B.3: HadGEM2-ES historical climatological mean (1980-2005) of $\delta \theta / \delta p\left(10^{-2}\right.$ $K h P a^{-1}$ in the (c) summer and (d) winter; $\delta \theta_{e} / \delta p\left(10^{-2} K h P a^{-1}\right.$ in the (e) summer and (f) winter; and low-level vertically integrated humidity $\left(k g \mathrm{~kg}^{-1} \mathrm{~Pa}\right)$ in the (g) summer and (h) winter. 


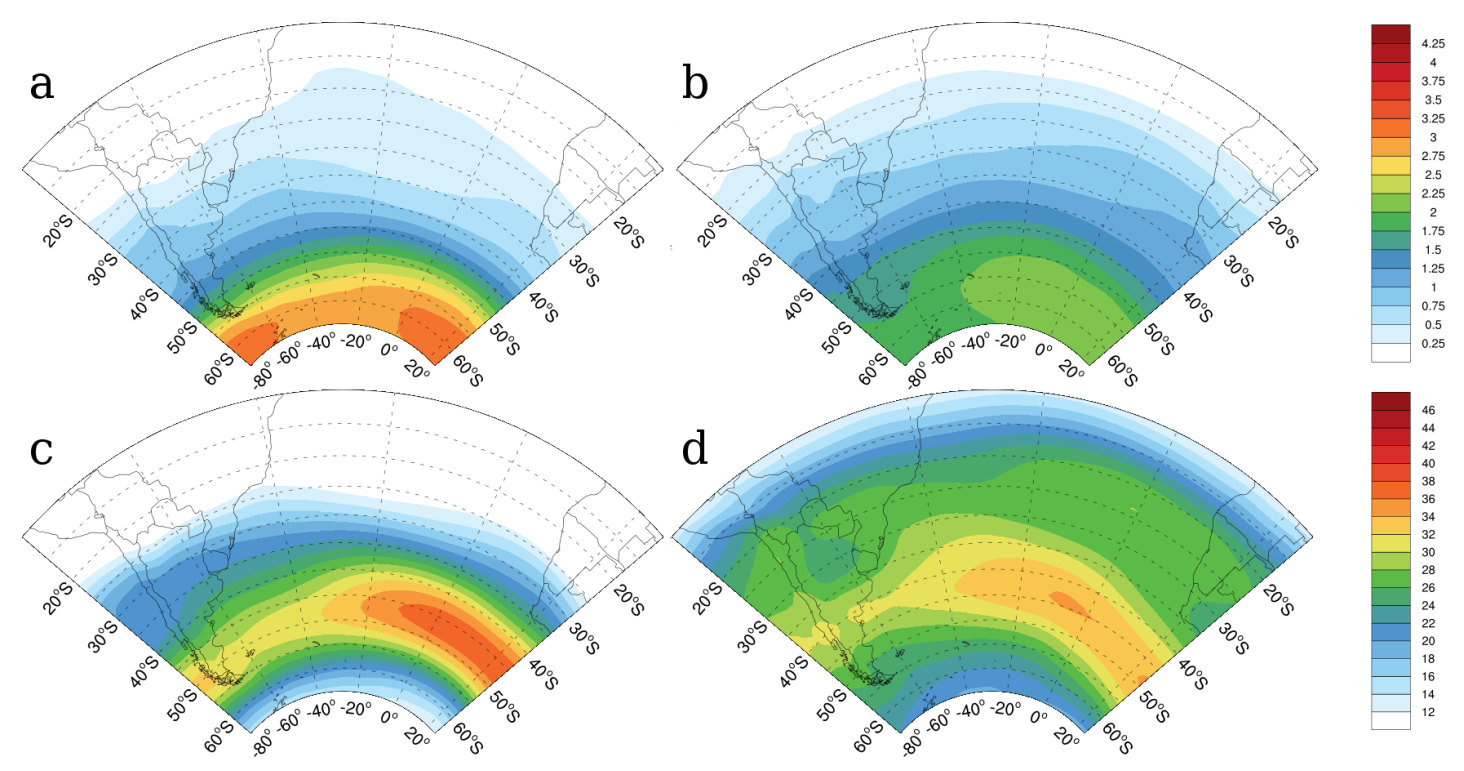

Figure B.4: HadGEM2-ES historical climatological mean (1980-2005) of the PV at $300 \mathrm{hPa}(\times-1 P V U)$ in the (a) summer and (b) winter; and the upper level jet speed $\left(\mathrm{m} \mathrm{s}^{-1}\right)$ in the (c) summer and (d) winter. 
Appendix $\mathrm{C}$

Complementary figures of Chapter 6 
Table C.1 - The mean $850 \mathrm{hPa}$ relative vorticity at genesis time $\left(-1 \times 10^{-5} \mathrm{~s}^{-1}\right)$, mean lifetime (days) and mean cyclone displacement speed $\left(m s^{-1}\right)$ and standards deviations computed within South Atlantic domain $\left(15^{\circ} \mathrm{S}-55^{\circ} \mathrm{S}, 75^{\circ} \mathrm{W}-20^{\circ} \mathrm{E}\right)$ and within each defined genesis region. The means were calculated for the HadGEM2-ES RCP8.5 experiment (2074-2099) for the summer (DJF) and winter (JJA).

\begin{tabular}{rccc}
\hline \hline \multicolumn{4}{c}{ DJF } \\
region & initial vort. & lifetime & speed \\
\hline \hline South Atlantic & $2.5 \pm 1.2$ & $4.9 \pm 3.3$ & $13.2 \pm 4.9$ \\
SE-BR & $3.0 \pm 1.2$ & $7.0 \pm 3.4$ & $10.6 \pm 4.2$ \\
LA PLATA & $2.6 \pm 0.9$ & $6.4 \pm 3.7$ & $10.9 \pm 4.1$ \\
ARG & $2.3 \pm 1.0$ & $4.2 \pm 2.6$ & $14.0 \pm 3.9$ \\
SE-SAO & $2.8 \pm 1.3$ & $4.0 \pm 2.8$ & $15.5 \pm 5.0$ \\
\hline \multicolumn{4}{c}{ JJA } \\
region & initial vort. & lifetime & speed \\
\hline \hline South Atlantic & $3.1 \pm 1.5$ & $4.2 \pm 2.8$ & $14.5 \pm 5.2$ \\
SE-BR & $3.6 \pm 1.5$ & $4.6 \pm 2.8$ & $13.7 \pm 4.5$ \\
LA PLATA & $3.1 \pm 1.0$ & $6.0 \pm 3.7$ & $11.6 \pm 4.5$ \\
ARG & $2.5 \pm 1.2$ & $4.1 \pm 2.6$ & $13.7 \pm 4.2$ \\
SE-SAO & $3.7 \pm 1.7$ & $3.5 \pm 2.2$ & $17.1 \pm 5.0$ \\
\hline
\end{tabular}



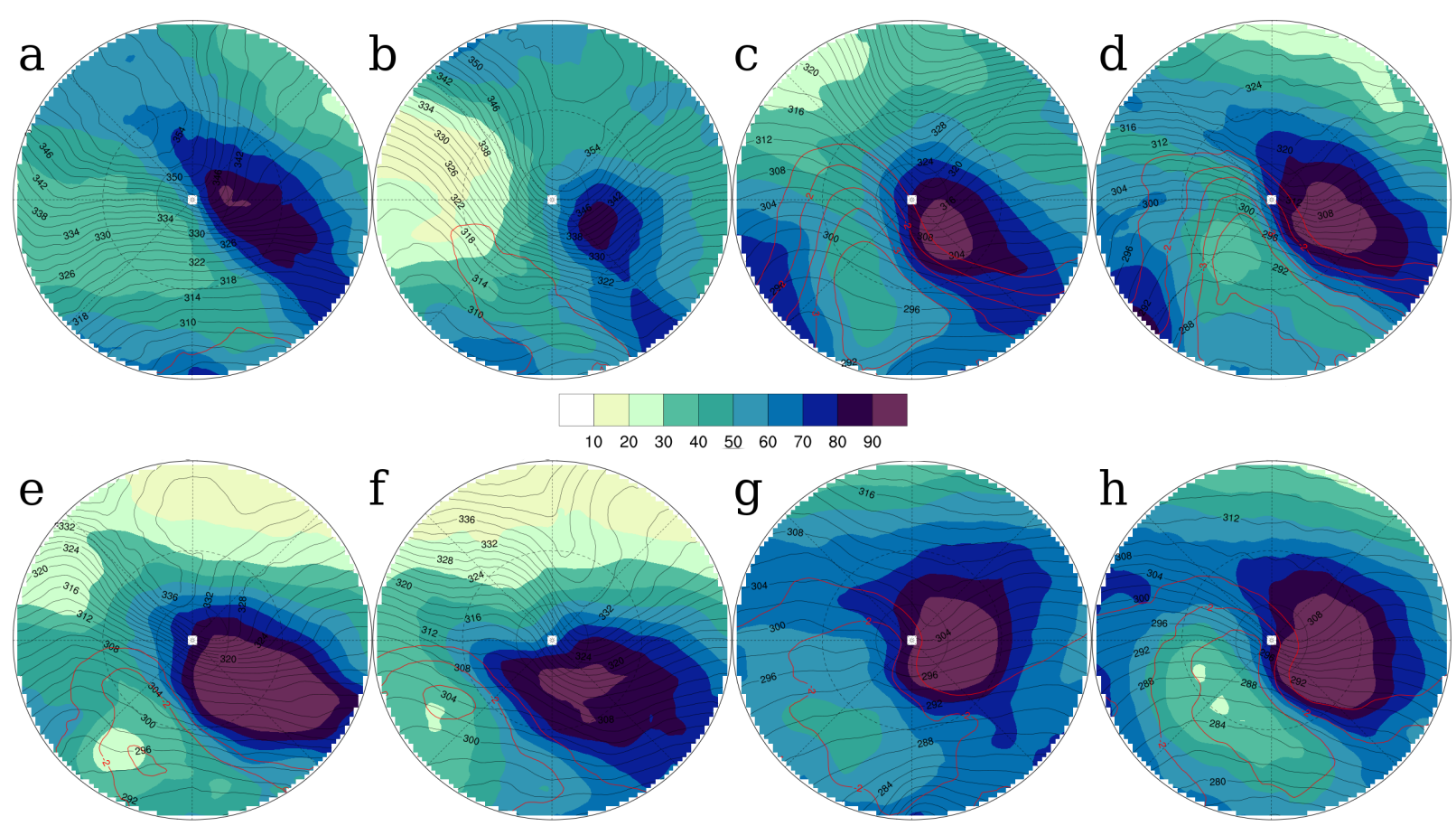

Figure C.1: Composites of mean equivalent potential temperature $\left(\theta_{e}\right)$ at $925 \mathrm{hPa}$ (K; black lines), $\mathrm{RH}(\%$; shaded) and PV at $300 \mathrm{hPa}$ (PVU; red line) from different genesis regions in the (a-d) summer and (f-g) winter : (a,e) SE-BR, (b,f) LA PLATA, (c,g) ARG and $(d, h)$ SE-SAO. 


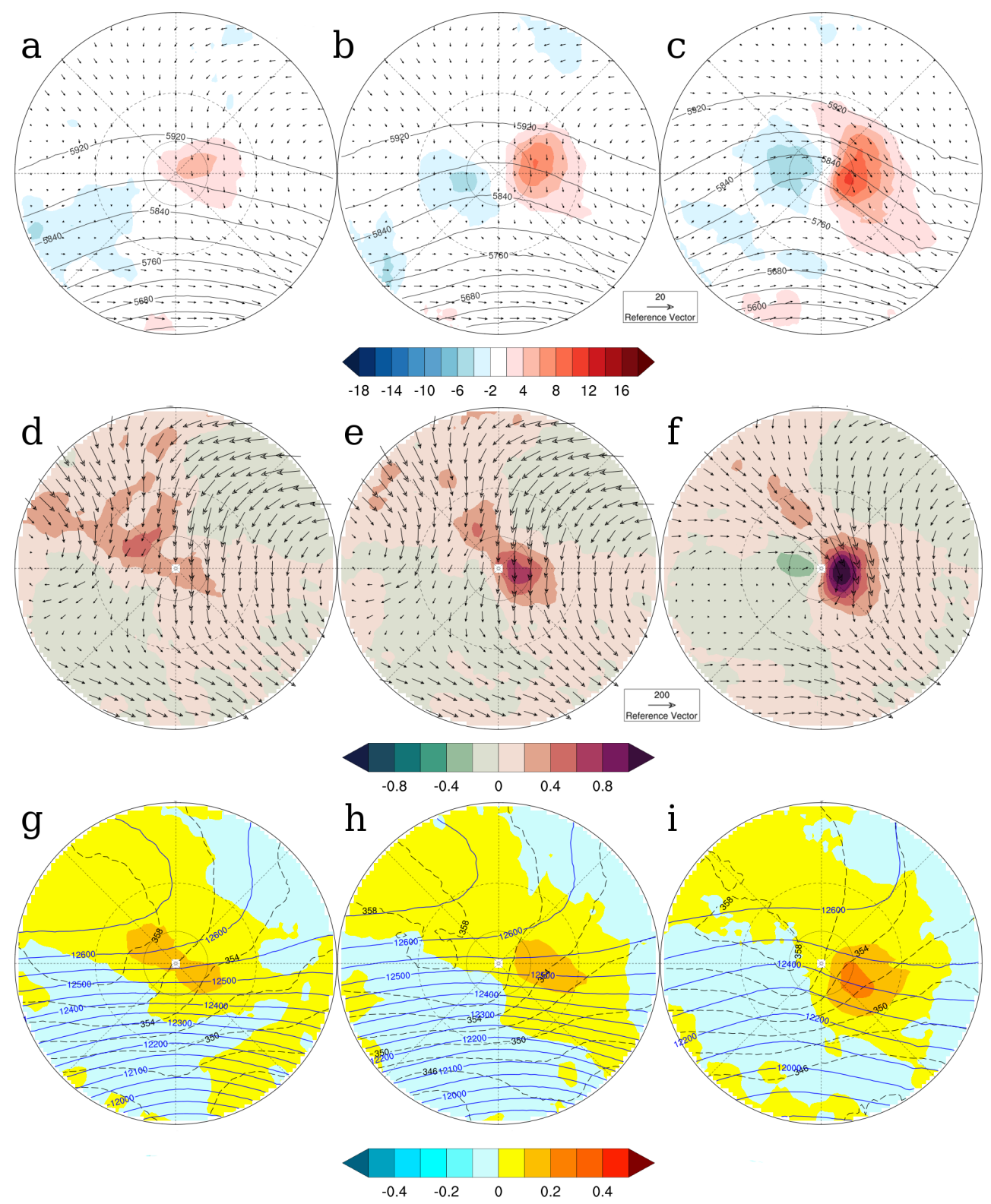

Figure C.2: Composites of SE-BR cyclones in the summer: (a-c) temperature advection at 850 $\mathrm{hPa}\left(10^{-5} \mathrm{~K} \mathrm{~s}^{-1}\right.$; shaded), geopotential height at $500 \mathrm{hPa}$ (gpm; black line) and winds at $850 \mathrm{hPa}\left(\mathrm{m} \mathrm{s}^{-1}\right) ;$ (d-f) vertically integrated moisture flux convergence $\left(10^{-3} \mathrm{~kg}\right.$ $\mathrm{m}^{-2} s-1$; shaded) and moisture transport $\left(\mathrm{kg} \mathrm{m}^{-1} \mathrm{~s}^{-1}\right.$; arrows) and at low level (925 $700 \mathrm{hPa}$ ), and; (g-i) potential temperature ( $K$; black line), geopotential height (gpm; blue line) and divergence of mass $\left(s^{-1}\right.$; shaded) at $200 \mathrm{hPa}$. Composites (a,d,g) at 12 hours before the time of genesis; (b,e,h) at the time of genesis, and; (c,f,i) at 24 hours after the time of genesis. 

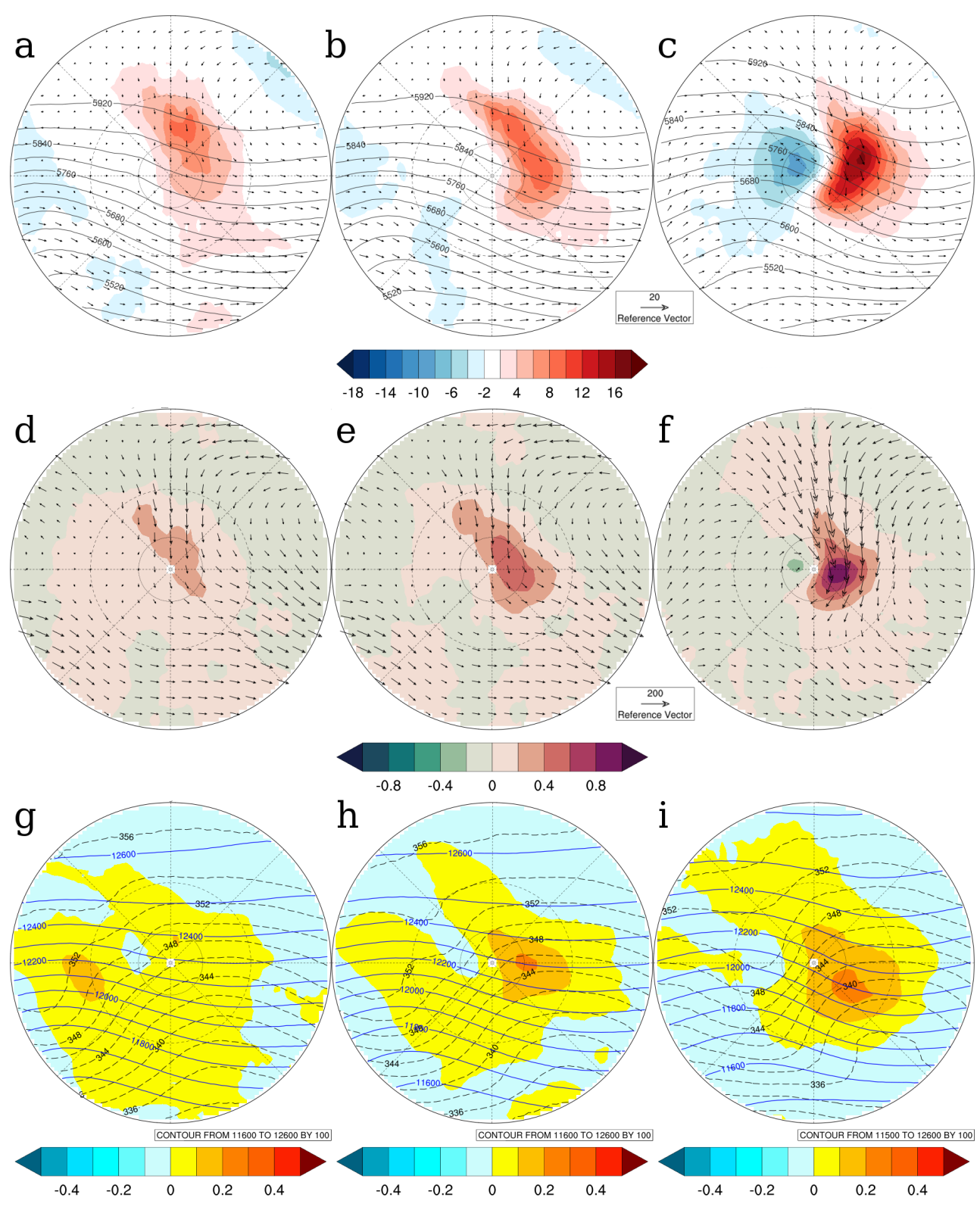

Figure C.3: As Fig C.2 but for the LA PLATA cyclones in the winter. 

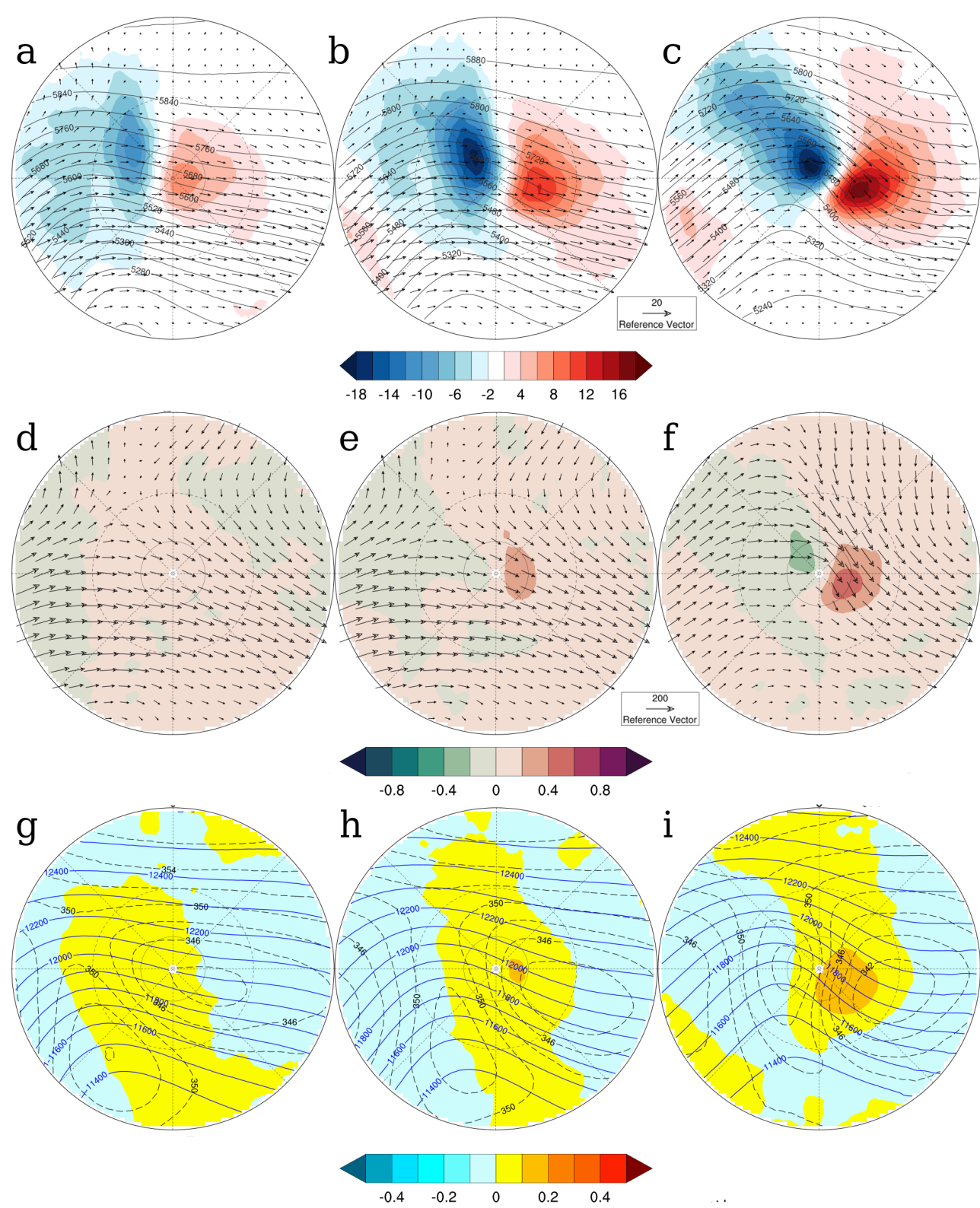

Figure C.4: As Fig C.2 but for the ARG cyclones in the summer. 

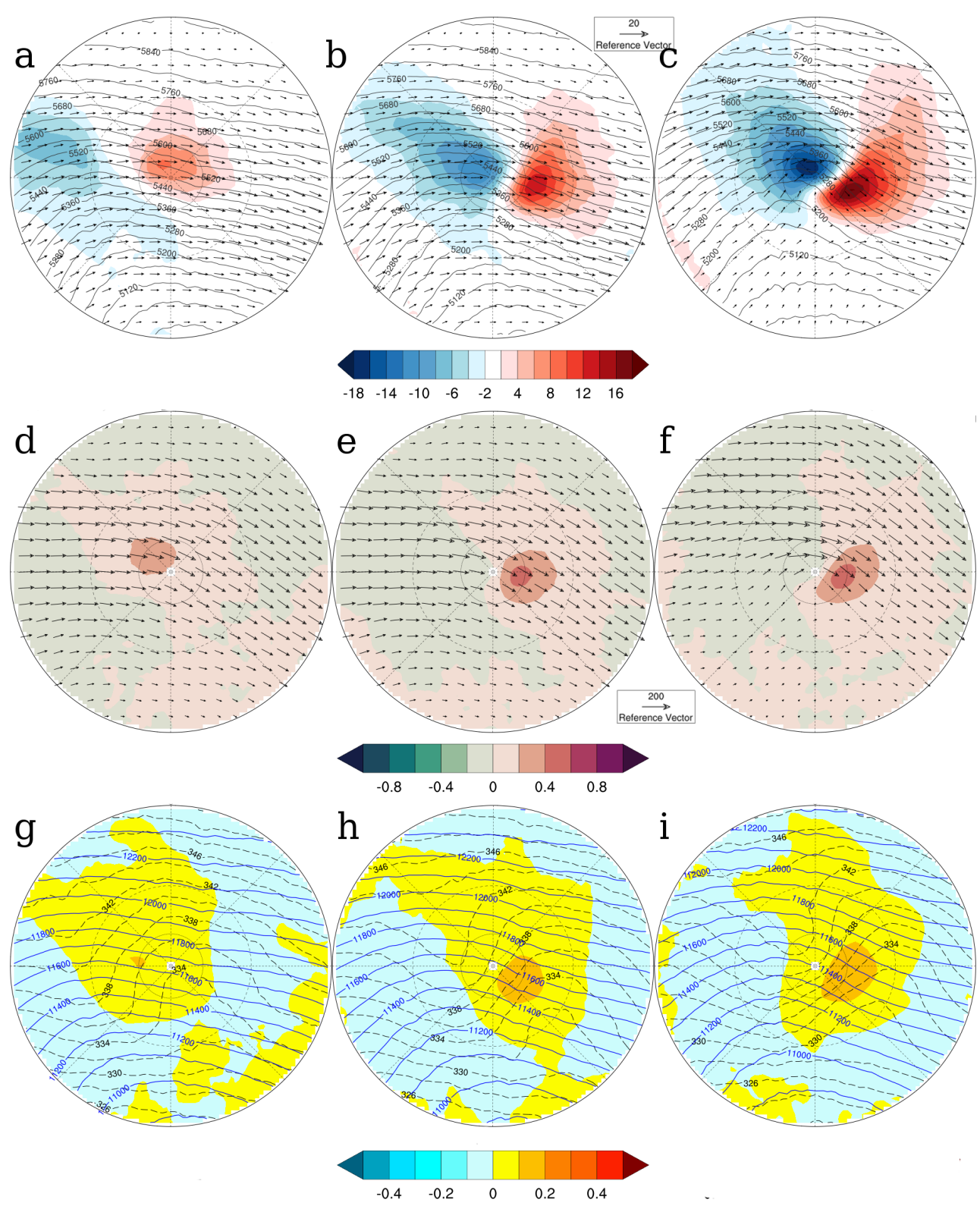

Figure C.5: As Fig. C.2 but for the SE-SAO cyclones in the winter. 
Appendix D

Complementary figures of Chapter 7 

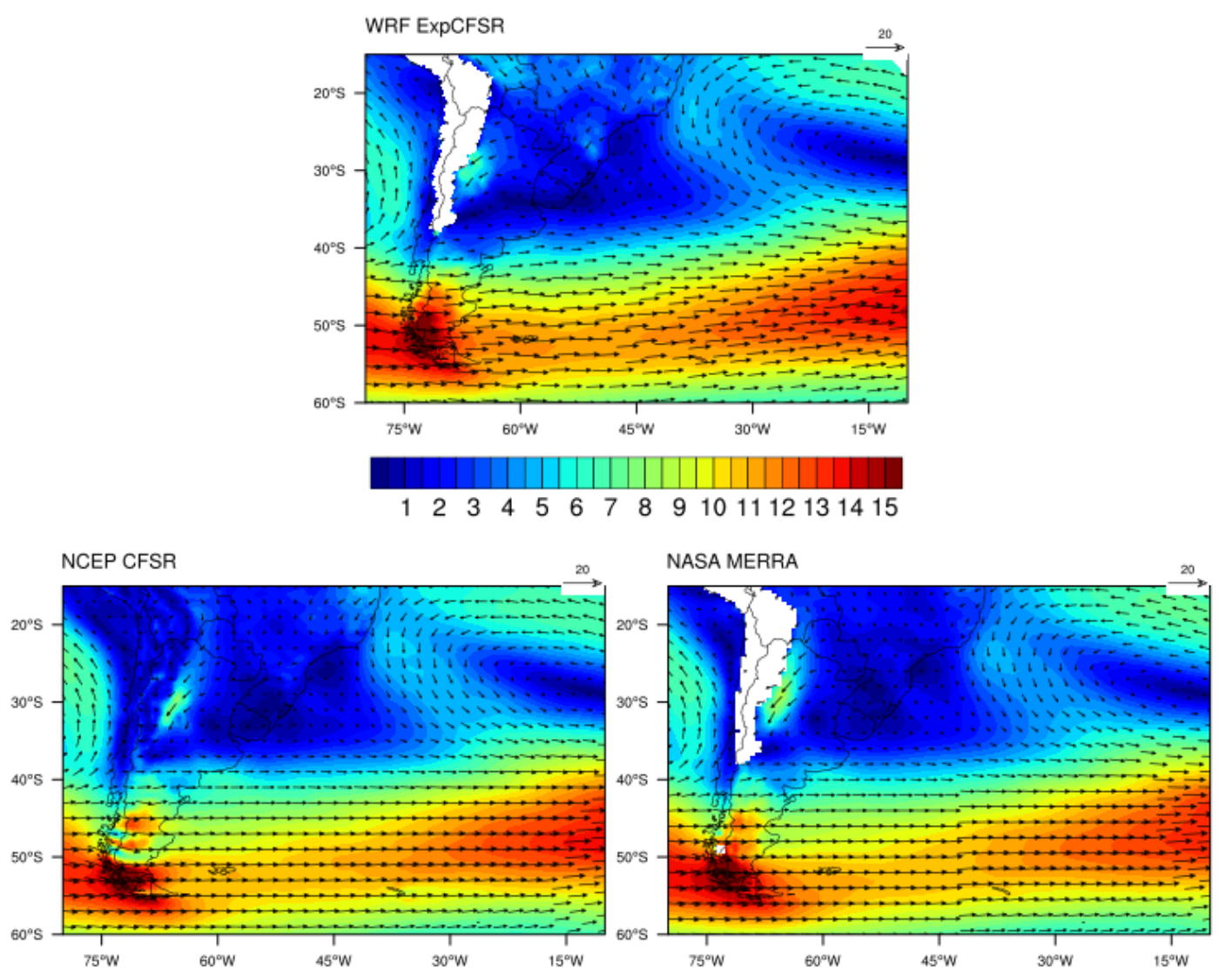

WRF EXPCFSR - NCEP CFSR

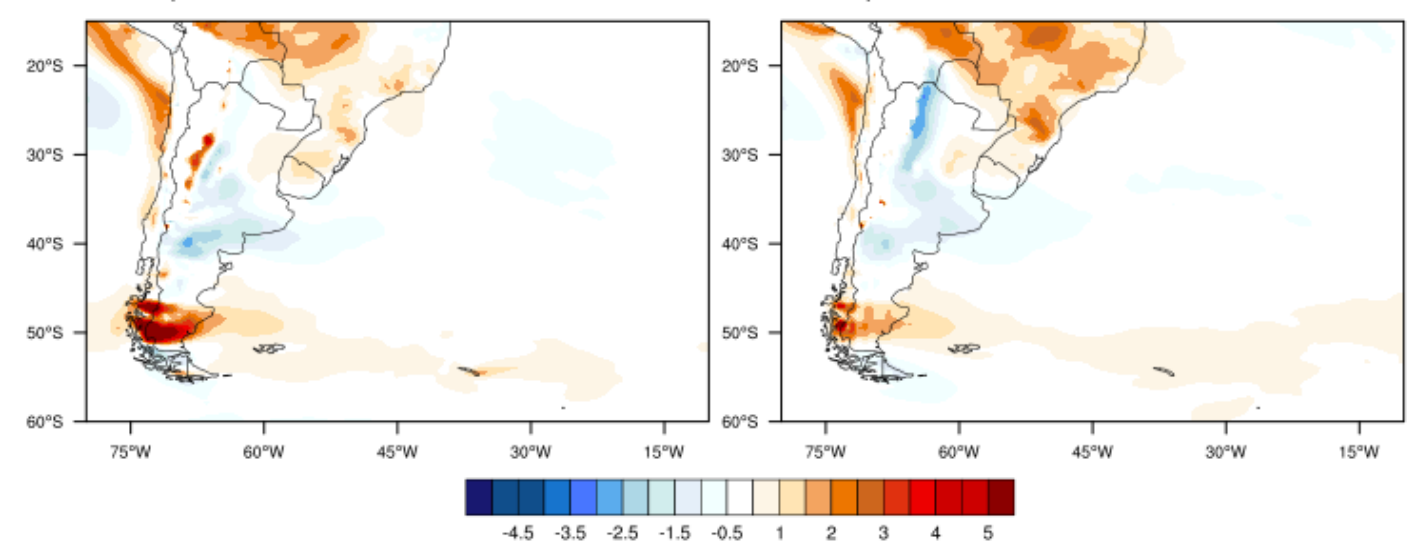

Figure D.1: Mean velocity at $850 \mathrm{hPa}\left(\mathrm{ms}^{-1}\right)$ distribution in austral summer for the ExpCFSR, NCEP-CFSR, NASA-MERRA; and the differences ExpCFSR - NCEP-CFSR and ExpCFSR - NASA-MERRA. The climatological mean comprises the 1991-2005 period. 

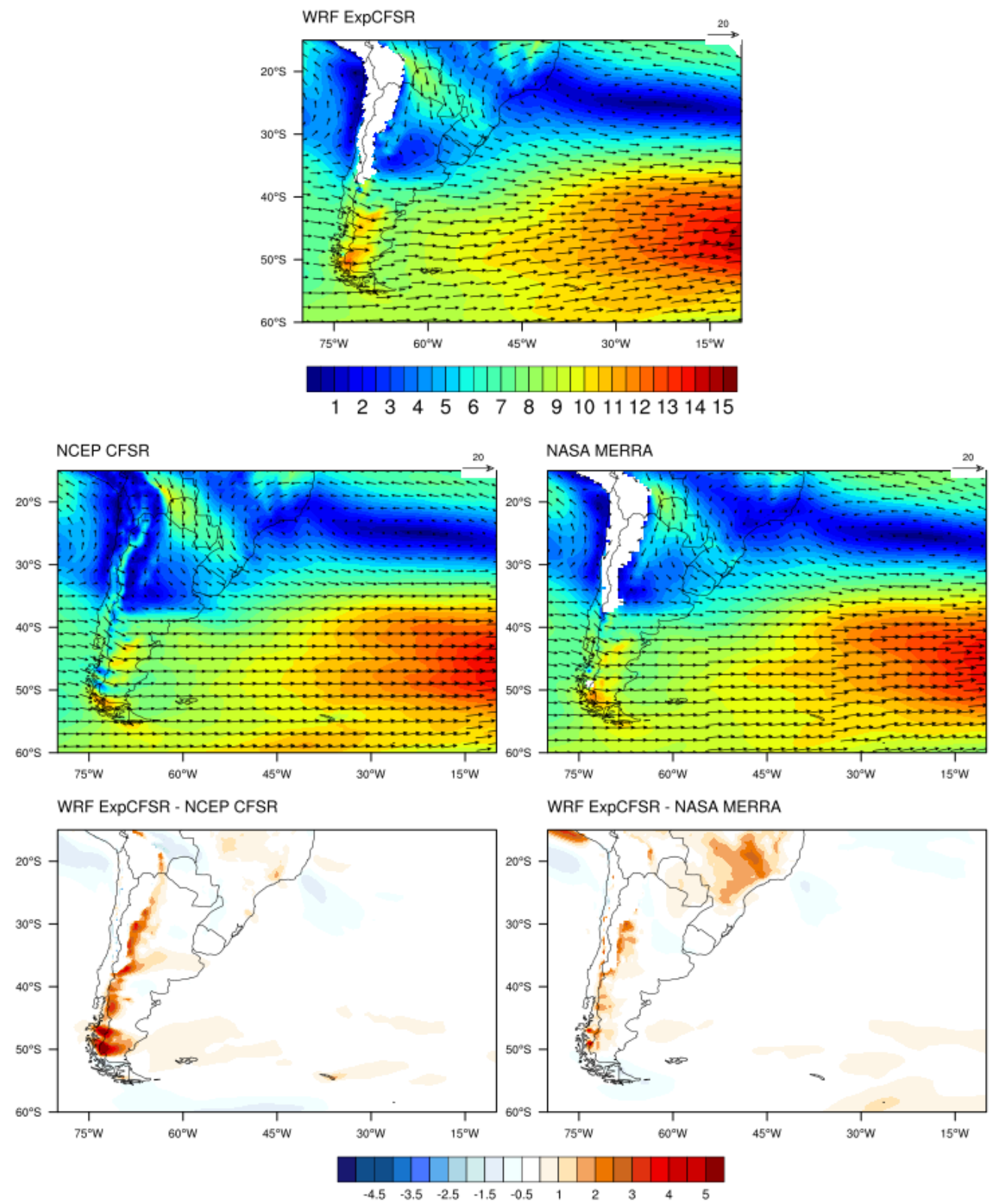

Figure D.2: As in Fig, D.1 but for the winter. 

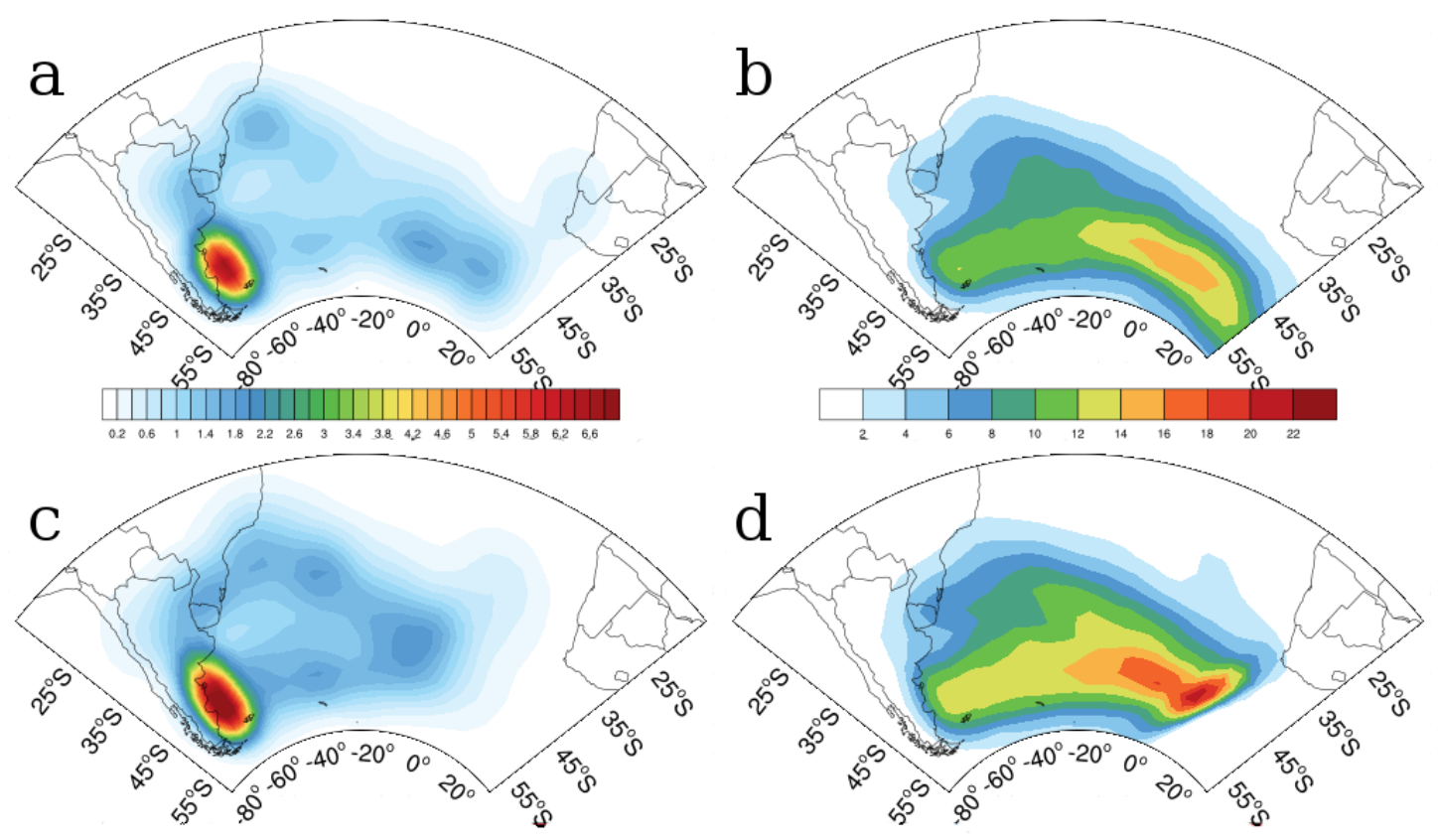

Figure D.3: Genesis and track density in the austral summer for the (a,b) NCEP-CFSR T42 global data, (c,d) NCEP-CFSR spatial filter in the regional model grid. 

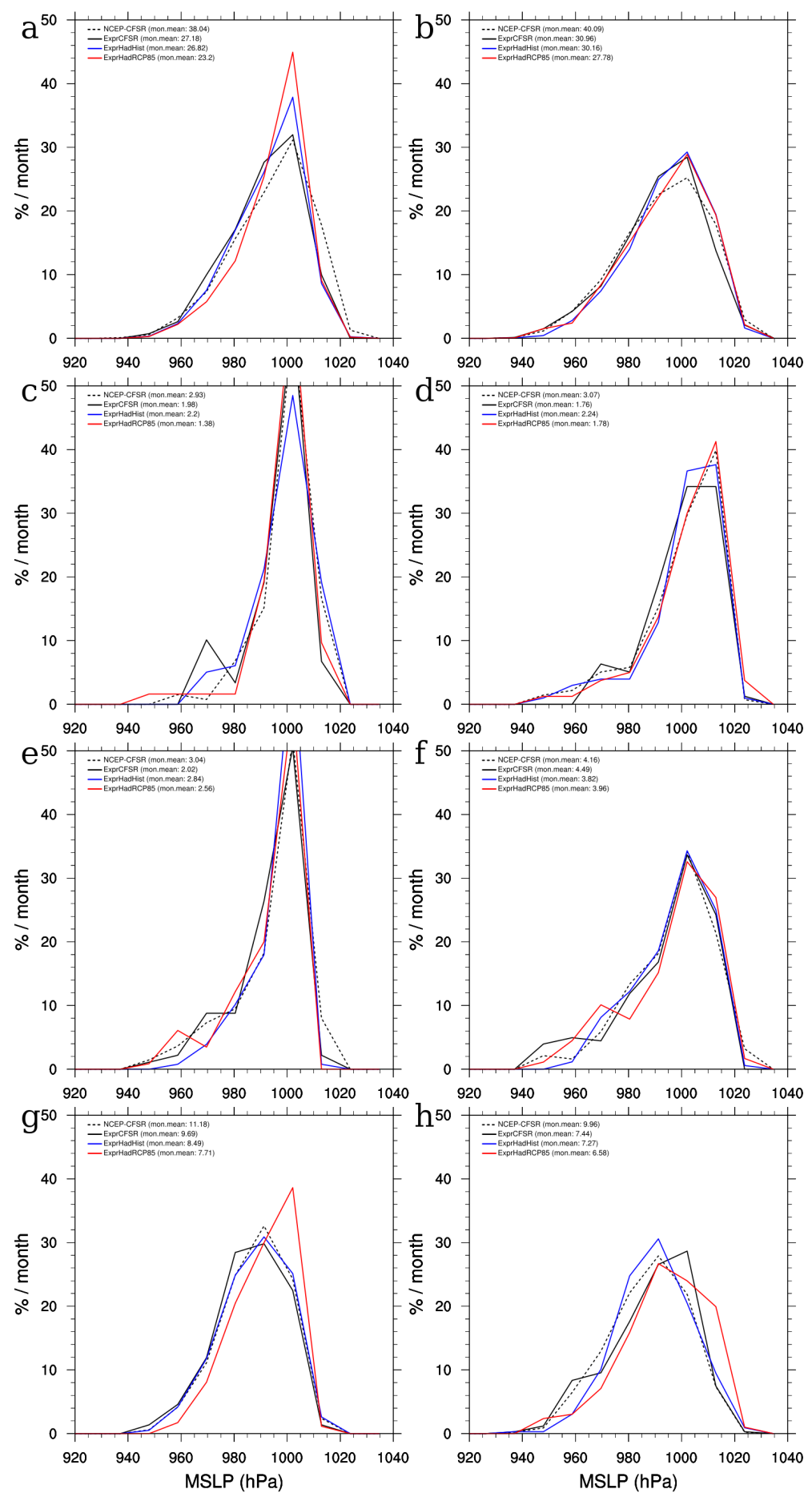

Figure D.4: Histograms of the minimum MSLP (hPa) in the summer (left) and winter (right) for (a,b) South Atlantic, (c,d) SE-BR, (e,f) LA PLATA, and (g,h) ARG. The minimum MSLP was searched within $5^{\circ}$ radius from the center of the cyclone. The NCEP-CFSR (dashed line), ExpCFSR (black solid line) and ExpHad-Hist (blue line) for 1991-2005, and ExpHadRCP85 (red line) for 2085-2099. The intensity histograms were produced for cyclones originated in each genesis region separately. The percentage was computed based on the mean cyclones per month for each region. 

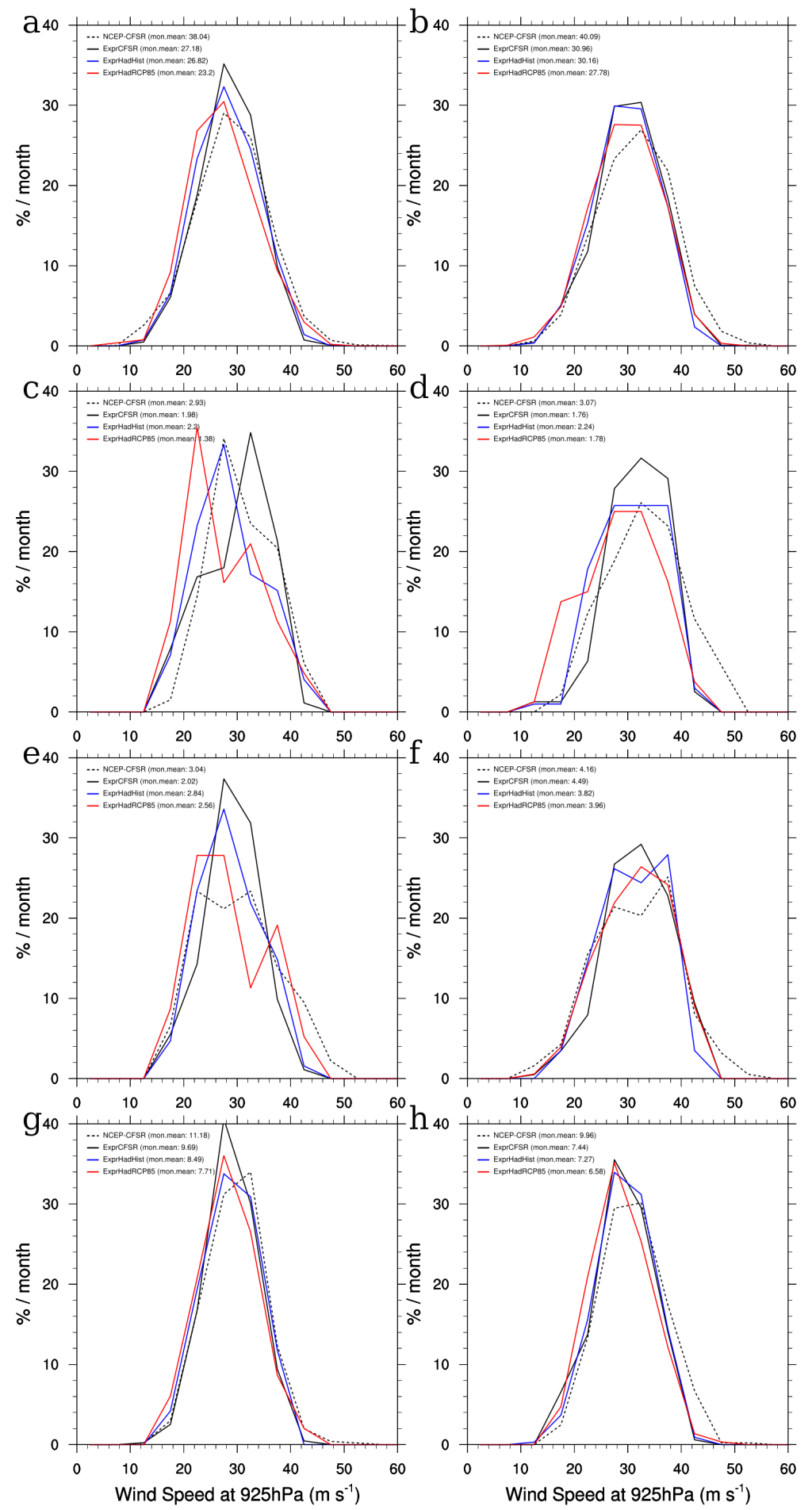

Figure D.5: Histograms of the maximum wind speed at $925 \mathrm{hPa}\left(\mathrm{ms}^{-1}\right)$ in the summer (left) and winter (right) for (a,b) South Atlantic, (c,d) SE-BR, (e,f) LA PLATA, and (g,h) ARG. The NCEP-CFSR (dashed line), ExpCFSR (black solid line) and ExpHad-Hist (blue line) for 1991-2005, and ExpHadRCP85 (red line) for 2085-2099. The maximum wind speed was searched within $6^{\circ}$ radius from the center of the cyclone. The intensity histograms were produced for cyclones originated in each genesis region separately. The percentage was computed based on the mean cyclones per month for each region. 